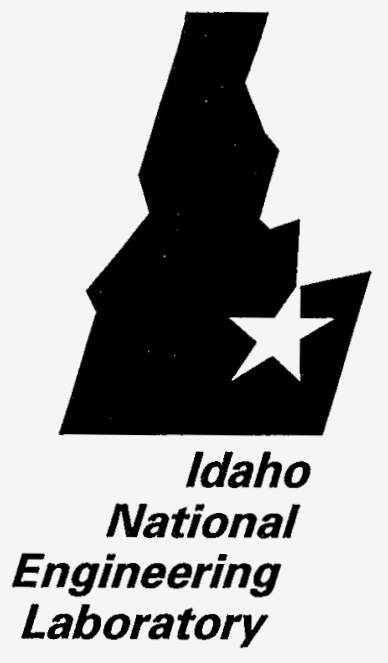

INEL-95/0499

October 1995

\title{
A Risk-Based Approach to Liquid Effluent Monitoring
}

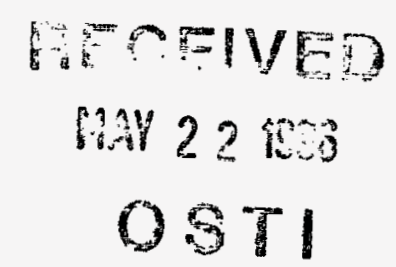

Laurence C. Hull

IT Corporation

\section{MASTER}

ZWLockheed
Idaho Technologles Company 


\section{DISCLAIMER}

This report was prepared as an account of work sponsored by an agency of the United States Government. Neither the United States Government nor any agency thereof, nor any of their employees, makes any warranty, express or implied, or assumes any legal liability or responsibility for the accuracy, completeness, or usefulness of any information, apparatus, product, or process disclosed, or represents that its use would not infringe privately owned rights. Reference herein to any specific commercial product, process, or service by trade name, trademark, manufacturer, or otherwise does not necessarily constitute or imply its endorsement, recommendation, or favoring by the United States Government or any agency thereof. The views and opinions of authors expressed herein do not necessarily state or reflect those of the United States Government or any agency thereof. 


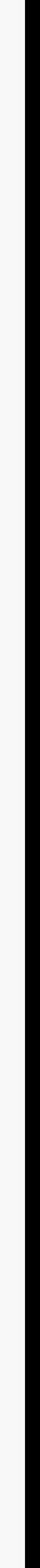




\title{
A Risk-Based Approach to Liquid Effluent Monitoring
}

\author{
Laurence C. Hull \\ IT Corporation
}

Published October 1995

\section{Idaho National Engineering Laboratory Lockheed Idaho Technologies Company Idaho Falls, Idaho 83415}





\section{ABSTRACT}

DOE Order 5400.1 identifies six objectives of a liquid effluent monitoring program. A strategy is proposed that meets these objective in one of two ways; 1) by showing that effluent concentrations are below concentration limits set by permits or are below concentrations that could cause environmental problems (release limits), or 2) by showing that concentrations in effluent have not changed form a period when treatment process were in control and there were no unplanned releases. The intensity of liquid effluent monitoring should be graded to the importance of the source being monitored. This can be accomplished by determining the risk posed by the source. A definition of risk is presented that defines risk in terms of the statistical probability of exceeding a release limit and the time available to recover from an exceedance of a release limit. Three examples are presented that show this approach to grading an effluent monitoring program can be implemented at the Idaho National Engineering Laboratory and will reduce monitoring requirements. 



\section{CONTENTS}

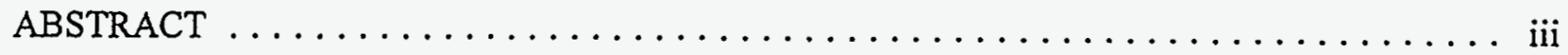

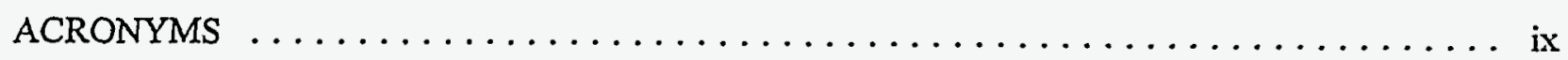

1. INTRODUCTION $\ldots \ldots \ldots \ldots \ldots \ldots \ldots \ldots \ldots \ldots \ldots \ldots \ldots \ldots \ldots \ldots \ldots \ldots \ldots \ldots$

1.1 Purpose $\ldots \ldots \ldots \ldots \ldots \ldots \ldots \ldots \ldots \ldots \ldots \ldots \ldots \ldots \ldots \ldots \ldots \ldots \ldots \ldots \ldots \ldots$

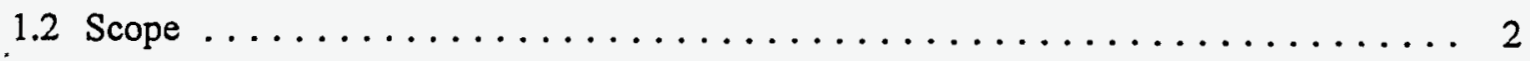

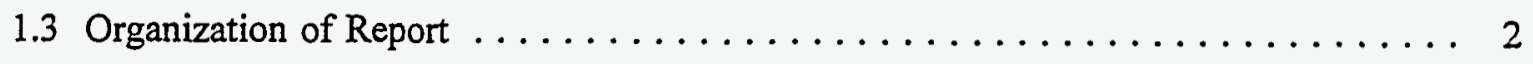

2. REQUIREMENTS AND OBJECTIVES $\ldots \ldots \ldots \ldots \ldots \ldots \ldots \ldots \ldots \ldots \ldots \ldots \ldots \ldots \ldots$

2.1 City of Idaho Falls $\ldots \ldots \ldots \ldots \ldots \ldots \ldots \ldots \ldots \ldots \ldots \ldots \ldots \ldots \ldots \ldots \ldots \ldots$

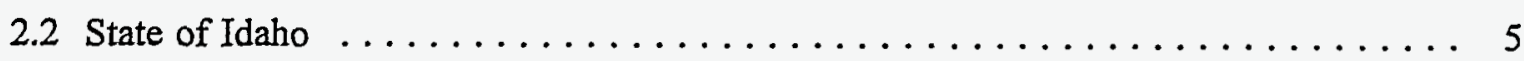

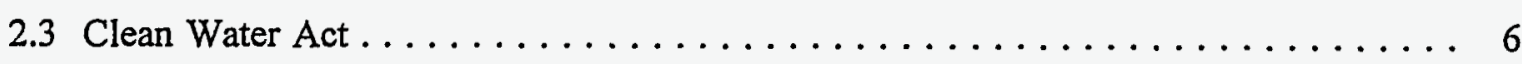

2.4 Department of Energy $\ldots \ldots \ldots \ldots \ldots \ldots \ldots \ldots \ldots \ldots \ldots \ldots \ldots$

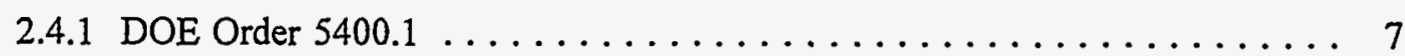

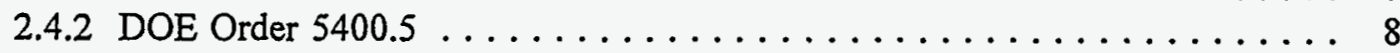

2.4.3 Environmental Regulatory Guide $\ldots \ldots \ldots \ldots \ldots \ldots \ldots \ldots \ldots$

2.5 INEL Guidance for Disposal of Wastewater $\ldots \ldots \ldots \ldots \ldots \ldots \ldots \ldots$

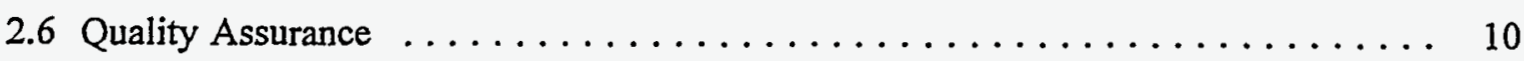

2.7 Summary of Requirements and Objectives $\ldots \ldots \ldots \ldots \ldots \ldots \ldots \ldots \ldots \ldots \ldots \ldots \ldots$

2.7.1 Comparison to Release Limits $\ldots \ldots \ldots \ldots \ldots \ldots \ldots \ldots \ldots \ldots \ldots \ldots \ldots \ldots \ldots$

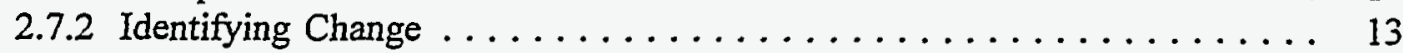

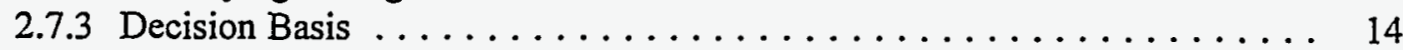

3. RISK BASED DESIGN BASIS FOR AN EFFLUENT MONITORING PROGRAM $\ldots \ldots \ldots 14$

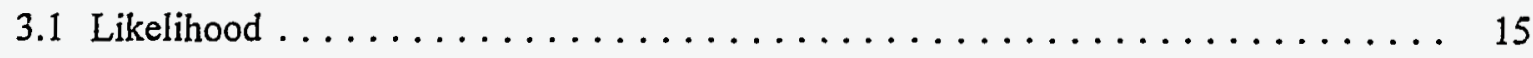

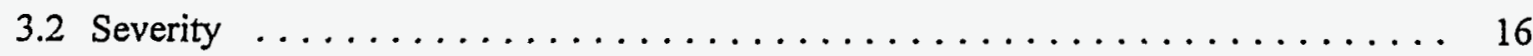

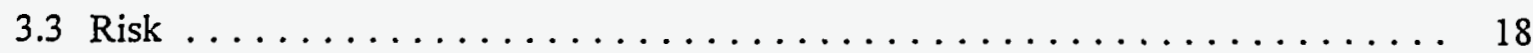

4. PHASED IMPLEMENTATION OF EFFLUENT MONITORING $\ldots \ldots \ldots \ldots \ldots \ldots 20$

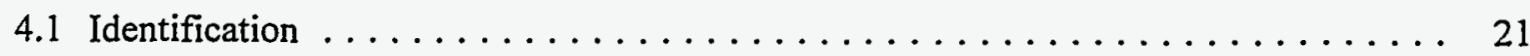




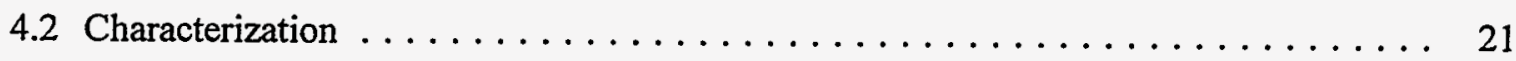

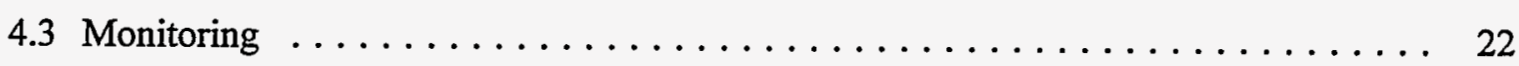

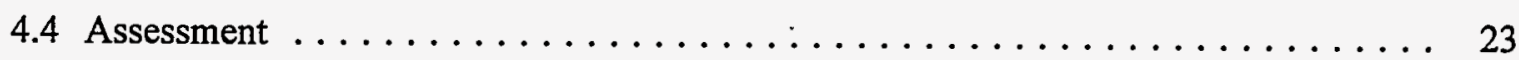

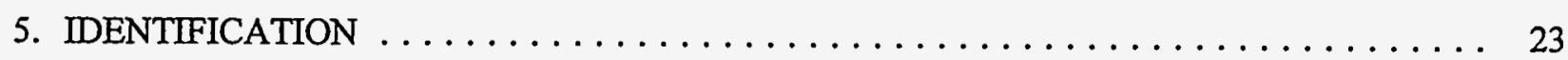

5.1 Continuing Effluent Identification $\ldots \ldots \ldots \ldots \ldots \ldots \ldots \ldots \ldots \ldots \ldots \ldots \ldots \ldots \ldots \ldots$

5.2 Identification of Characterization and Monitoring Parameters $\ldots \ldots \ldots \ldots \ldots$

6. CHARACTERIZATION $\ldots \ldots \ldots \ldots \ldots \ldots \ldots \ldots \ldots \ldots \ldots \ldots \ldots \ldots \ldots \ldots$

6.1 Objectives of Characterization $\ldots \ldots \ldots \ldots \ldots \ldots \ldots \ldots \ldots \ldots \ldots \ldots \ldots$

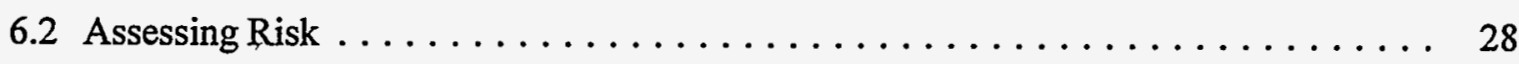

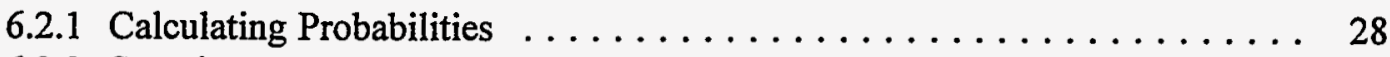

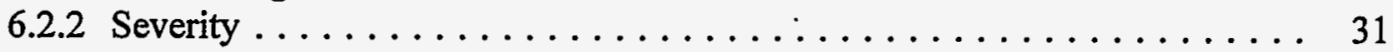

6.3 Determining Monitoring Frequency Based on Risk ............. 31

6.3.1 Low Likelihood Parameters with No Release Limit . . . . . . . . . . . . . 32

6.3.2 Low Likelihood Parameters with Release Limits . . . . . . . . . . . . 32

6.3.3 High Likelihood or High Severity Parameters . . . . . . . . . . . . . . 32

6.3.4 Intermediate Likelihood, Intermediate Severity Parameters . . . . . . . . 32

6.4 Example Calculation for Risk Based Monitoring $\ldots \ldots \ldots \ldots \ldots \ldots \ldots$

6.5 Determining Monitoring Frequency for Performance Monitoring Objectives . . . . 44

7. MONITORING $\ldots \ldots \ldots \ldots \ldots \ldots \ldots \ldots \ldots \ldots \ldots \ldots \ldots \ldots \ldots \ldots$

7.1 Evaluating Changes During a Decision Period $\ldots \ldots \ldots \ldots \ldots \ldots$

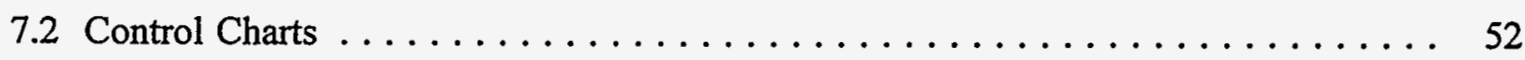

7.3 Evaluating Changes Over Longer Time Periods $\ldots \ldots \ldots \ldots \ldots$

8. ASSESSMENT $\ldots \ldots \ldots \ldots \ldots \ldots \ldots \ldots \ldots \ldots \ldots \ldots \ldots \ldots \ldots \ldots$

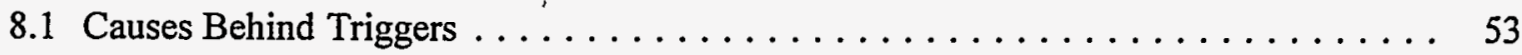

8.2 Determining the Potential for Change in Risk $\ldots \ldots \ldots \ldots \ldots \ldots$

8.3 Assessment When Release Limits are Exceeded $\ldots \ldots \ldots \ldots \ldots \ldots$

8.3.1 Violations of Permit Conditions $\ldots \ldots \ldots \ldots \ldots \ldots \ldots \ldots \ldots \ldots$

8.3.2 Limits with Response Time $\ldots \ldots \ldots \ldots \ldots \ldots \ldots \ldots \ldots$ 
8.4 Assessment When Change is Indicated $\ldots \ldots \ldots \ldots \ldots \ldots \ldots \ldots$

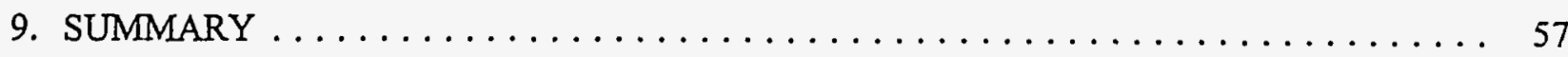

10. REFERENCES $\ldots \ldots \ldots \ldots \ldots \ldots \ldots \ldots \ldots \ldots \ldots \ldots \ldots \ldots \ldots \ldots$

\section{TABLES}

1. Regulatory drivers for liquid effluent monitoring programs $\ldots \ldots \ldots \ldots \ldots \ldots \ldots \ldots$

2. Probabilities of exceeding limits and number of samples needed to demonstrate compliance for TRA764. All data are transformed by taking the natural logarithm except for $\mathrm{pH}$ which is a logarithmic

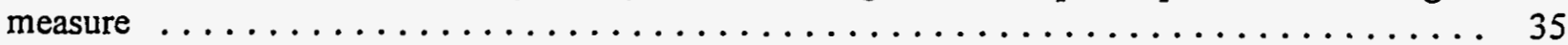

3. Probabilities of exceeding limits and number of samples needed to demonstrate compliance for CFA691. All data are transformed by taking the natural logarithm except for $\mathrm{pH}$ which is a logarithmic

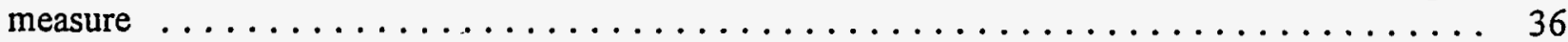

4. Probabilities of exceeding limits and number of samples needed to demonstrate compliance for IF-603 (IRC). All data are transformed by taking the natural logarithm except for $\mathrm{pH}$ which is a logarithmic

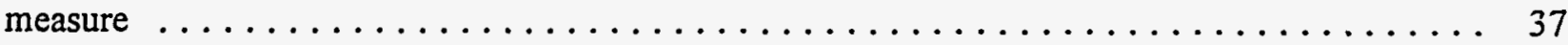

5. Probability of organic compounds exceeding site-specific release limits based on a Poisson

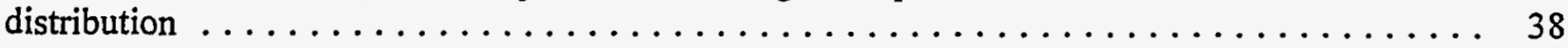

6. Changes in parameters with time and times to reach release limits for CFA-691. . . . . 45

7. Changes in parameters with time and times to reach release limits for IF-603 (IRC) $\ldots \ldots .47$

8. Changes in parameters with time and times to reach release limits for TRA-764 $\ldots \ldots \ldots 4$

\section{FIGURES}

1. Frequency distribution bar charts, where the release limit is above the actual and expected (Part A),

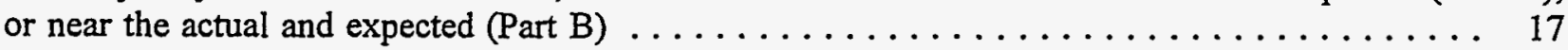

2. Monitoring strategies for effluents based on levels of risk $\ldots \ldots \ldots \ldots \ldots \ldots$

3. Overview of the identification process $\ldots \ldots \ldots \ldots \ldots \ldots \ldots \ldots \ldots \ldots \ldots \ldots \ldots$

4. Example of effluent stream identification questionnaire $\ldots \ldots \ldots \ldots \ldots \ldots$

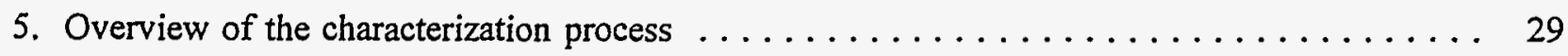

6. Risk diagram for effluent to the TRA Cold Waste Pond . . . . . . . . . . 39

7. Risk diagram for influent to the CFA Sewage Treatment Plant $\ldots \ldots \ldots \ldots \ldots$

8. Risk diagram for effluent from the $\mathbb{N} E L$ Research Center . . . . . . . . . . . . . 43 
9. Overview of monitoring . 


\section{ACRONYMS}

CERCLA Comprehensive Environmental Response, Compensation, and Liability Act

CFR Code of Federal Regulations

CFA Central Facilities Area

DCG derived concentration guides

DOE Department of Energy

DOE-ID Department of Energy Idaho Operations Office

EM Environmental Monitoring

EPA Environmental Protection Agency

ICP inductively coupled plasma emission spectrophotometry

ICPP Idaho Chemical Processing Plant

IDAPA Idaho Administrative Procedures Act

IF Idaho Falls

INEL Idaho National Engineering Laboratory

IRC INEL Research Center

LEI liquid effluent inventory

LITCO Lockheed Idaho Technologies Company

MAC maximum allowable concentration

MCL maximum contaminant level

NPDES National Pollutant Discharge Elimination System

POTW publicly owned treatment works

QA quality assurance

QC quality control

SMCL secondary maximum contaminant level

TDS total dissolved solids

TRA Test Reactor Area

TSS total suspended solids

USL upper specification limit

WCB Willow Creek Building 



\section{A RISK-BASED APPROACH TO LIQUID EFFLUENT MONITORING}

\section{INTRODUCTION}

The Idaho National Engineering Laboratory (INEL) was consolidated under one management and operating contractor, Lockheed Idaho Technologies Company (LITCO), in October 1994. Liquid effluent monitoring programs run by the previous contractors are being consolidated into one program under LITCO. The consolidation provides an opportunity to review existing programs and identify opportunities for improvement.

In addition to the consolidation, other factors are having a significant impact on environmental monitoring activities. The U. S. Department of Energy, Idaho Falls Operations Office (DOE-ID) has just completed a liquid effluent inventory of the INEL to identify all liquid effluent streams. The results of this inventory may identify additional effluent streams that must be accommodated by the effluent monitoring program. DOE-ID has also just begun to obtain Wastewater Land Application Permits for units that treat or dispose of wastewater by application to the land surface. These permits contain significant requirements for effluent monitoring that will increase the sampling and analysis load of the liquid effluent monitoring program.

In sharp contrast to these pressures to increase liquid effluent monitoring, there is movement in the U. S. Congress to decrease DOE budgets. The reduction in budgets pushes the environmental monitoring program to achieve efficiency in monitoring programs to the maximum extent possible.

\subsection{Purpose}

The purpose of this report is to lay out the design of an effluent monitoring program for the LITCO Environmental Monitoring (EM) Program. The objectives for the liquid effluent monitoring program are to:

- Demonstrate compliance with regulations as implemented through permits,

- Demonstrate compliance with DOE Order 5400.5 for radiological liquid effluent streams,

- Meet performance monitoring objectives of DOE Order 5400.1.

Objectives for the technical review of the monitoring program are to:

- Grade the intensity of effluent monitoring to the risk posed by the effluent stream, 
- Implement the data quality objective process by orienting the program to a decision basis. That is, activities are conducted to make decisions, not collect data,

- Document the logic and technical basis of all decisions,

- Minimize sampling and record keeping while demonstrating compliance.

\subsection{Scope}

Included in the scope of this review are all liquid effluent monitoring activities conducted by the LITCO EM Program at the INEL and at LITCO in-town facilities. Included are:

- Liquid effluent streams monitored to demonstrate compliance with permit conditions.

- $\quad$ Liquid effluent streams monitored for compliance with DOE Order 5400.5 .

- Liquid effluent streams monitored to meet the performance monitoring objectives of DOE Order 5400.1.

This report does not address storm water discharges monitored for compliance with storm water discharge permits. This report does not address process monitoring for control of processes, which is conducted by facility or process managers. This report does not address permitting requirements and activities. Permitting activities are closely tied to monitoring activities, and exchange of information is needed. Permit applications include results from effluent monitoring, and effluent monitoring must be modified to comply with permit conditions. The report covers only liquid effluent streams, and not other types of effluent streams such as air.

Previously, liquid effluent streams were divided into radiological liquid effluent streams and nonradiological liquid effluent streams. Two program plans were prepared to cover the two programs. In practice, however, field sampling activities did not differentiate between the two programs. No value seems to be added by dividing effluent streams into radiological and nonradiological categories. Only one liquid effluent monitoring program is discussed in this report, and it addresses both radiological and nonradiological parameters.

\subsection{Organization of Report}

The first section of this report identifies the purpose and scope of the project, and the overall goals identified to be achieved for the liquid effluent monitoring review. Section 2 reviews the requirements for the program. Section 3 describes the proposed approach of how monitoring is graded to risk. The components of risk are defined in the context of the effluent monitoring program. Section 4 sets out the outline for the effluent monitoring program in generalities to give the "big picture" of how the program will be organized. 
Sections 5 through 8 give more details on each of the four phases of the effluent monitoring program. Phase one involves identification of liquid effluent streams that need to be monitored (Section 5). Once an effluent stream has been identified, it needs to be characterized (Section 6) to determine the risk the stream poses and the baseline conditions against which change will be measured. Once characterized, an effluent stream is monitored (Section 7) at the design frequency, and the data evaluated against decision criteria on a periodic basis. If evaluation of monitoring data indicates that a decision level has been reached, an assessment is initiated (Section 8). An assessment is a very specific activity to respond to a particular stimulus. The assessment concludes with a decision as to whether a response action is needed such as recharacterizing, modifying the effluent monitoring program, or installing treatment on the source process.

\section{REQUIREMENTS AND OBJECTIVES}

This section discusses the requirements and objectives of the liquid effluent monitoring program conducted by LITCO at the INEL. DOE orders identify additional objectives for effluent monitoring beyond demonstrating compliance with regulations. This section discuses how these additional effluent monitoring objectives are met.

Applicable regulations and requirements come from many sources at a variety of levels, and are summarized in Table 1. Regulations and requirements have been identified as originating from the following sources:

- City Ordinances,

- State Regulations,

- Federal Regulations,

- DOE Orders,

- Lockheed Idaho Technologies Company.

Regulations are continually changing, and so the effluent monitoring program must periodically be evaluated to assure that the program remains in compliance. This proposed plan presents an approach to monitoring that will facilitate the process of remaining in compliance.

\subsection{City of Idaho Falls}

The City of Idaho Falls, as the operator of a publicly owned treatment works (POTW), is authorized by the Clean Water Act to set pretreatment standards for non-domestic dischargers to the POTW (40 CFR 403 General Pretreatment Regulations for Existing and New Sources of Pollution). Discharges from industrial facilities to the City of Idaho Falls sewer system are covered in Section 8 
Table 1. Regulatory drivers for liquid effluent monitoring programs.

40 CFR 403 General Pretreatment Regulations for Existing and New Sources of Pollution

Section 8 City of Idaho Falls Sewer Ordinance

IDAPA 16.01.02 Water Quality Standards and Wastewater Treatment Requirements

IDAPA 16.01.17 Wastewater Land Application Permit Requirements

40 CFR 122 National Pollutant Discharge Elimination System

DOE Order 5400.1 General Environmental Protection Program

DOE Order 5400.5 Radiation Protection of the Public and the Environment

DOE Order 5700.6C Quality Assurance

of the City of Idaho Falls Sewer Ordinance. This ordinance requires that a "significant industrial User" obtain a wastewater discharge permit from the Director of the Public Works Division before discharging wastewater to the city sewer system. Sampling and analytical requirements for characterization and effluent monitoring programs are given in Sections 8-1-47 and 8-1-48 respectively. Section 8-1-9 sets general standards for prohibited discharges which could interfere with the operation of the POTW or could result in the POTW exceeding permit limitations. Specific local discharge limits for wastewater discharged to the POTW are defined in Section 8-1-12.

The discharge permit sets the general requirement that all discharges must be in accordance with Section 8 of the City of Idaho Falls Sewer Ordinance. The permit sets additional requirements on monitoring parameters, analytical methods, monitoring frequency, sampling locations, and reporting.

LITCO has obtained a "City of Idaho Falls Industrial Wastewater Acceptance Form" for the INEL Research Center (IRC) and the Willow Creek Building (WCB). The permits set release criteria for 18 parameters and prohibit the discharge of 126 Priority Pollutants at concentrations exceeding $0.099 \mathrm{mg} / \mathrm{L}$. The permits also specify sampling frequency and the locations from which samples are to be collected. Release criteria are "daily maximum allowable discharge limits" and are expressed in terms of concentration. Every six months a 24-hr composite sample is collected from the sewer discharge from the IRC and WCB. Compliance for the six-month period is based on whether the single composite sample is in compliance. More frequent weekly and daily sampling is required for some parameters. Analytical methods are specified in 40 CFR 136 Guidelines Establishing Test Procedures for the Analysis of Pollutants.

The City of Idaho Falls identifies no quality assurance (QA) or quality control (QC) requirements for the monitoring but 40 CFR 136 contains analytical, container, preservation, QA, and other requirements that are applicable. All results must be reported to the city within 30 days of the end of the month in which the data were collected. For the twice-yearly samples, the results are to be reported in July and December. The current permit requires that if any additional self-monitoring is conducted, the results shall be reported to the city. 


\subsection{State of Idaho}

The State of Idaho regulates the discharge of liquid effluent under Idaho Administrative Procedures Act (IDAPA) 16.01.02 Water Quality Standards and Wastewater Treatment Requirements. Essentially all wastewater discharged at the INEL Site is to the ground surface through infiltration ponds, septic systems, and shallow injection wells. This discharge to the land surface percolates downward, eventually reaching the Snake River Plain Aquifer. The State of Idaho has an antidegradation policy (IDAPA 16.01.02,051) to maintain existing uses of waters of the state, including groundwater. Groundwater is designated and protected for use as a potable water supply whenever possible (IDAPA 16.01.02,299.03.a).

Discharge of wastewater to the land surface must be permitted under IDAPA 16.01.17 Wastewater Land Application Rules. The regulation applies to any structure or system designed or used to treat municipal or industrial wastewater through application to the land. The purpose of the permit system is to regulate land disposal practices to protect groundwater. There are very few monitoring requirements or discharge limits explicitly specified in IDAPA 16.01.17. Permit conditions are generally developed on a facility specific basis to fulfill the requirements in IDAPA 16.01 .02 concerning the protection of groundwater for use as a potable water source.

The only regulatory limitations on effluent discharges to land application treatment units are for rapid infiltration units. For rapid infiltration units, total suspended solids (TSS) may not exceed a 30 -day average concentration of $100 \mathrm{mg} / \mathrm{L}$ and total nitrogen may not exceed a 30-day average concentration of $20 \mathrm{mg} / \mathrm{L}$ (IDAPA 16.01.17,600.05). Numerical groundwater quality criteria are specified in IDAPA 16.01.02,299.04 and IDAPA 16.01.02,299.05. Qualitative groundwater quality criteria are identified in IDAPA 16.01.02,299,04 (a) and (b). Numerical standards are set in terms of maximum allowable concentrations (MACs) for 19 parameters listed in DAPA 16.01.02,299.05. Secondary drinking water standards [secondary maximum contaminant limits (SMCL)] from 40 CFR 143.3 are also invoked as applicable standards in IDAPA 16.01.02,299.05.

A number of land application permits have been applied for by the INEL. Additional permit applications are being prepared for submittal. Only a few permits have been approved to date. Therefore, exact monitoring requirements for effluent under the land application permit program are not defined for all surface ponds. As additional permits are issued, the liquid effluent monitoring program at the facilities will have to be reviewed and revised to comply with the permit requirements. The permits obtained to date invoke the 30-day average concentration requirements on TSS and total nitrogen for liquid effluent, and MACs and secondary drinking water standards for groundwater. Effluent to the permitted unit has monitoring requirements which are generally based on 24-hour composite samples collected monthly. There are few concentration limits associated with the effluent monitoring requirements.

The State of Idaho regulations and wastewater permit applications reviewed identify no specific QA/QC requirements for monitoring programs. An annual Wastewater Land Application Site Performance Report must be submitted for each permit no later than January 31 of each year. The 
period covered by the report varies somewhat from permit to permit but generally follows the water year of November 1 through October 31. The report must include all permit-specific monitoring data (preferably on computer disk), discussion of special compliance activities, and a discussion of the monitoring data with particular attention to the environmental impacts of the facility.

The Idaho regulations and the Wastewater Land Application Permits require that groundwater not exceed MACs or SMCLs. However, discharge to the pond does not necessarily have to comply with these levels if retention, decay, and dispersion will reduce concentrations to the point that groundwater is not adversely affected. The INEL has developed release limits to control releases of pollutants to ponds to levels that will not adversely impact groundwater or pose an unacceptable risk to human health by other exposure pathways. INEL proposed release limits are discussed in a later section.

\subsection{Clean Water Act}

Activities that discharge pollutants from a point source into waters of the United States are regulated under the National Pollutant Discharge Elimination System (NPDES) program (40 CFR 122). Pollutants are defined in 40 CFR 122.2. Waters of the United States at the INEL include the Big Lost River, Little Lost River, Birch Creek, and sinks, playas, and wetlands associated

with these streams. Percolation ponds at the INEL are not waters of the United States (DOE 1993).

The U.S. Environmental Protection Agency (EPA) makes a determination to grant or deny an NPDES permit. Only one discharge subject to NPDES permitting has been identified at the INEL. This discharge consists of groundwater drawn from two production wells at the Idaho Chemical Processing Plant (ICPP) discharged to the channel of the Big Lost River. A permit application was submitted to EPA in January 1992 (A. A. Pitrolo to H. Green, January 28, 1992, NPDES Permit Application for the Idaho Chemical Processing Plant, Idaho National Engineering Laboratory). The EPA concluded that the discharge was of such a low priority, that no permit would be issued at that time. The letter from the EPA did specify that Idaho water quality standards should be met (G. Kellogg to C. M. Bennett, May 1992, NPDES Application No. ID-002722-7, Idaho National Engineering Laboratory). Idaho water quality standards for surface waters are contained in IDAPA 16.01.02.

\subsection{Department of Energy}

This section discusses DOE orders that govern liquid effluent monitoring programs. DOE orders do not currently have the weight of federal regulation, but do set requirements for activities conducted by LITCO at the INEL. There is currently an activity underway to include some of the DOE Orders in the Code of Federal Regulations. When this occurs, some of the effluent monitoring activities conducted to comply with DOE Orders may fall under federal regulations. 


\subsubsection{DOE Order $\mathbf{5 4 0 0 . 1}$}

DOE Order 5400.1 General Environmental Protection Program sets forth monitoring objectives for liquid effluent monitoring programs at DOE facilities. The six objectives of an effluent monitoring program set out in Chapter IV, Section 5.a of DOE Order 5400.1 are:

1.) Verify compliance with applicable Federal, State, and local effluent regulations and DOE Orders.

2.) Determine compliance with commitments made in Environmental Impact Statements, Environmental Assessments, or other official documents.

3.) Evaluate effectiveness of effluent treatment and control.

4.) Identify potential environmental problems and evaluate the need for remedial actions or mitigation measures.

5.) Support permit revision and/or reissuance.

6.) Detect, characterize, and report unplanned releases.

The monitoring program must be capable of measuring both quantities and concentrations of pollutants in liquid discharges.

Additional requirements for liquid effluent monitoring programs given in DOE Order 5400.1 Chapter IV, Part 5.a are:

- Effluent from on-site waste treatment or disposal systems shall be monitored in accordance with applicable regulations. Influents to on-site waste treatment or disposal systems should be monitored as needed,

- Sample collection programs shall reflect specific facility needs. Type and frequency of sampling shall be adequate to characterize effluent streams,

- Standard analyses or equivalent shall be used to analyze samples whenever such methods are required by regulatory programs,

- Auditable records shall be established in accordance with the requirements of DOE Order 5700.6C.

Chapter IV, Part 10 of DOE Order 5400.1 requires that liquid effluent monitoring programs be covered by a quality assurance program consistent with DOE Order 5700.6C Quality Assurance. Specific elements that the quality program must cover are discussed. 
Results of liquid effluent monitoring programs are to be reported in the annual site environmental report. Effluent data are to be summarized and discharge volumes, masses, and curies are to be reported. Where the data are collected for comparison to applicable standards, a discussion of the comparison should be presented.

\subsubsection{DOE Order 5400.5}

DOE Order 5400.5 Radiation Protection of the Public and the Environment sets the requirements for protection of the public from releases of radionuclides from DOE operations. The contents of this DOE Order are currently under review in draft form for adoption as federal regulation 10 CFR 834 . The protection criteria are set in terms of dose limits to the public that generally must be calculated from effluent data. Maximum concentrations that can be discharged without exposing the public to an unacceptable dose are presented as derived concentration guides (DCGs). The objective of a radioactive liquid effluent monitoring program is to gather data sufficient to evaluate dose to the public. Chapter I, Section 5.a and Section 8.a discuss the purposes of a radiological liquid effluent monitoring program. Radiological liquid effluent monitoring data are used to:

- Calculate dose to the general public,

- Detect and quantify unplanned releases,

- Demonstrate compliance with DOE dose-based limits on radionuclide concentrations in liquid effluent.

The objectives of a radiological liquid effluent program are consistent with the general liquid effluent monitoring objectives in DOE Order 5400.1.

\subsubsection{Environmental Regulatory Guide}

The Environmental Regulatory Guide for Radiological Effluent Monitoring and Environmental Protection (DOE 1991) is a guidance manual for radiological monitoring and surveillance programs at DOE facilities. Because it is a guidance document, it does not present requirements. The manual does present what are considered by DOE to be the acceptable practices that should be employed by a radiological liquid effluent monitoring program. The manual presents guidance on the design and application of liquid effluent monitoring programs.

- Continuous monitoring should be provided on release points that could exceed the DCG averaged over a year,

- Monitoring efforts should be commensurate with the importance of the source during routine operations and accidents, 
- Grab sampling is suitable for ensuring that previously determined release rates have not changed or that radionuclides are not now being released to previously clean streams.

Quality assurance and reporting requirements are the same for both radiological and nonradiological parameters.

\subsection{INEL Guidance for Disposal of Wastewater}

The policy of the Department of Energy is to conduct operations in a manner that does not adversely impact human health or the environment. With the addition of the INEL to the National Priority List under the Comprehensive Environmental Response, Compensation, and Liability Act (CERCLA), it has become clear that routine operations need to be evaluated to assure that current operations do not generate releases to the environment that result in future expense to clean up. In addition, Wastewater Land Application Permits require that wastewater disposal facilities do not degrade the quality of groundwater so that it cannot be used as a potable water source. DOE Order 5400.5 significantly curtails the discharge of radionuclides to soil columns. Guidance was needed for disposal of wastewater effluent to surface ponds to meet these objectives:

- Do not discharge quantities of pollutants that could result in soil or groundwater concentrations that could pose an unacceptable risk to human health

- Do not discharge quantities of pollutants that could cause groundwater concentrations to exceed Idaho groundwater quality standards

The second objective is contained within the scope of the first because groundwater quality standards are set to protect the public from an unacceptable exposure to hazardous materials. The second objective is stated because it has the added imperative of being required to comply with Wastewater Land Application Permits.

Proposed release limits for one time, periodic, and routine disposal of wastewater are contained in a draft report by Ansley et al. (1994). Of concern for effluent monitoring are the limits for routine disposal of wastewater to ponds. The item that needs to be controlled to control risk is the total mass (or curies) of each compound released to the pond on an annual basis. The report (Ansley et al. 1994) gives the limiting annual mass or activity for many compounds for many of the RNEL ponds. Additional limits will be developed as needed. These annual masses and activities are also converted to average concentrations based on the average annual flow to the ponds. The effluent monitoring program must collect sufficient data to quantify the mass or activity of compounds routinely discharged to each surface application site. To the routine releases, quantities from non-routine releases will be added by Wastewater Specialists to determine compliance to the release limits.

Liquid effluent monitoring for routine releases to ponds provides only part of the information needed to assess compliance to INEL release limits. Non-routine releases must be added to the routine releases to determine compliance. For this document, this distinction is not explicitly carried 
through the analyses and only routine releases are compared to release limits. The routine releases form the base load to the ponds. While non-routine releases will be constrained by the available capacity above the mass discharged routinely, it is not likely that routine releases will be constrained by non-routine releases. Therefore, not explicitly including non-routine releases in the development of the monitoring program will not invalidate the conclusions developed from the analysis. For actual implementation, the impact that the non-routine releases have on compliance will have to be evaluated to determine if they significantly alter the decision criteria. It is not expected that they will.

\subsection{Quality Assurance}

DOE Order 5400.1 states that "A quality assurance program consistent with DOE Order 5700.6C shall be established covering each element of environmental monitoring and surveillance programs commensurate with its nature and complexity." The quality assurance program shall include, but not be limited to, the following:

- Organizational responsibility,

- Program design,

- Procedures,

- Field quality control,

- Laboratory quality control,

- Human factors,

- Record keeping,

- Chain of custody,

- Audits,

- Performance reporting,

- Independent data verification.

DOE Order 5700.6C requires development of a contractor Quality Program Plan that addresses the following 10 criteria:

Management

- Quality program, 
- Personnel training and qualifications,

- Quality improvement process,

- Documents and records.

\section{Performance}

- Work process,

- Design,

- Procurement,

- Inspection and acceptance testing.

\section{$\underline{\text { Assessment }}$}

- Management assessment,

- Independent assessment.

The order further states that the format and number of criteria contained in an organization's quality program are important only if they affect the organization's performance. ASME/NQA-1 is not identified as a requirement.

EPA has developed guidance for quality programs for environmental monitoring and sampling activities (QAMS-005/80; EPA 1983). Because this guidance has been developed specifically for environmental investigations (and not, say, for building nuclear reactors) it is commonly adopted by environmental sampling and monitoring programs. The data collected by compliance monitoring programs are generally sent to a State of Idaho or EPA regulator for review. These regulators are most familiar with quality programs based on EPA guidance, and are more likely to readily accept a program designed around QAMS-005/80. All 10 elements of a quality program required by DOE Order $5700.6 \mathrm{C}$ are readily incorporated into a quality program following the format of QAMS-005/80. The elements of a QAMS-005/80 quality program are:

- Project description,

- Project organization and responsibilities,

- Quality assurance objectives for measurement,

- Sampling procedures, 
- Sample custody,

- Calibration procedures and frequency,

- Analytical procedures,

- Data reduction, validation, and reporting,

- Internal quality control checks,

- Performance and system audits,

- Preventative maintenance,

- Assessment of data,

- Corrective action,

- Quality assurance reports to management.

\subsection{Summary of Requirements and Objectives}

DOE Order 5400.1 presents six objectives of a liquid effluent monitoring program

(Section 2.4.1). DOE does not provide guidance on how these objectives are to be met other than to indicate that effluent monitoring be commensurate with the importance of the source. A strategy must be developed to meet the six objectives of monitoring. This effluent monitoring approach proposes a strategy that meets objectives in one of two ways.

- By showing that effluent concentrations are below concentration limits set by permits or are below concentrations that could cause an environmental problem (release limits).

- By showing that concentrations in effluent have not changed from a period when treatment processes were in control and there were no unplanned releases.

The following sections discuss which objectives are met in each of these two ways.

\subsubsection{Comparison to Release Limits}

Release limits are set in permits issued to the INEL or in the INEL Management Guidance for Disposal of Wastewater (Ansley et al. 1994). There are three sources of regulatory requirements based on permits:

- City of Idaho Falls Industrial Wastewater Acceptance Permits, 
- State of Idaho Wastewater Land Application Permits,

- $\quad$ EPA expectations that discharge to the Big Lost River from ICPP meet Idaho water quality criteria.

Comparing concentrations measured in liquid effluent to the appropriate release limits in the applicable permit verifies compliance with Federal, State, and local regulations.

Monitoring to comply with permit conditions fulfills two of the six objectives of a liquid effluent monitoring program specified in DOE Order 5400.1. Monitoring to meet permit conditions verifies compliance with regulations (objective 1.) and also provides data to support permit revision or reissuance (objective 5.). There have been no commitments identified in past effluent monitoring program plans as governing effluent monitoring programs. For now, there are no official commitments to monitor under objective 2. of DOE Order 5400.1.

Compliance with Wastewater Land Application permits requires that groundwater beneath the facility not contain pollutant concentrations exceeding Idaho water quality standards. The approach to meeting this requirement has been to evaluate the retention and dispersion characteristics of the vadose zone and aquifer, set release limits to the permitted units, and operate the units within the release limits. Effluent monitoring is used to demonstrate that the units are being operated within the release limits. While release limits are not explicitly identified in Wastewater Land Application Permits, staying within the release limits is the way that the INEL has chosen to assure that permit conditions are met.

INEL Management Guidance for Disposal of Wastewater (Ansley et al. 1994) presents release limits for ponds. These limits were developed to assure that long-term use of the ponds for wastewater disposal would not result in accumulation of contaminants that could result in unacceptable risk to human health. Monitoring for compliance with INEL release limits assures that effluent releases to ponds do not result in adverse environmental affects or create a remediation liability (objective 4. of DOE Order 5400.1).

\subsubsection{Identifying Change}

Two objectives of liquid effluent monitoring are to evaluate the effectiveness of treatment and control (objective 3.) and to detect, characterize, and report unplanned releases (objective 6.). The approach to meeting these two objectives is to look for a change in effluent concentrations. An effluent stream is first characterized to determine the expected concentrations during a period when the effluent is in control. Monitoring is conducted to identify any change in effluent concentrations from the historical norm. Changes may indicate treatment or control processes have failed or an unplanned release has occurred. A followup assessment is necessary to determine if change is related to one of these causes. 


\subsubsection{Decision Basis}

The two approaches to meeting monitoring objectives lead to the decision basis of the liquid effluent monitoring program. For compliance with permits and avoiding adverse environmental impacts, the decision made by the program is:

- Does the concentration of a parameter exceed the release limit set for this effluent stream?

If the answer to this question is "no", then the effluent stream is in compliance with regulations and there is no indication of adverse environmental affects. The second decision the program has to make is:

- Does the concentration of a parameter indicate that a change has occurred?

As long as there is no evidence of change, then there is no evidence of a loss of control or an unplanned release.

This section has presented the requirements and objectives of a liquid effluent monitoring program. The section has also presented how the effluent monitoring program meets the objectives. The next section begins to discuss the issue of how monitoring is made commensurate with the importance of the source.

\section{RISK BASED DESIGN BASIS FOR AN EFFLUENT MONITORING PROGRAM}

A prime objective of the program review is to develop an approach to liquid effluent monitoring that is commensurate with the importance of the source. The approach proposed in this report uses risk as the measure of the importance of the source. This section defines risk and discusses how risk is used as the design basis in the development of the liquid effluent monitoring program. The resulting effluent monitoring program is graded so that monitoring intensity or frequency is based on risk in accordance with DOE guidance for monitoring (DOE 1991).

Risk is defined to have two components (ASME 1991):

- Likelihood - the probability of an adverse consequence, and

- Severity - the impact of an adverse consequence.

The concepts of "adverse consequence", "likelihood", and "severity" need to be defined as they apply to the liquid effluent monitoring program. 
Adverse consequence is defined to be that the concentration of a parameter measured in a sample collected from a liquid effluent exceeds the corresponding release limit. A release limit can come from a variety of sources including a permit limit, a DCG in a DOE Order, or a self-developed limit based on adverse human health effects. By this definition, an adverse consequence can only occur if a release limit has been defined.

\subsection{Likelihood}

The likelihood of adverse consequences is defined to be the probability that the concentration of a parameter will exceed a release limit. Two statistical probabilities are calculated:

- The probability that a single measurement $(x)$ of a parameter could equal or exceed the release limit $[P(x \geq L)]$, and

- The probability that the average $(\mu)$ concentration of a parameter could equal or exceed the release limit $[P(\mu \geq L)]$.

For each parameter, there is a statistical probability $(P)$ that the parameter could exceed the release limit (L). If there is no limit, then a probability cannot be calculated. For each parameter, likelihood can fall into one of three categories:

LOW

No limit or

$\mathrm{P}(\mathrm{x} \geq \mathrm{L})$ is acceptable

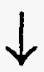

MEDIUM

$\mathrm{P}(\mathrm{x} \geq \mathrm{L})$ is not acceptable

but $\mathrm{P}(\mu \geq \mathrm{L})$ is acceptable

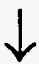

HIGH

$\mathrm{P}(\mu \geq \mathrm{L})$ is not acceptable

The probability that represents an acceptable likelihood is a management decision. For parameters where the entire range of observations is well below the release limit, the probability of a single observation $(x)$ exceeding the limit is very small. If concentrations are higher, there may be an unacceptable probability that a single measurement $(x)$ could be above the limit while the average concentration of the parameter over time $(\mu)$ could still be below the limit. For some parameters, the average concentration $(\mu)$ may be above the limit, or so close that it would be hard to demonstrate that the mean was below the limit with any confidence. 
Figure 1 illustrates two examples of the relation between the data, the release limit, and the probability of exceeding the limit. The graphs show the frequency distribution of the monitoring data as a bar chart; the expected distribution of the data if it were normally distributed with the same mean and variance as the monitoring data as a bell-shaped curve; the mean concentration (nominal); the concentrations three standard deviations above and below the mean $(-3 . S$ and $+3 . S)$; and the release limit [called the upper specification limit (USL) by the statistical package used to generate the plots]. Figure 1A illustrates a case where the release limit is well above the actual and expected range of the monitoring data. For a normal distribution, $99.9 \%$ of the observations are expected to lie below the value that is three standard deviations above the mean. The probability of obtaining a measurement that is at or above the release limit in case $A$ is much less than 1 in 10,000 .

Figure 1B illustrates a case where the monitoring data are much closer to the release limit. None of the monitoring data have exceeded the release limit yet. If the data come from a normally distributed population, there is a $5 \%$ chance of obtaining a measurement that does exceed the limit. That is $P(x \geq 4.605)=0.05$. The $5 \%$ number represents the fraction of the total area under the bellshaped curve that lies to the right of the release limit (the line labeled USL in Figure 1B). Calculating the probability that the mean exceeds the release limit gives a probability of less then 0.001 .

Figure $1 \mathrm{~A}$ represents a case where there is a very low, and thus acceptable, probability that a sample collected from the effluent would exceed the release limit. This is a situation where there is a low likelihood of an adverse consequence. In Figure 1B, there is a 5\% chance that a sample could exceed the release limit, but a very small chance that a mean calculated from several samples would exceed the limit. If $5 \%$ is considered to be too high a chance of an adverse consequence for a single sample, then Figure 1B illustrates an example with a medium likelihood of an adverse consequence.

\subsection{Severity}

Release limits are not necessarily regulatory in nature, and so exceeding a release limit may not result in a noncompliance. Most release limits are based on the effects of long-term chronic exposure, and so a brief exceedance may not result in any human health effects. Compliance may be based on an average concentration over a time interval, so that one sample above a release limit does not necessarily result in a noncompliance. Rather than define severity in terms of noncompliance, severity is defined in terms of the time available to recover from exceeding a release limit. Some regulations or permits are based on a single measurement exceeding a limit. In this case, there is no time to recover from an exceedance. An example of a regulatory limit without response time is the Idaho Falls Sewer Ordinance. The regulatory limit is based on maximum daily concentration and is determined from one 8-hr or 24-hr composite sample. If the sample exceeds the limit, then a violation has occurred. In other cases, the limit is based on the average over some time period. In this case, there is time to respond - correct the problem or collect more samples to include in an average. An example of parameters with time to implement corrective action and avoid a noncompliance are derived concentration guides for radionuclides. DOE places limits on the discharge of radionuclides to the environment based on the total annual curie release. Over the course of a year, high concentration samples will be averaged with low concentration samples. If releases early in the 

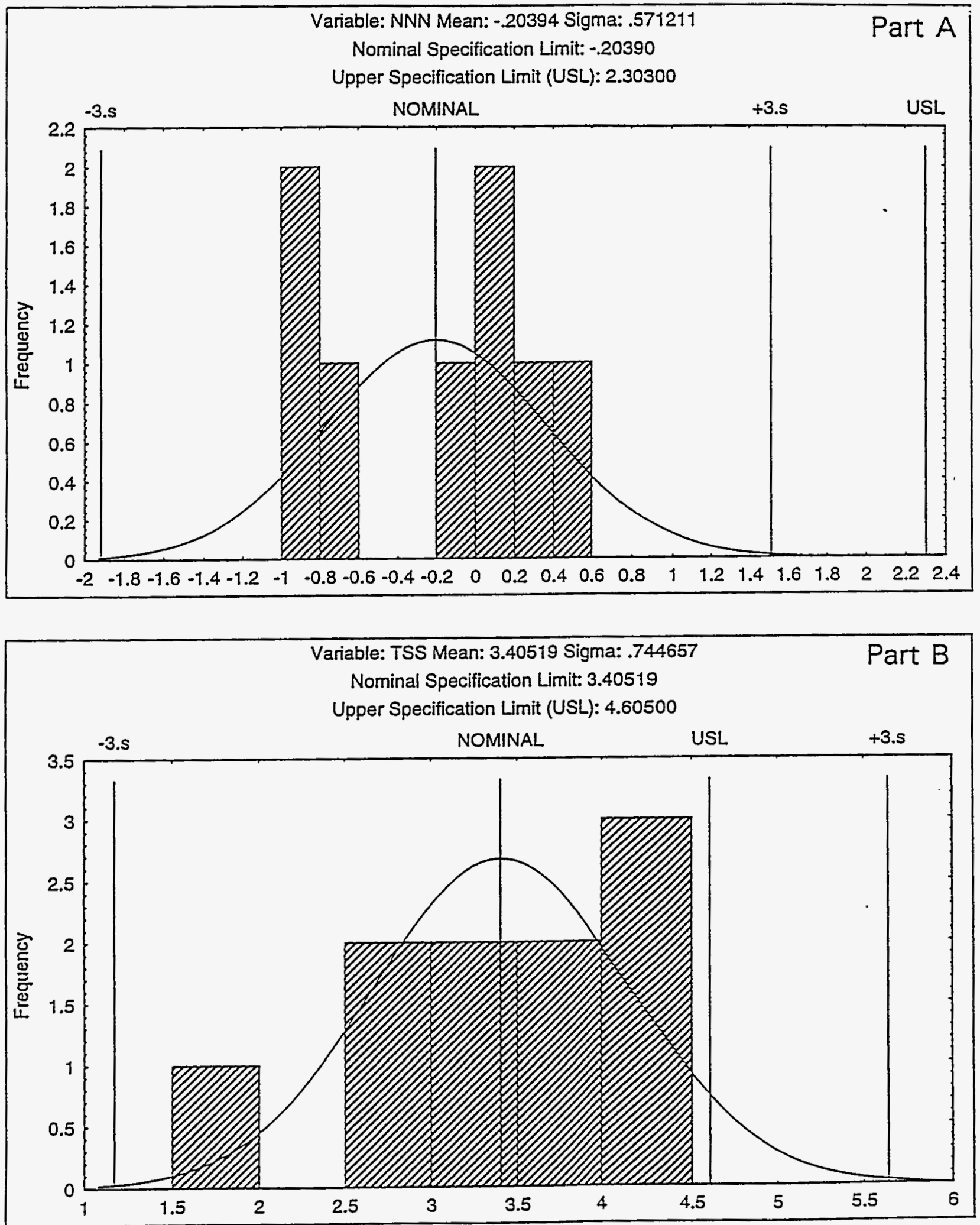

Figure 1. Frequency distribution bar charts, where the release limit is above the actual and expected (Part A), or near the actual and expected (Part B) distribution of monitoring data. 
year indicate the possibility of exceeding the derived concentration guides, then process modifications can be implemented.

Adequate response time, for the purpose of evaluating severity, is the availability of sufficient time to take corrective action when possible limit violations are detected. Severity increases from low to high as:

LOW

MEDIUM
No Limit

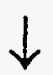

Limit with response time

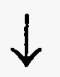

$\mathrm{HIGH}$
Limit with no response time.

Severity is driven by the regulatory requirements, and is generally outside the control of the monitoring program or facility. For high severity cases, monitoring is conducted to confirm that the effluent or groundwater is in compliance. The sources must be operated to assure that effluent concentrations remain below release limits. For medium severity cases, single samples that indicate a potential lack of compliance can trigger corrective action to control processes or collect additional samples to include in the calculation of the average. Corrective action can be taken to achieve compliance with release limits by the end of the compliance period.

\subsection{Risk}

The two components of risk, likelihood and severity, are measured on two separate scales and cannot be readily combined into a single number that represents overall risk. The next paragraphs show how the two components are used to develop a monitoring strategy. The two components of risk, likelihood and severity, are plotted in Figure 2. Monitoring strategies are developed based on the combination of likelihood and severity. Four different strategies have been identified to cover the range of possible combinations.

For situations where there is a medium or high probability of a result with high severity, or a high probability of a result with medium or high severity, the problem is not a monitoring problem but a waste reduction issue. This strategy is designated "Change process" in Figure 2. The source to the waste stream must be reduced so that the probability of the medium or high severity event occurring is reduced to an acceptable level.

Where compliance is based on a mean concentration over time, the number of samples can be calculated needed to show, with acceptable uncertainty, that the mean is below the limit (center box, 

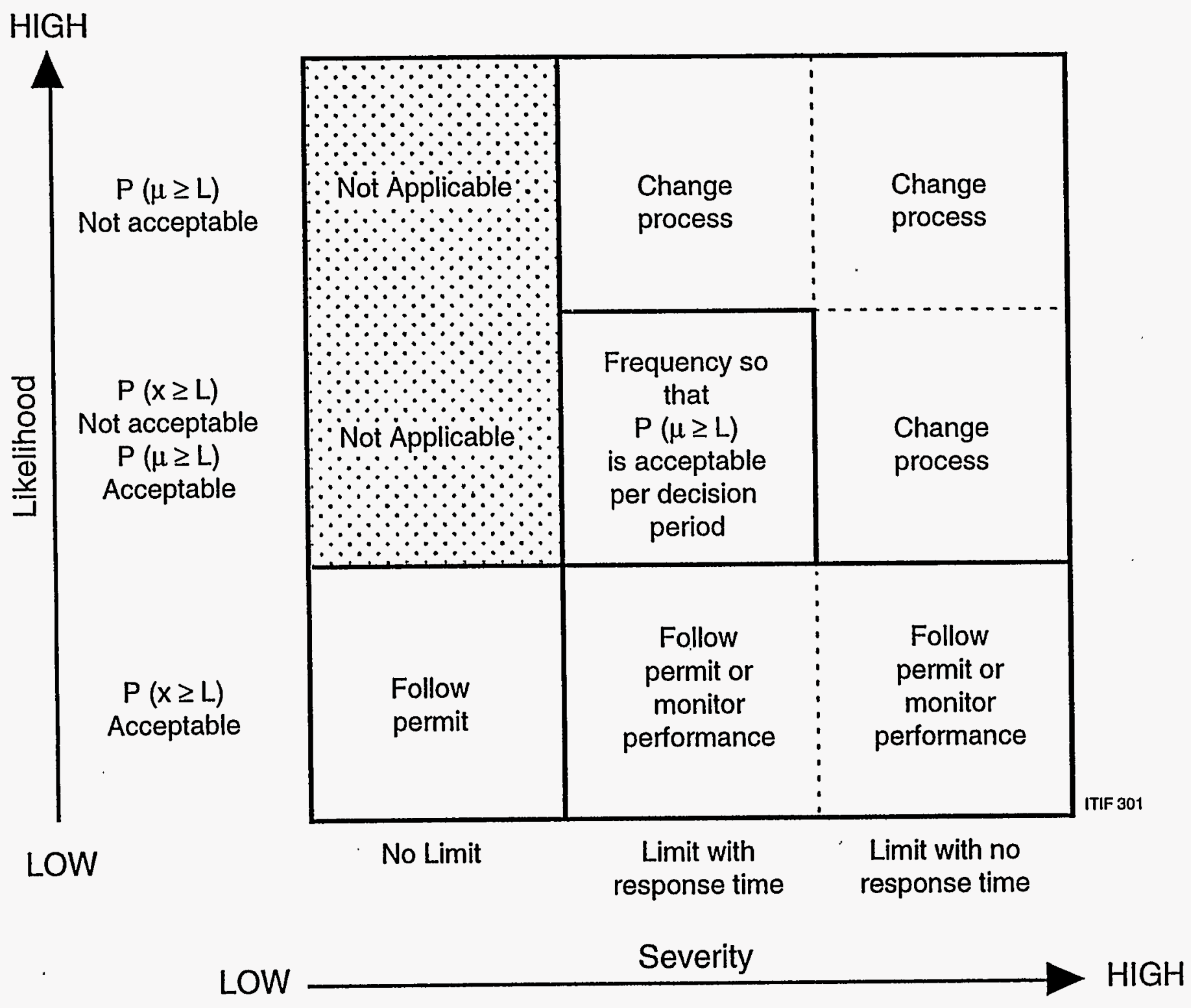
Figure 2). If the number of samples, required to demonstrate that the mean is below the limit, is too high to be cost effective, then control mechanisms must be put in place. If the calculated number of samples is acceptable, then this number can be used as the design basis for the monitoring program.

For cases where the probability of even one measurement exceeding the limit is acceptably low (right two boxes, bottom row, Figure 2), monitoring frequency is governed by the monitoring requirements associated with the release limit. Wastewater Land Application Permits generally require monthly sampling. The City of Idaho Falls requires sampling twice per year. In other cases, the monitoring frequency is not explicitly defined along with the source of the limits. In this case, frequency would be based on the need to detect change. Changes that could modify the probability of exceeding a release limit need to be identified to assure that the program continues to be properly graded to risk.

A fourth monitoring strategy is identified for effluent streams that are not governed by release limits. Some permits require periodic monitoring for parameters for which no release limits are set. In this situation, monitoring frequency is controlled by permit conditions. Wastewater Land Application Permits require monthly monitoring for a number of parameters without release limits. If a parameter has no release limit, and monitoring is not required by permit, then a decision should be made as to whether there is any justification for monitoring that parameter. Without a release limit, risk is low, and there are likely no decisions to be made from the parameter.

The design basis for an effluent monitoring program is risk. Risk is defined two have two components: (1) the likelihood of exceeding a release limit, and (2) the response time available to recover from a condition that indicates a limit may be exceeded. Where there is an unacceptably high probability of exceeding a limit without time to take corrective action, process changes should be implemented. Where there is adequate time to take corrective action, monitoring frequency is set to give an acceptable probability that compliance will be demonstrated over the duration of the compliance period. For conditions with a very low probability of exceeding a limit, monitoring frequency is determined by governing requirements (usually the permit) or set to a level to assure that the process has not changed to the extent that the probability of exceeding the limit has increased to an unacceptable level. Where no limit exists, monitoring is conducted when required by a permit. Parameters without a limit or permit requirement should be evaluated to determine if there is justification for continued monitoring.

\section{PHASED IMPLEMENTATION OF EFFLUENT MONITORING}

This chapter provides an overview of the proposed implementation of liquid effluent monitoring by the LITCO EM Program at the INEL. Four phases are identified to meet different objectives during different parts of the life cycle of the monitoring of an effluent stream. The benefits to be gained from a program with clearly identified phases are:

- More focused effort during each phase, 
- Clearly defined decision points marking transition.

The four phases are identified as:

- Identification,

- Characterization,

- Monitoring,

- Assessment.

Each phase is briefly discussed in this section and key characteristics of each phase are emphasized. Following sections discuss each phase in more detail.

\subsection{Identification}

During the identification phase, a decision is reached as to whether the liquid effluent is derived from a process, activity, or source that has the potential to introduce contaminants into the effluent stream. This may be achieved by process knowledge or by sampling. Decisions concerning the need to permit the effluent waste stream are also made during this phase. A liquid effluent inventory (LEI) has been conducted at the INEL. The objective of the LEI was to determine whether there are potential sources of contaminants for each effluent stream and to identify the effluent streams that require monitoring.

Identification is an on-going process. New effluent streams are added, old ones are dropped, and processes contributing to effluent streams change. Periodic review is necessary to assure that the effluent monitoring program is functioning properly.

\subsection{Characterization}

Once a liquid effluent waste stream has been identified, and it is determined that there is a source with the potential to introduce contaminants into the waste stream, the effluent needs to be characterized. The objectives of characterization are to provide data from which risk can be quantified and to establish baseline conditions for measuring change. Decision drivers are identified for each effluent stream. These decision drivers are either compliance or performance based. Compliance drivers are based on permit conditions, INEL release limits, DOE Order 5400.5 DCGs, or other specified release limits. Performance drivers are based on the need to detect changes in the mean or variance that indicate a loss of control or an unplanned release.

Each of these decision drivers has an associated time frame which must be considered. Compliance drivers are based on a compliance period that ranges from daily maximum concentrations 
to average annual concentrations. For others, the time frame for decisions is not defined by regulation, but by the need to identify changes in the process. The performance review period is based on a management decision concerning the frequency at which independent evaluation of system control and unplanned releases is necessary.

Characterization involves determining the flow and concentration characteristics of an effluent stream. With this characterization information, three key analyses are performed:

- What is the probability that a single measurement of a parameter can exceed a release limit?

- What is the probability that the average concentration of a parameter can exceed a release limit?

- What is the expected concentration and the variance of concentrations for parameters?

Using these analyses, an effluent monitoring program is designed that is focused by risk and system performance. The frequency of sampling and the list of parameters are adjusted to address risk and to comply with permit conditions.

\subsection{Monitoring}

During the monitoring phase of the program, data are gathered from effluent streams following the monitoring plan developed during the characterization phase. The monitoring data collected are periodically input to the decision process. The timing and frequency of the decision process will generally be driven by external factors such as permit reporting requirements. In the decision process, monitoring data are compared to trigger levels. Trigger levels are release limits and concentration levels which indicate that the measured concentration is not consistent with historical data. The decisions, based on trigger levels, are:

- Does the concentration of a parameter exceed the release limit set for this effluent stream?

- Does the concentration of a parameter indicate that a change has occurred?

The procedure by which monitoring data are compared to trigger levels is documented in EM Program procedures. When trigger levels are exceeded, an assessment is initiated.

Results of monitoring are documented in reports. The reports do more than just list results. For each parameter in each effluent stream, a decision is made and documented in the report as to whether release limits have been exceeded and whether there is evidence of a change in the level of the parameter. 


\subsection{Assessment}

The assessment phase runs concurrently with the monitoring phase. An assessment is initiated whenever certain, well defined, criteria are met by the monitoring data. When monitoring results indicate an "out of control" condition, assessment is performed. Out of control conditions are indicated when:

- A concentration exceeds a release limit,

- A concentration is outside the expected range of historical data.

An assessment is an activity conducted to reach a decision concerning the out of control condition. As such, it has a specific time duration, involves well defined activities, and ends with a decision. Based on the assessment, an appropriate response action is initiated. This could range from "do nothing" to recharacterization of the effluent, to installation of a treatment technology.

\section{IDENTIFICATION}

The DOE-ID Environmental Support Branch initiated a project to identify all facility liquid effluent discharges at the INEL and DOE-DD buildings located in the City of Idaho Falls that discharge liquid effluent that could require permitting, monitoring under DOE Orders, or could adversely impact the Snake River Plain Aquifer or waters of the United States. The liquid effluent inventory was conducted to identify all liquid effluent streams from INEL buildings and equipment to septic systems, percolation ponds, ditches, French drains, shallow injection wells, and the land surface.

To further characterize these liquid effluent streams, a sampling and analysis program was conducted during the summer and fall of 1994 (Pinzel 1994) to sample effluent streams and soils at discharge points. Sampling data augments process knowledge information to determine whether any permitting, monitoring, or reporting is required for these liquid effluent streams.

The flow of the identification process is shown in Figure 3. For effluent streams where permits set effluent monitoring requirements, the process can be bypassed and monitoring requirements identified from permit conditions. The identification process is as much to document those effluent streams that do not need to be monitored as to identify effluent streams that do need to be monitored. The criteria for determining that an effluent requires additional evaluation are:

- There is a source of contaminants to the effluent, and

- The effluent is released to the environment. 


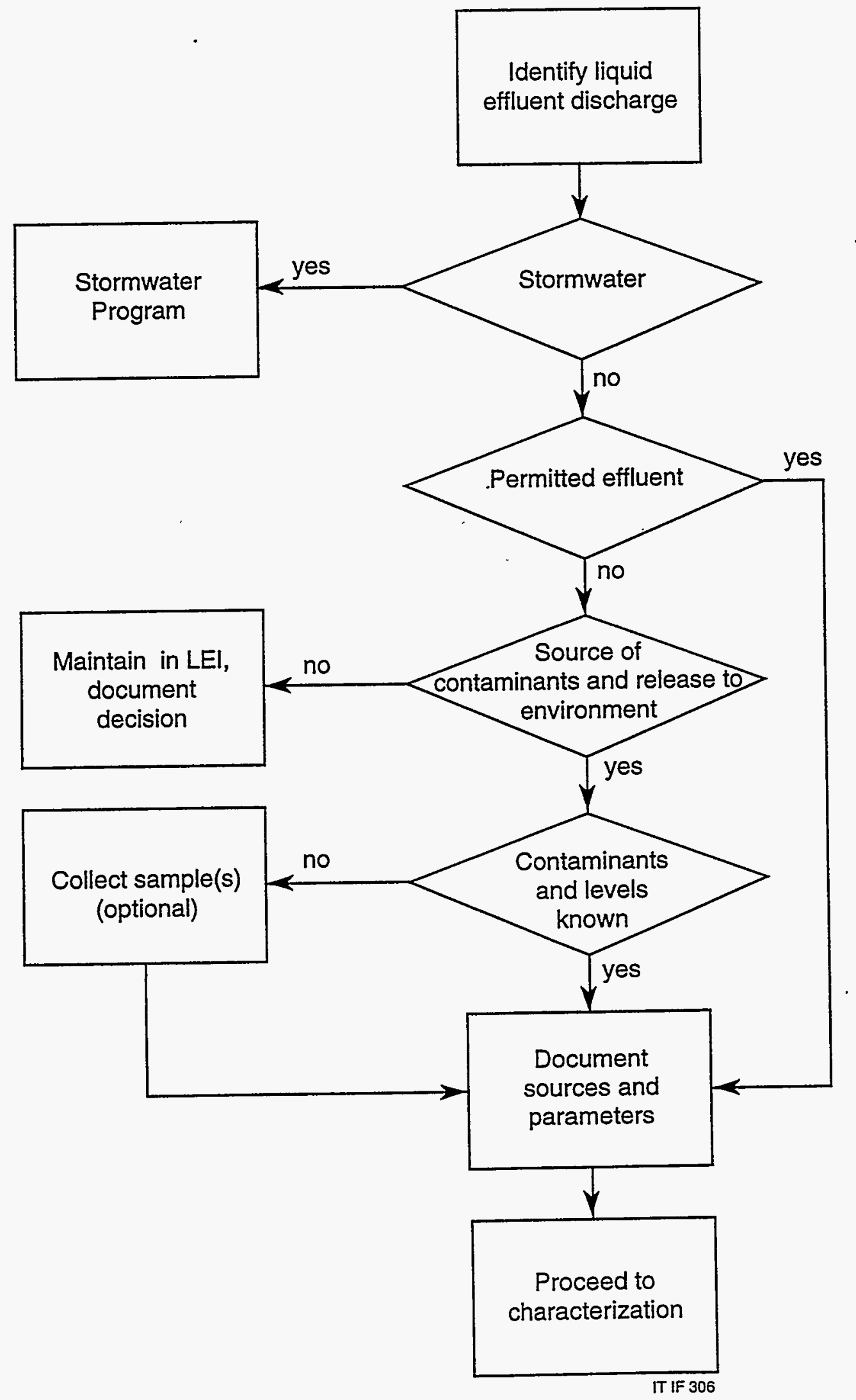

Figure 3. Overview of the identification process. 
Both of these conditions are necessary to require that an effluent be passed on to the characterization phase. Liquid effluent streams that do not meet these two criteria can also be identified for characterization and monitoring at the request of the facility manager.

\subsection{Continuing Effluent Identification}

While the LEI has been conducted to identify all present effluent releases, a periodic reassessment is necessary. Identification is not a one-time effort that is now complete. Periodically, the EM program or other responsible organizations will have to reassess systems for effluent releases. For effluent streams that are being monitored, the data review and evaluation are adequate to identify effluent streams that may reflect a change in source conditions. Activity is needed outside of the sampling and analysis approach to identify new effluent streams or non-monitored streams where changes may have invalidated the initial assessment that monitoring was not necessary.

A questionnaire has been compiled as an example of the types of information that should be gathered during a review to identify new effluent streams. The questionnaire is shown in Figure 4. If the effluent stream was covered in the initial 1994 LEI and there have been no changes in processes or sources, then the original conclusion can stand. If no changes have taken place that alter the initial conclusion, documentation can be added to the files that the monitoring status of each effluent reflects current conditions.

If the effluent stream is new since the 1994 LEI, or changes in sources or processes have occurred, then the questionnaire can be used to document the decision process for the new/altered effluent stream. The questionnaire is to document the characteristics of an effluent stream that form the basis of the decision to take no further action on the effluent stream or to characterize the effluent stream. If monitoring is not required by a permit and the effluent is not released to the environment or the effiuent is not connected to a source of contaminants, then characterization and monitoring are not required. However, facility managers may request characterization and/or monitoring of liquid effluent streams.

\subsection{Identification of Characterization and Monitoring Parameters}

For each effluent stream, the list of monitoring parameters is derived from permit requirements and contaminants with potential sources contributing to the effluent. For in-town facilities, the list of parameters is provided in the City of Idaho Falls Wastewater Acceptance Permits. For wastewater land application facilities at the INEL, monitoring parameters are specified by State of Idaho permits. In addition, the permits specify that groundwater cannot exceed MACs and SMCLs. Not all parameters would have to be monitored, but to be comprehensive, effluent streams would have to be evaluated for the presence of all compounds. This could be done by sampling or process knowledge. Therefore, during the identification phase, documentation should be developed for the files for chemicals used in processes contributing to effluent streams. This will result in a subset of parameters 


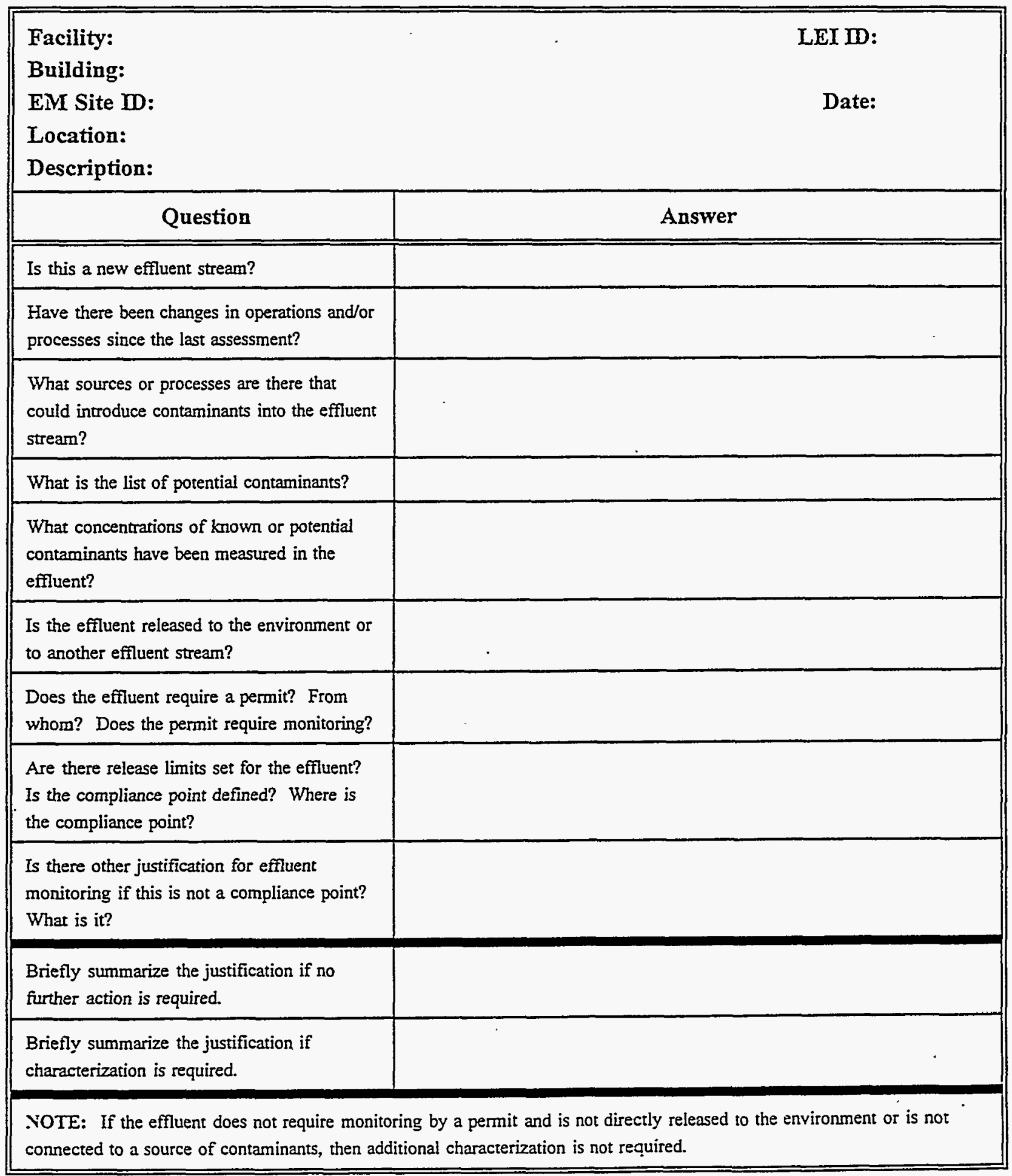

Figure 4. Example of effluent stream identification questionnaire. 
with INEL release limits that require characterization and monitoring because they are potential contaminants (Ansley et al. 1994).

In the past, radiological liquid effluent has been identified and monitored in a separate program than the nonradiological effluent. However, the radiological liquid effluent streams were usually monitored for nonradiological parameters duplicating documentation and effort. This proposed program does not differentiate effluent streams into radiological and nonradiological. Radionuclides are another group of parameters that are monitored in an effluent stream based on the presence of sources to that effluent.

Effluent parameters can generally be grouped based on analytical method and permitted sampling requirements. For example, if inductively coupled plasma emission spectophometry (ICP) is used to analyze metals, then a long list of metals can be analyzed simultaneously. These metals can be grouped together and a monitoring decision concerning metals within the group be applied to the group as a whole. Wastewater Land Application Permits generally require analysis of a suite of parameters such as total nitrogen, total suspended solids, biological oxygen demand, and others. Because this suite of parameters occurs frequently, it also could form the basis of a group. Decisions concerning the need to monitor and monitoring frequency will generally be applied across a group of parameters. Decisions, characterization, and sampling runs will not have to be made on a parameter by parameter basis (potentially dozens per effluent stream) but for a few groups of parameters.

\section{CHARACTERIZATION}

Once an effluent stream has been identified as potentially requiring monitoring, it must be characterized.

\subsection{Objectives of Characterization}

There are two primary goals of the characterization phase of a monitoring program. These are to:

- Identify the risk posed by the effluent stream,

- Identify the expected conditions against which future deviations can be measured.

One goal of characterization is to gather the basic data needed to determine the risk posed by an effluent stream so that an appropriate effluent monitoring program can be designed. The graded approach presented in DOE Orders indicates that the amount of effort expended in monitoring a liquid effluent stream should be a function of the risk that is posed by the effluent stream. Risk is comprised of two components:

- likelihood of exceeding a release limit; and 
- $\quad$ severity of exceeding a release limit.

If there is a high likelihood of exceeding a release limit, then there is a high probability of an adverse consequence. The second component of risk is the impact of exceeding a release limit and is measured by the time frame available to recover from an exceedance. If a one time measurement results in a permit violation, there is no time to recover.

Three pieces of information are expected to be generated by the characterization phase:

- What is the probability of a single observation exceeding a release limit?

- What is the probability of the average of several observations collected over a specified time interval exceeding a release limit?

- What is the expected value and variance of effluent stream concentrations?

The first two questions are directly linked to a specified release limit. Therefore, characterization for probabilities is only meaningful for effluent streams that have a defined release limit. For waste streams that are covered, the time frame of the release limit must also be considered.

Effluent streams need to have a baseline established from which future deviations can be measured. The third question addresses the need to monitor for effectiveness of control or unplanned releases. This requirement is derived from DOE Order 5400.1 and forms the basis for a performance monitoring program. Unplanned releases and loss of control are identified by detecting changes in the effluent stream. An overview of the characterization process is shown as a flow diagram in Figure 5.

\subsection{Assessing Risk}

An analysis of effluent waste streams has been conducted to develop the methodology to calculate risk for liquid effluent streams. A limit must exist to be able to calculate a probability. If no limit exists, then, by definition the likelihood of exceeding a limit is low. Closely tied with this is that the limit is only applicable at a point of compliance.

\subsubsection{Calculating Probabilities}

The first step in assessing risk is to determine the probability of exceeding a release limit. There are a number of hurdles that must be cleared to determine probability. To calculate a probability, the frequency distribution (i.e., normal, log-normal) that the data follow must be known. Effluent data frequently involve the measurement of trace constituents that are either absent or present below the method detection limit. These data are not missing, but are not quantified and can bias the estimate of the mean and variance. Historical effluent monitoring data may not be comparable over the entire time period if there have been changes in sampling locations, sampling methodology, analytical laboratories, etc. Generalities about the liquid effluent may not be meaningful if the data upon which 


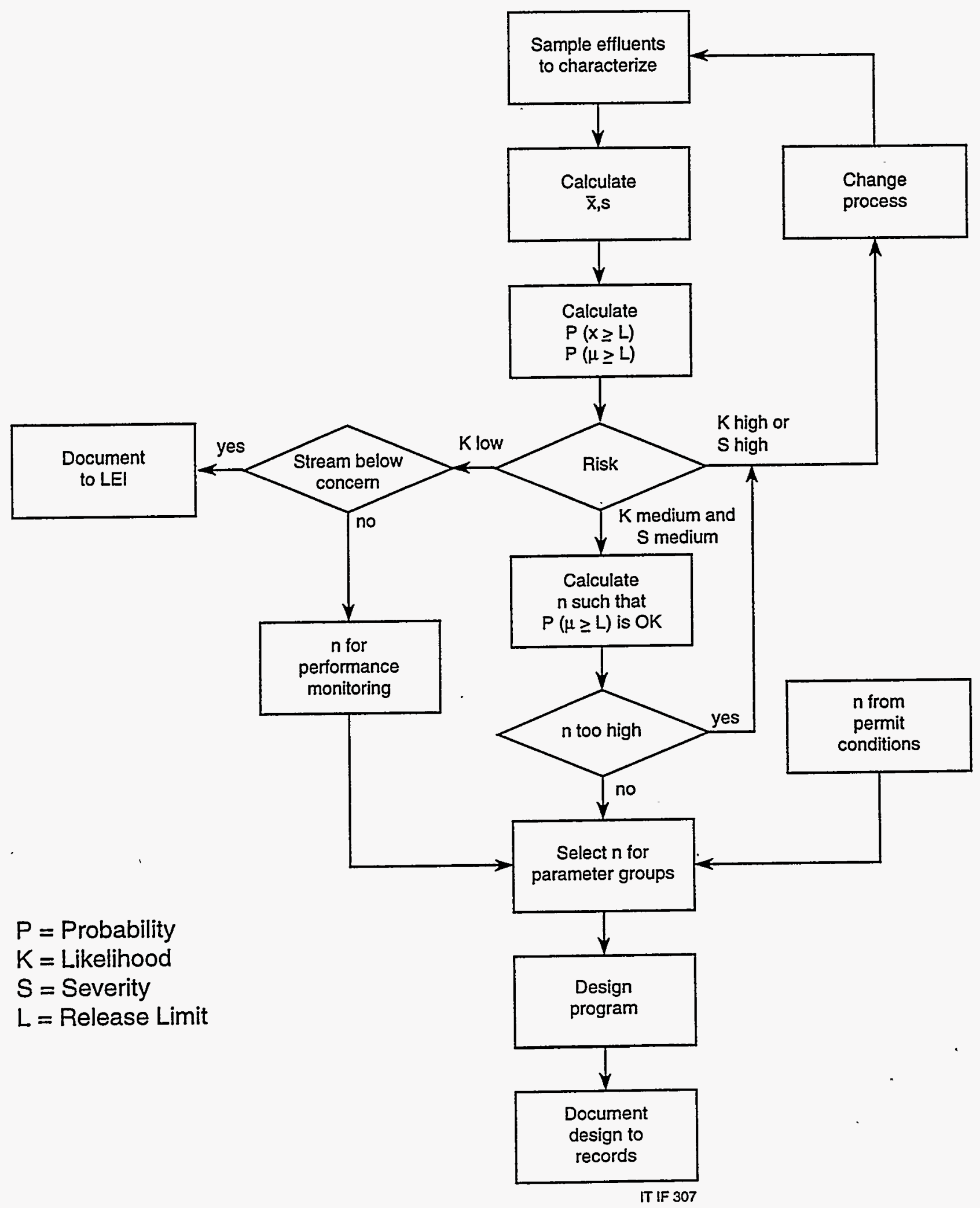

Figure 5. Overview of the characterization process. 
they are based are not comparable. Finally, there may be occurrences when the effluent stream was "out of control" during characterization. The "out of control" samples may bias the mean and variance used to calculate the probability. For collection of new characterization data, comparability and "out of control" situations will be easier to identify and avoid. When historical monitoring data are used for characterization, all of these issues may exist.

The purpose of calculating probability is to determine the likelihood of exceeding a release limit. Likelihood has only three categories, and so probabilities can vary over a wide range and not affect the determination of likelihood. Overestimating the probability of exceeding a limit could result in some additional sample collection. Underestimating the probability of exceeding a release limit could result in a permit violation or undesirable environmental concentrations. Therefore, additional sources of variation (noncomparability, out of control conditions) would generally be included in the estimate of the mean and variance of effluent concentrations. Estimates of probability would then be expected to be biased high so that errors would be protective in terms of compliance and environmental effects.

Many environmental data are skewed towards higher values, and are not normally distributed. Problems with skewness can frequently be corrected by working with the logarithms of the data (Gilbert 1987; EPA 1989; EPA 1992). Two analyses of the impact of assuming different frequency distributions have been conducted by G. A. Harris ${ }^{1}$ and L. C. Hull ${ }^{2}$ using EM Program effluent monitoring data. Various statistical techniques were used to measure the fit of the data to normal and $\log$ normal distributions. For many parameters, the data did not fit either model very well. The effluent data exhibited a wide range of frequency distributions including some that were distinctly bimodal. Probabilities of exceeding limits were calculated for both normal and log normal distributions. Both distributions showed very similar probabilities. Both Harris and Hull concluded that it was reasonable to assume that effluent monitoring data were log-normally distributed, and that this assumption would not appreciable affect decisions concerning the exceedance of release limits.

Harris and Hull also looked at approaches of dealing with data that were below the detection limit. The conceptual model adopted for inorganic compounds and metals is that the compound or metal is present in the effluent, but at a concentration below the detection limit. A number of methods of estimating the less than detection data were evaluated. One significant impediment for the EM Program effluent data is that for many parameters, the detection limit changes over time. Almost all methods of estimating the less than detection data require a constant detection limit. Hull and Harris concluded that there were no methods that offered a significant advantage over replacing all less than detection limit concentrations with $1 / 2$ the detection limit.

For volatile organic compounds, a different conceptual model is used. Harris and Hull did not investigate volatile organic compounds so an approach modeled after one presented by EPA (1992) is

1. Harris, G. A. to L. J. Peterson-Wright, Probability of Exceeding Regulatory Limits in Effluent Streams GAH-10-91, Interoffice Correspondence, EG\&G Idaho, Inc. September 23, 1991.

2. Hull, L. C. to L. V. Street, Methods of determining means and variances for estimating risks, Informal Project Report, IT Corporation, May 18, 1995. 
adopted. For volatile organic compounds, it is assumed that there is no natural source and that any . volatile organic compound detected has been added to the effluent stream. When the compound is not detected, it is assumed to be absent. A Poisson distribution is used to model rare events where it is important to include the magnitude of the event as well as its occurrence (EPA 1992).

Because of the Poisson distribution assumption for volatile organic compounds, the number of samples needed to show that the mean is below the limit with an acceptable probability cannot be calculated. The following implementation is recommended. If the Poisson probability for observations exceeding the limit is unacceptable, but the mean of the Poisson distribution is less than the limit, the parameter is plotted in the medium likelihood row of the risk diagram. If the mean of the Poisson distribution exceeds the limit, then the parameter plots in the high likelihood row of the risk diagram.

Radionuclide data from the three effluent streams were not evaluated in this analysis. No conceptual model and approach for radionuclides is presented here in final form. For effluent streams where radionuclides are identified as potential contaminants of concern, an appropriate approach and model following those proposed for trace metals or volatile organic compounds can be used.

The proposed approach will maximize the use of existing data and greatly simplify all characterizations. The studies by Harris and Hull found that much more elaborate approaches to determining frequency distributions and accounting for less-than-detection values in calculating the mean and variance did not substantially alter the decisions made using the data.

Once the mean and variance for each parameter at each compliance point have been calculated, the probability of a single measurement exceeding the release limit and the probability of the mean exceeding the release limit are calculated. The number of samples needed within a decision period to demonstrate with sufficient certainty that the sample mean does not exceed the release limit is also calculated. These three numbers are used in the development of sampling strategy based on risk using the risk diagram (Figure 2).

\subsubsection{Severity}

Severity is the time available to respond to an exceedance (or potential exceedance) of a release limit. This is determined from the governing requirement for each effluent stream. This can range from none to one year. This information is used to determine the category on the severity axis of the risk diagram (Figure 2) to determine the necessary monitoring strategy.

\subsection{Determining Monitoring Frequency Based on Risk}

The likelihood and severity for each parameter for each effluent stream are plotted on the risk diagram (Figure 2). Based on the preliminary analyses conducted to date, there will be a very few parameters that drive the monitoring frequency. Most parameters are so far below their associated 
release limits that performance monitoring will be the driving factor. For each effluent stream, identify the parameters that will drive the frequency.

\subsubsection{Low Likelihood Parameters with No Release Limit}

For some situations, there may be parameters with no release limits. These parameters may still be of interest for performance monitoring or monitoring may be required by permits even though limits are not set. The probability of adverse consequences cannot be calculated for these parameters. Monitoring design criteria for these parameters is to assess performance and to comply with permits. These parameters fall into the lowest box along the left hand column of Figure 2. labeled "Frequency to monitor performance". Parameters that fall into this box and are not required by permits to be monitored, should be evaluated for deletion from the monitoring program.

\subsubsection{Low Likelihood Parameters with Release Limits}

For parameters that have a very low probability of even a single measurement resulting in an adverse consequence, response time is not of concern. Monitoring frequency will be driven by performance monitoring considerations or permit conditions, not by risk. These are the two boxes on the right hand side of the bottom row in Figure 2 labeled "Follow Permit". For these parameters, document that risk is not a driving factor and proceed to the assessment for performance monitoring.

\subsubsection{High Likelihood or High Severity Parameters}

For parameters that are in the three boxes in the upper right portion of the risk diagram, there is an unacceptable probability of adverse consequences. If a parameter falls in one of the three boxes labeled "Change process", the chance of exceeding a release limit is unacceptably high with insufficient time for corrective action. Monitoring can only indicate that a noncompliance has occurred, and the characterization data indicate that this event is too likely to occur. The waste stream needs to be modified to lower the parameter concentrations to bring the probability of adverse consequences into an acceptable range.

\subsubsection{Intermediate Likelihood, Intermediate Severity Parameters}

The center box of the risk diagram represents the remaining monitoring strategy. For parameters that fall into the central box in Figure 2, there is a small but significant probability that a single measurement could exceed the release limit, and a very small but acceptable probability that the average of the parameter would exceed the release limit. There is also sufficient time, because the limit is based on a monthly or annual average, to recover if a single measurement exceeds the limit.

For parameters falling in the central box of the risk diagram, the number of samples needed to provide the acceptable probability that the sample mean is not above the release limit is calculated. Monitoring frequency within each decision period is then based on that number. If the number of samples per decision period necessary to show the mean is not above the limit, is too large from a 
logistical and/or cost perspective, then the parameter really belongs one box up in the diagram. When the probability that the sample mean could be above the limit is unacceptably large from a sampling point of view, then it is better to reduce the source than monitor at an extremely high frequency.

\subsection{Example Calculation for Risk Based Monitoring}

Examples of how this strategy is implemented are given in this section. Three waste streams were selected to test and illustrate the approach. The effluent streams were selected to illustrate the range of sources that effluent monitoring encounters: industrial, sanitary, and laboratory. Monitoring data used in the examples were collected from:

- TRA-764, Effluent to the Test Reactor Area (TRA) Cold Waste Pond

- CFA-691, Influent to the Central Facilities Area (CFA) Sewage Treatment Plant

- IF-603A, Effluent from the INEL Research Center (IRC) in Idaho Falls.

Data were collected from effluent to the Cold Waste Pond between January 1991 and December 1994. For CFA-691, data were collected between March 1992 and November 1994. Data from the IRC were collected between January 1991 and December 1994. Data collected during 1991, 1992, and 1993 are considered to be "characterization" data. Data collected during 1994 were used as "monitoring" data. Some parameters were sampled throughout the period while others were sampled for only part of the period. Analyses were performed for a range of inorganic compounds, physical properties, metals, and volatile organic compounds. All data used in the analyses are contained in Appendices A through F.

The liquid effluent program has, in the past, collected a very high percentage of replicate samples. Replicate samples contain information on the variability introduced by the sampling and analysis process. Results of the replicate samples from the three waste streams selected for this example are highly correlated indicating, in general, that the sampling and analysis process is in control. The high correlation also indicates that replicates are highly redundant. The program has recently cut back significantly on the rate of replicate collection, and future monitoring data cannot be expected to have a high percentage of replicate samples. The analysis of historical data to determine probabilities of exceeding release limits must be conducted in such a way that the probabilities are meaningful for ongoing and future monitoring data. Averaging the replicates or biasing the selection of replicates to those with values close to or far from the average could bias the determination of probability and likelihood. Therefore, only one replicate was used (replicate \#1) in the example analysis. This was considered the best way to give an estimate of probability and likelihood that would be comparable to future monitoring data.

Many of the parameters have a very high percentage of measurements below the detection limit. All values below the detection limit (except for volatile organic compounds) were replaced with $1 / 2$ the detection limit. All data (except $\mathrm{pH}$ and the volatile organic compounds) were transformed by 
taking natural logarithms. Summary statistics for metals, inorganic compounds, and physical properties were calculated (shown in Table 2 for TRA-764, Table 3 for CFA-691, and Table 4 for IF-603A) and probabilities of exceeding limits calculated. Probabilities of exceeding limits for volatile organic compounds were calculated based on a Poisson distribution and are shown in Table 5 for TRA-764, CFA-691, and IF-603A.

Limits applicable to the Cold Waste Pond are the draft INEL release limits from Ansley et al. (1994). The limits used in this analysis are draft limits and are subject to revision before final acceptance. The limits are based on a decision period of one year. No Wastewater Land Application Permit has been issued for this pond, and limits and monitoring requirements will have to comply with any additional permit requirements. Limits for the IRC are from City of Idaho Falls Wastewater Discharge Permit.

No limits had been established for discharges from the CFA sewage treatment plant at the time this analysis was begun. Maximum contaminant levels (MCLs) and secondary MCLs (SMCLs) were used as limits. These are not applicable to CFA-691 and are for illustration purposes only. The monitoring station at CFA-691 has been replaced, and the wastewater land application permit requires monitoring in a different location. Release limits have been developed for this new location. The analysis of data from CFA-691 will still provide meaningful information on the applicability of the risk-based approach to monitoring sanitary effluent streams. However, an analysis of the new sewage treatment plant at the new compliance point will have to be conducted for implementation.

Probabilities of one measurement exceeding the limit and for the mean (based on the number of samples actually collected) to exceed the limit were calculated for parameters in all three effluent streams. This calculation was done with data collected during 1991, 1992, and 1993. Frequency histograms showing the distribution of the effluent monitoring data, the expected normal distribution curve, and the release limit were prepared. Copies of the frequency histograms are contained in Appendices $\mathrm{G}, \mathrm{H}$, and $\mathrm{I}$. The histograms visually show the relation between the data, the expected distribution of the data and the release limit.

Results of the probability calculations for the TRA Cold Waste Pond are plotted on a risk diagram (Figure 6). An acceptable probability was set to 1 chance in 100 of exceeding the limit. Figure 6 shows that almost all of the parameters fall into the category of low likelihood of exceeding the release limit. For these parameters, compliance with INEL release limits can be shown with as little as one sample per year (or even less). For three parameters, antimony, total dissolved solids (TDS), and sulfate, the probability of one sample exceeding the release limit is greater than 0.01 . The number of samples needed to show that the mean was less than the release limit at the $99 \%$ confidence level was calculated from: 


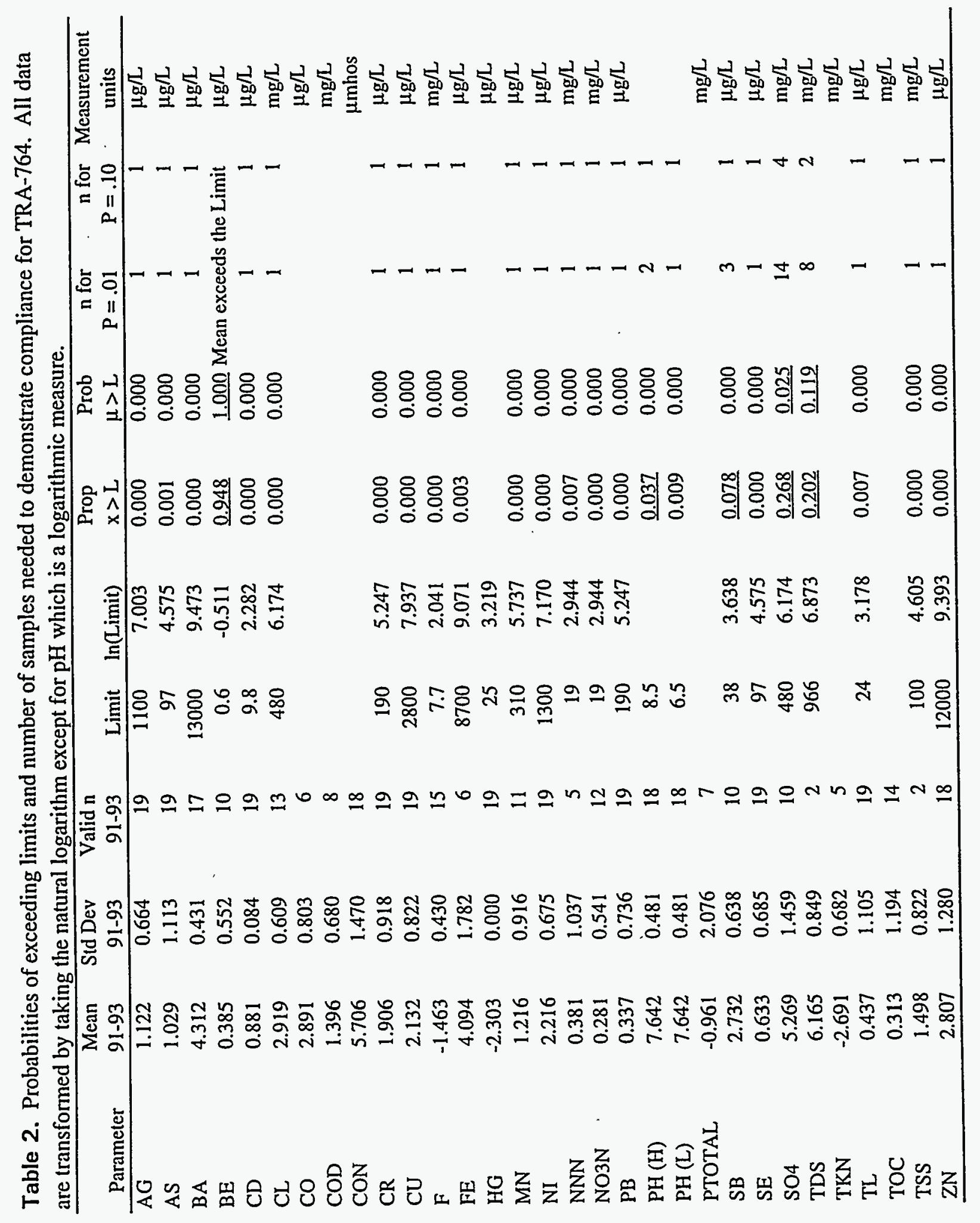


Table 3. Probabilities of exceeding limits and number of samples needed to demonstrate compliance for CFA-691. All data are transformed by taking the natural logarithm except for $\mathrm{pH}$ which is a logarithmic measure.

\begin{tabular}{|c|c|c|c|c|c|c|c|c|c|c|}
\hline Parameter & $\begin{array}{l}\text { Mean } \\
92-93 \\
\end{array}$ & $\begin{array}{r}\text { Std Dev } \\
92-93 \\
\end{array}$ & $\begin{array}{r}\text { Valid n } \\
92-93 \\
\end{array}$ & Limit & $\ln ($ Limit) & $\begin{array}{l}\text { Prop } \\
x>L\end{array}$ & $\begin{array}{l}\text { Prob } \\
\mu>L\end{array}$ & $\begin{array}{r}n \text { for } \\
\mathrm{P}=.01 \\
\end{array}$ & $\begin{array}{r}n \text { for } \\
\mathrm{P}=.10 \\
\end{array}$ & $\begin{array}{c}\text { Measurement } \\
\text { units }\end{array}$ \\
\hline$\overline{A G}$ & 1.386 & 0.453 & 7 & 100 & 4.605 & 0.000 & 0.000 & 1 & 1 & $\mu g / L$ \\
\hline AS & 1.099 & 0.922 & 7 & 50 & 3.912 & 0.001 & 0.000 & 1 & 1 & $\mu \mathrm{g} / \mathrm{L}$ \\
\hline $\mathrm{BA}$ & 4.531 & 0.128 & 7 & 2000 & 7.601 & 0.000 & 0.000 & 1 & 1 & $\mu g / L$ \\
\hline $\mathrm{BE}$ & 0.495 & 0.688 & 6 & 4 & 1.386 & $\underline{0.098}$ & 0.001 & 3 & 1 & $\mu \mathrm{g} / \mathrm{L}$ \\
\hline $\mathrm{CD}$ & 0.884 & 0.084 & 7 & 5 & 1.609 & 0.000 & 0.000 & 1 & 1 & $\mu \mathrm{g} / \mathrm{L}$ \\
\hline $\mathrm{CL}$ & 4.821 & 0.153 & 3 & 250 & 5.521 & 0.000 & 0.000 & 1 & 1 & $\mathrm{mg} / \mathrm{L}$ \\
\hline $\mathrm{CO}$ & 2.538 & 1.056 & 6 & & & & & & & $\mu \mathrm{g} / \mathrm{L}$ \\
\hline COD & 4.395 & 0.528 & 7 & & & & & . & & $\mathrm{mg} / \mathrm{L}$ \\
\hline $\mathrm{CON}$ & 6.709 & 0.169 & 8 & & & & & & & $\mu \mathrm{mhos}$ \\
\hline $\mathrm{CR}$ & 2.207 & 0.581 & 7 & 100 & 4.605 & 0.000 & 0.000 & 1 & 1 & $\mu \mathrm{g} / \mathrm{L}$ \\
\hline CU & 2.968 & 0.538 & 6 & 1000 & 6.908 & 0.000 & 0.000 & 1 & 1 & $\mu g / L$ \\
\hline$F$ & -1.716 & 0.056 & 3 & 2 & 0.693 & 0.000 & 0.000 & 1 & 1 & $\mathrm{mg} / \mathrm{L}$ \\
\hline $\mathrm{FE}$ & 5.677 & 0.542 & 6 & 300 & 5.704 & $\underline{0.480}$ & $\underline{0.452}$ & 2195 & 662 & $\mu \mathrm{g} / \mathrm{L}$ \\
\hline $\mathrm{HG}$ & -2.303 & 0.000 & 7 & 2 & 0.693 & & & & & $\mu \mathrm{g} / \mathrm{L}$ \\
\hline $\mathrm{MN}$ & 2.216 & 0.311 & 6 & 50 & 3.912 & 0.000 & 0.000 & 1 & 1 & $\mu \mathrm{g} / \mathrm{L}$ \\
\hline $\mathrm{NI}$ & 2.641 & 0.586 & 6 & 100 & 4.605 & 0.000 & 0.000 & 1 & 1 & $\mu \mathrm{g} / \mathrm{L}$ \\
\hline NNN & -0.204 & 0.571 & 8 & 10 & 2.303 & 0.000 & 0.000 & 1 & 1 & $\mathrm{mg} / \mathrm{L}$ \\
\hline PB & 1.365 & 0.949 & 7 & 15 & 2.708 & $\underline{0.078}$ & 0.000 & 3 & 1 & $\mu \mathrm{g} / \mathrm{L}$ \\
\hline $\mathrm{PH}(\mathrm{H})$ & 7.212 & 0.384 & 10 & 8.5 & & 0.000 & 0.000 & 1 & 1 & \\
\hline PH (L) & 7.212 & 0.384 & 10 & 6.5 & & $\underline{0.032}$ & 0.000 & 2 & 1 & \\
\hline $\mathrm{SB}$ & 3.236 & 0.307 & 6 & 6 & 1.792 & 1.000 & \multicolumn{3}{|c|}{ 1,000 Mean exceeds the Limit } & $\mu \mathrm{g} / \mathrm{L}$ \\
\hline SE & 0.865 & 0.103 & 7 & 50 & 3.912 & 0.000 & 0.000 & 1 & 1 & $\mu \mathrm{g} / \mathrm{L}$ \\
\hline SO4 & & & 0 & 250 & 5.521 & & & & & $\mathrm{mg} / \mathrm{L}$ \\
\hline TDS & 6.173 & 0.067 & 3 & 500 & 6.215 & $\underline{0.268}$ & $\underline{0.142}$ & 14 & 4 & $\mathrm{mg} / \mathrm{L}$ \\
\hline TKN & 2.567 & 0.319 & 9 & & & & & & & $\mathrm{mg} / \mathrm{L}$ \\
\hline $\mathrm{TL}$ & 0.957 & 1.034 & 6 & 2 & 0.693 & $\underline{0.601}$ & $\underline{0.734}$ & ean exceed & he Limit & $\mu \mathrm{g} / \mathrm{L}$ \\
\hline TOC & 2.892 & 0.855 & 7 & & & & & & & $\mathrm{mg} / \mathrm{L}$ \\
\hline TOG & 1.493 & 0.564 & 7 & & & & & & & $\mathrm{mg} / \mathrm{L}$ \\
\hline TSS & 3.405 & 0.745 & 10 & 100 & 4.605 & $\underline{0.054}$ & 0.000 & 2 & 1 & $\mathrm{mg} / \mathrm{L}$ \\
\hline $\mathrm{ZN}$ & 4.186 & 0.400 & 6 & 5000 & 8.517 & 0.000 & 0.000 & 1 & 1 & $\mu \mathrm{g} / \mathrm{L}$ \\
\hline
\end{tabular}


Table 4. Probabilities of exceeding limits and number of samples needed to demonstrate compliance for IF-603 (IRC). All data are transformed by taking the natural logarithm except for $\mathrm{pH}$ which is a logarithmic measure.

$\stackrel{w}{w}$

\begin{tabular}{|c|c|c|c|c|c|c|c|c|c|c|}
\hline Parameter & $\begin{array}{l}\text { Mean } \\
91-93\end{array}$ & $\begin{array}{r}\text { Std Dev } \\
91-93\end{array}$ & $\begin{array}{r}\text { Valid n } \\
91-93\end{array}$ & Limit & $\ln ($ Limit) & $\begin{array}{l}\text { Prop } \\
x>L\end{array}$ & $\begin{array}{l}\text { Prob } \\
\mu>L\end{array}$ & $\begin{array}{r}n \text { for } \\
\mathrm{P}=.01\end{array}$ & $\begin{array}{r}n \text { for } \\
P=.10\end{array}$ & $\begin{array}{c}\text { Measurement } \\
\text { units }\end{array}$ \\
\hline$\overline{A G}$ & 1.258 & 0.487 & 29 & 500 & 6.215 & 0.000 & 0.000 & 1 & 1 & $\mu \mathrm{g} / \mathrm{L}$ \\
\hline AS & 1.220 & 0.753 & 29 & 500 & 6.215 & 0.000 & 0.000 & 1 & 1 & $\mu \mathrm{g} / \mathrm{L}$ \\
\hline BA & 4.510 & 0.149 & 27 & 5000 & 8.517 & 0.000 & 0.000 & 1 & 1 & $\mu \mathrm{g} / \mathrm{L}$ \\
\hline $\mathrm{BE}$ & -0.462 & 0.400 & 3 & 5000 & 8.517 & 0.000 & 0.000 & 1 & 1 & $\mu g / L$ \\
\hline $\mathrm{CD}$ & 0.973 & 0.283 & 29 & 500 & 6.215 & 0.000 & 0.000 & 1 & 1 & $\mu \mathrm{g} / \mathrm{L}$ \\
\hline $\mathrm{CL}$ & 2.979 & 0.468 & 8 & & & & & & & $\mathrm{mg} / \mathrm{L}$ \\
\hline $\mathrm{CN}$ & 1.661 & 0.242 & 29 & 500 & 6.215 & 0.000 & 0.000 & 1 & 1 & $\mu \mathrm{g} / \mathrm{L}$ \\
\hline $\mathrm{CON}$ & 5.785 & 1.011 & 29 & & & & & & & $\mu \mathrm{mhos}$ \\
\hline $\mathrm{CR}$ & 1.608 & 0.830 & 29 & 500 & 6.215 & 0.000 & 0.000 & 1 & 1 & $\mu \mathrm{g} / \mathrm{L}$ \\
\hline CR6 & 2.387 & 0.895 & 24 & 90 & 4.500 & 0.009 & 0.000 & 1 & I & $\mu g / L$ \\
\hline $\mathrm{CU}$ & 3.805 & 0.531 & 29 & 1500 & 7.313 & 0.000 & 0.000 & 1 & 1 & $\mu \mathrm{g} / \mathrm{L}$ \\
\hline $\mathrm{F}$ & -1.188 & 0.801 & 8 & & & & & & & $\mathrm{mg} / \mathrm{L}$ \\
\hline $\mathrm{HG}$ & -2.158 & 0.639 & 29 & 50 & 3.912 & 0.000 & 0.000 & 1 & 1 & $\mu \mathrm{g} / \mathrm{L}$ \\
\hline $\mathrm{MN}$ & 0.903 & 0.948 & 5 & & & & & & & $\mu g / L$ \\
\hline NI & 2.589 & 0.646 & 29 & 500 & 6.215 & 0.000 & 0.000 & 1 & 1 & $\mu g / L$ \\
\hline NO3 & 1.320 & 0.570 & 2 & & & & & & . & $\mathrm{mg} / \mathrm{L}$ \\
\hline NO3N & 1.004 & 0.614 & 6 & & & & & & & $\mathrm{mg} / \mathrm{L}$ \\
\hline PB & 0.824 & 0.794 & 29 & 1500 & 7.313 & 0.000 & 0.000 & 1 & 1 & $\mu g / L$ \\
\hline $\mathrm{PH}(\mathrm{L})$ & 7.454 & 0.493 & 29 & 5.5 & & 0.000 & 0.000 & 1 & 1 & \\
\hline $\mathrm{PH}(\mathrm{H})$ & 7.454 & 0.493 & 29 & 9 & & 0.001 & 0.000 & 1 & 1 & \\
\hline PHENOL & 3.638 & 1.495 & 3 & & & & & & & $\mu \mathrm{g} / \mathrm{L}$ \\
\hline PORTHO & -2.303 & 0.000 & 2 & & & & & & & $\mathrm{mg} / \mathrm{L}$ \\
\hline PTOTAL & -0.797 & 1.673 & 6 & & & & & & & $\mathrm{mg} / \mathrm{L}$ \\
\hline SB & 2.919 & 0.413 & 3 & 5000 & 8.517 & 0.000 & 0.000 & 1 & 1 & $\mu g / L$ \\
\hline SE & 0.585 & 0.736 & 29 & 5000 & 8.517 & 0.000 & 0.000 & 1 & 1 & $\mu \mathrm{g} / \mathrm{L}$ \\
\hline SO4 & 3.781 & 0.083 & 8 & & & & & & & $\mathrm{mg} / \mathrm{L}$ \\
\hline TDS & 5.726 & 0.292 & 8 & & & & & & & $\mathrm{mg} / \mathrm{L}$ \\
\hline TL & 0.299 & 1.057 & 13 & 5000 & 8.517 & 0.000 & 0.000 & 1 & 1 & $\mu g / L$ \\
\hline TOC & 1.636 & 1.282 & 8 & & & & & & & $\mathrm{mg} / \mathrm{L}$ \\
\hline TOG & 2.644 & 0.090 & 2 & 100 & 4.605 & 0.000 & 0.000 & 1 & $1^{\circ}$ & $\mathrm{mg} / \mathrm{L}$ \\
\hline TSS & 1.507 & 0.844 & 8 & & & & & & & $\mathrm{mg} / \mathrm{L}$ \\
\hline $\mathrm{ZN}$ & 3.700 & 0.384 & 29 & 1500 & 7.313 & 0.000 & 0.000 & 1 & 1 & $\mu g / L$ \\
\hline
\end{tabular}


Table 5. Probability of organic compounds exceeding site-specific release limits based on a Poisson distribution.

\begin{tabular}{|c|c|c|c|c|}
\hline $\begin{array}{l}\text { Number } \\
\text { of hits }\end{array}$ & Sum & $\begin{array}{l}\text { Mean } \\
(\mu \mathrm{g} / \mathrm{L})\end{array}$ & $\begin{array}{c}\text { Limit } \\
(\mu \mathrm{g} / \mathrm{L})\end{array}$ & $\begin{array}{c}\text { Probability } \\
x>L\end{array}$ \\
\hline
\end{tabular}

TRA-764 (Cold Waste Pond) probability of organic compounds exceeding INEL release limit.

\begin{tabular}{lcccccc}
\hline Methylene Chloride. & (MC) & 2 & 6 & 2 & 9 & $<0.001$ \\
Trichlorofluoromethane & (TCFM) & 1 & 1 & 0.333 & 21,000 & $<0.001$ \\
Total number of samples & & 3 & & & & \\
\hline
\end{tabular}

CFA-691 (Sewage Treatment Plant) probability of organic compounds exceeding MCLs.

\begin{tabular}{lcccccc}
\hline 1,1,1-Trichloroethane & (TCA) & 2 & 3 & 0.6 & 200 & $<0.001$ \\
1,4-Dichlorobenzene & (DCB) & 5 & 59 & 11.8 & 75 & $<0.001$ \\
Methylene Chloride & (MC) & 3 & 15 & 3 & 5 & 0.084 \\
Xylene (Total) & (XY) & 1 & 3 & 0.6 & 10,000 & $<0.001$ \\
Total number of samples & & 5 & & & & \\
\hline
\end{tabular}

IF-603 (TRC) probability of organic compounds exceeding $100 \mu \mathrm{g} / \mathrm{L}$.

\begin{tabular}{lcccccc}
\hline Chloroform & (CF) & 1 & 5 & 0.19 & 100 & $<0.001$ \\
Ethylbenzene & (EB) & 1 & 3 & 0.12 & 100 & $<0.001$ \\
Methylene Chloride & (MC) & 15 & 953 & 36.65 & 100 & $<0.001$ \\
Toluene & (TOL) & 5 & 27 & 1.04 & 100 & $<0.001$ \\
Trichloroethylene & (TCE) & 1 & 1 & 0.04 & 100 & $<0.001$ \\
Xylene (total) & (XY) & 3 & 170 & 6.54 & 100 & $<0.001$ \\
Total Number of samples & & 26 & & & & \\
\hline
\end{tabular}

$$
n=\left(\frac{z_{.01} \cdot s}{L-\bar{x}}\right)^{2}
$$

where:

$$
\begin{array}{lll}
\mathrm{n} & = & \text { number of samples } \\
\mathrm{z}_{.01} & = & \mathrm{z} \text { score at } 99 \% \text { confidence level }=2.33 \\
\mathrm{~s} & = & \text { sample standard deviation } \\
\mathrm{L} & = & \text { release limit } \\
\overline{\mathrm{x}} & = & \text { sample mean }
\end{array}
$$




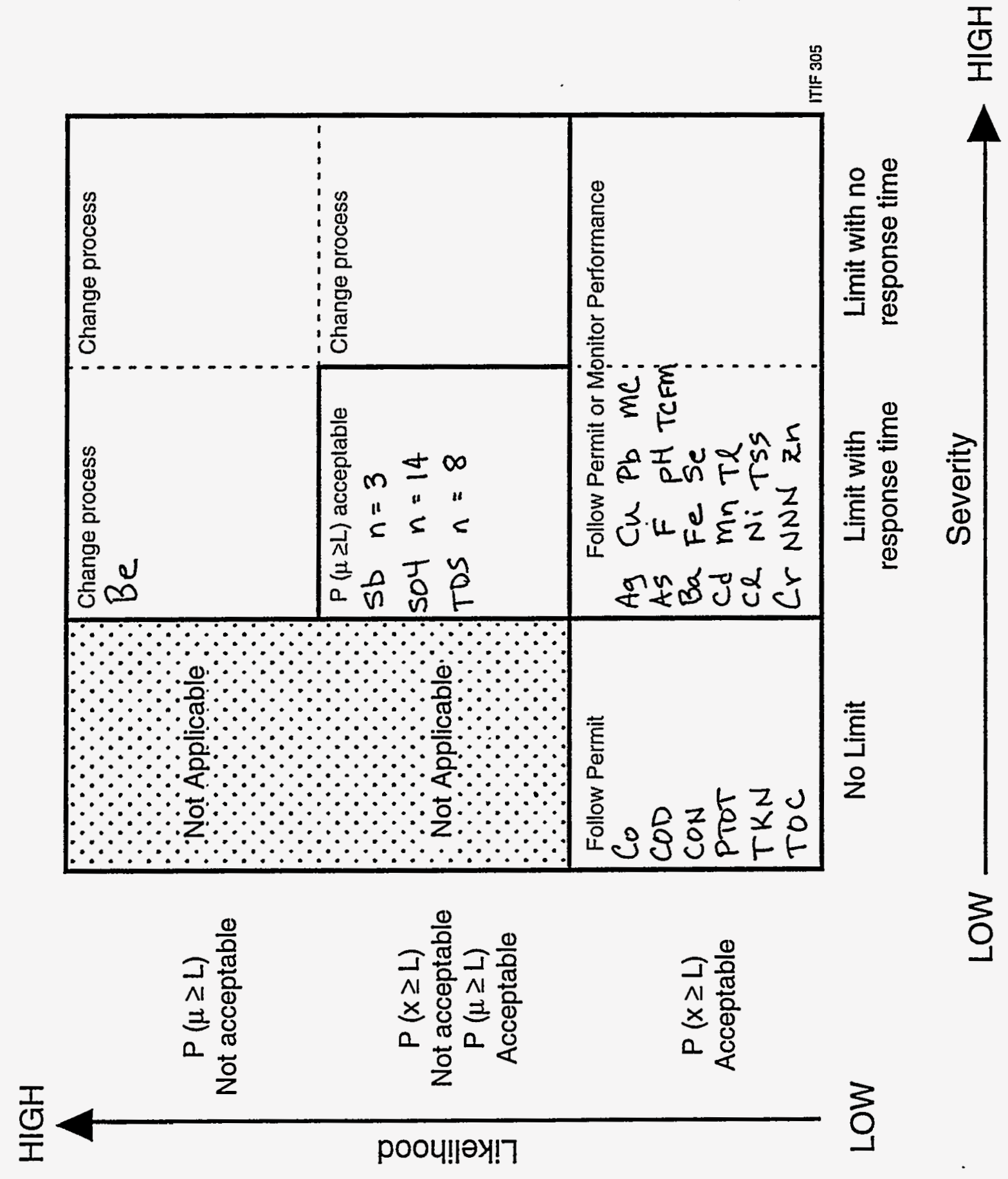

Figure 6. Risk diagram for effluent to the TRA Cold Waste Pond. 
From 3 to 14 samples are needed to achieve the desired level of confidence in demonstrating compliance with the release limits (Table 2 and Figure 6). Quarterly sampling would be sufficient to show that antimony is below the release limits.

A management decision needs to be made concerning sulfate and TDS. Options available are:

- Collect 8 to 14 samples per year,

- Change plant processes to reduce TDS and sulfate concentrations,

- Accept a greater level of uncertainty in showing compliance with INEL release limits.

The average concentrations of sulfate and TDS are below INEL release limits. Therefore, the concern is not that the annual average will exceed the limit, but that there is a chance that sampling will not substantiate this. The adverse consequence in this case is that annual sampling results may indicate that sulfate or TDS concentrations exceed the INEL release limit. This could initiate corrective action unnecessarily. The probability of the mean sulfate concentration exceeding the limit based on quarterly samples is about $10 \%$. The mean is expected to be below the release limit, but in about 1 in 10 years, the calculated average of the four samples would exceed the limit by chance. The decision of what action to take will depend on a comparison of the cost of monitoring, the cost of modifying the process, and the cost of exceeding the release limit. A different decision could be made for different effluent streams depending on the balance of these factors.

Beryllium plots in the portion of the risk diagram (Figure 6) that indicates an unacceptable probability of exceeding the release limit. Beryllium has a very low release limit, which is also below the analytical detection limit. The INEL release limit for beryllium is not driven by the groundwater ingestion pathway but by the inhalation pathway. One way of addressing the issue with beryllium would be to require that the pond be filled with dirt after use. This would break the inhalation pathway. The release limit for beryllium would then be based on ingestion of groundwater which could substantially raise the beryllium release limit. The detection limit for beryllium is between 2 and $5 \mu \mathrm{g} / \mathrm{L}$, or 3 to 8 times the release limit of $0.6 \mu \mathrm{g} / \mathrm{L}$. Thirteen of 14 samples analyzed for beryllium were below the detection limit, and may have been below the release limit. There is no way to demonstrate this, however. A second option with beryllium would be to use a different analytical method with a detection limit less than $0.6 \mu \mathrm{g} / \mathrm{L}$.

One objective of the INEL release limits is to protect human health and to avoid future cleanup costs. Therefore, the potential to create an unacceptable risk from beryllium due to disposal in the pond should not be ignored. However, a more likely exposure scenario would significantly raise the release limit without creating an unacceptable risk.

Assuming that beryllium would drop into the lowest tier of risk after reevaluating exposure scenarios and recalculating a release limit, a monitoring frequency for this pond can be established. Quarterly samples would need to be collected for total dissolved solids and sulfate. All other 
parameters could be sampled annually (or even less frequently). This frequency is all that is necessary to demonstrate compliance with INEL release limits for the pond.

Results for the analysis of CFA-691 are very similar in nature. Characterization data from parameters measured on CFA-691 are plotted on a risk diagram (Figure 7). Most parameter indicate very little likelihood of exceeding the MCLs. A few parameters have a probability greater than $1 \%$ of a single measurement exceeding the limit, but with a mean that does not exceed the limit. Beryllium, lead, $\mathrm{pH}, \mathrm{TDS}$, and TSS all would require a few samples a year to calculate a sample mean and show with a less than $1 \%$ chance of error, that the mean is less than the MCL or SMCL. Methylene chloride also has a probability of greater than 1 in 100 that a single observation could exceed the MCL of $5 \mu \mathrm{g} / \mathrm{L}$. TDS is the limiting parameter, requiring 14 samples per year to demonstrate compliance with the SMCLs. In general, if the acceptable risk of exceeding the SMCL for TDS can be raised to $10 \%$, quarterly sampling would be more than adequate to address compliance for most other parameters.

Two parameters fall into the high risk area for CFA-691. Iron has an average concentration that is slightly less than the limit. It would require an extremely large number of samples to demonstrate that iron was less than the limit with an acceptable level of probability. Therefore, iron must be considered for source reduction. Antimony is identified as a high risk parameter also. In this case, this is because the detection limit for antimony is above the MCL. As a result, the actual quantity of antimony in the effluent cannot be estimated. A decision would have to be made as to whether antimony was a parameter of concern. If so, then a more sensitive analytical method would have to be used to measure antimony.

The IRC example illustrates a case with high severity consequences. The City of Idaho Falls Sewer regulations set maximum daily concentration limits. One 24-hr composite sample is collected to compare to the limits. If the sample exceeds the limits, then a violation of the permit has occurred. There is no time to recover from an exceedance. A risk diagram for the IRC effluent is shown in Figure 8. All parameters plot in the lower right-hand block of the diagram. While there is high severity for an adverse consequence in this effluent stream, the likelihood of an adverse consequence is acceptably low for all parameters with release limits.

These three examples illustrate that it is possible to develop a practical and defensible monitoring frequency for effluent streams based on risk. For the two Site waste streams, the monitoring frequency works out to be quarterly. For the Idaho Falls waste stream, monitoring will be driven by permit conditions. Not all parameters require the same level of intensity, and so the parameters can be monitored at different frequencies to achieve the appropriate level of risk reduction. 


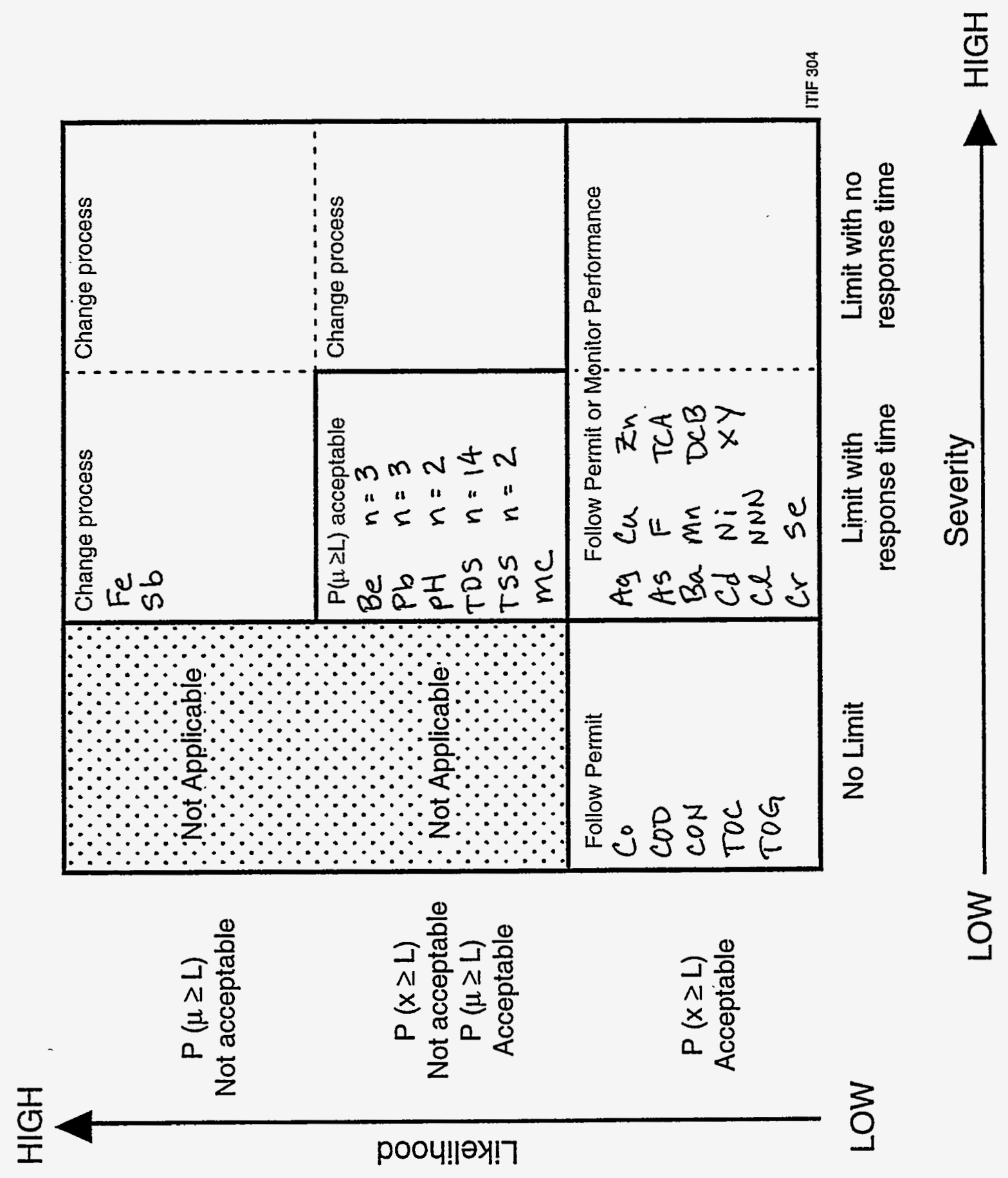

Figure 7. Risk diagram for influent to the CFA Sewage Ttreatment Plant. 


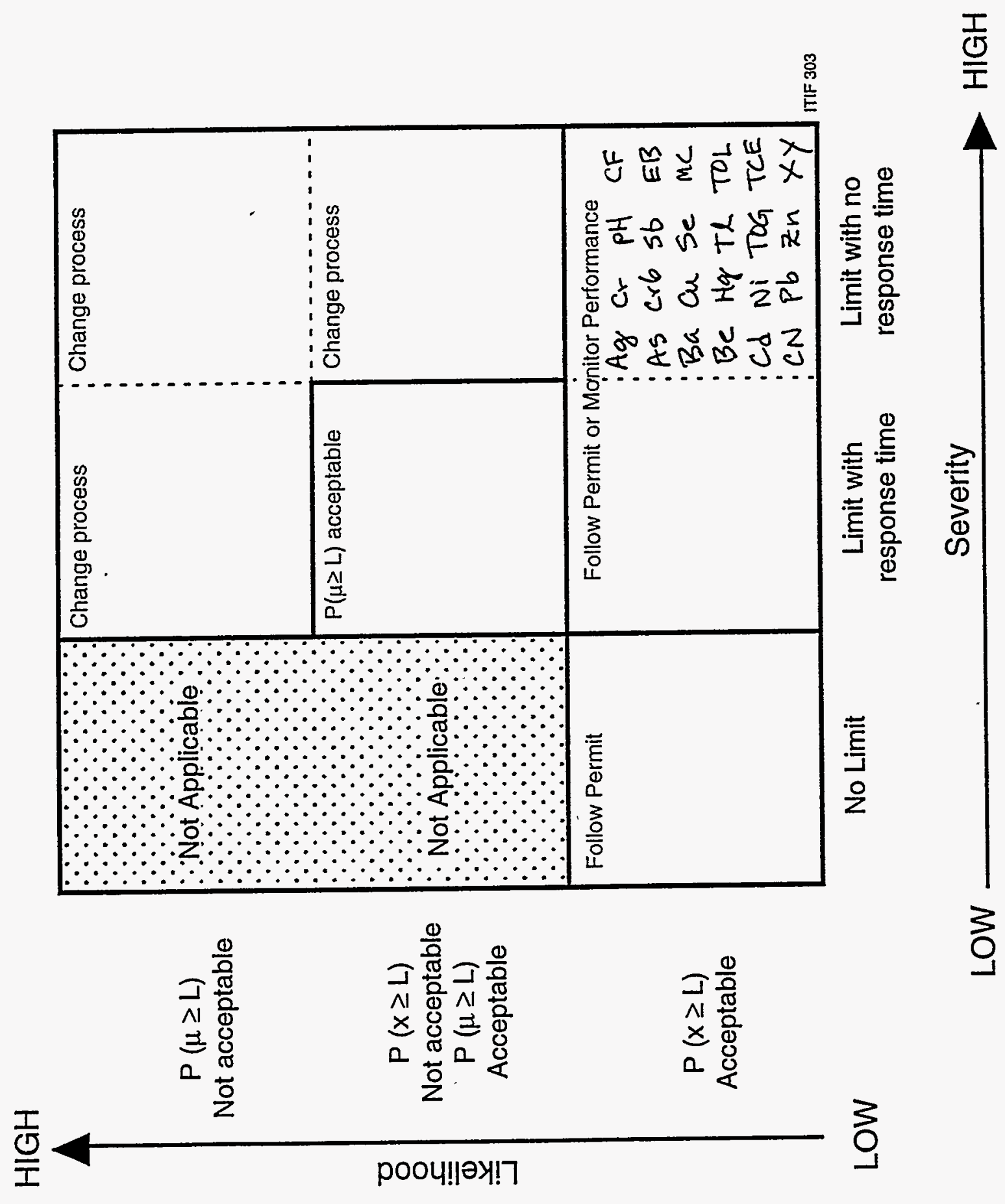

Figure 8. Risk diagram for effluent from the INEL Research Center. 


\subsection{Determining Monitoring Frequency for Performance Monitoring Objectives}

From the analysis of risk, the sampling frequency needed to demonstrate compliance for monitoring parameters can be calculated. For the majority of parameters, there is a very low likelihood of exceeding a release limit and consequently very little risk. With such low risk, there is little need to monitor for most parameters. This assessment remains valid as long as the release limit does not change and the characteristics of the effluent stream do not change. The driver for monitoring most parameters is to evaluate change, loss of control, or identify unplanned releases. This is necessary both to meet performance monitoring objectives in DOE Order 5400.1 and to show that the level of risk has not increased. Change could be from a new source of a contaminant or from a loss of dilution water. Therefore, losses of water sources may be as significant in changing the risk as additional contaminant sources.

Many parameters for INEL Site effluent streams will be only indirectly covered by Wastewater Land Application Permits. Where groundwater impact is the issue of concern, and a parameter is covered by an INEL release limit, there is no regulatory driver for the decision period. The INEL release limits are based on annual mass. Where there is a very low probability that the annual mass could be exceeded, it may not be necessary to collect samples every year. The decision period for many parameters will have to be a management decision.

Where performance monitoring is the driver for monitoring frequency, a technical basis needs to be established for the minimum justified monitoring frequency. Most effluent streams have an extensive historical data base. New effluent streams will be characterized by collecting samples. This characterization data can be used to evaluate trends in the data. If trends are present, the time it would take a significant change to occur in the effluent concentration can be calculated. In addition to this initial assessment, testing for changes will be done periodically on the monitoring data. This additional testing during monitoring is discussed in Section 7.

The approach proposed to determine the minimum acceptable monitoring frequency for performance monitoring is to use linear regression to calculate the change in concentration units per year for each parameter. The time required to change the present mean concentration to the release limit can be calculated from the slope of the regression equation. This calculation is only performed for parameters with slopes that are significantly different than zero. For the time to change the mean to the limit to have meaning; the slope must also be in the direction of the limit. Regression analyses were performed for parameters measured on CFA-691, IF-603, and TRA-764. Data collected in 1991,1992 , and 1993 (the characterization data) were used for the regression analyses.

Results of the regression analyses for data from CFA-691 are shown in Table 6. Seven parameters had slopes that were significantly different from 0 at the $95 \%$ confidence level. All of these parameters are metals, and for most of them, the slope could be directly linked to a change in the analytical detection limit during the characterization period. Therefore, the changes do not reflect 
Table 6. Changes in parameters with time and times to reach release limits for CFA-691.

\begin{tabular}{|c|c|c|c|c|c|c|c|c|}
\hline Parameter & $\begin{array}{l}\text { Mean } \\
92-93 \\
\end{array}$ & $\begin{array}{r}\text { Std Dev } \\
92-93 \\
\end{array}$ & $\begin{array}{r}\text { Valid n } \\
92-93 \\
\end{array}$ & Limit & $\ln$ (Limit) & $\begin{array}{r}\text { Slope } \\
y r^{-1} \\
\end{array}$ & $\begin{array}{r}\text { Prob } \\
\text { Slope }=0\end{array}$ & $\begin{array}{r}\text { years to } \\
\text { Limit }\end{array}$ \\
\hline $\mathrm{AG}$ & 1.386 & 0.453 & 7 & 100 & 4.605 & 0.625 & 0.06 & 5.1 \\
\hline AS & 1.099 & 0.922 & 7 & 50 & 3.912 & 1.361 & $\underline{0.03}$ & 2.1 \\
\hline BA & 4.531 & 0.128 & 7 & 2000 & 7.601 & 0.180 & $\underline{0.05}$ & 17.1 \\
\hline $\mathrm{BE}$ & 0.495 & 0.688 & 6 & 4 & 1.386 & 0.956 & 0.06 & 0.9 \\
\hline$C D$ & 0.884 & 0.084 & 7 & 5 & 1.609 & 0.097 & 0.14 & 7.5 \\
\hline $\mathrm{CL}$ & 4.821 & 0.153 & 3 & 250 & 5.521 & $n<6$ & & \\
\hline $\mathrm{CO}$ & 2.538 & 1.056 & 6 & & & 1.625 & $\underline{0.02}$ & \\
\hline COD & 4.395 & 0.528 & 7 & & & -0.585 & 0.16 & \\
\hline $\mathrm{CON}$ & 6.073 & 1.372 & 10 & & & -0.146 & 0.42 & \\
\hline $\mathrm{CR}$ & 2.207 & 0.581 & 7 & 100 & 4.605 & -0.388 & 0.43 & \\
\hline $\mathrm{CU}$ & 2.968 & 0.538 & 6 & 1000 & 6.908 & -0.730 & 0.07 & \\
\hline $\mathrm{F}$ & -1.716 & 0.056 & 3 & 2 & 0.693 & $\mathrm{n}<6$ & & \\
\hline $\mathrm{FE}$ & 5.677 & 0.542 & 6 & 300 & 5.704 & -0.932 & $\leq .01$ & \\
\hline $\mathrm{HG}$ & -2.303 & 0.000 & 7 & 2 & 0.693 & $s d=0$ & & \\
\hline $\mathrm{MN}$ & 2.216 & 0.311 & 6 & 50 & 3.912 & -0.480 & $\underline{0.02}$ & \\
\hline $\mathrm{NI}$ & 2.641 & 0.586 & 6 & 100 & 4.605 & 0.906 & $\underline{0.02}$ & 2.2 \\
\hline NNN & -0.204 & 0.571 & 8 & 10 & 2.303 & -0.785 & 0.18 & \\
\hline $\mathrm{PB}$ & 1.365 & 0.949 & 7 & 15 & 2.708 & -0.378 & 0.65 & \\
\hline $\mathrm{PH}(\mathrm{H})$ & 7.212 & 0.384 & 10 & 8.5 & 8.500 & -0.464 & 0.10 & \\
\hline $\mathrm{PH}(\mathrm{L})$ & 7.212 & 0.384 & 10 & 6.5 & 6.500 & -0.464 & 0.10 & \\
\hline $\mathrm{SB}$ & 3.236 & 0.307 & 6 & 6 & 1.792 & 0.355 & 0.15 & \\
\hline SE & 0.865 & 0.103 & 7 & 50 & 3.912 & 0.143 & 0.06 & 21.3 \\
\hline SO4 & & & 0 & 250 & 5.521 & $\mathrm{n}<6$ & & \\
\hline TDS & 6.173 & 0.067 & 3 & 500 & 6.215 & $\mathrm{n}<6$ & & \\
\hline TKN & 2.567 & 0.319 & 9 & & & -0.455 & 0.11 & \\
\hline TL & 0.957 & 1.034 & 6 & 2 & 0.693 & 1.624 & $\underline{0.01}$ & \\
\hline TOC & 2.892 & 0.855 & 7 & & & -0.766 & 0.28 & \\
\hline TOG & 1.493 & 0.564 & 7 & & & -0.167 & 0.73 & \\
\hline TSS & 3.405 & 0.745 & 10 & 100 & 4.605 & -0.674 & 0.22 & \\
\hline $\mathrm{ZN}$ & 4.186 & 0.400 & 6 & 5000 & 8.517 & -0.555 & 0.06 & \\
\hline
\end{tabular}


changes in the effluent stream, but in the effluent monitoring program. This type of effect must be addressed in the characterization phase and steps taken to avoid programatic influences masking (or creating) changes in effluent streams. The conclusion from the regression analysis on CFA-691 is that there is no evidence of long-term trends or changes in the data from the CFA sewage treatment plant. Unfortunately, this does not provide technical justification for a particular performance monitoring period for this effluent stream. It does, however, provide technical justification that the effluent was evaluated for change and no evidence was found.

Results of the regression analyses for data from IF-603 are shown in Table 7. Eight parameters had slopes that were significantly different from 0 at the $95 \%$ confidence level. Most of these parameters are metals, and for most of them, the slope could be directly linked to a change in analytical detection limit. For two parameters, chloride and total organic carbon, slopes were statistically significant and not tied to a change in detection limit. There are no release limits for either parameter, so time to exceed release limit is not germane. The total organic carbon and chloride data were only collected in 1991 . This represents only one-third of the characterization period and the data may not be representative of the effluent over longer time periods.

Results of the regression analyses for data from TRA-764 are shown in Table 8. Seven parameters had slopes that were significantly different from 0 at the $95 \%$ confidence level. Most of these parameters are metals, and for most of them, the slope could be directly linked to a change in analytical detection limit. For fluoride and chemical oxygen demand, slopes were statistically significant and not tied to a change in detection limit. Chemical oxygen demand does not have a release limit and the change in fluoride is decreasing, away from the limit.

The analysis of trends in effluent monitoring data indicates that most data do not show a significant trend with time. This provides basic justification for not performing frequent monitoring for parameters with low likelihood of exceeding release limits. Most changes that were identified could be linked to programmatic changes in the effluent monitoring program (i.e. a change in analytical detection limits) or nonrepresentative sampling rather than changes in the effluent stream. A few parameters showed significant trends. These trends could not be used as an indicator of how often an effluent stream should be sampled because none of the parameters with statistically significant slopes had release limits.

\section{MONITORING}

The emphasis of this review is the setting of monitoring frequency and the analysis of the monitoring data once collected. The actual collection of monitoring data has not been identified as an area of concern. Therefore, this section will skip over the collection and laboratory analysis of monitoring samples and proceed directly to the analysis and interpretation of the monitoring results. One caveat will be added here however. Monitoring data collected at different times must be comparable to be meaningful. Programmatic changes, such as changing to a laboratory with a different analytical detection limit, can result in data that are not comparable over time. Conclusions 
Table 7. Changes in parameters with time and times to reach release limits for IF-603 (IRC).

\begin{tabular}{|c|c|c|c|c|c|c|c|c|}
\hline Parameter & $\begin{array}{l}\text { Mean } \\
91-93\end{array}$ & $\begin{array}{r}\text { Std Dev } \\
91-93 \\
\end{array}$ & $\begin{array}{r}\text { Valid n } \\
91-93 \\
\end{array}$ & Limit & $\ln ($ Limit) & $\begin{array}{r}\text { Slope } \\
\mathrm{yr}^{-1}\end{array}$ & $\begin{array}{r}\text { Prob } \\
\text { Slope }=0\end{array}$ & $\begin{array}{r}\text { years to } \\
\text { Limit }\end{array}$ \\
\hline $\mathrm{AG}$ & 1.258 & 0.487 & 29 & 500 & 6.215 & 0.252 & $\underline{0.01}$ & 19.7 \\
\hline AS & 1.220 & 0.753 & 29 & 500 & 6.215 & 0.324 & 0.04 & 15.4 \\
\hline $\mathrm{BA}$ & 4.510 & 0.149 & 27 & 5000 & 8.517 & 0.093 & $\leq .01$ & 43.1 \\
\hline $\mathrm{BE}$ & -0.462 & 0.400 & 3 & 5000 & 8.517 & $\mathrm{n}<6$ & & \\
\hline$C D$ & 0.973 & 0.283 & 29 & 500 & 6.215 & 0.012 & 0.84 & 436.8 \\
\hline $\mathrm{CL}$ & 2.979 & 0.468 & 8 & & & -1.437 & 0.05 & \\
\hline $\mathrm{CN}$ & 1.661 & 0.242 & 29 & 500 & 6.215 & 0.056 & 0.28 & 81.3 \\
\hline $\mathrm{CON}$ & 5.785 & 1.011 & 29 & & & 0.095 & 0.66 & \\
\hline CR & 1.608 & 0.830 & 29 & 500 & 6.215 & 0.472 & $\leq .01$ & 9.8 \\
\hline CR6 & 2.387 & 0.895 & 24 & 90 & 4.500 & 0.125 & 0.53 & 16.9 \\
\hline $\mathrm{CU}$ & 3.805 & 0.531 & 29 & 1500 & 7.313 & -0.196 & 0.08 & \\
\hline $\mathrm{F}$ & -1.188 & 0.801 & 8 & & & 1.280 & 0.36 & \\
\hline $\mathrm{HG}$ & -2.158 & 0.639 & 29 & 50 & 3.912 & -0.019 & 0.89 & \\
\hline $\mathrm{MN}$ & 0.903 & 0.948 & 5 & & & $\mathrm{n}<6$ & & \\
\hline NI & 2.589 & 0.646 & 29 & 500 & 6.215 & 0.450 & $\leq .01$ & 8.1 \\
\hline NO3 & 1.320 & 0.570 & 2 & & & $\mathrm{n}<6$ & & \\
\hline NO3N & 1.004 & 0.614 & 6 & & & 0.454 & 0.83 & \\
\hline PB & 0.824 & 0.794 & 29 & 1500 & 7.313 & -0.053 & 0.76 & \\
\hline PH (L) & 7.454 & 0.493 & 29 & 5.5 & 5.500 & 0.123 & 0.24 & \\
\hline $\mathrm{PH}(\mathrm{H})$ & 7.454 & 0.493 & 29 & 9 & 9.000 & 0.123 & 0.24 & 12.6 \\
\hline PHENOL & 3.638 & 1.495 & 3 & & & $\mathrm{n}<6$ & & \\
\hline PORTHO & -2.303 & 0.000 & 2 & & & $\mathrm{n}<6$ & & \\
\hline PTOTAL & -0.797 & 1.673 & 6 & & & -3.048 & 0.58 & \\
\hline SB & 2.919 & 0.413 & 3 & 5000 & 8.517 & $\mathrm{n}<6$ & & \\
\hline SE & 0.585 & 0.736 & 29 & 5000 & 8.517 & 0.070 & 0.66 & 113.3 \\
\hline SO4 & 3.781 & 0.083 & 8 & & & -0.183 & 0.19 & \\
\hline TDS & 5.726 & 0.292 & 8 & & & -0.637 & 0.20 & \\
\hline $\mathrm{TL}$ & 0.299 & 1.057 & 13 & 5000 & 8.517 & -2.014 & $\leq .01$ & \\
\hline TOC & 1.636 & 1.282 & 8 & & & -4.610 & $\leq .01$ & \\
\hline TOG & 2.644 & 0.090 & 2 & 100 & 4.605 & $\mathrm{n}<6$ & & . \\
\hline TSS & 1.507 & 0.844 & 8 & & & -2.049 & 0.14 & \\
\hline $\mathrm{ZN}$ & 3.700 & 0.384 & 29 & 1500 & 7.313 & 0.075 & 0.36 & 48.2 \\
\hline
\end{tabular}


Table 8. Changes in parameters with time and times to reach release limits for TRA-764.

\begin{tabular}{|c|c|c|c|c|c|c|c|c|}
\hline Parameter & $\begin{array}{r}\text { Mean } \\
91-93 \\
\end{array}$ & $\begin{array}{r}\text { Std Dev } \\
91-93 \\
\end{array}$ & $\begin{array}{r}\text { Valid n } \\
91-93 \\
\end{array}$ & Limit & $\ln$ (Limit) & $\begin{array}{r}\text { Slope } \\
y^{-1}\end{array}$ & $\begin{array}{r}\text { Prob } \\
\text { slope }=0\end{array}$ & $\begin{array}{r}\text { years to } \\
\text { Limit }\end{array}$ \\
\hline$\overline{\mathrm{AG}}$ & 1.122 & 0.664 & 19 & 1100 & 7.003 & 0.130 & 0.48 & 45.2 \\
\hline AS & 1.029 & 1.113 & 19 & 97 & 4.575 & 0.191 & 0.31 & 18.6 \\
\hline $\mathrm{BA}$ & 4.312 & 0.431 & 17 & 13000 & 9.473 & 0.060 & 0.45 & 86.0 \\
\hline $\mathrm{BE}$ & 0.385 & 0.552 & 10 & 0.6 & -0.511 & 0.555 & $\underline{0.04}$ & \\
\hline $\mathrm{CD}$ & 0.881 & 0.084 & 19 & 9.8 & 2.282 & -0.002 & 0.95 & \\
\hline $\mathrm{CL}$ & 2.919 & 0.609 & 13 & 480 & 6.174 & -0.204 & 0.27 & \\
\hline $\mathrm{CO}$ & 2.891 & 0.803 & 6 & & & 1.134 & 0.08 & \\
\hline COD & 1.396 & 0.680 & 8 & & & 0.958 & $\leq .01$ & \\
\hline CON & 5.706 & 1.470 & 18 & & & -0.266 & 0.52 & \\
\hline $\mathrm{CR}$ & 1.906 & 0.918 & 19 & 190 & 5.247 & -0.134 & 0.60 & \\
\hline $\mathrm{CU}$ & 2.132 & 0.822 & 19 & 2800 & 7.937 & 0.249 & 0.27 & 23.3 \\
\hline $\mathrm{F}$ & -1.463 & 0.430 & 15 & 7.7 & 2.041 & -0.384 & $\leq .01$ & \\
\hline $\mathrm{FE}$ & 4.094 & 1.782 & 6 & 8700 & 9.071 & 2.633 & 0.06 & 1.9 \\
\hline $\mathrm{HG}$ & -2.303 & 0.000 & 19 & 25 & 3.219 & $s d=0$ & & \\
\hline $\mathrm{MN}$ & 1.216 & 0.916 & 11 & 310 & 5.737 & 1.122 & $\leq .01$ & 4.0 \\
\hline $\mathrm{NI}$ & 2.216 & 0.675 & 19 & 1300 & 7.170 & 0.445 & $\leq .01$ & 11.1 \\
\hline NNN & 0.381 & 1.037 & 5 & 19 & 2.944 & $n<6$ & & \\
\hline NO3N & 0.281 & 0.541 & 12 & 19 & 2.944 & -0.254 & 0.46 & \\
\hline PB & 0.337 & 0.736 & 19 & 190 & 5.247 & -0.062 & 0.76 & \\
\hline PH (H) & 7.642 & 0.481 & 18 & 8.5 & 8.500 & -0.201 & 0.12 & \\
\hline $\mathrm{PH}(\mathrm{L})$ & 7.642 & 0.481 & 18 & 6.5 & 6.500 & -0.201 & 0.12 & 5.7 \\
\hline PTOTAL & -0.961 & 2.076 & 7 & & & -3.387 & 0.28 & \\
\hline SB & 2.732 & 0.638 & 10 & 38 & 3.638 & 0.714 & $\underline{0.02}$ & 1.3 \\
\hline SE & 0.633 & 0.685 & 19 & 97 & 4.575 & 0.006 & 0.98 & 657.0 \\
\hline SO4 & 5.269 & 1.459 & 10 & 480 & 6.174 & -1.968 & 0.17 & \\
\hline TDS & 6.165 & 0.849 & 2 & 966 & 6.873 & $\mathrm{n}<6$ & & \\
\hline TKN & -2.691 & 0.682 & 5 & & & $\mathrm{n}<6$ & & \\
\hline $\mathrm{TL}$ & 0.437 & 1.105 & 19 & 24 & 3.178 & 0.549 & 0.06 & 5.0 \\
\hline TOC & 0.313 & 1.194 & 14 & & & -0.236 & 0.50 & \\
\hline TSS & 1.498 & 0.822 & 2 & 100 & 4.605 & $n<6$ & & \\
\hline $\mathrm{ZN}$ & 2.807 & 1.280 & 18 & 12000 & 9.393 & 1.050 & $\leq .01$ & 6.3 \\
\hline
\end{tabular}


from performance monitoring regarding changes or loss of control based on noncomparable data will not be valid.

Figure 9 gives an overview of the data analysis process of monitoring data in the form of a flow chart. Monitoring data are validated for conformance to $\mathrm{QC}$ criteria when they are received from the laboratory. Each decision period, the results are compared to decision limits. Decision limits are release limits and control limits. Release limits determine if the effluent stream is in compliance. Control limits test whether the effluent stream has changed. Exceeding either type of limit can trigger an assessment.

\subsection{Evaluating Changes During a Decision Period}

This section discusses the approach recommended to determine whether there is a possibility that a change has occurred in the concentration or variation of a parameter. This evaluation is made periodically for each parameter in each effluent stream. The principal concern about change is that an increase in the concentration of a parameter can increase the likelihood of an adverse consequence (i.e. increase the risk). With the exception of $\mathrm{pH}$ (which has upper and lower limits) all parameters have a release limit as a ceiling. Changes that indicate an increase in concentration are of more concern that changes that indicate a decrease.

The period over which change is evaluated is called the decision period. For many parameters and effluent streams, the decision period is based on a permit requirement. For effluent covered by Wastewater Land Application Permits, an annual report is required by the State of Idaho. In the annual report, the data must be discussed in terms of potential environmental impact. The absence of change in parameters over the year would be one indication that environmental impacts had not changed. An annual effluent monitoring report is prepared by the program. Data will be evaluated at least annually for discussion in the annual report.

There are a number of parametric and nonparametric statistical tests to evaluate the difference in mean and variance between two samples. This would be one approach to take to evaluate change between historical samples collected from an effluent stream and the latest group of samples. To achieve a reasonable power to differentiate a change, something on the order of four to eight samples per group would be required (based on the t-test). This could force sampling to be more frequent than desired to achieve the required number of samples, or drive the decision period to be longer than desired. Another problem with this approach is that with a large amount of less than detection results, parameters can have a zero variance for a sampling period.

Currently, the liquid effluent monitoring program assesses the potential for change using control charts and three levels of trigger criteria. This is a good technique and the same or a similar approach is recommended. When a process is in control, the control chart will show the following characteristics:

- Most points will fall near the centerline, 


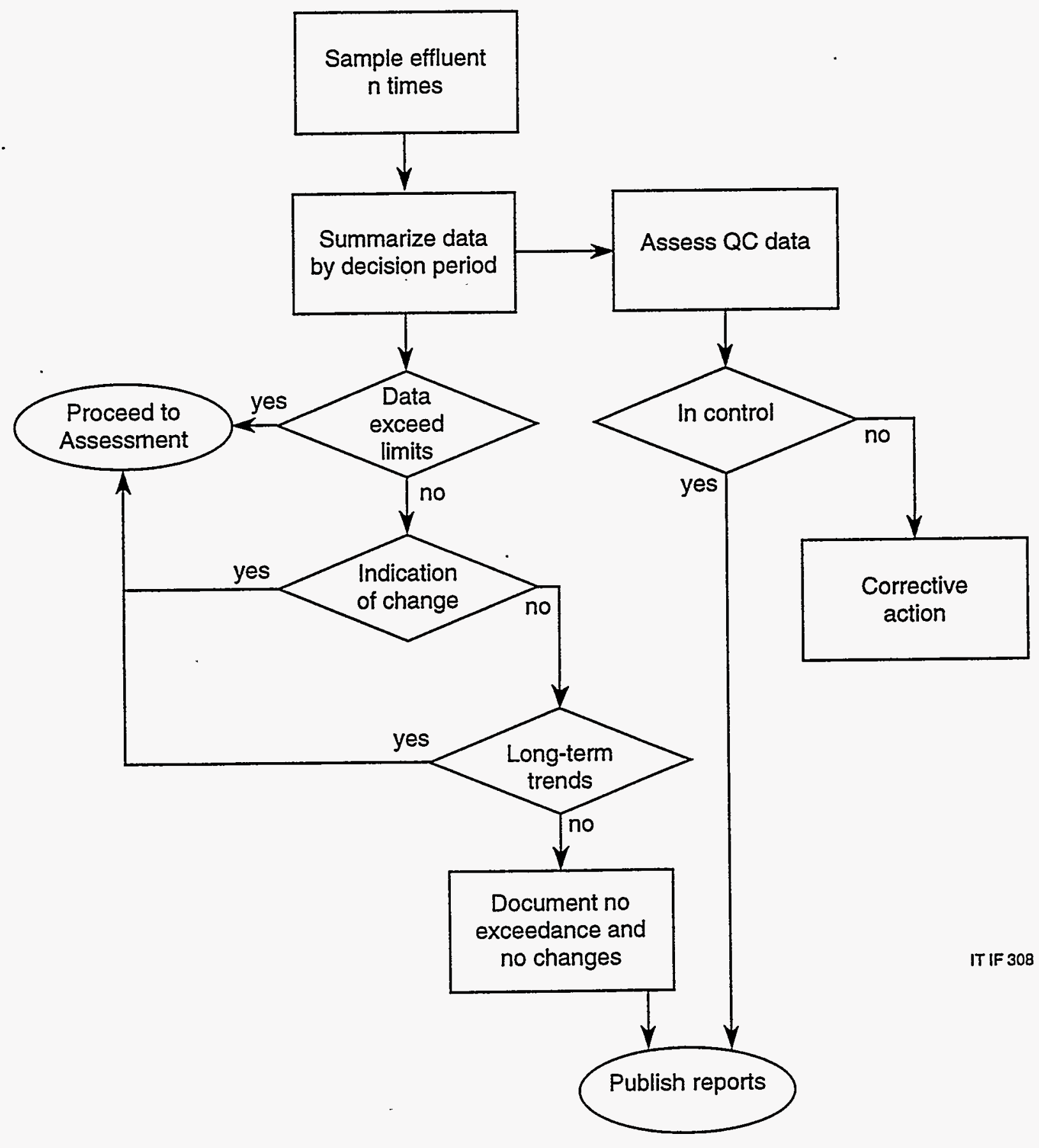

Figure 9. Overview of monitoring. 
- A few points will spread out and approach specific limits,

- No points will fall a great distance from the centerline, and

- Values will fall both above and below the centerline.

Assessment for change is triggered when an event occurs that is considered unlikely when compared to the previously observed conditions. Three types of unlikely events are identified as:

- A single measurement falls extremely far from the centerline (outside the control limit),

- A series of a few measurements falls far enough from the centerline to be considered unlikely (outside the warning limit), and

- A long series of measurements falls on one side of the centerline (above of below the average).

A number of statistical techniques are available so that terms such as "extremely far" and "considered unlikely" can be quantified.

Currently, the liquid effluent monitoring program uses the Student's $t$ distribution to determine warning and control limits. Other possibilities that could be used include tolerance limits, prediction limits, and nonparametric techniques. Other techniques do not seem to offer any distinct advantages over the current approach, so continuation of the current approach is recommended.

Implementation involves using the characterization data to determine the centerline, warning limit, and control limit. The control chart approach is based on the assumption that the data used to develop the chart are in control. Testing for change also requires that historical data represent a period of "control." Characterization data are therefore screened to remove outliers and data that represent periods when the effluent was "out of control." New data are tested against the limits determined from previous data. If the new data do not indicate that changes have occurred, they are included in the characterization data to compare to futures years monitoring results. New data that indicate a loss of control are not included for future control charts. Because Student's t distribution is used to calculate the limits, the more data available, the more degrees of freedom there are and the value of $t$ used in the calculation of the limits will gradually decrease and converge on the $z$ score. Control charts are calculated so that there is a 5\% chance of exceeding a warning limit and a $1 \%$ chance of exceeding a control limit.

At the end of each decision period, the samples collected from that period are plotted on control charts with the upper and lower warning and control limits being used as the bounding criteria. Three decision criteria are used to evaluate whether a change is indicated for a parameter. These criteria are:

- One measurement outside the control limits, 
- Three measurements in a row outside the warning limits,

- Seven out of eight measurements in a row on one side of the mean.

Meeting any one of these criteria will trigger an assessment in which the possibility of change will be evaluated and a conclusion reached concerning the parameter.

There are a number of parameters (trace metals, volatile organic compounds) that may have all of the observations below the detection limit. The major problem with these compounds is that the sample variance is undefined preventing the calculation of probabilities and control limits. As long as the release limit is above the detection limit, the effluent monitoring program will assume that the probability of a single measurement and of the mean exceeding the limit are acceptably low, even though they cannot be quantified. For parameters with all data below the detection limit, the warning limit will be set to the detection limit and the control limit set to 10 times the detection limit, or the release limit, whichever is less.

Monitoring data are analyzed to determine if change may have occurred at the end of each decision period. If there is indication that a change may have occurred, assessment is needed to determine whether the probability of exceeding a limit has changed. Possible changes are evaluated in an assessment to determine if the probability of exceeding a limit has changed as well as evaluating for unplanned releases or loss of process control. If all data meet the control chart decision criteria, then there is no evidence of change and no assessment is needed. Development of control charts and testing for change will be done at least once each year and documented to the files and in the EM Program annual report.

\subsection{Control Charts}

Control charts with warning and control limits for parameters in the three effluent streams studied (TRA-764, CFA-691, and IF-603A) have been prepared for the 1994 Compliance Monitoring Program annual report. These control charts were reviewed. The center line of the control chart is the historical mean which represents the expected central value. The mean was calculated using the historical data, which can represent different time periods for each parameter on each effluent stream. The warning and control limits are also calculated from the historical data. The 1994 data are compared to the expected values from the characterization period.

Relative to the number of parameters monitored on each of the three effluent streams, the number of control charts published in the annual report is fairly small. A control chart is needed for each parameter with a release limit to evaluate the possibility that the likelihood of exceeding the release limit has changed. To demonstrate control and a lack of unplanned releases, the control chart is needed to demonstrate that change has not occurred. The release limits and sources for each effluent are the determining factor in what control charts are needed. The appropriate data then needs to be gathered to characterize the parameter for the effluent stream. Monitoring then documents whether change has occurred. 


\subsection{Evaluating Changes Over Longer Time Periods}

It is possible that small changes may have occurred which do not cause the data to plot outside the warning or control limits. Small changes may, however, become apparent over longer time periods. An evaluation of long-term changes is also needed. The third criteria for control charts, seven out of eight observations on one side of the central value, is the triggering indicator that a trend is slowly altering the mean value of the parameter or a small change has occurred. If the mean shifts, then the data should center around the new mean and be offset from the previous mean value. If seven out of eight observations on one side of the central value trigger an assessment, then the assessment will include a linear regression for trend to determine if a statistically significant trend is present in the data.

\section{ASSESSMENT}

This section discusses the assessments that will be conducted in response to monitoring results that indicate possible permit violations or that changes have occurred. Because of the statistical nature of the comparison to control limits, there will be false positive situations where the data trigger an alarm even though no change has occurred. To account for this false positive rate, confirmation sampling is part of assessment. Confirmation sampling greatly reduces the false positive rate for compliance monitoring programs (Davis and McNichols 1994a). Assessment must also be graded to risk to avoid overly rigorous responses to triggers. In some instances, the change, even if real, will not substantially change the likelihood of exceeding a limit. In this case, there is no need to do an extensive analysis of the change, but to flag the parameter for continued awareness. In other cases, the change, if real, could mean a change in the probability of exceeding a limit. In this case, rapid data collection would be indicated to make a more definitive determination of whether the change was real.

\subsection{Causes Behind Triggers}

An assessment will be conducted to determine the cause behind the concentration that exceeded a trigger value. Five causes have been identified for investigation during assessments:

1) Errors in data such as field notes, laboratory problems, or data manipulation.

2) Changes to procedures, sampling locations, laboratories or other programmatic change.

3) Outliers due to one-time spikes from out of control equipment or an unusual disposal.

4) Samples that fall in the tails of the distribution.

5) Changes to the sources or processes that result in a change in mean or variance in the effluent stream. 
The first two causes can be investigated by reviewing data packages and programmatic activities. No confirmation sampling needs to be conducted to evaluate the first two sources of error or change. However, new characterization data may need to be collected in response to changes caused by programatic changes. The third cause may be identified by talking to facility and process managers and evaluating the source and processes contributing to the effluent stream. If the assessment does not identify any errors, changes in programmatic activities, or known releases then confirmation sampling would be conducted to test for an outlier, a rare response, or a change in the process.

Confirmatory sampling will consist of two additional samples. Each of the three samples must be statistically independent. This can be accomplished by collecting and submitting the samples to the laboratory separated by sufficient time to assure that they are not analyzed in the same sample delivery group. Two samples analyzed within the same sample delivery group might not qualify as statistically independent (Davis and McNichols 1994b).

\subsection{Determining the Potential for Change in Risk}

If review of data packages, programmatic issues, and facility operations does not reveal the source of error or change, then confirmation sampling is indicated. The timing of the additional sampling would depend on the potential that the change would increase the probability of exceeding a release limit for the parameter. The timing would also depend on the response time available and whether compliance was based on a single sample or the average of a number of samples over a compliance period.

To measure the potential that the new measurement could change the assessment of risk, the ratio of the difference between the new value and the limit divided by the standard deviation is calculated.

$$
M_{r}=\frac{(L-x)}{s}
$$

where:

$\mathrm{L}=$ Release limit

$\mathrm{x}=$ Observation outside the control limit, or mean of three samples outside the warning -limit, or mean of seven samples to one side of the process mean

$\mathrm{s}=$ Standard deviation of characterization data

$M_{r}=$ Ratio measure of risk

If this ratio $\left(M_{r}\right)$ is greater than 3 , then there is little chance that the process has changed enough to significantly increase the probability of the parameter exceeding the release limit. The assumption of this calculation is that the value outside the control or warning limit represents a new mean concentration for the parameter in the effluent stream with a variance that has not changed. There is no theoretical basis for the ratio measure of risk. It merely serves as a flag to indicate when monitoring data require a closer look. If the ratio $\left(M_{r}\right)$ is less than 3 , then this indicates that there 
may be a moderate to high likelihood of exceeding a release limit for this parameter and more analysis is indicated. When $M_{r}$ is less than 3 , the assessment response may need to be more intense because of the potential for greater risk. The actual assessment intensity will depend on the response time available.

\subsection{Assessment When Release Limits are Exceeded}

This section discusses assessment activities that are conducted when the concentration of a parameter measured in an effluent stream exceeds a release limit. This may or may not trigger a noncompliance depending on the response time associated with the release limit and whether the limit is a self-imposed limit or a permit limit.

\subsubsection{Violations of Permit Conditions}

If the concentration measured in the effluent stream exceeds a release limit in a permit and there is no response time, then a permit violation may have occurred. An assessment for causes one and two is conducted to make sure that there is not an error in data reduction or reporting and that no programmatic changes occurred that may have lead to the result. The facility manager is then requested to evaluate sources and processes to determine if the cause of the high concentration can be determined. If simple explanations cannot be found, then confirmatory sampling is conducted to determine if the concentration in the discharge is still over the limit. Two additional samples are collected in an expeditious manner but retaining statistical independence. If even one of these samples also exceeds the limit, then the facility manager will conduct additional source or process investigations to determine the cause of the increased level of contamination and to take action to decrease the releases. If neither of the confirmatory samples exceeds the release limit, and the source investigation does not identify a likely cause, then it will be concluded that the extreme observation was an outlier.

\subsubsection{Limits with Response Time}

If a release limit is exceeded, but there is response time, the actions will be different than if a permit violation has occurred. Some parameters will only be planned to be sampled once per compliance period because the likelihood associated with the parameter was deemed to be sufficiently low. If no additional samples were planned for this parameter, then two confirmatory samples will be collected sometime during the remainder of the compliance period. This will give a total of three samples to calculate a mean for comparison to the release limit. If additional sampling is already planned, no additional actions are necessary. For samples with response time, parameters near the limit may have significant probabilities of single samples exceeding the limit. For these parameters, sampling frequency is set so that the average over the compliance period will be below the limit. The program should be designed to accommodate occasional measurements above release limits for parameters with response time. 


\subsection{Assessment When Change is Indicated}

Change can be indicated by one of three possible events:

- One sample exceeds a control limit,

- Three samples in a row exceed a warning limit,

- Seven of eight samples fall on one side of the mean.

Responses to each of these events will be somewhat different.

The response to one sample exceeding the control limit will be similar to the response to exceeding a release limit. An assessment for causes one, two, and three will be conducted to determine if the extreme value is attributable to error, programmatic change, or a known facility condition. If the cause cannot be identified from this review, confirmatory sampling is indicated. When $M_{r}$ indicates that the change has the potential for a significant change in likelihood of exceeding a limit $\left(M_{r}<3\right)$, then two confirmation samples will be collected in an expeditious manner while still maintaining statistical independence. If all three samples exceed the warning limit, more extensive review of sources to the effluent will be conducted to attempt to determine the cause of the change. If $M_{r}$ is less than 3, and a change is confirmed, recharacterization to calculate a new probability of exceeding the limit is necessary. If the additional samples do not confirm the change, no response action is necessary. If $M_{r}$ is greater than three, then it is not likely that the change would significantly change the likelihood of exceeding a release limit. In this case, confirmatory sampling is not necessary but review for causes one, two, and three would be conducted.

When three samples in a row exceed a warning limit, it is an indication that a change has occurred in the effluent. A review is conducted for causes one, two, and three to determine if the change is attributable to known causes. If the calculation of $M_{r}$ indicates that the likelihood of exceeding a release limit may have increased, then the new data is used to estimate a new probability of exceeding a release limit. This probability is used to determine if the effluent has changed to the point that monitoring strategy needs to be adjusted. If a conclusion is reached that the concentration in an effluent stream has changed, then recharacterization must be done for that parameter. With the new characterization data, likelihood is evaluated and a new monitoring strategy or frequency established if necessary. For parameters where likelihood is low and $M_{r}$ is greater than 3, no special recharacterization is necessary. Additional data collected from the effluent stream will be used to develop a new base line starting from the point where the change occurred.

If change is indicated by a series of seven out of eight samples falling to one side of the center line, a small change or long term trend may be indicated. Review of historical control charts indicates that this type of trigger is commonly related to a change in the detection limit for a parameter. Cause two, therefore, needs to be carefully evaluated when this trigger is activated. The probability of 
exceeding the release limit is calculated from the last eight data points and a determination made whether the change could alter the likelihood of exceeding a release limit. If no increase in likelihood is indicated, then the data are used to establish a new base line for the effluent stream. If the likelihood of exceeding a release limit has moved to a different level, the frequency and strategy of the monitoring program are evaluated to determine if a program modification is warranted based on the new information.

When change is indicated, and the calculation of $M_{r}$ indicates that the likelihood of exceeding a release limit may have increased, then more rapid assessment is warranted so that a determination can be made as to whether risk has increased. If risk has increased, then the frequency or strategy of monitoring may need to be adjusted. If there is no indication that risk may have increased, then no immediate response is needed. A new base line is established for the effluent stream with routine monitoring data.

\section{SUMMARY}

This document has presented a methodology for the prioritization of liquid effluent monitoring and/or sampling frequencies. The proposed monitoring approach is risk-based, where the risk is defined relative to the likelihood and severity of exceeding an effluent release limit. Likelihood is defined as the probability of exceeding a release limit. Probability is statistically based and refers to the chance of a sample concentration or a mean of multiple concentrations exceeding a release limit. Severity is based on time available to recover from an exceedance or potential exceedance. Each component of risk has three levels; low, medium, and high. Based on the interplay between the two components of risk, likelihood and severity, monitoring strategies are developed.

Examples of the proposed strategies using actual INEL effluent concentrations were presented to evaluate the implementability of the approach. These problems demonstrate use of the risk based decision process, showing how this process can be used to greatly simplify the current monitoring program.

This document also presents simplified techniques for the analysis and interpretation of sampling data. The technique utilizes control charts that allow for a rapid graphical determination of changes in effluent concentrations. The ability to detect change is important for an effective performance monitoring program.

Criteria are presented that are used to test whether monitoring data indicate a potential to exceed a release limit or that a change may have occurred in effluent concentrations. If the monitoring data exceed the trigger criteria, then an assessment is conducted to determine if the change requires some response. If a change in a effluent parameter does not significantly alter the likelihood of exceeding a release limit, no response is necessary. If likelihood is altered, then response actions such as recharacterization or installation of treatment may be warranted.

Use of these methods should allow for the development of a sampling program that will: 
- Focus monitoring effort by risk,

- Orient the program to making decisions (exceed/not exceed; change/no change), and

- Justify a reduction in monitoring effort. 


\section{REFERENCES}

ASME, 1991, Risk-based Inspection - Development of Guidelines, CRTD-vol. 20-1, American Society of Mechanical Engineers, New York, NY, 1991.

Ansley, S., T. Brock, D. Walker, A. Rood, and M. Abbot, 1994, Idaho National Engineering Laboratory Management Guidance for Disposal of Wastewater, DRAFT, Lockheed Idaho Technologies Co., Idaho Falls, ID, September 1994.

Davis, C. B., and R. J. McNichols, 1994a, Groundwater Monitoring Statistics Update: Part I: Progress Since 1988, Groundwater Monitoring and Remediation, Vol XIV, No 4, pp. 148-158, Fall 1994.

Davis, C. B., and R. J. McNichols, 1994b, Groundwater Monitoring Statistics Update: Part II: Nonparametric Prediction Limits, Groundwater Monitoring and Remediation, Vol XIV, No 4, pp. 159-175, Fall 1994.

DOE, 1991, Environmental Regulatory Guide for Radiological Effluent Monitoring and Environmental Surveillance, DOE/EH-0173T, U. S. Department of Energy, Washington, DC, January 1991.

DOE, 1993, Idaho National Engineering Laboratory Environmental Compliance Planning Manual, DOE/ID-10166, U. S. Department of Energy, Idaho Falls, ID, September 1993.

EPA, 1983, Interim Guidelines and Specifications. for Preparing Quality Assurance Project Plans, QAMS-005/80, EPA-600/4-83-004, U. S. Environmental Protection Agency, Washington, DC, February 1983.

EPA, 1989, Statistical Analysis of Groundwater Monitoring Data at RCRA Facilities, Interim Final Guidance, EPA/530-SW-89-026, Office of Solid Waste, U. S. Environmental Protection Agency, Washington, DC, April 1989.

EPA, 1992, Statistical Analysis of Groundwater Monitoring Data at RCRA Facilities, Addendum to Interim Final Guidance, DRAFT, EPA/530-R-93-003, Office of Solid Waste, U. S. Environmental Protection Agency, Washington, DC, July 1992.

Gilbert, Richard O., 1987, Statistical Methods for Environmental Pollution Monitoring, Van Nostrand . Reinhold, New York, NY.

Pinzel, M. A., 1994, Idaho National Engineering Laboratory Liquid Effluent Inventory Phase II Sampling and Analysis Plan, QJ1301:0002I, Ecology and Environment Inc., Idaho Falls, ID, June 1994. 



\section{Appendix A. Analytical Data from CFA-691, Influent to the CFA Sewage Treatment Plant}


A-2 
Appendix A. Analytical data from CFA-691, Influent to CFA Sewage Treatment Plant.

\begin{tabular}{|c|c|c|c|c|c|c|c|c|c|}
\hline Date & Rep & $\begin{array}{r}\text { TSS } \\
(\mathrm{mg} / \mathrm{L}) \\
\end{array}$ & $\begin{array}{r}\text { TDS } \\
(\mathrm{mg} / \mathrm{L}) \\
\end{array}$ & $\begin{array}{r}\text { BOD5 } \\
(\mathrm{mg} / \mathrm{L})\end{array}$ & $\begin{array}{r}\mathrm{COD} \\
(\mathrm{mg} / \mathrm{L})\end{array}$ & $\begin{array}{r}\text { CON } \\
\text { (umhos) } \\
\end{array}$ & $\mathrm{PH}$ & $\begin{array}{r}\text { TOC } \\
(\mathrm{mg} / \mathrm{L})\end{array}$ & $\begin{array}{r}\text { TOG } \\
(\mathrm{mg} / \mathrm{L})\end{array}$ \\
\hline $5 / 21 / 92$ & 1 & 64 & & 66.5 & 84.8 & 58.1 & 7.84 & 15.8 & 8.4 \\
\hline $5 / 21 / 92$ & 2 & 74 & & 47.7 & 102 & 47.1 & 7.73 & 17.1 & 35.4 \\
\hline $8 / 26 / 92$ & 1 & 60 & & 40.6 & 257 & 820 & 7.48 & 118 & -5 \\
\hline $8 / 26 / 92$ & 2 & 99 & & 24.9 & 223 & 673 & 7.63 & 112 & -5 \\
\hline $9 / 3 / 92$ & 1 & 64 & & 52.2 & & & & & \\
\hline 9/3/92 & 2 & 45 & & 58.2 & & & & & \\
\hline $10 / 20 / 92$ & 1 & 35 & & 6.6 & & 766 & 7.3 & & \\
\hline $10 / 20 / 92$ & 2 & 38 & & 4.9 & & 669 & 7.36 & & \\
\hline $11 / 17 / 92$ & 1 & 7 & & 1.5 & 67 & 676 & 7.45 & 13.8 & 5.3 \\
\hline $11 / 17 / 92$ & 2 & $-5^{(a)}$ & & 4.3 & 69 & 667 & 7.44 & 11.6 & 6.5 \\
\hline $12 / 29 / 92$ & 1 & (b) & & 28.9 & & 1048 & 7.11 & & \\
\hline $12 / 29 / 92$ & 2 & & & 35.4 & & 1161 & & & \\
\hline $1 / 6 / 93$ & 1 & 30 & & 10 & & 974 & 6.49 & & \\
\hline $1 / 6 / 93$ & 2 & 70 & & 8 & & 1006 & 7.28 & & \\
\hline $2 / 18 / 93$ & 1 & 25 & & 19 & 64.8 & 945 & 7.36 & 10.9 & -5 \\
\hline $2 / 18 / 93$ & 2 & 21 & & 16 & 50.8 & 216 & 7.45 & 8.1 & -5 \\
\hline $5 / 20 / 93$ & 1 & 18 & 495 & 14 & 74.6 & 737 & 7.16 & 18.2 & 6 \\
\hline $5 / 20 / 93$ & 2 & 35 & 483 & 13 & 67.8 & 709 & 7.27 & 19.2 & -5 \\
\hline $8 / 18 / 93$ & 1 & 54 & 444 & & 58.7 & 20 & 6.72 & 9.7 & 8.3 \\
\hline $8 / 18 / 93$ & 2 & 16 & 437 & & 133 & 1800 & 7.59 & 14.6 & 9.3 \\
\hline $11 / 17 / 93$ & 1 & 14 & 502 & 9 & 55.4 & 677 & 7.21 & 12.5 & -5 \\
\hline $11 / 17 / 93$ & 2 & 13 & 474 & 8 & 216 & 658 & 7.42 & 9.2 & -5 \\
\hline $2 / 16 / 94$ & 1 & 578 & 424 & & 80.3 & 746 & 6.78 & 20.3 & 9.9 \\
\hline $5 / 31 / 94$ & 1 & 42 & 542 & 23 & 102 & 1167 & 7.73 & 24 & 9.9 \\
\hline $8 / 2 / 94$ & 1 & 12 & 440 & 9 & 39 & 707 & 7.26 & 22.8 & 329 \\
\hline $11 / 8 / 94$ & 1 & 9 & 480 & 17 & 64 & 755 & 7.44 & 37.3 & 8.3 \\
\hline
\end{tabular}

(a) Negative numbers indicate the result was below detection, the number is the detection limit.

(b) Blank cells indicate the sample was not analyzed for that parameter. 
Appendix A. Analytical data from CFA-691, Influent to CFA Sewage Treatment Plant.

\begin{tabular}{rrrrrrrrrr}
\hline \multicolumn{1}{c}{ Date } & Rep & $\begin{array}{r}\text { MBAS } \\
(\mathrm{mg} / \mathrm{L})\end{array}$ & $\begin{array}{r}\mathrm{AG} \\
(\mathrm{ug} / \mathrm{L})\end{array}$ & $\begin{array}{r}\mathrm{AS} \\
(\mathrm{ug} / \mathrm{L})\end{array}$ & $\begin{array}{r}\mathrm{BA} \\
(\mathrm{ug} / \mathrm{L})\end{array}$ & $\begin{array}{r}\mathrm{BE} \\
(\mathrm{ug} / \mathrm{L})\end{array}$ & $\begin{array}{r}\mathrm{CD} \\
(\mathrm{ug} / \mathrm{L})\end{array}$ & $\begin{array}{r}\mathrm{CO} \\
(\mathrm{ug} / \mathrm{L})\end{array}$ & $\begin{array}{r}\mathrm{CR} \\
(\mathrm{ug} / \mathrm{L})\end{array}$ \\
\hline $5 / 21 / 92$ & 1 & -1 & -3 & -1 & 80 & -2 & -4 & -7 & 16.8 \\
$5 / 21 / 92$ & 2 & -1 & -3 & -1 & 81.1 & -2 & -4 & -7 & 17 \\
$8 / 26 / 92$ & 1 & -0.1 & -7 & 1.4 & 74.4 & -1 & -5 & -6 & 17.7 \\
$8 / 26 / 92$ & 2 & -0.1 & -7 & 1.2 & 81.3 & -1 & -5 & -6 & 19.2 \\
$9 / 3 / 92$ & 1 & & & & & & & & \\
$9 / 3 / 92$ & 2 & & & & & & & & \\
$10 / 20 / 92$ & 1 & & & & & & & & \\
$10 / 20 / 92$ & 2 & & & & & & & & \\
$11 / 17 / 92$ & 1 & & -10 & -10 & -200 & & -5 & & -10 \\
$11 / 17 / 92$ & 2 & & -10 & -10 & -200 & & -5 & & -10 \\
$12 / 29 / 92$ & 1 & & & & & & & & \\
$12 / 29 / 92$ & 2 & & & & & & & & \\
\hline $1 / 6 / 93$ & 1 & & & & & & & & \\
$1 / 6 / 93$ & 2 & & & & & & & & \\
$2 / 18 / 93$ & 1 & -0.1 & -10 & -10 & -200 & -5 & -5 & -50 & -10 \\
$2 / 18 / 93$ & 2 & -0.1 & -10 & -10 & -200 & -5 & -5 & -50 & -10 \\
$5 / 20 / 93$ & 1 & -0.1 & -10 & -10 & -200 & -5 & -5 & -50 & 11.7 \\
$5 / 20 / 93$ & 2 & 0.12 & -10 & -10 & -200 & -5 & -5 & -50 & 10.4 \\
$8 / 18 / 93$ & 1 & 0.12 & -10 & -10 & -200 & -5 & -5 & -50 & -10 \\
$8 / 18 / 93$ & 2 & 0.1 & -10 & -10 & -200 & -5 & -5 & -50 & -10 \\
$11 / 17 / 93$ & 1 & -0.1 & -10 & -10 & -200 & -5 & -5 & -50 & 11.8 \\
$11 / 17 / 93$ & 2 & -0.1 & -10 & -10 & -200 & -5 & -5 & -50 & 13.5 \\
\hline $2 / 16 / 94$ & 1 & -0.1 & -10 & -10 & -200 & -5 & -5 & -50 & 11.9 \\
$5 / 31 / 94$ & 1 & -0.1 & -10 & -10 & -200 & -5 & -5 & -50 & 12.9 \\
$8 / 2 / 94$ & 1 & -0.1 & -10 & -10 & -200 & -5 & -5 & -50 & 12.4 \\
$11 / 8 / 94$ & 1 & 0.29 & -10 & -10 & -200 & -5 & -5 & -50 & 23.3 \\
\hline
\end{tabular}


Appendix A. Analytical data from CFA-691, Influent to CFA Sewage Treatment Plant.

\begin{tabular}{|c|c|c|c|c|c|c|c|c|c|}
\hline Date & Rep & $\begin{array}{r}\text { CR6 } \\
\text { (ug/L) }\end{array}$ & $\begin{array}{r}\mathrm{CU} \\
\text { (ug/L) }\end{array}$ & $\begin{array}{r}\text { HG } \\
(\mathrm{ug} / \mathrm{L})\end{array}$ & $\begin{array}{r}\text { NI } \\
\text { (ug/L) }\end{array}$ & $\begin{array}{r}P B \\
(\mathrm{ug} / \mathrm{L})\end{array}$ & $\begin{array}{r}S B \\
(\mathrm{ug} / \mathrm{L})\end{array}$ & $\begin{array}{r}S E \\
(\mathrm{ug} / \mathrm{L})\end{array}$ & $\begin{array}{r}T L \\
(\mathrm{ug} / \mathrm{L})\end{array}$ \\
\hline $5 / 21 / 92$ & 1 & & 39.6 & -0.2 & -10 & 6.1 & 23.8 & 1.9 & -1 \\
\hline $5 / 21 / 92$ & 2 & & 39.6 & -0.2 & -10 & -4 & -23 & 2.1 & -1 \\
\hline $8 / 26 / 92$ & 1 & & 19.8 & -0.2 & -19 & 12.9 & -28 & 2.3 & -2 \\
\hline $8 / 26 / 92$ & 2 & & 20.9 & -0.2 & -19 & 6.6 & -28 & 2.1 & -2 \\
\hline $9 / 3 / 92$ & 1 & & & & & & . & & \\
\hline $9 / 3 / 92$ & 2 & & & & & & & & \\
\hline $10 / 20 / 92$ & 1 & & & & & & & & \\
\hline $10 / 20 / 92$ & 2 & & & & & & & & \\
\hline $11 / 17 / 92$ & 1 & -0.02 & & -0.2 & & -3 & & -5 & \\
\hline $11 / 17 / 92$ & 2 & -0.02 & & -0.2 & & -3 & & -5 & \\
\hline $12 / 29 / 92$ & 1 & & & & & & & & \\
\hline $12 / 29 / 92$ & 2 & & & & & & & & \\
\hline $1 / 6 / 93$ & 1 & & & & & & & & \\
\hline $1 / 6 / 93$ & 2 & & & & & & & & \\
\hline $2 / 18 / 93$ & 1 & & 35.3 & -0.2 & -40 & 5.1 & -60 & -5 & -10 \\
\hline $2 / 18 / 93$ & 2 & & -25 & -0.2 & -40 & 4.5 & -60 & -5 & -10 \\
\hline $5 / 20 / 93$ & 1 & & -25 & -0.2 & -40 & -3 & -60 & -5 & -10 \\
\hline $5 / 20 / 93$ & 2 & & -25 & -0.2 & -40 & -3 & -60 & -5 & -10 \\
\hline $8 / 18 / 93$ & 1 & & -25 & -0.2 & -40 & -3 & -60 & -5 & -10 \\
\hline $8 / 18 / 93$ & 2 & & -25 & -0.2 & -40 & 17.5 & -60 & -5 & -10 \\
\hline $11 / 17 / 93$ & 1 & & -25 & -0.2 & -40 & 10.4 & -60 & -5 & -10 \\
\hline $11 / 17 / 93$ & 2 & & -25 & -0.2 & -40 & 8.7 & -60 & -5 & -10 \\
\hline $2 / 16 / 94$ & 1 & & 36 & -0.2 & -40 & -3 & -60 & -5 & -10 \\
\hline $5 / 31 / 94$ & 1 & & 30.1 & 0.21 & -40 & 5.3 & -60 & -5 & -10 \\
\hline $8 / 2 / 94$ & 1 & & -25 & -0.2 & -40 & -3 & -60 & -5 & -10 \\
\hline $11 / 8 / 94$ & 1 & & 27.6 & -0.2 & -40 & -3 & -60 & -5 & -10 \\
\hline
\end{tabular}


Appendix A. Analytical data from CFA-691, Influent to CFA Sewage Treatment Plant.

\begin{tabular}{|c|c|c|c|c|c|c|c|c|c|}
\hline Date & Rep & $\begin{array}{r}\mathrm{ZN} \\
(\mathrm{ug} / \mathrm{L})\end{array}$ & $\begin{array}{r}\mathrm{CA} \\
(\mathrm{ug} / \mathrm{L})\end{array}$ & $\begin{array}{r}F E \\
(u g / L)\end{array}$ & $\begin{array}{r}K \\
(\mathrm{ug} / \mathrm{L})\end{array}$ & $\begin{array}{r}M G \\
(u g / L)\end{array}$ & $\begin{array}{r}\mathrm{MN} \\
(\mathrm{ug} / \mathrm{L})\end{array}$ & $\begin{array}{r}\text { NA } \\
(\mathrm{ug} / \mathrm{L})\end{array}$ & $\begin{array}{r}\text { PHENOL } \\
(\mathrm{ug} / \mathrm{L})\end{array}$ \\
\hline $5 / 21 / 92$ & 1 & 91.6 & 57300 & 613 & & 19000 & 13.5 & 50400 & \\
\hline $5 / 21 / 92$ & 2 & 74.2 & 55400 & 378 & & 19000 & 11.1 & 44600 & \\
\hline $8 / 26 / 92$ & 1 & 96.4 & 57200 & 477 & & 19600 & 13.9 & 95300 & \\
\hline $8 / 26 / 92$ & 2 & 113 & 59200 & 527 & & 19900 & 16.5 & 146000 & \\
\hline $9 / 3 / 92$ & 1 & & & & & & & & \\
\hline 9/3/92 & 2 & & & & & & & & \\
\hline $10 / 20 / 92$ & 1 & & & & & & & & \\
\hline $10 / 20 / 92$ & 2 & & & & & & & & \\
\hline $11 / 17 / 92$ & 1 & & & & & & & & 13.6 \\
\hline $11 / 17 / 92$ & 2 & & & & & & & & 11.1 \\
\hline $12 / 29 / 92$ & 1 & & & & & & & & \\
\hline $12 / 29 / 92$ & 2 & & & & & & & & \\
\hline $1 / 6 / 93$ & 1 & & & & & & & & \\
\hline $1 / 6 / 93$ & 2 & & & & & & & & \\
\hline $2 / 18 / 93$ & 1 & 56.2 & 61500 & 296 & 7350 & 20600 & -15 & 122000 & \\
\hline $2 / 18 / 93$ & 2 & 44.9 & 65300 & 282 & 6280 & 21800 & -15 & 141000 & \\
\hline $5 / 20 / 93$ & 1 & 92.3 & 65500 & 268 & 7500 & 21900 & -15 & 47100 & 8.5 \\
\hline $5 / 20 / 93$ & 2 & 68.1 & 69800 & 213 & 7210 & 23600 & -15 & 47900 & 6.5 \\
\hline $8 / 18 / 93$ & 1 & 43.5 & 59500 & 163 & 7580 & 20600 & -15 & 46200 & \\
\hline $8 / 18 / 93$ & 2 & 39.8 & 57600 & 177 & 7220 & 19800 & -15 & 44100 & \\
\hline $11 / 17 / 93$ & 1 & 40.6 & 66600 & 164 & 7430 & 22900 & -15 & 62100 & \\
\hline $11 / 17 / 93$ & 2 & 42.4 & 66500 & 264 & 7220 & 22800 & -15 & 56200 & \\
\hline $2 / 16 / 94$ & 1 & 119 & 65200 & 628 & 7510 & 21100 & -15 & 58400 & \\
\hline $5 / 31 / 94$ & 1 & 82.7 & 59300 & 497 & 8220 & 20300 & 18.9 & 69200 & \\
\hline $8 / 2 / 94$ & 1 & 89.8 & 63400 & 255 & 6560 & 21300 & -15 & 37600 & \\
\hline $11 / 8 / 94$ & 1 & 123 & 57000 & 339 & 10300 & 19400 & 20.7 & 54900 & \\
\hline
\end{tabular}


Appendix A. Analytical data from CFA-691, Influent to CFA Sewage Treatment Plant.

\begin{tabular}{|c|c|c|c|c|c|c|c|c|c|}
\hline Date & $\operatorname{Rep}$ & $\begin{array}{r}\mathrm{NO} 3 \\
(\mathrm{mg} / \mathrm{L})\end{array}$ & $\begin{array}{l}\mathrm{HN} 3 \mathrm{~N} \\
(\mathrm{mg} / \mathrm{L})\end{array}$ & $\begin{array}{l}\text { NO3N } \\
(\mathrm{mg} / \mathrm{L})\end{array}$ & $\begin{array}{l}\text { NO2N } \\
(\mathrm{mg} / \mathrm{L})\end{array}$ & $\begin{array}{r}\mathrm{NNN} \\
(\mathrm{mg} / \mathrm{L})\end{array}$ & $\begin{array}{r}\text { TKN } \\
(\mathrm{mg} / \mathrm{L})\end{array}$ & $\begin{array}{r}\mathrm{CL} \\
(\mathrm{mg} / \mathrm{L})\end{array}$ & $\begin{array}{r}F \\
(\mathrm{mg} / \mathrm{L})\end{array}$ \\
\hline $5 / 21 / 92$ & 1 & & & & & & & & \\
\hline $5 / 21 / 92$ & 2 & & & & & & & & \\
\hline $8 / 26 / 92$ & 1 & & & & & & & & \\
\hline $8 / 26 / 92$ & 2 & & & & & & - & & \\
\hline $9 / 3 / 92$ & 1 & & & 0.155 & 0.05 & & 15.4 & & \\
\hline $9 / 3 / 92$ & 2 & & & 0.151 & 0.061 & & 13.5 & & \\
\hline $10 / 20 / 92$ & 1 & & & & & 0.47 & 11.7 & & \\
\hline $10 / 20 / 92$ & 2 & & & & & 0.53 & 11.4 & & \\
\hline $11 / 17 / 92$ & 1 & & 6.1 & & & 1.2 & 13.3 & & \\
\hline $11 / 17 / 92$ & 2 & & 5.5 & & & 1.2 & 11.7 & & \\
\hline $12 / 29 / 92$ & 1 & & & & & 1.1 & 24.5 & & \\
\hline $12 / 29 / 92$ & 2 & & & & & 1.3 & 23.5 & & \\
\hline $1 / 6 / 93$ & 1 & & & & & 1.7 & 10.5 & & \\
\hline $1 / 6 / 93$ & 2 & & & & & 1.7 & 10.9 & & \\
\hline $2 / 18 / 93$ & 1 & & & & & 0.87 & 16.6 & & \\
\hline $2 / 18 / 93$ & 2 & & & & & 1.2 & 12.3 & & \\
\hline $5 / 20 / 93$ & 1 & & & & & 1.3 & 12.5 & 125 & 0.19 \\
\hline $5 / 20 / 93$ & 2 & & & & & 1.2 & 9.8 & 123 & 0.19 \\
\hline $8 / 18 / 93$ & 1 & & & & & 0.41 & 10.3 & 106 & 0.18 \\
\hline $8 / 18 / 93$ & 2 & & & & & 0.45 & 15.1 & 325 & 0.18 \\
\hline $11 / 17 / 93$ & 1 & & & & & 0.4 & 8.2 & 144 & 0.17 \\
\hline $11 / 17 / 93$ & 2 & & & & & 0.27 & 8.1 & 129 & 0.19 \\
\hline $2 / 16 / 94$ & 1 & & & & & 0.3 & 14.9 & 151 & 0.32 \\
\hline $5 / 31 / 94$ & 1 & & & & & 0.84 & 20 & 178 & 0.19 \\
\hline $8 / 2 / 94$ & 1 & & & & & 0.97 & 8.4 & 122 & 0.19 \\
\hline $11 / 8 / 94$ & 1 & & & & & 1.1 & 22 & 160 & 0.2 \\
\hline
\end{tabular}


Appendix A. Analytical data from CFA-691, Influent to CFA Sewage Treatment Plant.

\begin{tabular}{|c|c|c|c|c|c|}
\hline \multirow[t]{2}{*}{ Date } & \multirow[t]{2}{*}{ Rep } & \multicolumn{2}{|c|}{ PO4PTOTAL } & \multirow{2}{*}{$\begin{array}{r}\mathrm{SO} 4 \\
(\mathrm{mg} / \mathrm{L}) \\
\end{array}$} & \multirow{2}{*}{$\begin{array}{r}\text { STOT } \\
(\mathrm{mg} / \mathrm{L})\end{array}$} \\
\hline & & $(\mathrm{mg} / \mathrm{L})$ & $(\mathrm{mg} / \mathrm{L})$ & & \\
\hline $5 / 21 / 92$ & 1 & & & & \\
\hline $5 / 21 / 92$ & 2 & & & & \\
\hline $8 / 26 / 92$ & 1 & & & & \\
\hline $8 / 26 / 92$ & 2 & & & & \\
\hline $9 / 3 / 92$ & 1 & & & & \\
\hline $9 / 3 / 92$ & 2 & & & $\cdot$ & \\
\hline $10 / 20 / 92$ & 1 & & & & \\
\hline $10 / 20 / 92$ & 2 & & & & \\
\hline $11 / 17 / 92$ & 1 & & & & -0.1 \\
\hline $11 / 17 / 92$ & 2 & & & & -0.1 \\
\hline $12 / 29 / 92$ & 1 & & & & \\
\hline $12 / 29 / 92$ & 2 & & & & \\
\hline $1 / 6 / 93$ & 1 & & & & \\
\hline $1 / 6 / 93$ & 2 & & & & \\
\hline $2 / 18 / 93$ & 1 & & & & \\
\hline $2 / 18 / 93$ & 2 & & & & \\
\hline $5 / 20 / 93$ & 1 & 0.57 & & & \\
\hline $5 / 20 / 93$ & 2 & 0.53 & & & \\
\hline $8 / 18 / 93$ & 1 & 1.5 & & & \\
\hline $8 / 18 / 93$ & 2 & 0.62 & & & \\
\hline $11 / 17 / 93$ & 1 & 1.6 & & & \\
\hline $11 / 17 / 93$ & 2 & 1.4 & & & \\
\hline $2 / 16 / 94$ & 1 & & & 39.9 & -0.1 \\
\hline $5 / 31 / 94$ & 1 & & 1.1 & 44.3 & -0.1 \\
\hline $8 / 2 / 94$ & 1 & & 2.5 & 43.1 & -0.1 \\
\hline $11 / 8 / 94$ & 1 & . & 2.4 & 45.4 & -0.1 \\
\hline
\end{tabular}


Appendix B. Analytical Data from TRA-764, Cold Waste Pond 
B-2 
Appendix B. Analytical data from TRA-764, Cold Waste Pond

\begin{tabular}{|c|c|c|c|c|c|c|c|c|c|}
\hline DATE & REP & $\begin{array}{r}\text { TSS } \\
(\mathrm{mg} / \mathrm{L})\end{array}$ & $\begin{array}{r}\text { TDS } \\
(\mathrm{mg} / \mathrm{L})\end{array}$ & $\begin{array}{l}\text { BOD5 } \\
(\mathrm{mg} / \mathrm{L})\end{array}$ & $\begin{array}{r}\text { COD } \\
(\mathrm{mg} / \mathrm{L})\end{array}$ & $\begin{array}{r}\text { CON } \\
\text { (umhos) }\end{array}$ & $\mathrm{PH}$ & $\begin{array}{r}\text { TOC } \\
(\mathrm{mg} / \mathrm{L})\end{array}$ & $\begin{array}{l}\text { MBAS } \\
(\mathrm{mg} / \mathrm{L})\end{array}$ \\
\hline $1 / 15 / 91$ & 1 & (b) & & & & 1093 & 8.78 & 7.1 & \\
\hline $1 / 15 / 91$ & 2 & & & & & 1070 & 8.45 & 5.2 & \\
\hline $2 / 15 / 91$ & 1 & & & & & 1250 & 7.75 & 5.7 & \\
\hline $2 / 15 / 91$ & 2 & & & & & & & -5 & \\
\hline $3 / 15 / 91$ & 1 & & & & & 504 & 7.8 & -1 & \\
\hline $3 / 15 / 91$ & 2 & & & & & 429 & $7.91^{\circ}$ & 1 & \\
\hline $4 / 15 / 91$ & 1 & & & & & 1260 & 7.57 & 1.79 & \\
\hline $4 / 15 / 91$ & 2 & & & & & & & 1.82 & \\
\hline $5 / 15 / 91$ & 1 & & & & & 1620 & 7.53 & -0.5 & \\
\hline $5 / 15 / 91$ & 2 & & & & & 1270 & 7.57 & -0.5 & \\
\hline $7 / 15 / 91$ & 1 & & & & & 1060 & 7.67 & 2.51 & \\
\hline $7 / 15 / 91$ & 2 & & & & & 1010 & 7.85 & 2.47 & \\
\hline $8 / 15 / 91$ & 1 & & & & & 900 & 7.43 & 3.24 & \\
\hline $8 / 15 / 91$ & 2 & & & & & 910 & 7.84 & 2.62 & \\
\hline $9 / 15 / 91$ & 1 & & & & & 64.2 & 7.86 & 2.21 & \\
\hline $9 / 15 / 91$ & 2 & & & & & 62 & 7.9 & 2.58 & \\
\hline $12 / 17 / 91$ & 1 & & & & & 26.1 & 7.11 & 1.2 & \\
\hline $12 / 17 / 91$ & 2 & & & & & 26.7 & 7.7 & 0.83 & \\
\hline $1 / 28 / 92$ & 1 & & & & & 30.4 & 8.52 & 0.56 & \\
\hline $1 / 28 / 92$ & 2 & & & & & 25 & 8.58 & 1.55 & \\
\hline $2 / 26 / 92$ & 1 & & & & & 34.1 & 7.9 & & \\
\hline $2 / 26 / 92$ & 2 & & & & & 27.1 & 7.99 & & \\
\hline $3 / 26 / 92$ & 1 & & & & -5 & & & & -0.1 \\
\hline $3 / 26 / 92$ & 2 & & & & -5 & & & & -0.1 \\
\hline $5 / 12 / 92$ & 1 & & & & -5 & 29.9 & 7.04 & & -0.1 \\
\hline $5 / 12 / 92$ & 2 & & & & -5 & 25 & 8.18 & & -0.1 \\
\hline $7 / 28 / 92$ & 1 & & & & -5 & 399 & 7.7 & & -0.1 \\
\hline $7 / 28 / 92$ & 2 & & & & 6.3 & 375 & 8.2 & & -0.1 \\
\hline $11 / 12 / 92$ & 1 & & & & -5 & 329 & 7.58 & & -0.1 \\
\hline $11 / 12 / 92$ & 2 & & & & -5 & 331 & 7.91 & & -0.1 \\
\hline $2 / 24 / 93$ & 1 & & & & -5 & 360 & 6.88 & -0.5 & -0.1 \\
\hline $2 / 24 / 93$ & 2 & & & & -5 & 364 & 7.29 & -0.5 & -0.1 \\
\hline $5 / 11 / 93$ & 1 & & & & 9.5 & 337 & 7.05 & -0.5 & -0.1 \\
\hline $5 / 11 / 93$ & 2 & & & & -5 & 337 & 7.53 & -0.5 & -0.1 \\
\hline $8 / 31 / 93$ & 1 & $-5^{(2)}$ & 261 & & 6.5 & 407 & 7.52 & 4.7 & 0.1 \\
\hline $8 / 31 / 93$ & 2 & -5 & 256 & & 45.2 & 393 & 7.71 & 1 & 0.1 \\
\hline $11 / 2 / 93$ & 1 & 8 & 867 & & 11.7 & 895 & 7.87 & 2.5 & -0.1 \\
\hline $11 / 2 / 93$ & 2 & 8 & 902 & & 11.7 & 891 & 7.95 & 2.9 & -0.1 \\
\hline $2 / 24 / 94$ & 1 & -5 & 804 & & 59.8 & 1046 & 7.51 & 2.3 & -0.1 \\
\hline $5 / 19 / 94$ & 1 & 8 & 250 & 3 & -5 & 573 & 8.2 & -0.5 & -0.1 \\
\hline $8 / 10 / 94$ & 1 & 7 & 270 & 1 & 8.4 & 377 & 7.42 & 0.7 & -0.1 \\
\hline $11 / 3 / 94$ & 1 & -5 & 710 & 99 & -5 & 978 & 7.54 & 16 & -0.1 \\
\hline
\end{tabular}

(a) Negative numbers indicate the result was below detection, the number is the detection limit.

(b) Blank cells indicate the sample was not analyzed for that parameter. 
Appendix B. Analytical data from TRA-764, Cold Waste Pond

\begin{tabular}{|c|c|c|c|c|c|c|c|c|c|}
\hline DATE & REP & $\begin{array}{r}A G \\
(\mathrm{ug} / \mathrm{L}) \\
\end{array}$ & $\begin{array}{r}\text { AS } \\
(\mathrm{ug} / \mathrm{L})\end{array}$ & $\begin{array}{r}\mathrm{BA} \\
(\mathrm{ug} / \mathrm{L}) \\
\end{array}$ & $\begin{array}{r}\mathrm{BE} \\
(\mathrm{ug} / \mathrm{L}) \\
\end{array}$ & $\begin{array}{r}C D \\
(\mathrm{ug} / \mathrm{L})\end{array}$ & $\begin{array}{r}\mathrm{CO} \\
(\mathrm{ug} / \mathrm{L}) \\
\end{array}$ & $\begin{array}{r}\mathrm{CR} \\
(\mathrm{ug} / \mathrm{L}) \\
\end{array}$ & $\begin{array}{r}\mathrm{CU} \\
(\mathrm{ug} / \mathrm{L})\end{array}$ \\
\hline $1 / 15 / 91$ & 1 & -10 & -10 & & & -5 & & 8.7 & -10 \\
\hline $1 / 15 / 91$ & 2 & -10 & -10 & & & -5 & & 9.7 & -10 \\
\hline $2 / 15 / 91$ & 1 & -10 & -10 & & & -5 & & 7.1 & -10 \\
\hline $2 / 15 / 91$ & 2 & -10 & -10 & & & -5 & & 7.8 & -10 \\
\hline $3 / 15 / 91$ & 1 & -10 & -5 & -200 & & -5 & & -10 & -20 \\
\hline $3 / 15 / 91$ & 2 & -10 & -5 & -200 & & -5 & & -10 & -20 \\
\hline $4 / 15 / 91$ & 1 & -5 & 6.5 & 125 & & -5 & & 12.2 & 6.4 \\
\hline $4 / 15 / 91$ & 2 & -5 & 6.5 & 133 & & -5 & & 14.2 & 6.4 \\
\hline $5 / 15 / 91$ & 1 & 13.1 & -3 & 46.8 & & -5 & & -5 & 4.8 \\
\hline $5 / 15 / 91$ & 2 & 10.7 & -3 & 44.3 & & -5 & & -5 & -4 \\
\hline $7 / 15 / 91$ & 1 & -2 & -3 & 113 & & -5 & & 7.7 & 5.5 \\
\hline $7 / 15 / 91$ & 2 & -2 & -4 & 109 & & -5 & & 7.4 & 5.5 \\
\hline $8 / 15 / 91$ & 1 & -3 & 10.5 & 118 & & -5 & . & 77.4 & 52.3 \\
\hline $8 / 15 / 91$ & 2 & -3 & 20.1 & 157 & & -5 & & 90.6 & 322 \\
\hline $9 / 15 / 91$ & 1 & -4 & 8.3 & 98.1 & & -5 & & 40.9 & 9 \\
\hline $9 / 15 / 91$ & 2 & -4 & 7.9 & 97.3 & & -5 & & 42.2 & 22.5 \\
\hline $12 / 17 / 91$ & 1 & -4 & -5 & 46.7 & & -5 & & -6 & 13.2 \\
\hline $12 / 17 / 91$ & 2 & -4 & -5 & 47.1 & & -5 & & -6 & -2 \\
\hline $1 / 28 / 92$ & 1 & -3 & -1 & 37.6 & -2 & -4 & & -7 & 11.5 \\
\hline $1 / 28 / 92$ & 2 & -3 & -1 & 35.5 & -2 & -4 & & -7 & 11 \\
\hline $2 / 26 / 92$ & 1 & -3 & 2 & 45.1 & -2 & -4 & & -7 & -2 \\
\hline $2 / 26 / 92$ & 2 & -3 & 2.3 & 45.1 & -2 & -4 & & -7 & -2 \\
\hline $3 / 26 / 92$ & 1 & -4 & -1 & 45 & -3 & -5 & & 5.9 & -5 \\
\hline $3 / 26 / 92$ & 2 & -4 & -1 & 43.4 & -3 & -5 & & -5 & -5 \\
\hline $5 / 12 / 92$ & 1 & -3 & -1 & 47.9 & -2 & -4 & -7 & -7 & 9.5 \\
\hline $5 / 12 / 92$ & 2 & -3 & -1 & 45.4 & -2 & -4 & -7 & -7 & 9.5 \\
\hline $7 / 28 / 92$ & 1 & -7 & -1 & 52.2 & 1.6 & -5 & & -5 & 17.8 \\
\hline $7 / 28 / 92$ & 2 & -7 & 1.7 & 58.2 & -1 & -5 & & -7 & 17.2 \\
\hline $11 / 12 / 92$ & 1 & -10 & -10 & -200 & -1 & -5 & -50 & -10 & -25 \\
\hline $11 / 12 / 92$ & 2 & -10 & -10 & -200 & -1 & -5 & -50 & -10 & -25 \\
\hline $2 / 24 / 93$ & 1 & -10 & -10 & -200 & -5 & -5 & -50 & -10 & -25 \\
\hline $2 / 24 / 93$ & 2 & -10 & -10 & -200 & -5 & -5 & -50 & -10 & -25 \\
\hline $5 / 11 / 93$ & 1 & -10 & -10 & -200 & -5 & -5 & -50 & -10 & -25 \\
\hline $5 / 11 / 93$ & 2 & -10 & -10 & -200 & -5 & -5 & -50 & -10 & -25 \\
\hline $8 / 31 / 93$ & 1 & -10 & -10 & -200 & -5 & -5 & -50 & -10 & -25 \\
\hline $8 / 31 / 93$ & 2 & -10 & -10 & -200 & -5 & -5 & -50 & -10 & -25 \\
\hline $11 / 2 / 93$ & 1 & -10 & 20 & -200 & -5 & -5 & -50 & 19.7 & -25 \\
\hline $11 / 2 / 93$ & 2 & -10 & 23 & -200 & -5 & -5 & -50 & 101 & 399 \\
\hline $2 / 24 / 94$ & 1 & -10 & 16.9 & -200 & -5 & -5 & -50 & 32.4 & 33.9 \\
\hline $5 / 19 / 94$ & 1 & -10 & -10 & -200 & -5 & -5 & -50 & -10 & -25 \\
\hline $8 / 10 / 94$ & 1 & -10 & -10 & -200 & -5 & -5 & -50 & -10 & -25 \\
\hline $11 / 3 / 94$ & 1 & -10 & 14.5 & -200 & -5 & -5 & -50 & -10 & -25 \\
\hline
\end{tabular}


Appendix B. Analytical data from TRA-764, Cold Waste Pond

\begin{tabular}{|c|c|c|c|c|c|c|c|c|c|}
\hline DATE & REP & $\begin{array}{r}\mathrm{HG} \\
(\mathrm{ug} / \mathrm{L})\end{array}$ & $\begin{array}{r}N I \\
(\mathrm{ug} / \mathrm{L})\end{array}$ & $\begin{array}{r}\mathrm{PB} \\
(\mathrm{ug} / \mathrm{L})\end{array}$ & $\begin{array}{r}S B \\
(\mathrm{ug} / \mathrm{L})\end{array}$ & $\begin{array}{r}\mathrm{SE} \\
(\mathrm{ug} / \mathrm{L}) \\
\end{array}$ & $\begin{array}{r}T L \\
(\mathrm{ug} / \mathrm{L}) \\
\end{array}$ & $\begin{array}{r}\mathrm{ZN} \\
(\mathrm{ug} / \mathrm{L})\end{array}$ & $\begin{array}{r}\mathrm{CA} \\
(\mathrm{ug} / \mathrm{L})\end{array}$ \\
\hline $1 / 15 / 91$ & 1 & -0.2 & -10 & -3 & & -5 & -10 & 17.7 & \\
\hline $1 / 15 / 91$ & 2 & -0.2 & -10 & -3 & & -5 & -10 & 16.7 & \\
\hline $2 / 15 / 91$ & 1 & -0.2 & -10 & -3 & & -5 & -10 & -10 & \\
\hline $2 / 15 / 91$ & 2 & -0.2 & -10 & -3 & & -5 & -10 & 13.3 & \\
\hline $3 / 15 / 91$ & 1 & -0.2 & -40 & -3 & & -5 & -5 & -20 & \\
\hline $3 / 15 / 91$ & 2 & -0.2 & -40 & -3 & & -5 & -5 & -20 & \\
\hline $4 / 15 / 91$ & 1 & -0.2 & -12 & -1 & & -15 & -1 & 4.2 & \\
\hline $4 / 15 / 91$ & 2 & -0.2 & -12 & -1 & & -15 & -1 & 3.7 & \\
\hline $5 / 15 / 91$ & 1 & -0.2 & -13 & 5.6 & & -3 & -1 & -5 & \\
\hline $5 / 15 / 91$ & 2 & -0.2 & -13 & 3.5 & & -3 & -1 & -5 & \\
\hline $7 / 15 / 91$ & 1 & -0.2 & -8 & 3.9 & & -4 & -2 & -2 & \\
\hline $7 / 15 / 91$ & 2 & -0.2 & -8 & 2.9 & & -4 & -2 & -2 & \\
\hline $8 / 15 / 91$ & 1 & -0.2 & -13 & 4.5 & & 2.7 & -2 & 19 & \\
\hline $8 / 15 / 91$ & 2 & -0.2 & 17.7 & 19.7 & & -2 & -2 & 117 & \\
\hline $9 / 15 / 91$ & 1 & -0.2 & 28 & -2 & & -2 & -1 & 6.1 & \\
\hline $9 / 15 / 91$ & 2 & -0.2 & 27.1 & -2 & & -2 & -1 & 6.1 & \\
\hline $12 / 17 / 91$ & 1 & -0.2 & -12 & -2 & & -2 & -1 & 10.1 & 44200 \\
\hline $12 / 17 / 91$ & 2 & 0.38 & -12 & -2 & & -2 & -1 & 4 & 43300 \\
\hline $1 / 28 / 92$ & 1 & -0.2 & -10 & -1 & -23 & 1.1 & -1 & 24.4 & 44200 \\
\hline $1 / 28 / 92$ & 2 & -0.2 & -10 & -1 & -23 & 2 & -1 & 21.3 & 44900 \\
\hline $2 / 26 / 92$ & 1 & -0.2 & -10 & 1.1 & -23 & 1.3 & -1 & 62 & 44000 \\
\hline $2 / 26 / 92$ & 2 & -0.2 & -10 & 1.5 & 24.2 & 1.2 & -1 & 62 & 44200 \\
\hline $3 / 26 / 92$ & 1 & -0.2 & -12 & -1 & -17 & -1 & -1 & 44.8 & 43600 \\
\hline $3 / 26 / 92$ & 2 & -0.2 & -12 & -1 & -17 & -1 & -1 & 42.9 & 42500 \\
\hline $5 / 12 / 92$ & 1 & -0.2 & -10 & -1 & -23 & -1 & -1 & 27.3 & 46100 \\
\hline $5 / 12 / 92$ & 2 & -0.2 & -10 & -1 & -23 & -1 & -1 & 27.3 & 44600 \\
\hline $7 / 28 / 92$ & 1 & -0.2 & -19 & 3.5 & -28 & -10 & 5.3 & 47.8 & 44900 \\
\hline $7 / 28 / 92$ & 2 & -0.2 & -19 & 2.9 & -28 & -10 & -5 & 42.3 & 45000 \\
\hline $11 / 12 / 92$ & 1 & -0.2 & -40 & -3 & -10 & -5 & -10 & 58.1 & 48200 \\
\hline $11 / 12 / 92$ & 2 & -0.2 & -40 & -3 & 16.4 & -5 & -10 & 52.4 & 46500 \\
\hline $2 / 24 / 93$ & 1 & -0.2 & -40 & -3 & -60 & -5 & -10 & 131 & 53400 \\
\hline $2 / 24 / 93$ & 2 & -0.2 & -40 & -3 & -60 & -5 & -10 & 128 & 52000 \\
\hline $5 / 11 / 93$ & 1 & -0.2 & -40 & -3 & -60 & -5 & -10 & 53.6 & 49100 \\
\hline $5 / 11 / 93$ & 2 & -0.2 & -40 & -3 & -60 & -5 & -10 & 88.3 & 49000 \\
\hline $8 / 31 / 93$ & 1 & -0.2 & -40 & -3 & -60 & -5 & -10 & & 48200 \\
\hline $8 / 31 / 93$ & 2 & -0.2 & -40 & 11.4 & -60 & -5 & -10 & & 48200 \\
\hline $11 / 2 / 93$ & 1 & -0.2 & -40 & -3 & -60 & -5 & -10 & 22.5 & 130000 \\
\hline $11 / 2 / 93$ & 2 & -0.2 & -40 & 12.2 & -60 & -5 & -10 & 398 & 142000 \\
\hline $2 / 24 / 94$ & 1 & 1.2 & -40 & 3.9 & -60 & -5 & -10 & 33.9 & 142000 \\
\hline $5 / 19 / 94$ & 1 & -0.2 & -40 & -3 & -60 & -5 & -10 & -20 & 45300 \\
\hline $8 / 10 / 94$ & 1 & -0.2 & -40 & -3 & -60 & -5 & -10 & -20 & 53200 \\
\hline $11 / 3 / 94$ & 1 & -0.2 & -40 & -3 & -60 & -5 & -10 & -20 & 126000 \\
\hline
\end{tabular}


Appendix B. Analytical data from TRA-764, Cold Waste Pond

\begin{tabular}{|c|c|c|c|c|c|c|c|c|c|}
\hline DATE & REP & $\begin{array}{r}\mathrm{FE} \\
(\mathrm{ug} / \mathrm{L}) \\
\end{array}$ & $\begin{array}{r}\mathrm{K} \\
(\mathrm{ug} / \mathrm{L})\end{array}$ & $\begin{array}{r}\mathrm{MG} \\
(\mathrm{ug} / \mathrm{L})\end{array}$ & $\begin{array}{r}\mathrm{MN} \\
(\mathrm{ug} / \mathrm{L})\end{array}$ & $\begin{array}{r}\text { NA } \\
(\mathrm{ug} / \mathrm{L})\end{array}$ & $\begin{array}{r}\mathrm{NO} 3 \\
(\mathrm{mg} / \mathrm{L})\end{array}$ & $\begin{array}{l}\mathrm{NO} 3 \mathrm{~N} \\
(\mathrm{mg} / \mathrm{L})\end{array}$ & $\begin{array}{r}\mathrm{NNN} \\
(\mathrm{mg} / \mathrm{L})\end{array}$ \\
\hline $1 / 15 / 91$ & 1 & & & & & & 3.7 & & \\
\hline $1 / 15 / 91$ & 2 & & & & & & 3.1 & & \\
\hline $2 / 15 / 91$ & 1 & & & & & & 4 & & \\
\hline $2 / 15 / 91$ & 2 & & & & & & 4 & & \\
\hline $3 / 15 / 91$ & 1 & & & & & & & & . \\
\hline $3 / 15 / 91$ & 2 & & & & & & & & \\
\hline $4 / 15 / 91$ & 1 & & & & & & & 3.44 & \\
\hline $4 / 15 / 91$ & 2 & & & & & & & 3.36 & \\
\hline $5 / 15 / 91$ & 1 & & & & & & & 0.9 & \\
\hline $5 / 15 / 91$ & 2 & & & & & & & 0.88 & \\
\hline $7 / 15 / 91$ & 1 & & & & & & & 1.95 & \\
\hline $7 / 15 / 91$ & 2 & & & & & & & 2.05 & \\
\hline $8 / 15 / 91$ & 1 & & & & & & & 2.55 & \\
\hline $8 / 15 / 91$ & 2 & & & & & & & 2.36 & \\
\hline $9 / 15 / 91$ & 1 & & & & & & & 3.06 & \\
\hline $9 / 15 / 91$ & 2 & & & & & & & 3.07 & \\
\hline $12 / 17 / 91$ & 1 & & & 15800 & -3 & 8100 & & 0.925 & \\
\hline $12 / 17 / 91$ & 2 & & & 15400 & -3 & 8040 & & 0.93 & \\
\hline $1 / 28 / 92$ & 1 & & & 16300 & -2 & 7970 & & 0.927 & \\
\hline $1 / 28 / 92$ & 2 & & & 16600 & -2 & 8130 & & 1 & \\
\hline $2 / 26 / 92$ & 1 & & & 16600 & -2 & 7370 & & & \\
\hline $2 / 26 / 92$ & 2 & & & 16800 & -2 & 7460 & & & \\
\hline $3 / 26 / 92$ & 1 & & & 16400 & 4.3 & 7520 & & 0.978 & \\
\hline $3 / 26 / 92$ & 2 & & & 16000 & -4 & 7240 & & 1.01 & \\
\hline $5 / 12 / 92$ & 1 & -6 & & 17800 & -2 & 7900 & & 1.05 & \\
\hline $5 / 12 / 92$ & 2 & -6 & & 17200 & -2 & 7620 & & 1.07 & \\
\hline $7 / 28 / 92$ & 1 & & & 16200 & 4.2 & 8850 & & 0.936 & \\
\hline $7 / 28 / 92$ & 2 & & & 16200 & 97 & 8570 & & 0.934 & \\
\hline $11 / 12 / 92$ & 1 & -100 & -5000 & 17900 & -15 & 8430 & & & 1 \\
\hline $11 / 12 / 92$ & 2 & -100 & -5000 & 17300 & -15 & 8140 & & & 0.99 \\
\hline $2 / 24 / 93$ & 1 & 210 & 19500 & 18500 & -15 & 30900 & & & 0.9 \\
\hline $2 / 24 / 93$ & 2 & 194 & 19100 & 18100 & -15 & 29900 & & & 0.92 \\
\hline $5 / 11 / 93$ & 1 & -100 & -5000 & 18200 & -15 & 8410 & & & 0.81 \\
\hline $5 / 11 / 93$ & 2 & -100 & -5000 & 18300 & -15 & 8300 & & & 0.84 \\
\hline $8 / 31 / 93$ & 1 & -100 & -5000 & 18000 & -15 & 7970 & & & 0.99 \\
\hline $8 / 31 / 93$ & 2 & -100 & -5000 & 18000 & -15 & 8120 & & & 1.2 \\
\hline $11 / 2 / 93$ & 1 & 592 & 9180 & 49000 & -15 & 23000 & & & 9.3 \\
\hline $11 / 2 / 93$ & 2 & 4220 & 9620 & 50000 & 82.1 & 22900 & & & 7.8 \\
\hline $2 / 24 / 94$ & 1 & 1400 & 11500 & 53900 & 26.1 & 23900 & & & 2.1 \\
\hline $5 / 19 / 94$ & 1 & -100 & -5000 & 17100 & -15 & 7370 & & & 0.98 \\
\hline $8 / 10 / 94$ & 1 & -100 & -5000 & 20300 & -15 & 9080 & & & 0.89 \\
\hline $11 / 3 / 94$ & 1 & 153 & 8990 & 47700 & -15 & 20800 & & & 2.4 \\
\hline
\end{tabular}


Appendix B. Analytical data from TRA-764, Cold Waste Pond

\begin{tabular}{|c|c|c|c|c|c|c|c|}
\hline DATE & REP & $\begin{array}{r}\mathrm{TKN} \\
(\mathrm{mg} / \mathrm{L})\end{array}$ & $\begin{array}{r}\mathrm{CL} \\
(\mathrm{mg} / \mathrm{L})\end{array}$ & $\begin{array}{r}F \\
(\mathrm{mg} / \mathrm{L})\end{array}$ & $\begin{array}{r}\text { PORTHO } \\
(\mathrm{mg} / \mathrm{L})\end{array}$ & $\begin{array}{r}\text { PTOTAL } \\
(\mathrm{mg} / \mathrm{L})\end{array}$ & $\begin{array}{r}\mathrm{SO} 4 \\
(\mathrm{mg} / \mathrm{L})\end{array}$ \\
\hline $1 / 15 / 91$ & 1 & & 29 & 0.3 & -0.2 & & 419 \\
\hline $1 / 15 / 91$ & 2 & & 28.5 & 0.3 & -0.2 & & 405 \\
\hline $2 / 15 / 91$ & 1 & & 35.5 & 0.4 & -0.2 & & 437 \\
\hline $2 / 15 / 91$ & 2 & & 36.7 & 0.4 & -0.2 & & 422 \\
\hline $3 / 15 / 91$ & 1 & & 10 & -0.5 & 0.07 & & 21 \\
\hline $3 / 15 / 91$ & 2 & & 10 & -0.5 & 0.06 & & 20 \\
\hline $4 / 15 / 91$ & 1 & & 33.2 & 0.44 & & 1.86 & 498 \\
\hline $4 / 15 / 91$ & 2 & & 33.6 & 0.43 & & 1.88 & 500 \\
\hline $5 / 15 / 91$ & 1 & & 11.2 & 0.2 & & 0.045 & 714 \\
\hline $5 / 15 / 91$ & 2 & & 11.9 & 0.16 & & 0.024 & 734 \\
\hline $7 / 15 / 91$ & 1 & & 28.4 & 0.38 & & 1.84 & 446 \\
\hline $7 / 15 / 91$ & 2 & & 29.1 & 0.38 & & 1.96 & 414 \\
\hline $8 / 15 / 91$ & 1 & & 29 & 0.38 & & 2.03 & 413 \\
\hline $8 / 15 / 91$ & 2 & & 29.3 & 0.39 & & 1.69 & 412 \\
\hline $9 / 15 / 91$ & 1 & & 32.4 & 0.34 & & 2.32 & 476 \\
\hline $9 / 15 / 91$ & 2 & & 32.2 & 0.41 & & 2.24 & 491 \\
\hline $12 / 17 / 91$ & 1 & & 10.2 & 0.14 & & 0.029 & 25.5 \\
\hline $12 / 17 / 91$ & 2 & & 10 & 0.13 & & 0.031 & 25 \\
\hline $1 / 28 / 92$ & 1 & & 11.3 & 0.16 & & 0.057 & 25.1 \\
\hline $1 / 28 / 92$ & 2 & & 10.6 & 0.17 & & 0.082 & 22.5 \\
\hline $2 / 26 / 92$ & 1 & & & & & & \\
\hline $2 / 26 / 92$ & 2 & & & & & & \\
\hline $3 / 26 / 92$ & 1 & & & 0.16 & & & \\
\hline $3 / 26 / 92$ & 2 & & & 0.16 & & & \\
\hline $5 / 12 / 92$ & 1 & & & 0.19 & & & \\
\hline $5 / 12 / 92$ & 2 & & & 0.18 & & & \\
\hline $7 / 28 / 92$ & 1 & & & 0.14 & & & \\
\hline $7 / 28 / 92$ & 2 & & & 0.15 & & & \\
\hline $11 / 12 / 92$ & 1 & -0.1 & & & & & \\
\hline $11 / 12 / 92$ & 2 & -0.1 & & & & & \\
\hline $2 / 24 / 93$ & 1 & -0.1 & & & & & \\
\hline $2 / 24 / 93$ & 2 & -0.1 & & & & & \\
\hline $5 / 11 / 93$ & 1 & -0.1 & 10.6 & 0.16 & & & \\
\hline $5 / 11 / 93$ & 2 & -0.1 & 10.9 & 0.15 & & & \\
\hline $8 / 31 / 93$ & 1 & -0.1 & 7.2 & 0.15 & 0.038 & & \\
\hline $8 / 31 / 93$ & 2 & -0.1 & 6.9 & 0.15 & 0.84 & & \\
\hline $11 / 2 / 93$ & 1 & 0.23 & 33.7 & & 0.83 & & \\
\hline $11 / 2 / 93$ & 2 & 0.17 & 32.4 & & 0.84 & & \\
\hline $2 / 24 / 94$ & 1 & 0.27 & 29.4 & 0.4 & & 1.3 & \\
\hline $5 / 19 / 94$ & 1 & -0.1 & 11.2 & 0.14 & & 0.053 & \\
\hline $8 / 10 / 94$ & 1 & -0.1 & 10.9 & 0.15 & & 0.29 & \\
\hline $11 / 3 / 94$ & 1 & -0.1 & 28.7 & 0.42 & & 1.7 & \\
\hline
\end{tabular}




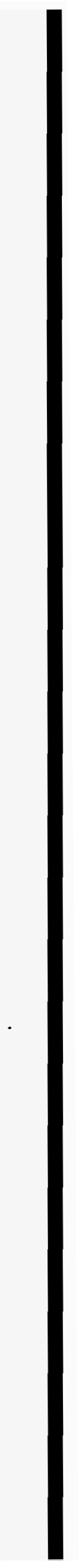




\section{Appendix C. Analytical Data from IF-603A, INEL Research Center}


C-2 
Appendix C. Analytical data from IF-603, INEL Research Center

\begin{tabular}{|c|c|c|c|c|c|c|c|c|c|c|}
\hline DATE & REP & $\begin{array}{r}\text { TSS } \\
(\mathrm{mg} / \mathrm{L}) \\
\end{array}$ & $\begin{array}{r}\mathrm{TDS} \\
(\mathrm{mg} / \mathrm{L}) \\
\end{array}$ & $\begin{array}{r}\text { CON } \\
\text { (umhos) }\end{array}$ & $\mathrm{PH}$ & $\begin{array}{r}\text { TOC } \\
(\mathrm{mg} / \mathrm{L}) \\
\end{array}$ & $\begin{array}{r}\text { TOG } \\
(\mathrm{mg} / \mathrm{L}) \\
\end{array}$ & $\begin{array}{r}\mathrm{TPH} \\
(\mathrm{mg} / \mathrm{L})\end{array}$ & $\begin{array}{r}A G \\
(u g / L)\end{array}$ & $\begin{array}{r}\text { AS } \\
(\mathrm{ug} / \mathrm{L})\end{array}$ \\
\hline $1 / 15 / 91$ & 1 & 4 & 360 & 617 & 7.6 & 20.9 & & & -10 & -10 \\
\hline $1 / 15 / 91$ & 2 & 3 & 367 & 597 & 7.94 & 17.6 & & & -10 & -10 \\
\hline $2 / 15 / 91$ & 1 & 14 & 565 & 618 & 6.54 & 31.4 & & & -10 & -10 \\
\hline $2 / 15 / 91$ & 2 & 35 & 573 & 604 & 7.32 & 31.4 & & & -10 & -10 \\
\hline $4 / 15 / 91$ & 1 & 16 & 283 & 635 & 7.83 & 8.77 & 15 & & -3 & -4 \\
\hline $4 / 15 / 91$ & 2 & 15 & 311 & & & 7.51 & & & -3 & -4 \\
\hline $5 / 15 / 91$ & 1 & $-4^{(a)}$ & 215 & 627 & 6.3 & 2.12 & & & -5 & -3 \\
\hline $5 / 15 / 91$ & 2 & -4 & 203 & 547 & 7.59 & 2.15 & & & -5 & -3 \\
\hline $6 / 15 / 91$ & 1 & 4 & 265 & 706 & 7.72 & 3.34 & & & 3.2 & 4.9 \\
\hline $6 / 15 / 91$ & 2 & -4 & 276 & 550 & 7.18 & 4.13 & & & 5.5 & 3.7 \\
\hline $7 / 15 / 91$ & 1 & 6 & 253 & 612 & 7.22 & 3.82 & & & 3.7 & 4 \\
\hline $7 / 15 / 91$ & 2 & -4 & 295 & 622 & 7.72 & 3.05 & & & 3.3 & 6.1 \\
\hline $8 / 15 / 91$ & 1 & -4 & 326 & 862 & 8.26 & 5.54 & & & 2.5 & -3 \\
\hline $8 / 15 / 91$ & 2 & -4 & 286 & 764 & 8.08 & 4.44 & & & -2 & 4.2 \\
\hline $9 / 15 / 91$ & 1 & -4 & 290 & 452 & 8.08 & 0.56 & & & 5.1 & -2 \\
\hline $9 / 15 / 91$ & 2 & -4 & 273 & 429 & 7.82 & 0.78 & & & 5.2 & -2 \\
\hline $11 / 5 / 91$ & 1 & (b) & & 42 & 6.95 & & & & -2 & -3 \\
\hline $11 / 5 / 91$ & 2 & & & 35 & 7.46 & & & & -2 & -3 \\
\hline $12 / 4 / 91$ & 1 & & & 34.9 & 7.91 & & & & 3.7 & -3 \\
\hline $12 / 4 / 91$ & 2 & & & 34.3 & 7.64 & & & & -2 & -3 \\
\hline $1 / 14 / 92$ & 1 & & & 31.8 & 7.38 & & & & -4 & -3 \\
\hline $1 / 14 / 92$ & 2 & & & 32.4 & 7.88 & & & & -4 & -3 \\
\hline $2 / 13 / 92$ & 1 & & & 62 & 6.92 & & & & -4 & 2.4 \\
\hline $2 / 13 / 92$ & 2 & & & 45.7 & 7.14 & & & & -4 & 2.1 \\
\hline $4 / 28 / 92$ & 1 & & & 31.6 & 7.79 & & & & -3 & 1.3 \\
\hline $4 / 28 / 92$ & 2 & & & 32.2 & 8.18 & & & & -3 & 1.1 \\
\hline $7 / 23 / 92$ & 1 & & & 500 & 7.44 & & & & -3 & -33 \\
\hline $7 / 23 / 92$ & 2 & & & 520 & 7.85 & & & & -3 & -33 \\
\hline $8 / 19 / 92$ & 1 & & & & & & 13.2 & -0.21 & -7 & -20 \\
\hline $8 / 19 / 92$ & 1 & & & 622 & 7.48 & & & & & \\
\hline $8 / 19 / 92$ & 2 & & & & & & 18.6 & -0.2 & -7 & -20 \\
\hline $8 / 19 / 92$ & 2 & & & & & & & & & \\
\hline $9 / 23 / 92$ & 1 & & & & & & & & & \\
\hline $9 / 23 / 92$ & 1 & & & 474 & 7.6 & & & & -7 & -1 \\
\hline $9 / 23 / 92$ & 2 & & & & & & & & & \\
\hline 9/23/92 & 2 & & & 446 & 7.52 & & & & -7 & -1 \\
\hline $10 / 8 / 92$ & 1 & & & & & & & & & \\
\hline $10 / 8 / 92$ & 2 & & & & & & & & & \\
\hline $10 / 8 / 92$ & 1 & & & 415 & 7.3 & & & & -10 & -10 \\
\hline $10 / 8 / 92$ & 2 & & & 420 & 7.59 & & & & -10 & -10 \\
\hline $11 / 23 / 92$ & 1 & & & 430 & 6.84 & & & & -10 & -10 \\
\hline $11 / 23 / 92$ & 2 & & & 436 & 7.53 & & & & -10 & -10 \\
\hline $12 / 16 / 92$ & 1 & & & 420 & 6.88 & & & & -10 & -10 \\
\hline $12 / 16 / 92$ & 2 & & & 438 & 7.51 & & & & -10 & -10 \\
\hline $1 / 21 / 93$ & 1 & & & 427 & 7.08 & & & & -10 & -10 \\
\hline $1 / 21 / 93$ & 2 & & & 427 & 7.36 & & & & -10 & -10 \\
\hline $2 / 10 / 93$ & 1 & & & 443 & 6.98 & & & & -10 & -10 \\
\hline $2 / 10 / 93$ & 2 & & & 439 & 7.53 & & & & -10 & -10 \\
\hline
\end{tabular}


Appendix C. Analytical data from IF-603, INEL Research Center

\begin{tabular}{|c|c|c|c|c|c|c|c|c|c|c|}
\hline DATE & REP & $\begin{array}{r}\mathrm{TSS} \\
(\mathrm{mg} / \mathrm{L})\end{array}$ & $\begin{array}{r}\mathrm{TDS} \\
(\mathrm{mg} / \mathrm{L})\end{array}$ & $\begin{array}{r}\mathrm{CON} \\
\text { (umhos) }\end{array}$ & $\mathrm{PH}$ & $\begin{array}{r}\text { TOC } \\
(\mathrm{mg} / \mathrm{L})\end{array}$ & $\begin{array}{r}\mathrm{TOG} \\
(\mathrm{mg} / \mathrm{L})\end{array}$ & $\begin{array}{r}\mathrm{TPH} \\
(\mathrm{mg} / \mathrm{L})\end{array}$ & $\begin{array}{r}A G \\
(u g / L)\end{array}$ & $\begin{array}{r}A S \\
(u g / L)\end{array}$ \\
\hline $3 / 11 / 93$ & 1 & & & 431 & 7.54 & & & & -10 & -10 \\
\hline $3 / 11 / 93$ & 2 & & & 434 & 7.56 & & & & -10 & -10 \\
\hline $5 / 25 / 93$ & 1 & & & 634 & 7.97 & & & & -10 & -10 \\
\hline $5 / 25 / 93$ & 2 & & & 630 & 7.99 & & & & -10 & -10 \\
\hline $6 / 2 / 93$ & 1 & & & 467 & 7.7 & & & & -10 & -10 \\
\hline $6 / 2 / 93$ & 2 & & & 469 & 7.81 & & & & -10 & -10 \\
\hline $7 / 7 / 93$ & 1 & & & 498 & 7.18 & & & & -10 & -10 \\
\hline $7 / 7 / 93$ & 2 & & & 483 & 7.51 & & & & -10 & -10 \\
\hline 9/23/93 & 1 & & & 421 & 8.11 & & & & -10 & -10 \\
\hline $9 / 23 / 93$ & 2. & & & 418 & 8.09 & & & & -10 & -10 \\
\hline $10 / 13 / 93$ & 1 & & & 413 & 7.79 & & & & -10 & -10 \\
\hline $10 / 13 / 93$ & 2 & & & 394 & 7.77 & & & & -10 & -10 \\
\hline $11 / 30 / 93$ & 1 & & & 373 & 7.94 & & & & -10 & -10 \\
\hline $11 / 30 / 93$ & 2 & & & 368 & 8.08 & & & & -10 & -10 \\
\hline $12 / 14 / 93$ & 1 & & & 357 & 7.84 & & & & -10 & -10 \\
\hline $12 / 14 / 93$ & 2 & & & 341 & 7.78 & & & & -10 & -10 \\
\hline $1 / 12 / 94$ & 1 & & & 352 & 7.89 & & & & -10 & -10 \\
\hline $1 / 12 / 94$ & 2 & & & 346 & 7.15 & & & & -10 & -10 \\
\hline $2 / 8 / 94$ & 1 & & & 358 & 7.55 & & & & -10 & -10 \\
\hline $2 / 8 / 94$ & 2 & & & 329 & 7.86 & & & & -10 & -10 \\
\hline $3 / 23 / 94$ & 1 & & & 418 & 7.98 & & & & -10 & -10 \\
\hline $3 / 23 / 94$ & 2 & & & & & & & & & \\
\hline $4 / 6 / 94$ & 1 & & & 429 & 7.38 & & & & -10 & -10 \\
\hline $4 / 6 / 94$ & 2 & & & & & & & & & \\
\hline $4 / 6 / 94$ & 1 & & & & & & & & & \\
\hline $4 / 6 / 94$ & 2 & & & & & & & & & \\
\hline $6 / 29 / 94$ & 1 & . & & 582 & 7.55 & & & & -10 & -10 \\
\hline $7 / 19 / 94$ & 1 & & & 495 & 7.77 & & & & -10 & -10 \\
\hline $7 / 27 / 94$ & 1 & & & 441 & 7.67 & & & & & \\
\hline $8 / 23 / 94$ & 1 & & & 443 & 8.01 & & & & -10 & -10 \\
\hline $9 / 21 / 94$ & 1 & & & 566 & 6.44 & & & & -10 & -10 \\
\hline $11 / 17 / 94$ & 1 & & & 401 & 7.12 & & & & -10 & -10 \\
\hline $12 / 8 / 94$ & 1 & & & 405 & 7.55 & & & & -10 & -10 \\
\hline
\end{tabular}

(a) Negative numbers indicate the result was below detection, the number is the detection limit.

(b) Blank cells indicate the sample was not analyzed for that parameter. 
Appendix C. Analytical data from IF-603, INEL Research Center

\begin{tabular}{|c|c|c|c|c|c|c|c|c|c|c|}
\hline DATE & REP & $\begin{array}{r}\mathrm{BA} \\
(\mathrm{ug} / \mathrm{L})\end{array}$ & $\begin{array}{r}B E \\
(\mathrm{ug} / \mathrm{L})\end{array}$ & $\begin{array}{r}C D \\
\text { (ug/L) }\end{array}$ & $\begin{array}{r}\mathrm{CN} \\
(\mathrm{ug} / \mathrm{L})\end{array}$ & $\begin{array}{r}\mathrm{CR} \\
(\mathrm{ug} / \mathrm{L})\end{array}$ & $\begin{array}{r}\text { CR6 } \\
(\mathrm{ug} / \mathrm{L})\end{array}$ & $\begin{array}{r}C U \\
(\mathrm{ug} / \mathrm{L})\end{array}$ & $\begin{array}{r}H G \\
(\mathrm{ug} / \mathrm{L})\end{array}$ & $\begin{array}{r}N I \\
(\mathrm{ug} / \mathrm{L})\end{array}$ \\
\hline $1 / 15 / 91$ & 1 & & & -5 & -10 & -5 & -50 & 37.5 & -0.2 & -10 \\
\hline $1 / 15 / 91$ & 2 & & & -5 & -10 & -5 & -50 & 36.7 & -0.2 & -10 \\
\hline $2 / 15 / 91$ & 1 & & & -5 & -10 & -5 & -100 & 77.9 & -0.2 & 14.3 \\
\hline $2 / 15 / 91$ & 2 & & & -5 & -10 & -5 & -100 & 76.3 & -0.2 & 12.4 \\
\hline $4 / 15 / 91$ & 1 & 98.2 & & -5 & -10 & -5 & -10 & 70.1 & -0.2 & -13 \\
\hline $4 / 15 / 91$ & 2 & 95.3 & & -5 & -10 & -5 & -10 & 58.6 & -0.2 & 15 \\
\hline $5 / 15 / 91$ & 1 & 69.4 & & -5 & -10 & -6 & -10 & 28.8 & -0.2 & -12 \\
\hline $5 / 15 / 91$ & 2 & 67.8 & , & -5 & -10 & 8.4 & -10 & 24 & -0.2 & -12 \\
\hline $6 / 15 / 91$ & 1 & 78.6 & & -5 & -10 & -4 & -10 & 197 & -0.2 & 25.5 \\
\hline $6 / 15 / 91$ & 2 & 79.2 & & -5 & -10 & -4 & -10 & 222 & 0.49 & 22.7 \\
\hline $7 / 15 / 91$ & 1 & 82.6 & & -5 & -10 & -4 & -10 & 54.5 & 0.23 & -8 \\
\hline $7 / 15 / 91$ & 2 & 87.9 & & -5 & -10 & -4 & -10 & 56.7 & -0.2 & -8 \\
\hline $8 / 15 / 91$ & .1 & 89.6 & & -5 & -10 & -4 & -10 & 42.4 & -0.2 & -8 \\
\hline $8 / 15 / 91$ & 2 & 86.9 & & -5 & -10 & -4 & -10 & 45.6 & -0.2 & -8 \\
\hline $9 / 15 / 91$ & 1 & 105 & & 8 & -10 & 29.2 & -10 & 40.6 & -0.2 & 19.8 \\
\hline $9 / 15 / 91$ & 2 & 103 & & 6.4 & -10 & 30.7 & -10 & 44.6 & -0.2 & 28 \\
\hline $11 / 5 / 91$ & 1 & 83.4 & & -5 & -10 & 6.6 & -10 & 49.5 & -0.2 & 13.6 \\
\hline $11 / 5 / 91$ & 2 & 83.6 & & -5 & -10 & -4 & -10 & 44.6 & -0.2 & 11.1 \\
\hline $12 / 4 / 91$ & 1 & 87.1 & & -5 & -10 & -4 & -10 & 42.6 & -0.2 & -8 \\
\hline $12 / 4 / 91$ & 2 & 85.3 & & -5 & -10 & -4 & -10 & 44.8 & -0.2 & -8 \\
\hline $1 / 14 / 92$ & 1 & 52.7 & -1 & -5 & -10 & -6 & -10 & 39 & -0.2 & -12 \\
\hline $1 / 14 / 92$ & 2 & 56.6 &.-1 & -5 & -10 & -6 & -10 & 36.2 & -0.2 & -12 \\
\hline $2 / 13 / 92$ & 1 & 92.4 & -1 & -5 & -10 & -6 & -10 & 54.6 & -0.2 & -12 \\
\hline $2 / 13 / 92$ & 2 & 93 & -1 & -5 & -10 & -6 & -10 & 55.3 & -0.2 & -12 \\
\hline $4 / 28 / 92$ & 1 & 87.5 & -2 & -4 & -10 & -7 & -100 & 53.7 & -0.2 & 19.8 \\
\hline $4 / 28 / 92$ & 2 & 87.5 & -2 & -4 & -10 & -7 & -100 & 55.3 & -0.2 & 17.2 \\
\hline $7 / 23 / 92$ & 1 & 84.2 & & -4 & -10 & -7 & -100 & 52.6 & -0.2 & 17.4 \\
\hline $7 / 23 / 92$ & 2 & 86.3 & & -4 & -10 & -7 & -100 & 52.6 & -0.2 & 13 \\
\hline $8 / 19 / 92$ & 1 & 88.7 & & -5 & -10 & -5 & & 43.2 & 2.9 & -19 \\
\hline $8 / 19 / 92$ & 1 & & & & & & -100 & & & \\
\hline $8 / 19 / 92$ & 2 & 90.2 & & -5 & -10 & -5 & & 41.3 & 2.7 & -19 \\
\hline $8 / 19 / 92$ & 2 & & & & & & -100 & & & \\
\hline $9 / 23 / 92$ & 1 & & & & -10 & & & & & \\
\hline $9 / 23 / 92$ & 1 & 80.6 & & -5 & & 12.4 & -100 & 35 & -0.2 & 33.9 \\
\hline $9 / 23 / 92$ & 2 & & & & -10 & & & & & \\
\hline $9 / 23 / 92$ & 2 & 80 & & -5 & & 13.2 & -100 & 36.4 & -0.2 & 41.9 \\
\hline $10 / 8 / 92$ & 1 & & & & -10 & & & & & \\
\hline $10 / 8 / 92$ & 2 & & & & -10 & & & & & \\
\hline $10 / 8 / 92$ & 1 & -200 & & -5 & & -10 & & 49.6 & -0.2 & -40 \\
\hline $10 / 8 / 92$ & 2 & -200 & & -5 & & -10 & & 47.8 & -0.2 & -40 \\
\hline $11 / 23 / 92$ & 1 & -200 & & -5 & -10 & 13.2 & & 63 & -0.2 & -40 \\
\hline $11 / 23 / 92$ & 2 & -200 & & -5 & -10 & 18.1 & & 65.8 & -0.2 & -40 \\
\hline $12 / 16 / 92$ & 1 & -200 & & -5 & -11 & -10 & & 42 & -0.2 & -40 \\
\hline $12 / 16 / 92$ & 2 & -200 & & -5 & -11 & -10 & & 40.9 & -0.2 & -40 \\
\hline $1 / 21 / 93$ & 1 & -200 & & -5 & -10 & 22.8 & & 83.3 & -0.2 & -40 \\
\hline $1 / 21 / 93$ & 2 & -200 & & -5 & -10 & 20.5 & & 83.1 & -0.2 & -40 \\
\hline $2 / 10 / 93$ & 1 & -200 & & -5 & -11.1 & -10 & -20 & 54.1 & -0.2 & -40 \\
\hline $2 / 10 / 93$ & 2 & -200 & & -5 & -11.1 & -10 & -20 & 50.7 & -0.2 & -40 \\
\hline
\end{tabular}


Appendix C. Analytical data from IF-603, INEL Research Center

\begin{tabular}{|c|c|c|c|c|c|c|c|c|c|c|}
\hline DATE & REP & $\begin{array}{r}\mathrm{BA} \\
(\mathrm{ug} / \mathrm{L}) \\
\end{array}$ & $\begin{array}{r}\mathrm{BE} \\
\text { (ug/L) } \\
\end{array}$ & $\begin{array}{r}C D \\
\text { (ug/L) }\end{array}$ & $\begin{array}{r}\mathrm{CN} \\
(\mathrm{ug} / \mathrm{L})\end{array}$ & $\begin{array}{r}\mathrm{CR} \\
(\mathrm{ug} / \mathrm{L}) \\
\end{array}$ & $\begin{array}{r}\text { CR6 } \\
(\mathrm{ug} / \mathrm{L}) \\
\end{array}$ & $\begin{array}{r}\mathrm{CU} \\
\text { (ug/L) }\end{array}$ & $\begin{array}{r}\mathrm{HG} \\
\text { (ug/L) }\end{array}$ & $\begin{array}{r}N I \\
\text { (ug/L) }\end{array}$ \\
\hline $3 / 11 / 93$ & 1 & -200 & & -5 & -10 & -10 & -20 & -25 & -0.2 & -40 \\
\hline $3 / 11 / 93$ & 2 & -200 & & -5 & -10 & -10 & -20 & 28.1 & -0.2 & -40 \\
\hline $5 / 25 / 93$ & 1 & -200 & & -5 & -10 & -10 & -20 & 33.2 & -0.2 & -40 \\
\hline $5 / 25 / 93$ & 2 & -200 & & -5 & -10 & -10 & -20 & 32.3. & -0.2 & -40 \\
\hline $6 / 2 / 93$ & 1 & -200 & & -5 & 18.4 & -10 & & $25.8^{\circ}$ & -0.2 & -40 \\
\hline $6 / 2 / 93$ & 2 & -200 & & -5 & 10.7 & -10 & & 25 & -0.2 & -40 \\
\hline $7 / 7 / 93$ & 1 & -200 & & -5 & -10 & -10 & -20 & 35.8 & -0.2 & -40 \\
\hline $7 / 7 / 93$ & 2 & -200 & & -5 & -10 & -10 & -20 & 35 & -0.2 & -40 \\
\hline 9/23/93 & 1 & -200 & & -5 & -10 & 14.6 & -20 & -25 & -0.2 & -40 \\
\hline 9/23/93 & 2 & -200 & & -5 & -10 & 13.5 & -20 & -25 & -0.2 & -40 \\
\hline $10 / 13 / 93$ & 1 & -200 & & 6.4 & -10 & 42.3 & -20 & 36.5 & -0.2 & -40 \\
\hline $10 / 13 / 93$ & 2 & -200 & & -5 & -10 & 55.4 & -20 & 34.6 & -0.2 & -40 \\
\hline $11 / 30 / 93$ & 1 & -200 & & -5 & -10 & -10 & -20 & 86.6 & -0.2 & -40 \\
\hline $11 / 30 / 93$ & 2 & -200 & & -5 & -10 & -10 & -20 & 86.2 & -0.2 & -40 \\
\hline $12 / 14 / 93$ & 1 & -200 & & -5 & -10 & -10 & -20 & 44.1 & -0.2 & -40 \\
\hline $12 / 14 / 93$ & 2 & -200 & & -5 & -10 & -10 & -20 & 43.2 & -0.2 & -40 \\
\hline $1 / 12 / 94$ & 1 & -200 & & -5 & -10 & -10 & -20 & 31.5 & -0.2 & -40 \\
\hline $1 / 12 / 94$ & 2 & -200 & & -5 & -10 & -10 & -20 & 28 & -0.2 & -40 \\
\hline $2 / 8 / 94$ & 1 & -200 & & -5 & -10 & -10 & -20 & 32.3 & -0.2 & -40 \\
\hline $2 / 8 / 94$ & 2 & -200 & & -5 & -10 & -10 & -20 & 32.3 & -0.2 & -40 \\
\hline $3 / 23 / 94$ & 1 & -200 & & -5 & 5.3 & -10 & -20 & -25 & -0.2 & -40 \\
\hline $3 / 23 / 94$ & 2 & & & & & & & & & \\
\hline $4 / 6 / 94$ & 1 & -200 & & -5 & -5 & -10 & & 26.6 & -0.2 & -40 \\
\hline $4 / 6 / 94$ & 2 & & & & & & & & & \\
\hline $4 / 6 / 94$ & 1 & & & & & & -20 & & & \\
\hline $4 / 6 / 94$ & 2 & & & & & & & & & \\
\hline $6 / 29 / 94$ & 1 & -200 & & -5 & -10 & -10 & -20 & 35 & -0.2 & -40 \\
\hline 7/19/94 & 1 & -200 & & -5 & & -10 & & 40.5 & -0.2 & -40 \\
\hline $7 / 27 / 94$ & 1 & & & & -10 & & -20 & & & \\
\hline $8 / 23 / 94$ & 1 & -200 & & -5 & -10 & -10 & -20 & 48.2 & -0.2 & -40 \\
\hline $9 / 21 / 94$ & 1 & -200 & & -5 & -10 & -10 & -20 & 32.8 & -0.2 & -40 \\
\hline $11 / 17 / 94$ & 1 & -200 & & -5 & -5 & -10 & -20 & -25 & -0.2 & -40 \\
\hline $12 / 8 / 94$ & 1 & -200 & & -5 & -5 & -10 & -20 & 35.6 & -0.2 & -40 \\
\hline
\end{tabular}


Appendix C. Analytical data from IF-603, INEL Research Center

\begin{tabular}{|c|c|c|c|c|c|c|c|c|c|c|}
\hline DATE & REP & $\begin{array}{r}\mathrm{PB} \\
(\mathrm{ug} / \mathrm{L}) \\
\end{array}$ & $\begin{array}{r}S B \\
(\mathrm{ug} / \mathrm{L}) \\
\end{array}$ & $\begin{array}{r}S E \\
(\mathrm{ug} / \mathrm{L}) \\
\end{array}$ & $\begin{array}{r}\mathrm{TL} \\
(\mathrm{ug} / \mathrm{L}) \\
\end{array}$ & $\begin{array}{r}\mathrm{ZN} \\
(\mathrm{ug} / \mathrm{L}) \\
\end{array}$ & $\begin{array}{r}\mathrm{CA} \\
(\mathrm{ug} / \mathrm{L}) \\
\end{array}$ & $\begin{array}{r}\mathrm{MG} \\
(\mathrm{ug} / \mathrm{L})\end{array}$ & $\begin{array}{r}\mathrm{MN} \\
(\mathrm{ug} / \mathrm{L}) \\
\end{array}$ & $\begin{array}{r}\mathrm{NA} \\
(\mathrm{ug} / \mathrm{L})\end{array}$ \\
\hline $1 / 15 / 91$ & 1 & 4.3 & & -5 & -10 & 36.6 & & & & \\
\hline $1 / 15 / 91$ & 2 & 4.8 & & -5 & -10 & 36.1 & & & & \\
\hline $2 / 15 / 91$ & 1 & -3 & & -5 & -10 & 64.7 & & & & \\
\hline $2 / 15 / 91$ & 2 & -3 & & -5 & -10 & 68.9 & & & & \\
\hline $4 / 15 / 91$ & 1 & 3.5 & & -3 & -20 & 66 & & & & \\
\hline $4 / 15 / 91$ & 2 & 8.5 & & -3 & -20 & 69.5 & & & & \\
\hline $5 / 15 / 91$ & 1 & -1 & & -3 & -5 & 24.8 & & & & \\
\hline $5 / 15 / 91$ & 2 & 1.8 & & -3 & -5 & 14.6 & & & & \\
\hline $6 / 15 / 91$ & 1 & 2 & & -3 & -2 & 54.1 & & & & \\
\hline $6 / 15 / 91$ & 2 & 2.7 & & -3 & -2 & 61.6 & & & & \\
\hline $7 / 15 / 91$ & 1 & 4.6 & & -40 & -2 & 28.1 & & & & \\
\hline $7 / 15 / 91$ & 2 & 2.2 & & -4 & -2 & 29.9 & & & & \\
\hline $8 / 15 / 91$ & 1 & 5.5 & & -4 & -1 & 29.7 & & & & \\
\hline $8 / 15 / 91$ & 2 & 4.7 & & -4 & -1 & 23.1 & & & & \\
\hline $9 / 15 / 91$ & 1 & 2.7 & & -3 & -1 & 20.7 & & & & \\
\hline 9/15/91 & 2 & -2 & & -3 & -1 & 20.8 & & & & \\
\hline $11 / 5 / 91$ & 1 & -2 & & -2 & -2 & 43.6 & 61900 & 16000 & -2 & 32500 \\
\hline $11 / 5 / 91$ & 2 & -2 & & -10 & -2 & 37 & 61600 & 16000 & 2.5 & 28300 \\
\hline $12 / 4 / 91$ & 1 & -2 & & -4 & -5 & 29.8 & 64500 & 16300 & 2.8 & 16100 \\
\hline $12 / 4 / 91$ & 2 & -2 & & -4 & -1 & 41.1 & 63200 & 16000 & 2.8 & 16000 \\
\hline $1 / 14 / 92$ & 1 & -2 & -47 & -2 & -1 & 17.4 & 49300 & 15200 & 3.4 & 20700 \\
\hline $1 / 14 / 92$ & 2 & 4 & -47 & -2 & -1 & 19 & 51300 & 15800 & -3 & 21600 \\
\hline $2 / 13 / 92$ & 1 & 4.7 & -47 & -2 & -1 & 59.6 & 64100 & 17000 & 9.6 & 27500 \\
\hline $2 / 13 / 92$ & 2 & 4.1 & -47 & -2 & -1 & 61.5 & 63900 & 17100 & 10.3 & 26900 \\
\hline $4 / 28 / 92$ & 1 & 1.5 & -23 & -1 & -1 & 47.8 & 63400 & 17100 & -2 & 15800 \\
\hline $4 / 28 / 92$ & 2 & 3.3 & -23 & -1 & -1 & 52.1 & 65300 & 17500 & -2 & 16100 \\
\hline $7 / 23 / 92$ & 1 & -23 & & -1 & & 50.9 & & & & \\
\hline $7 / 23 / 92$ & 2 & -23 & & -1 & & 47.9 & & & & \\
\hline $8 / 19 / 92$ & 1 & -32 & & -1 & & 34.8 & & & & \\
\hline $8 / 19 / 92$ & 1 & & & & & & & & & . \\
\hline $8 / 19 / 92$ & 2 & -32 & & -1 & & 36.4 & & & & \\
\hline $8 / 19 / 92$ & 2 & & & & & & & & & \\
\hline $9 / 23 / 92$ & 1 & & & & & & & & & \\
\hline $9 / 23 / 92$ & 1 & 4.2 & & -1 & & 26.7 & & & & \\
\hline $9 / 23 / 92$ & 2 & & & & & & & & & \\
\hline $9 / 23 / 92$ & 2 & 2.8 & & -1 & & 29.3 & & & & \\
\hline $10 / 8 / 92$ & 1 & & & & & & & & & \\
\hline $10 / 8 / 92$ & 2 & & & & & & & & & \\
\hline $10 / 8 / 92$ & 1 & -3 & & -5 & & 41.6 & & & & \\
\hline $10 / 8 / 92$ & 2 & -3 & & -5 & & 40.7 & & & & \\
\hline $11 / 23 / 92$ & 1 & 4.4 & & -5 & & 51.8 & & & & \\
\hline $11 / 23 / 92$ & 2 & -3 & & -5 & & 49.8 & & & & \\
\hline $12 / 16 / 92$ & 1 & -3 & & -5 & & 31.5 & & & & \\
\hline $12 / 16 / 92$ & 2 & -3 & & -5 & & 33.3 & & & & \\
\hline $1 / 21 / 93$ & 1 & -3 & & -5 & & 109 & & & & \\
\hline $1 / 21 / 93$ & 2 & -3 & & -5 & & 108 & & & & \\
\hline $2 / 10 / 93$ & 1 & -3 & & -5 & & 45.6 & & & & \\
\hline $2 / 10 / 93$ & 2 & -3 & & -5 & & 46.1 & & & & \\
\hline
\end{tabular}


Appendix C. Analytical data from IF-603, INEL Research Center

\begin{tabular}{|c|c|c|c|c|c|c|c|c|c|c|}
\hline DATE & REP & $\begin{array}{r}P B \\
(\mathrm{ug} / \mathrm{L})\end{array}$ & $\begin{array}{r}S B \\
(u g / L)\end{array}$ & $\begin{array}{r}S E \\
(u g / L)\end{array}$ & $\begin{array}{r}T L \\
(\mathrm{ug} / \mathrm{L})\end{array}$ & $\begin{array}{r}\mathrm{ZN} \\
\text { (ug/L) }\end{array}$ & $\begin{array}{r}\mathrm{CA} \\
(\mathrm{ug} / \mathrm{L})\end{array}$ & $\begin{array}{r}\mathrm{MG} \\
(\mathrm{ug} / \mathrm{L})\end{array}$ & $\begin{array}{r}\mathrm{MN} \\
(\mathrm{ug} / \mathrm{L})\end{array}$ & $\begin{array}{r}N A \\
(\mathrm{ug} / \mathrm{L})\end{array}$ \\
\hline $3 / 11 / 93$ & 1 & -3 & & -5 & & 32.1 & & & & \\
\hline $3 / 11 / 93$ & 2 & 7.6 & & -5 & & 32.1 & & & & \\
\hline $5 / 25 / 93$ & 1 & -3 & & -5 & & 45.3 & & & & \\
\hline $5 / 25 / 93$ & 2 & -3 & & -5 & & 53.2 & & & & \\
\hline $6 / 2 / 93$ & 1 & -3 & & -5 & & 52.9 & & & & \\
\hline $6 / 2 / 93$ & 2 & -3 & & -5 & & 49.3 & & & & \\
\hline $7 / 7 / 93$ & 1 & -3 & & -5 & & 36.9 & & & & \\
\hline $7 / 7 / 93$ & 2 & -3 & & -5 & & 40 & & & & \\
\hline 9/23/93 & 1 & 7.4 & & -5 & & 38.8 & & & & \\
\hline $9 / 23 / 93$ & 2 & -3 & & -5 & & 39.7 & & & & \\
\hline $10 / 13 / 93$ & 1 & -3 & & -5 & & 48.8 & & & & \\
\hline $10 / 13 / 93$ & 2 & -3 & & -5 & & 50.6 & & & & \\
\hline $11 / 30 / 93$ & 1 & -3 & & -5 & & 55.4 & & & & \\
\hline $11 / 30 / 93$ & 2 & -3 & & -5 & & 52.8 & & & & \\
\hline $12 / 14 / 93$ & 1 & -3 & & -5 & & 36 & & & & \\
\hline $12 / 14 / 93$ & 2 & -3 & & -5 & & 26.3 & & & & \\
\hline $1 / 12 / 94$ & 1 & -3 & & -5 & & 84.8 & & & & \\
\hline $1 / 12 / 94$ & 2 & -3 & & -5 & & 30.1 & & & & \\
\hline $2 / 8 / 94$ & 1 & -3 & & -5 & & 81.3 & & & & \\
\hline $2 / 8 / 94$ & 2 & -3 & & -5 & & 42.9 & & & & \\
\hline $3 / 23 / 94$ & 1 & -3 & & -5 & & 39.2 & & & & \\
\hline $3 / 23 / 94$ & 2 & & & & & & & & & \\
\hline $4 / 6 / 94$ & 1 & -3 & & -5 & & 37.5 & & & & \\
\hline $4 / 6 / 94$ & 2 & & & & & & & & & \\
\hline $4 / 6 / 94$ & 1 & & & & & & & & & \\
\hline $4 / 6 / 94$ & 2 & & & & & & & & & \\
\hline $6 / 29 / 94$ & 1 & -3 & & -5 & & 24.6 & & & & \\
\hline 7/19/94 & 1 & -3 & & -5 & & 29.3 & & & & \\
\hline $7 / 27 / 94$ & 1 & & & & & & & & & \\
\hline $8 / 23 / 94$ & 1 & -3 & & -5 & & 60 & & & & \\
\hline $9 / 21 / 94$ & 1 & -3 & & -5 & & 27.7 & & & & \\
\hline $11 / 17 / 94$ & 1 & -3 & & -5 & & 21.7 & & & & \\
\hline $12 / 8 / 94$ & 1 & -3 & & -5 & & 20.5 & & & & \\
\hline
\end{tabular}


Appendix C. Analytical data from IF-603, INEL Research Center

\begin{tabular}{|c|c|c|c|c|c|c|c|c|c|}
\hline DATE & REP & $\begin{array}{r}\text { PHENOL } \\
(\mathrm{ug} / \mathrm{L})\end{array}$ & $\begin{array}{r}\mathrm{NO3} \\
(\mathrm{mg} / \mathrm{L}) \\
\end{array}$ & $\begin{array}{l}\mathrm{NO} 3 \mathrm{~N} \\
(\mathrm{mg} / \mathrm{L}) \\
\end{array}$ & $\begin{array}{r}\mathrm{CL} \\
(\mathrm{mg} / \mathrm{L}) \\
\end{array}$ & $\begin{array}{r}F \\
(\mathrm{mg} / \mathrm{L}) \\
\end{array}$ & $\begin{array}{r}\text { PORTHO } \\
(\mathrm{mg} / \mathrm{L})\end{array}$ & $\begin{array}{l}\text { OTAL } \\
(\mathrm{mg} / \mathrm{L})\end{array}$ & $\begin{array}{r}\mathrm{SO} 4 \\
(\mathrm{mg} / \mathrm{L})\end{array}$ \\
\hline $1 / 15 / 91$ & 1 & & 2.5 & & 20.7 & 0.3 & -0.2 & & 43.1 \\
\hline $1 / 15 / 91$ & 2 & & 2.4 & & 20.7 & 0.3 & -0.2 & & 45.1 \\
\hline $2 / 15 / 91$ & 1 & 200 & 5.6 & & 41.5 & -0.1 & -0.2 & & 46.3 \\
\hline $2 / 15 / 91$ & 2 & 100 & 5.3 & & 41.3 & 0.3 & 0.6 & & 46.3 \\
\hline $4 / 15 / 91$ & 1 & -50 & & 1.94 & 37.2 & 0.41 & - & 0.578 & 50.5 \\
\hline $4 / 15 / 91$ & 2 & & & & & & & & \\
\hline $5 / 15 / 91$ & 1 & & & 2.17 & 17.4 & 0.67 & & 0.103 & 47 \\
\hline $5 / 15 / 91$ & 2 & & & 2.05 & 18 & 0.62 & & 0.255 & 52.6 \\
\hline $6 / 15 / 91$ & 1 & & & 2.3 & 12.8 & 0.58 & & 8.61 & 42.5 \\
\hline $6 / 15 / 91$ & 2 & & & 2.69 & 13 & 0.62 & & 11.4 & 47.5 \\
\hline $7 / 15 / 91$ & 1 & & & 8.99 & 18.1 & 0.3 & & 0.632 & 40.4 \\
\hline $7 / 15 / 91$ & 2 & & & 8.98 & 18.2 & 0.35 & & 0.602 & 40.2 \\
\hline $8 / 15 / 91$ & 1 & & & 2.89 & 15.3 & 0.4 & & 0.304 & 39.3 \\
\hline $8 / 15 / 91$ & 2 & & & 3.34 & 15.4 & 0.43 & . & 0.302 & 38.6 \\
\hline $9 / 15 / 91$ & 1 & & & 1.64 & 11.4 & 0.26 & & 0.085 & 43 \\
\hline $9 / 15 / 91$ & 2 & & & 1.73 & 10.3 & 0.25 & & 0.034 & 43.3 \\
\hline $11 / 5 / 91$ & 1 & & & & & & & & \\
\hline $11 / 5 / 91$ & 2 & & & & & & & & \\
\hline $12 / 4 / 91$ & 1 & & & & & & & & \\
\hline $12 / 4 / 91$ & 2 & & & & & & & & \\
\hline $1 / 14 / 92$ & 1 & & & & & & & & \\
\hline $1 / 14 / 92$ & 2 & & & & & & & & \\
\hline $2 / 13 / 92$ & 1 & & & & & & & & \\
\hline $2 / 13 / 92$ & 2 & & & & & & & & \\
\hline $4 / 28 / 92$ & 1 & & & & & & & & \\
\hline $4 / 28 / 92$ & 2 & & & & & & & & \\
\hline $7 / 23 / 92$ & 1 & & & & & & & & \\
\hline $7 / 23 / 92$ & 2 & & & & & & & & \\
\hline $8 / 19 / 92$ & 1 & 11 & & & & & & & \\
\hline $8 / 19 / 92$ & 1 & & & & & & & & \\
\hline $8 / 19 / 92$ & 2 & 19 & & & & & & & \\
\hline $8 / 19 / 92$ & 2 & & & & & & & & \\
\hline $9 / 23 / 92$ & 1 & & & & & & & & \\
\hline $9 / 23 / 92$ & 1 & & & & & & & & \\
\hline $9 / 23 / 92$ & 2 & & & & & & & & \\
\hline 9/23/92 & 2 & & & & & & & & \\
\hline $10 / 8 / 92$ & 1 & & & & & & & & \\
\hline $10 / 8 / 92$ & 2 & & & & & & & & \\
\hline $10 / 8 / 92$ & 1 & & & & & & & & \\
\hline $10 / 8 / 92$ & 2 & & & & & & & & \\
\hline $11 / 23 / 92$ & 1 & & & & & & & & \\
\hline $11 / 23 / 92$ & 2 & & & & & & & & \\
\hline $12 / 16 / 92$ & 1 & & & & & & & & \\
\hline $12 / 16 / 92$ & 2 & & & & & & & & \\
\hline $1 / 21 / 93$ & 1 & & & & & & & & \\
\hline $1 / 21 / 93$ & 2 & & & & & & & & \\
\hline $2 / 10 / 93$ & 1 & & & & & & & & \\
\hline $2 / 10 / 93$ & 2 & & & & & & & & \\
\hline
\end{tabular}


Appendix C. Analytical data from IF-603, INEL Research Center

\begin{tabular}{|c|c|c|c|c|c|c|c|c|c|}
\hline DATE & REP & $\begin{array}{r}\text { PHENOL } \\
(\mathrm{ug} / \mathrm{L}) \\
\end{array}$ & $\begin{array}{r}\mathrm{NO3} \\
(\mathrm{mg} / \mathrm{L}) \\
\end{array}$ & $\begin{array}{l}\text { NO3N } \\
(\mathrm{mg} / \mathrm{L}) \\
\end{array}$ & $\begin{array}{r}\mathrm{CL} \\
(\mathrm{mg} / \mathrm{L}) \\
\end{array}$ & $\begin{array}{r}F \\
(\mathrm{mg} / \mathrm{L}) \\
\end{array}$ & $\begin{array}{r}\text { PORTHO } \\
(\mathrm{mg} / \mathrm{L}) \\
\end{array}$ & $\begin{array}{l}\text { OTAL } \\
(\mathrm{mg} / \mathrm{L})\end{array}$ & $\begin{array}{r}\mathrm{SO} 4 \\
(\mathrm{mg} / \mathrm{L}) \\
\end{array}$ \\
\hline $3 / 11 / 93$ & 1 & & & & & & & & \\
\hline $3 / 11 / 93$ & 2 & & & & & & & & \\
\hline $5 / 25 / 93$ & 1 & & & & & & & & \\
\hline $5 / 25 / 93$ & 2 & & & & & & & & \\
\hline $6 / 2 / 93$ & 1 & & & & & & & & \\
\hline $6 / 2 / 93$ & 2 & & & & & & & & \\
\hline $7 / 7 / 93$ & 1 & & & & & & & & \\
\hline $7 / 7 / 93$ & 2 & & & & & & & & \\
\hline $9 / 23 / 93$ & 1 & & & & & & & & \\
\hline 9/23/93 & 2 & & & & & & & & \\
\hline $10 / 13 / 93$ & 1 & & & & & & & & \\
\hline $10 / 13 / 93$ & 2 & & & & & & & & \\
\hline $11 / 30 / 93$ & 1 & & & & & & & & \\
\hline $11 / 30 / 93$ & 2 & & & & & & & & \\
\hline $12 / 14 / 93$ & 1 & & & & & & & & \\
\hline $12 / 14 / 93$ & 2 & & & & & & & & \\
\hline $1 / 12 / 94$ & 1 & & & & & & & & \\
\hline $1 / 12 / 94$ & 2 & & & & & & & & \\
\hline $2 / 8 / 94$ & 1 & & & & & & & & \\
\hline $2 / 8 / 94$ & 2 & & & & & & & & \\
\hline $3 / 23 / 94$ & 1 & & & & & & & & \\
\hline $3 / 23 / 94$ & 2 & & & & & & & & \\
\hline $4 / 6 / 94$ & 1 & & & & & & & & \\
\hline $4 / 6 / 94$ & 2 & & & & & & & & \\
\hline $4 / 6 / 94$ & 1 & & & & & & & & \\
\hline $4 / 6 / 94$ & 2 & & & & & & & & \\
\hline $6 / 29 / 94$ & 1 & & & & & & & & \\
\hline $7 / 19 / 94$ & 1 & & & & & & & & \\
\hline $7 / 27 / 94$ & 1 & & & & & & & & \\
\hline $8 / 23 / 94$ & 1 & & & & & & & & \\
\hline $9 / 21 / 94$ & 1 & & & & & . & & & \\
\hline $11 / 17 / 94$ & 1 & & & & & & & & \\
\hline $12 / 8 / 94$ & 1 & & & & & & & & \\
\hline
\end{tabular}




\section{Appendix D. Organic Compounds from CFA-691, Influent to the CFA Sewage Treatment Plant}


D-2 
Appendix D. Organic compounds from CFA-691, Influent to CFA Sewage Treatment Plant.

\begin{tabular}{|c|c|c|c|}
\hline Date & $\begin{array}{c}\text { Concentration } \\
(\mathrm{ug} / \mathrm{L})\end{array}$ & Compound & Flags \\
\hline $11 / 17 / 92$ & 6 & Methylene Chloride & $\mathrm{B}$ \\
\hline $11 / 17 / 92$ & 2 & 1,1,1-Trichloroethane & $\mathbf{J}$ \\
\hline $11 / 17 / 92$ & 3 & Xylene (Total) & $\mathrm{J}$ \\
\hline $11 / 17 / 92$ & 6 & 1,4-Dichlorobenzene & \\
\hline $11 / 17 / 92$ & 37 & Acetone (TIC) & $\mathrm{CB}$ \\
\hline $11 / 17 / 92$ & 8 & Trimethyl Silanol (TIC) & $\mathbf{J}$ \\
\hline $11 / 17 / 92$ & & all other compounds & $\mathrm{U}$ \\
\hline $11 / 17 / 93$ & 22 & 1,4-Dichlorobenzene & \\
\hline $11 / 17 / 93$ & & all other compounds & $\mathrm{U}$ \\
\hline $5 / 31 / 94$ & 15 & 1,4-Dichlorobenzene & \\
\hline $5 / 31 / 94$ & 6 & Methylene Chloride & B \\
\hline $5 / 31 / 94$ & 5 & Siloxane (TIC) & JB \\
\hline $5 / 31 / 94$ & & all other compounds & $\mathrm{U}$ \\
\hline $8 / 2 / 94$ & 7 & 1,4-Dichlorobenzene & \\
\hline $8 / 2 / 94$ & 3 & Methylene Chloride & $\mathrm{JB}$ \\
\hline $8 / 2 / 94$ & 2 & Trichlorofluoromethane & $\mathbf{J}$ \\
\hline $8 / 2 / 94$ & & all other compounds & $\mathrm{U}$ \\
\hline $11 / 8 / 94$ & 1 & 1,1,1-Trichloroethane & $\mathrm{J}$ \\
\hline $11 / 8 / 94$ & 9 & 1,4-Dichlorobenzene & \\
\hline $11 / 8 / 94$ & & all other compounds & $\mathrm{U}$ \\
\hline
\end{tabular}

$\mathrm{B}=$ Detected in blank

$\mathrm{C}=$ Calibration range exceeded

$\mathrm{J}=$ Estimated concentration

$\mathrm{U}=$ Not detected

$\mathrm{X}=$ Rejected 
Appendix E. Organic Compounds from TRA-764, Cold Waste Pond 
E-2 
Appendix E. Organic compounds from TRA-764, Cold Waste Pond.

\begin{tabular}{lclc}
\hline Date & $\begin{array}{c}\text { Concentration } \\
\text { (ug/L) }\end{array}$ & Compound & Flags \\
\hline $11 / 3 / 94$ & & all compounds & $\mathrm{U}$ \\
\hline $5 / 19 / 94$ & 3 & Methylene Chloride & $\mathrm{JB}$ \\
$5 / 19 / 94$ & & all other compounds & $\mathrm{U}$ \\
\hline $8 / 10 / 94$ & 3 & Methylene Chloride & $\mathrm{JB}$ \\
$8 / 10 / 94$ & 1 & Trichlorofluoromethane & $\mathrm{J}$ \\
$8 / 10 / 94$ & & all other compounds & $\mathrm{U}$ \\
\hline
\end{tabular}

$\mathrm{B}=$ Detected in blank

$\mathrm{J}=$ Estimated concentration

$\mathrm{U}=$ Not detected

$\mathrm{X}=$ Rejected 
. 


\section{Appendix F. Organic Compounds from IF-603A,}

INEL Research Center 
Appendix F. Organic compounds from IF-603, INEL Research Center.

\begin{tabular}{|c|c|c|c|}
\hline Date & $\begin{array}{l}\text { oncentrati } \\
\text { (ug/L) }\end{array}$ & Compound & Flags \\
\hline $4 / 28 / 92$ & 52 & 2-Propanol (TIC) & $\mathrm{JN}$ \\
\hline $4 / 28 / 92$ & 47 & Acetone & \\
\hline $4 / 28 / 92$ & 3 & Ethylbenzene & \\
\hline $4 / 28 / 92$ & 3 & Toluene & \\
\hline $4 / 28 / 92$ & & all other compounds & \\
\hline $7 / 23 / 92$ & 21 & Acetone & \\
\hline $7 / 23 / 92$ & & all other compounds & $\mathrm{U}$ \\
\hline $8 / 19 / 92$ & 26 & Methylene Chloride & \\
\hline $8 / 19 / 92$ & 22 & Acetone & \\
\hline $8 / 19 / 92$ & 8 & Unknown (TIC) & $\mathrm{JN}$ \\
\hline $8 / 19 / 92$ & & all other compounds & $U$ \\
\hline $9 / 23 / 92$ & & all compounds & $\mathrm{U}$ \\
\hline $10 / 8 / 92$ & 6 & Methylene Chloride & B \\
\hline $10 / 8 / 92$ & 210 & Acetone (TIC) & CJ \\
\hline $10 / 8 / 92$ & & all other compounds & $U$ \\
\hline $11 / 23 / 92$ & & all compounds & $\mathrm{U}$ \\
\hline $12 / 16 / 92$ & 6 & Methylene Chloride & B \\
\hline $12 / 16 / 92$ & 20 & Trimethyl Silanol (TIC) & $\mathrm{J}$ \\
\hline $12 / 16 / 92$ & & all other compounds & $\mathrm{U}$ \\
\hline $1 / 21 / 93$ & 6 & Methylene Chloride & \\
\hline $1 / 21 / 93$ & 10 & Trimethyl Silanol (TIC) & $\mathrm{J}$ \\
\hline $1 / 21 / 93$ & & all other compounds & $\mathrm{U}$ \\
\hline $2 / 10 / 93$ & 1900 & Acetone (TIC) & $\mathrm{CJ}$ \\
\hline $2 / 10 / 93$ & & all other compounds & $\mathrm{U}$ \\
\hline $3 / 11 / 93$ & 2 & Methylene Chloride & JB \\
\hline $3 / 11 / 93$ & 28 & Xylene (Total) & \\
\hline $3 / 11 / 93$ & & all other compounds & $\mathrm{U}$ \\
\hline $5 / 25 / 93$ & 6 & Methylene Chloride & \\
\hline $5 / 25 / 93$ & 2 & Trichlorofluoromethane & $\mathrm{J}$ \\
\hline $5 / 25 / 93$ & & all other compounds & $\mathrm{U}$ \\
\hline $6 / 2 / 93$ & 2 & Methylene Chloride & JB \\
\hline $6 / 2 / 93$ & 2 & Trichlorofluoromethane & $\mathrm{J}$ \\
\hline $6 / 2 / 93$ & & all other compounds & U \\
\hline $7 / 7 / 93$ & 6 & Methylene Chloride & \\
\hline 7/7/93 & & all other compounds & $\mathrm{U}$ \\
\hline $9 / 23 / 93$ & 2 & Methylene Chloride & JB \\
\hline $9 / 23 / 93$ & & all other compounds & $\mathrm{U}$ \\
\hline $10 / 13 / 93$ & 5 & Fluorinated Alkane (TIC) & $\mathrm{J}$ \\
\hline $10 / 13 / 93$ & & all other compounds & $\mathrm{U}$ \\
\hline $11 / 13 / 93$ & 1 & Methylene Chloride & JB \\
\hline $11 / 13 / 93$ & & all other compounds & $U$ \\
\hline
\end{tabular}


Appendix F. Organic compounds from IF-603, INEL Research Center.

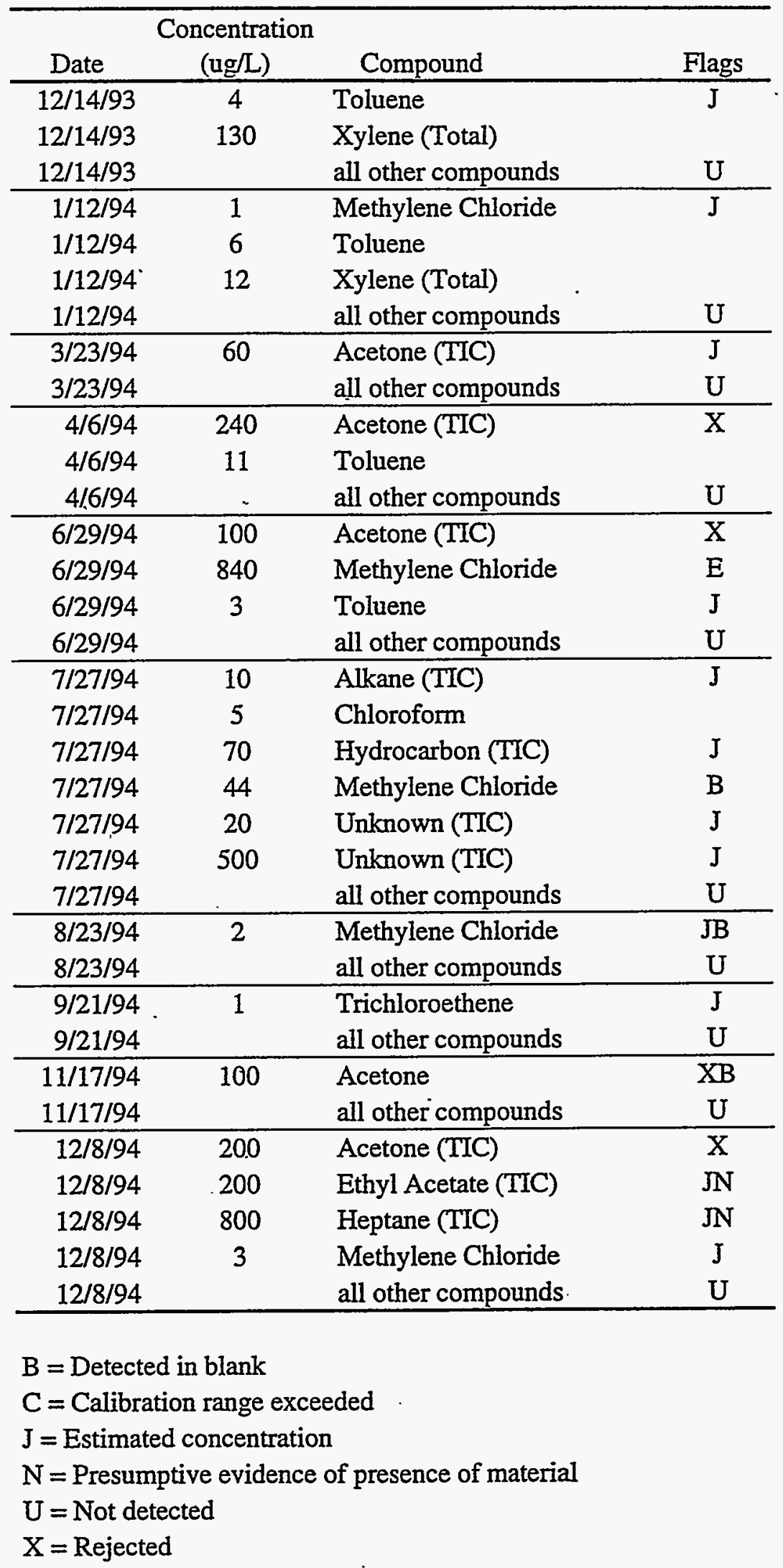


Appendix G. Frequency Histograms for Monitoring Parameters CFA-691, Influent to the CFA Sewage Treatment Plant 


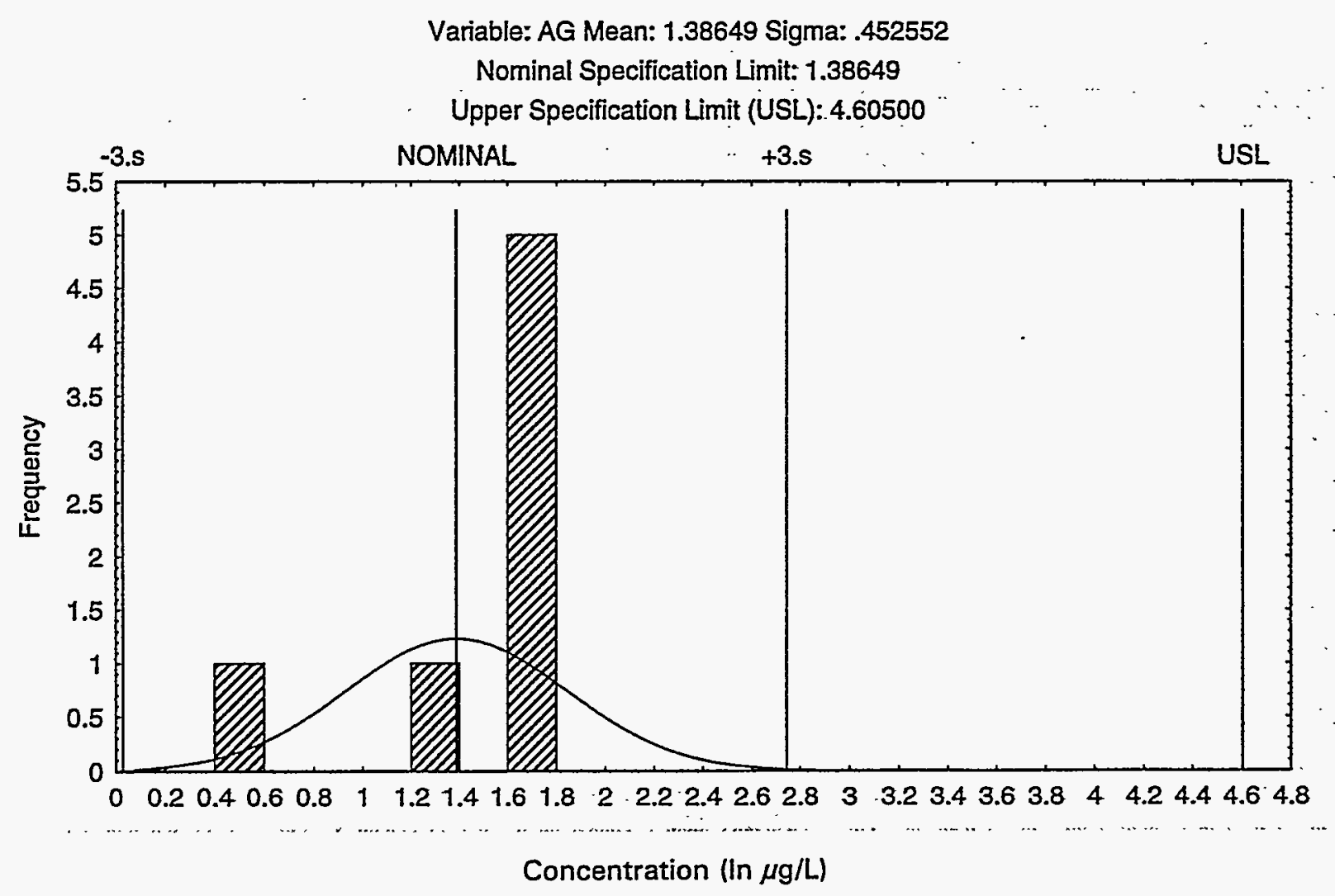

Figure G-1. Measured and log-normal distribution of silver in effluent steam CFA-691. 


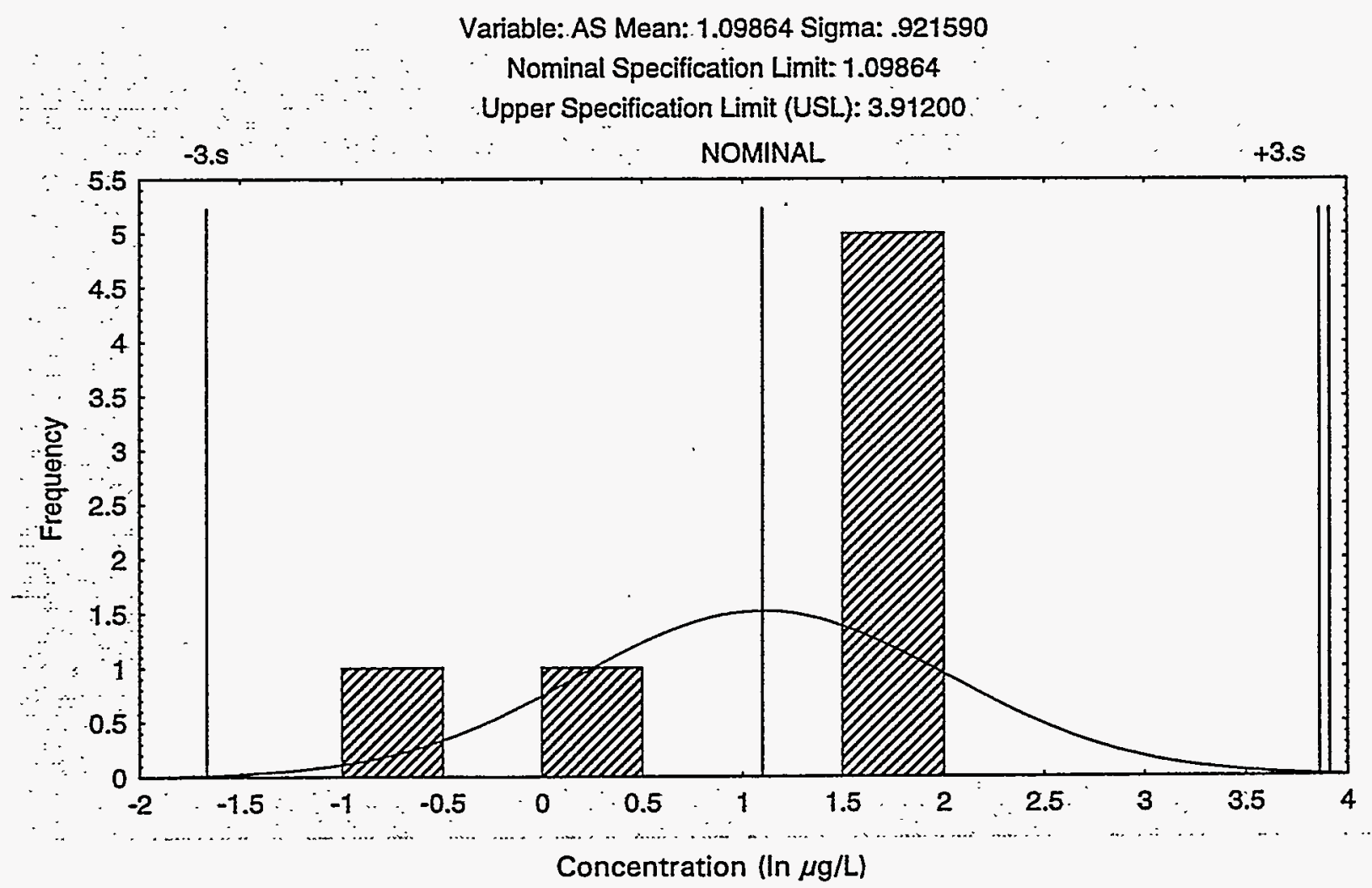

Figure G-2. Measured and log-normal distribution of arsenic in effluent steam CFA-691. 


\section{Variable: BA Mean: 4.53105 Sigma: .128310}

Nominal Specification Limit: 4.53105

Upper Specification Limit (USL) $: 7.60100$.

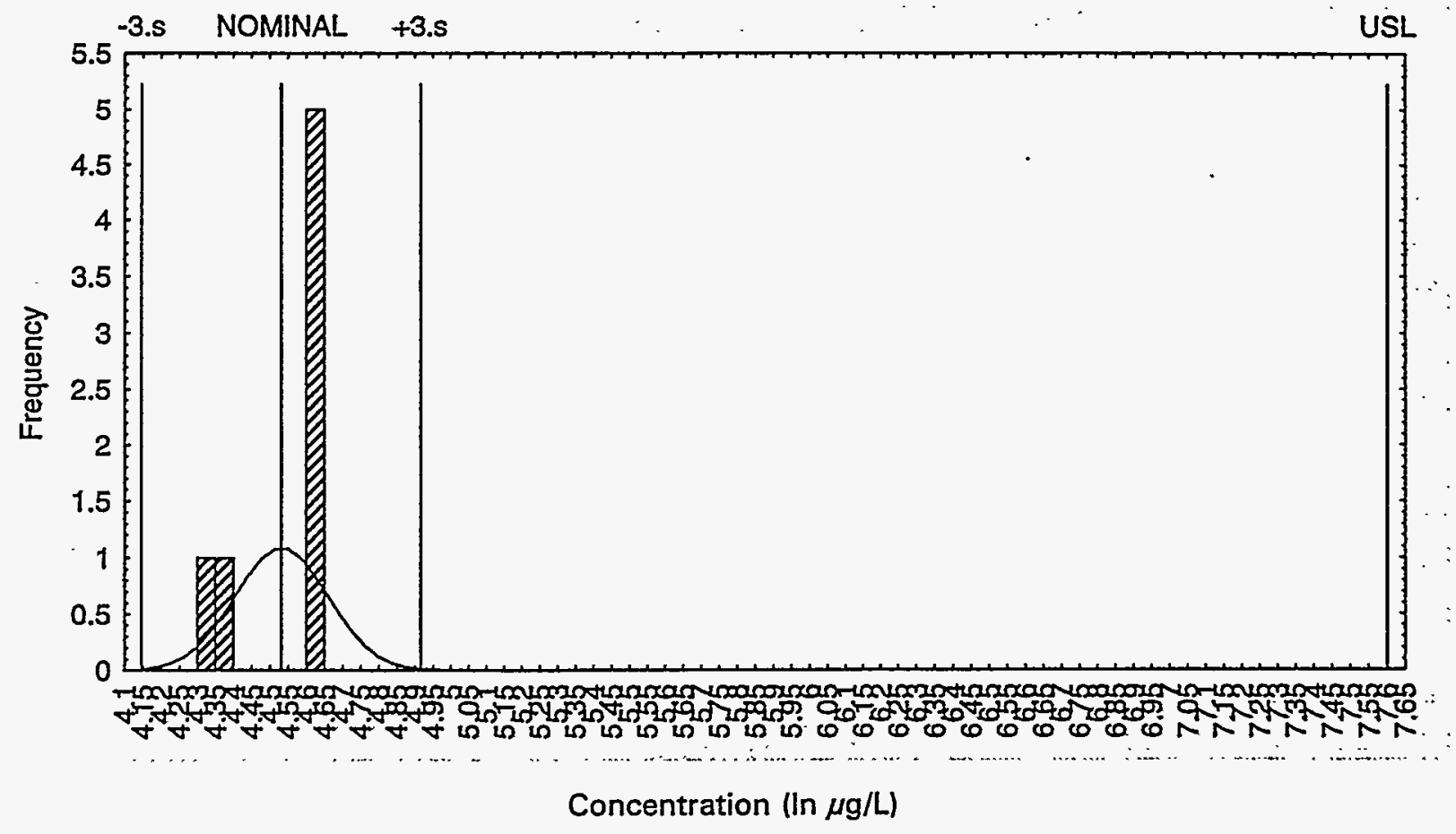

Figure G-3. Measured and log-normal distribution of barium in effluent steam CFA-691. 
Variable: CD Mean: .884413 Sigma: .084340

Nominal Specification Limit: .884410

Upper Specification Limit (USL): 1.60900

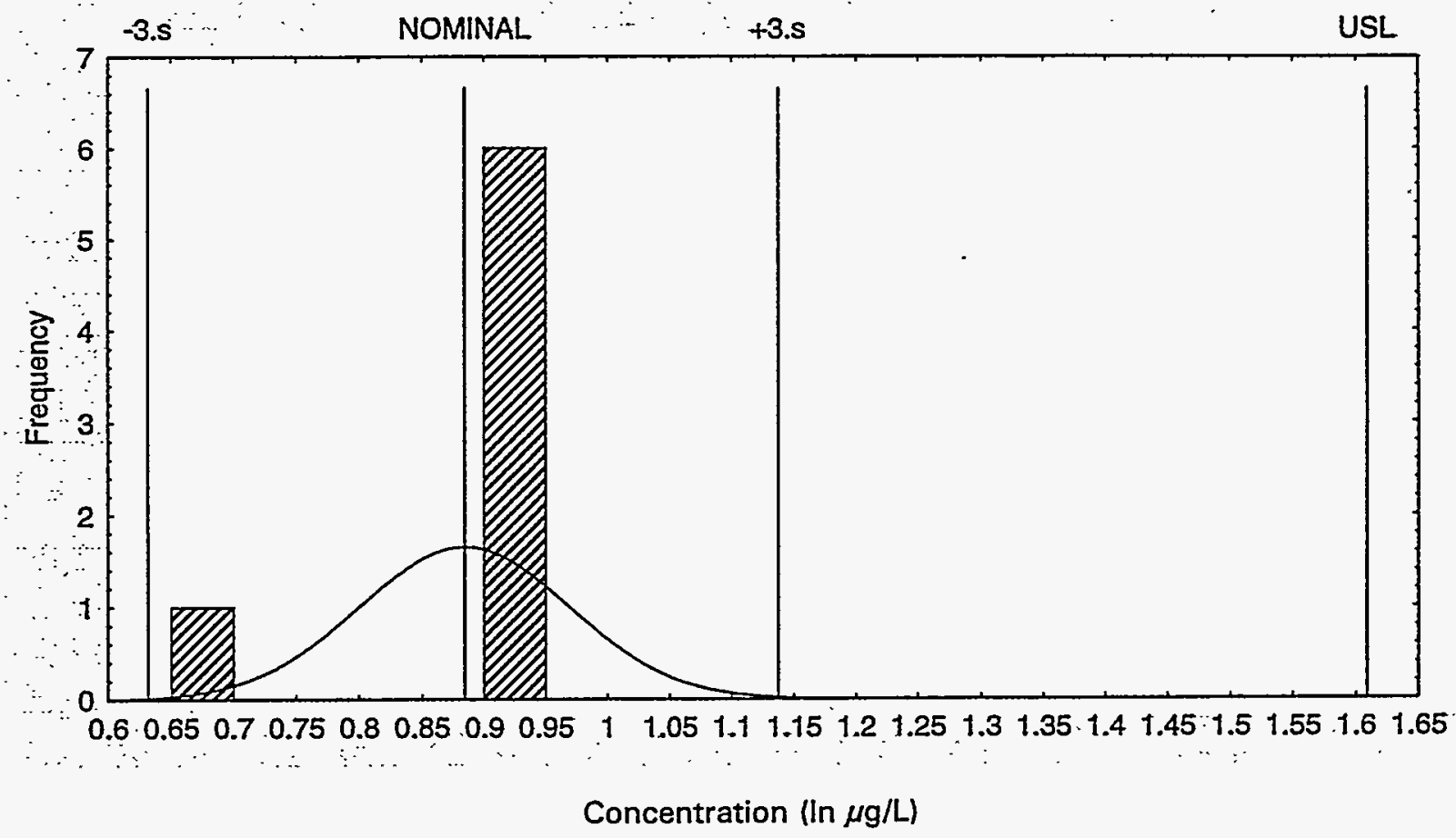

Figure G-4. Measured and log-normal distribution of cadmium in effluent steam CFA-691. 


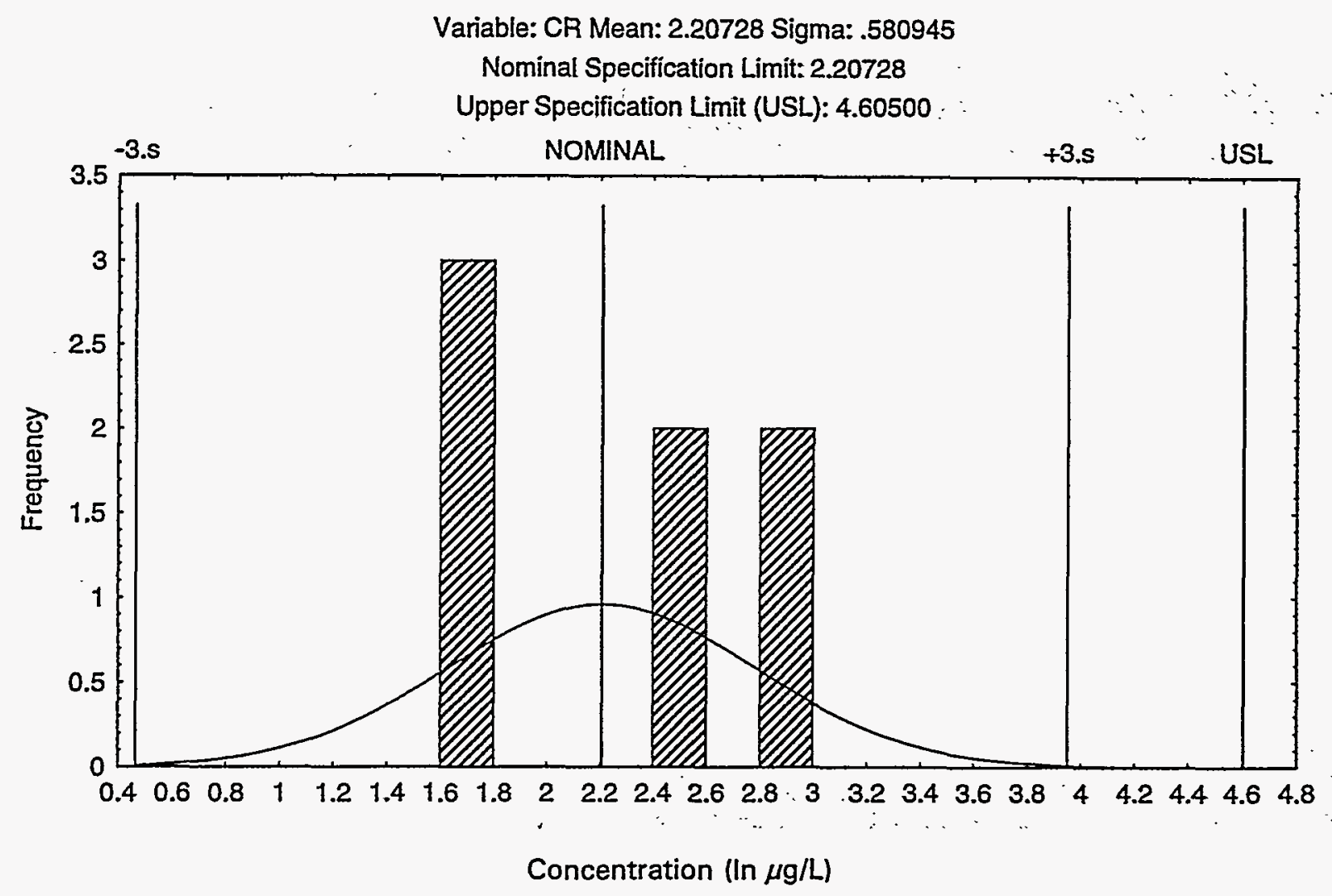

Figure G-5. Measured and log-normal distribution of chromium in effluent steam CFA-691. 


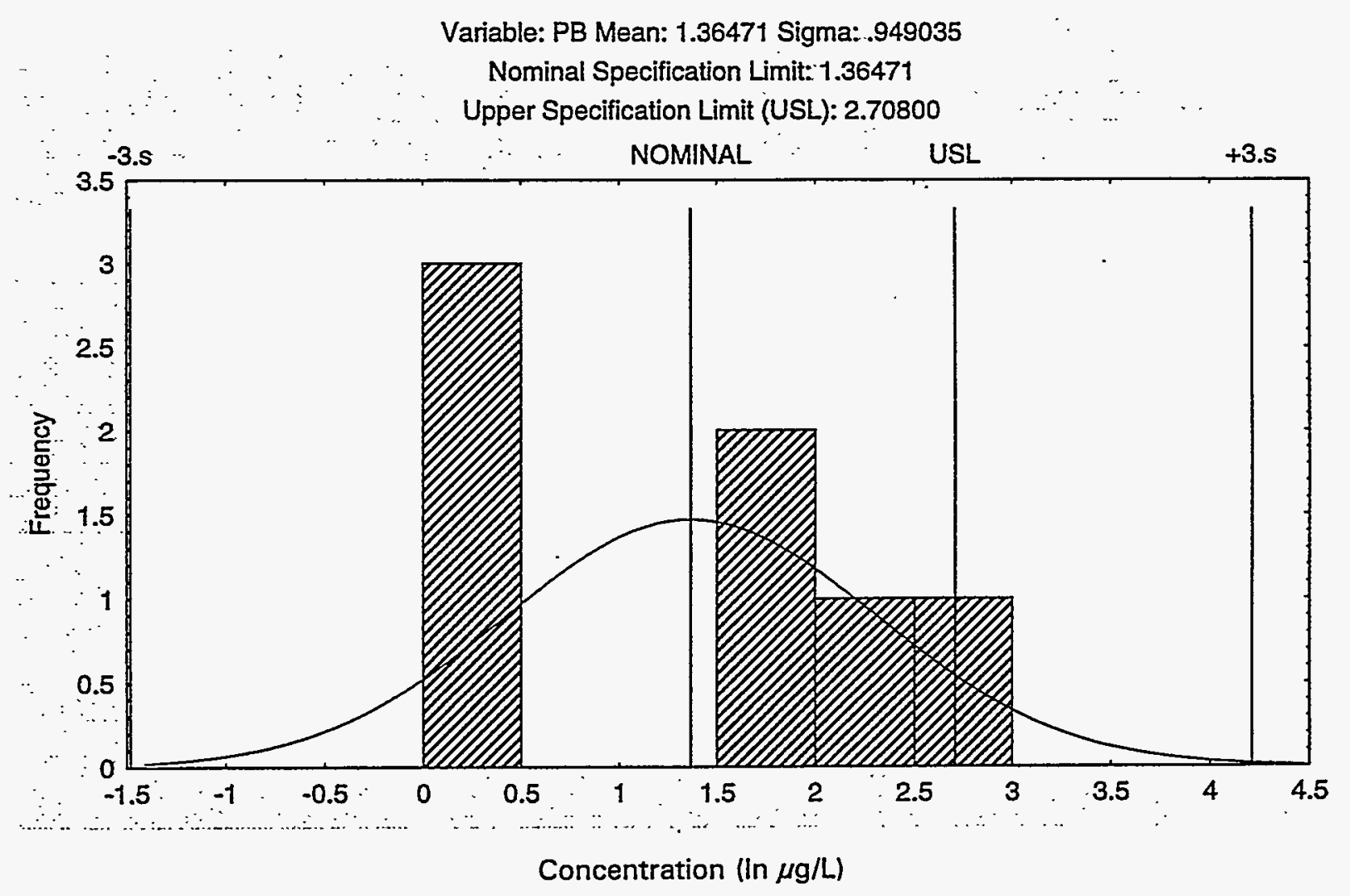

Figure G-6. Measured and log-normal distribution of lead in effluent steam CFA-691. 


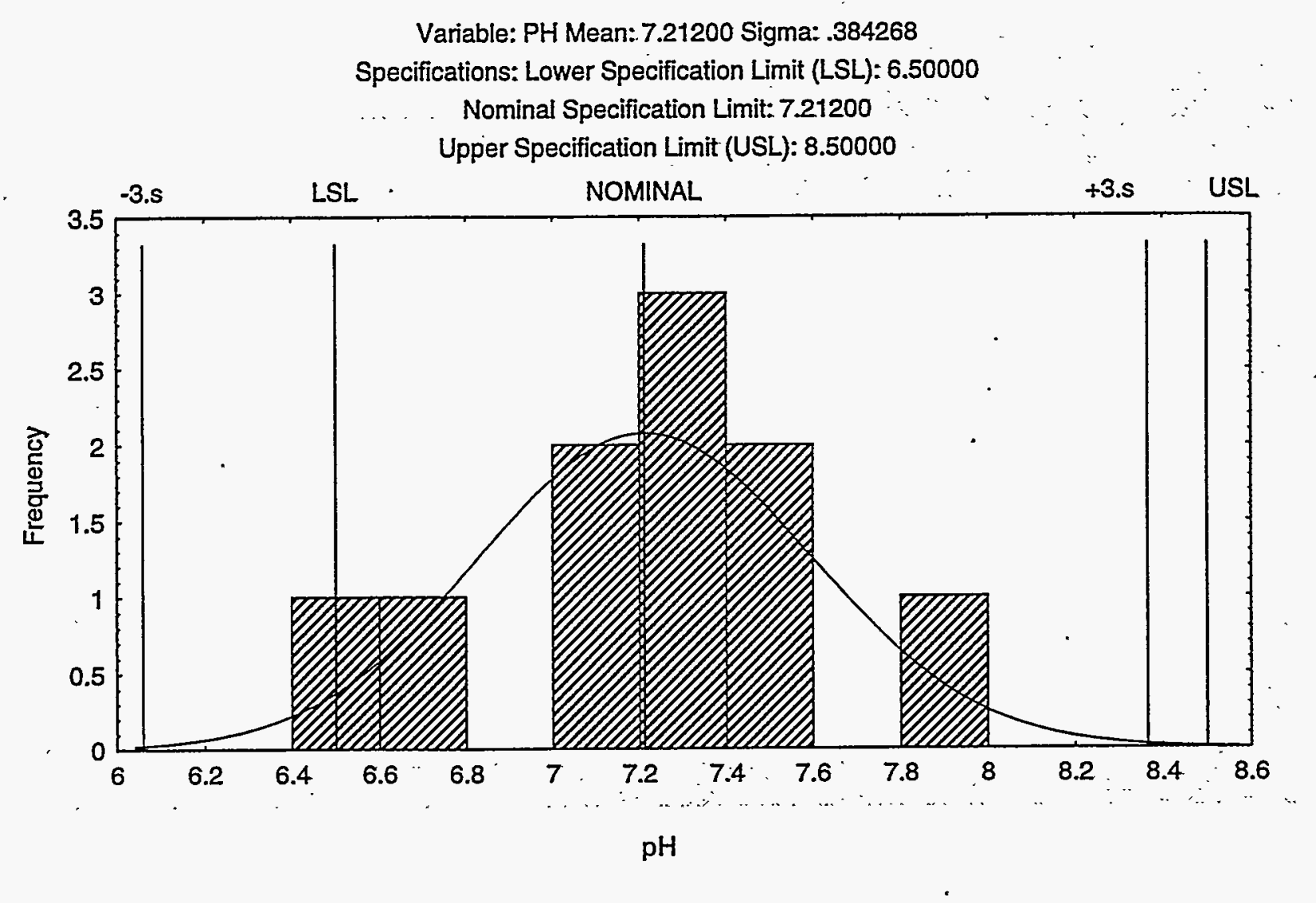

Figure G-7. Measured and normal distribution of $\mathrm{pH}$ in effluent steam CFA-691. 


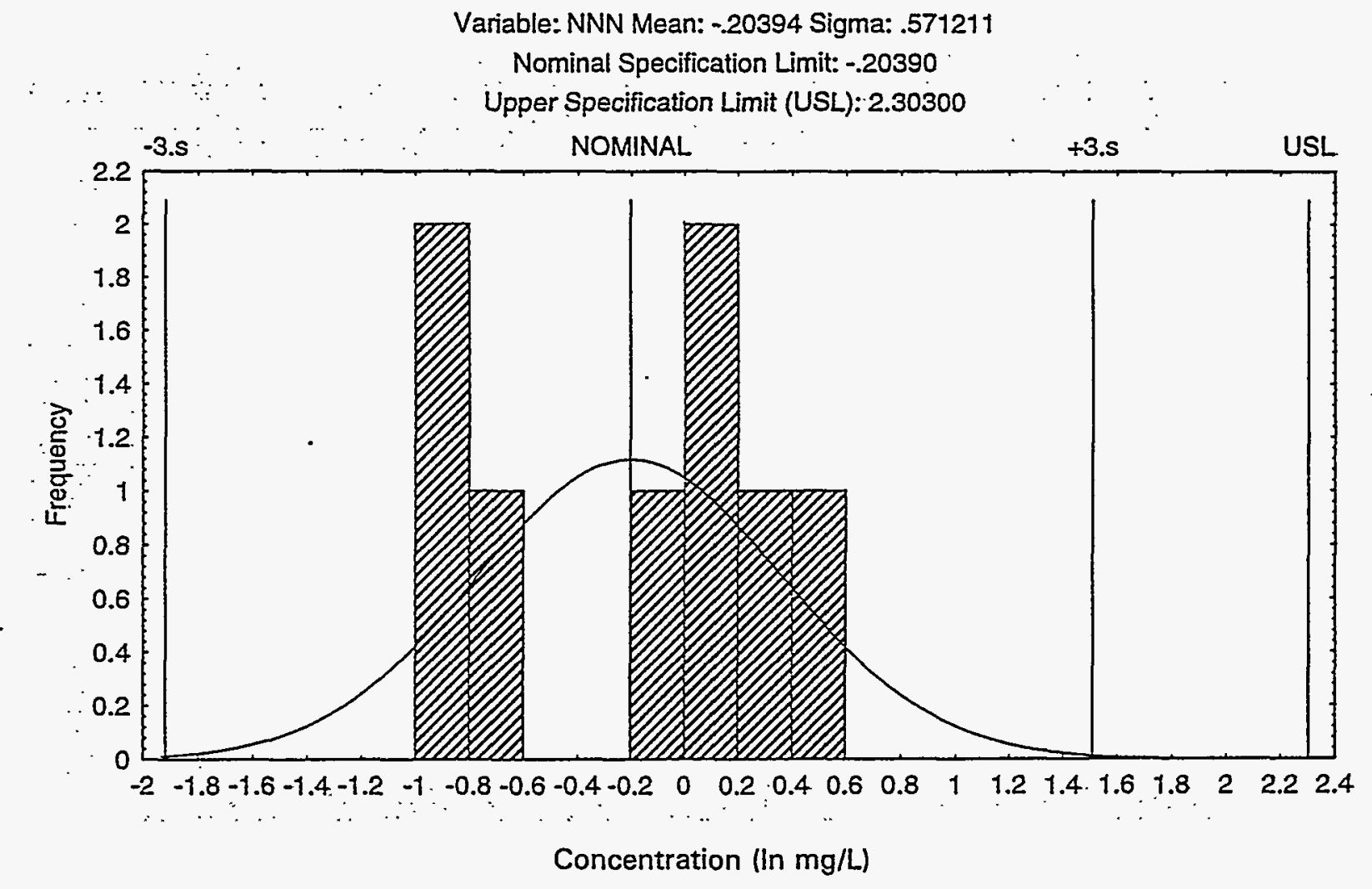

Figure G-8. Measured and log-normal distribution of nitrate plus nitrite nitrogen in effluent steam CFA-691. 
Variable: SE Mean: .865174 Sigma: .103261

Nominal Specification. Limit: .865170

Upper Specification Limit (USL): 3.91200

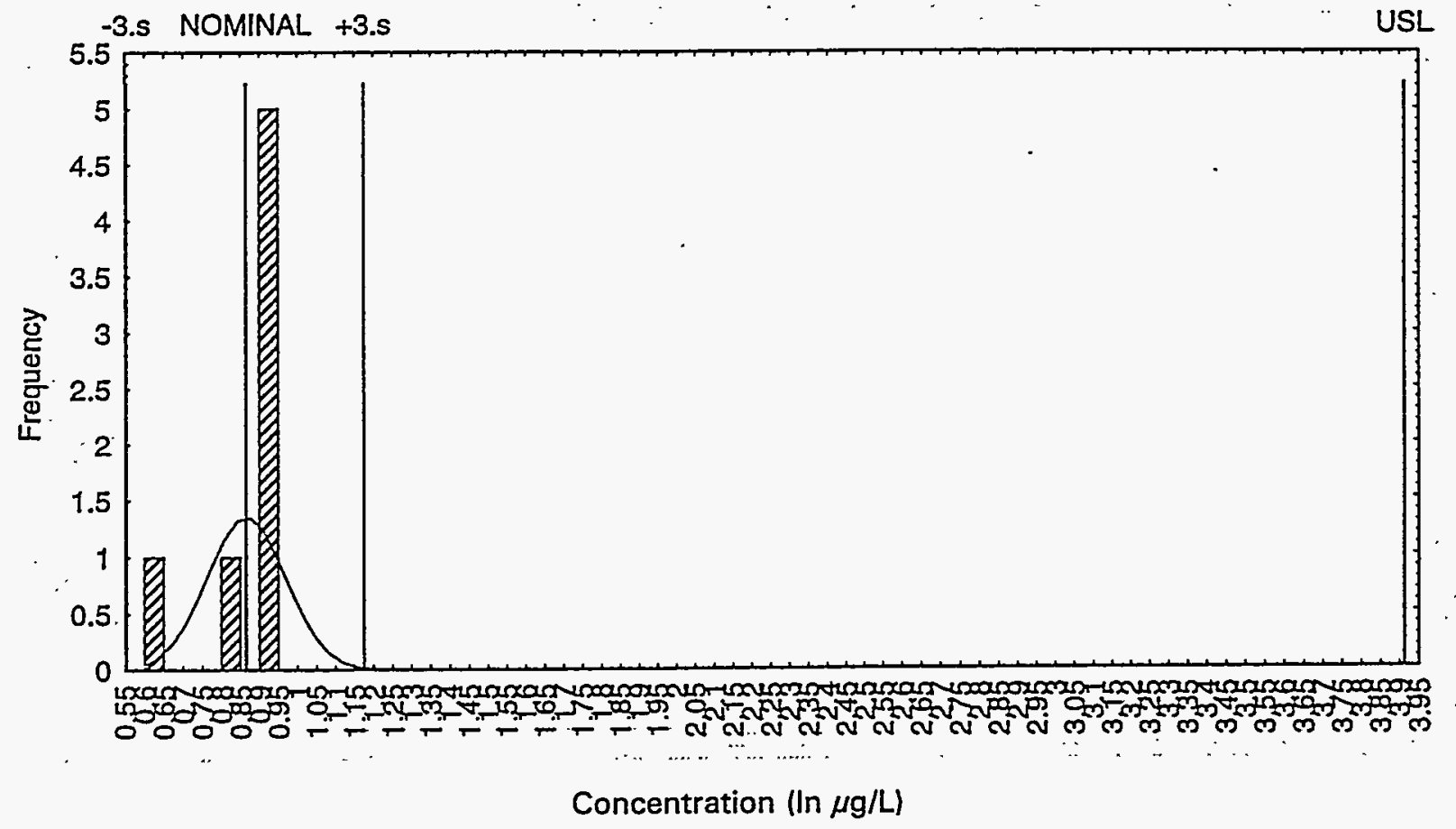

Figure G-9. Measured and log-normal distribution of selenium in effluent steam CFA-691. 


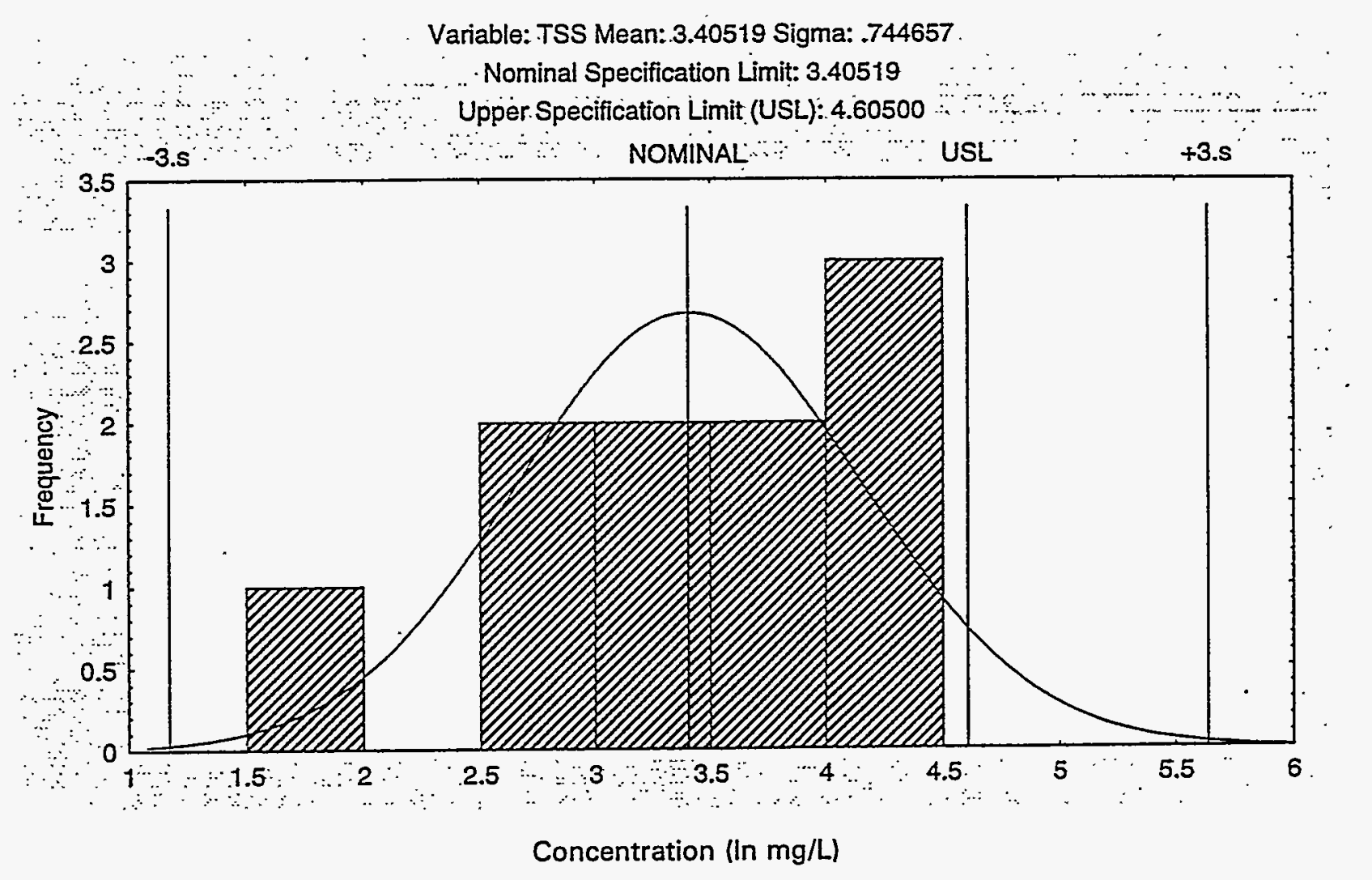

Figure G-10. Measured and log-normal distribution of total suspended solids in effluent steam CFA-691. 
Appendix H. Frequency Histograms for Monitoring Parameters TRA-764, Cold Waste Pond 
H-2 


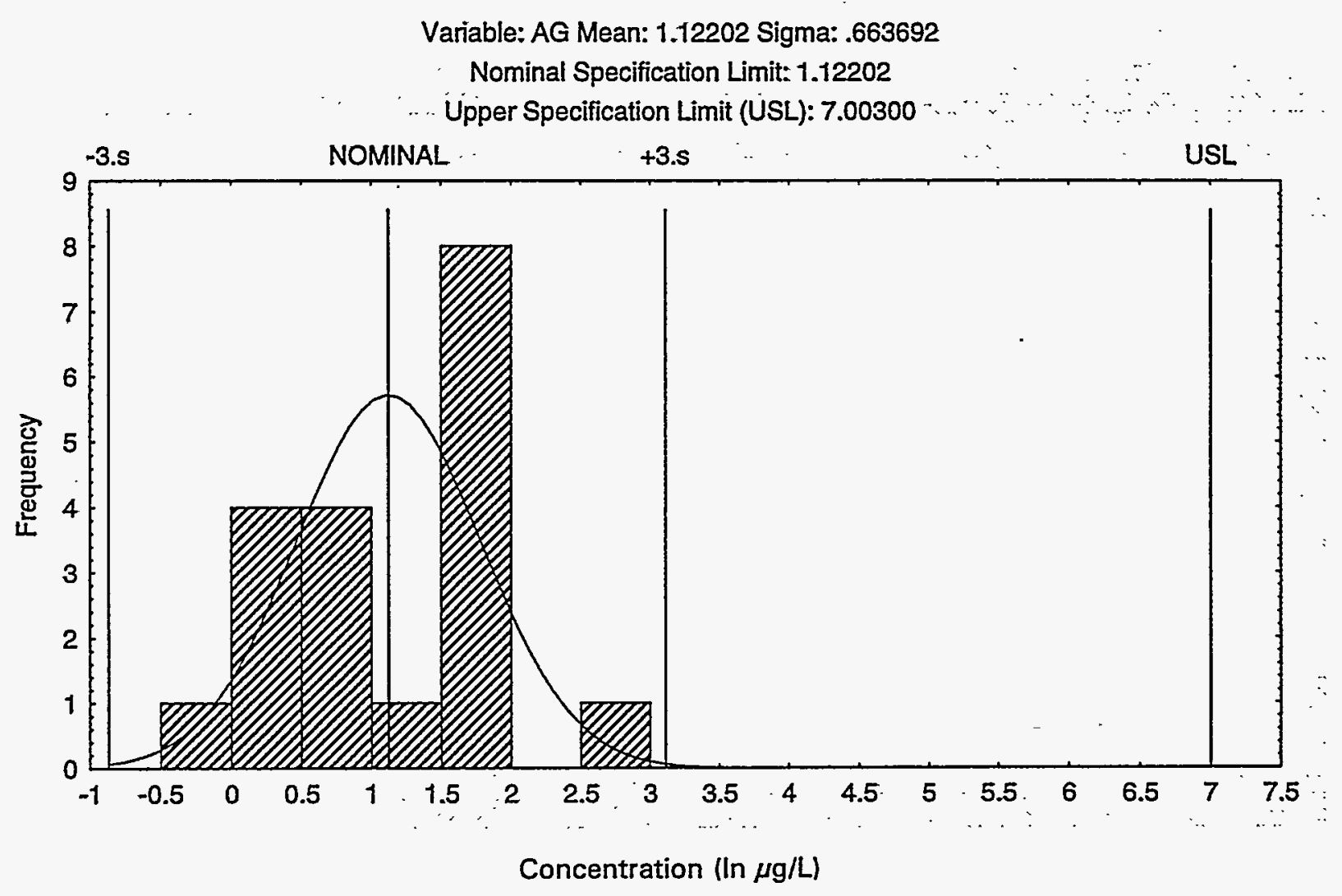

Figure H-1. Measured and log-normal distribution of silver in effluent steam TRA-764. 


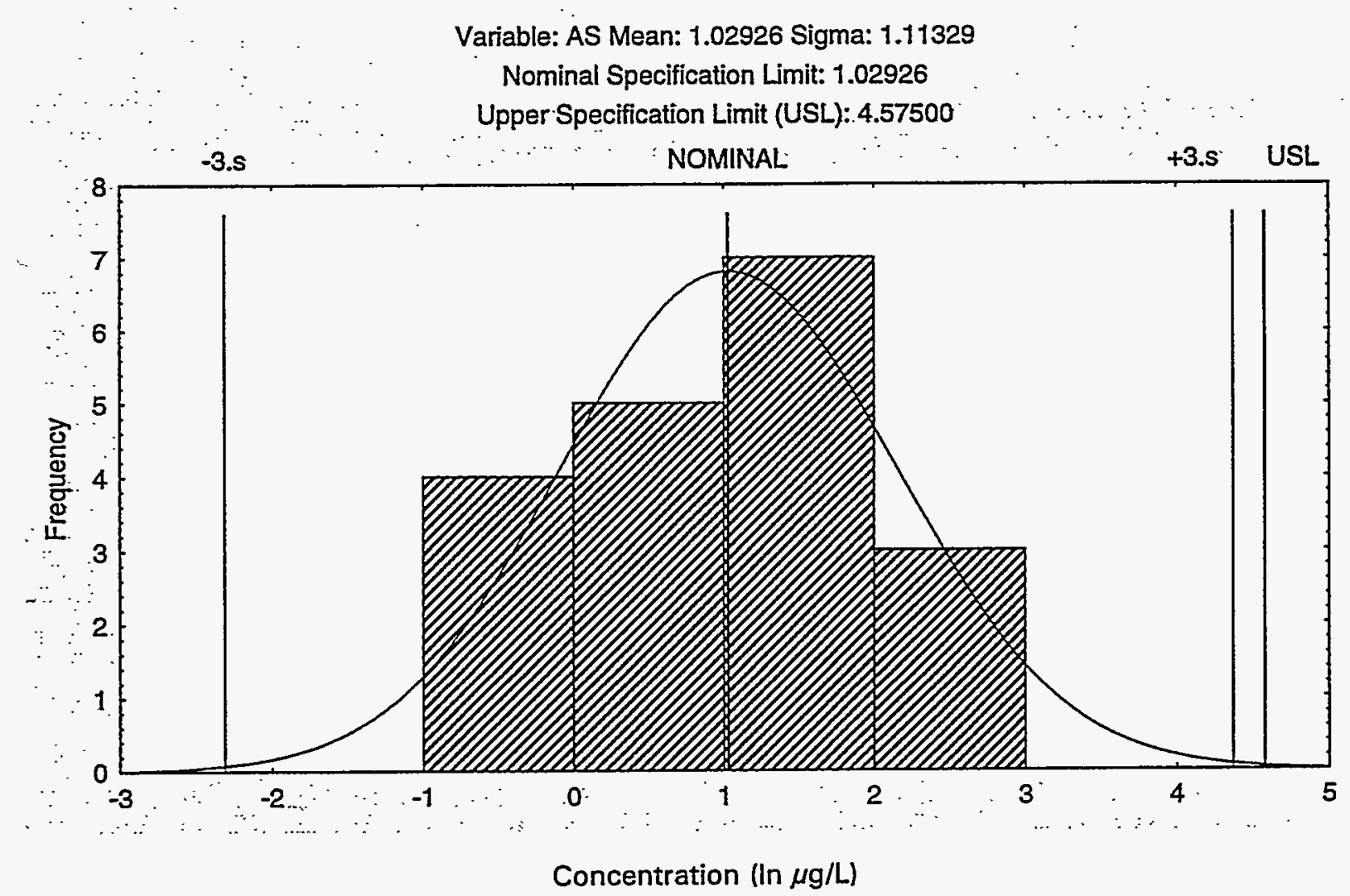

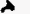

Figure H-2. Measured and log-normal distribution of arsenic in effluent steam TRA-764. 


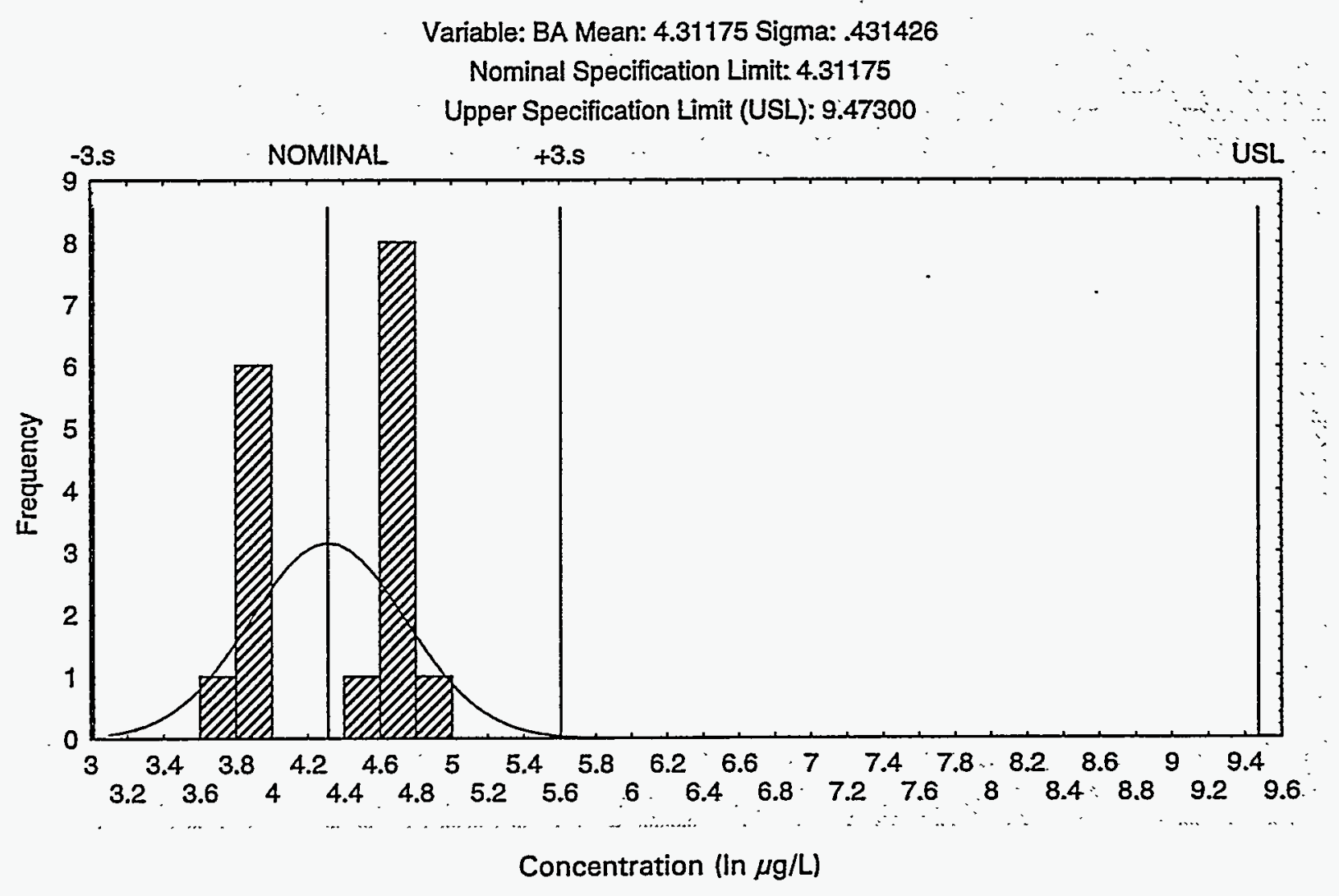

Figure H-3. Measured and log-normal distribution of barium in effluent steam TRA-764. 
Variable: BE Mean: .384748 Sigma: .552147

Specifications: Lower Specification Limit (LSL): -.51100

Nominal Specification Limit: $\mathbf{3 8 4 7 5 0}$

Upper Specification Limit (USL): 1.38600

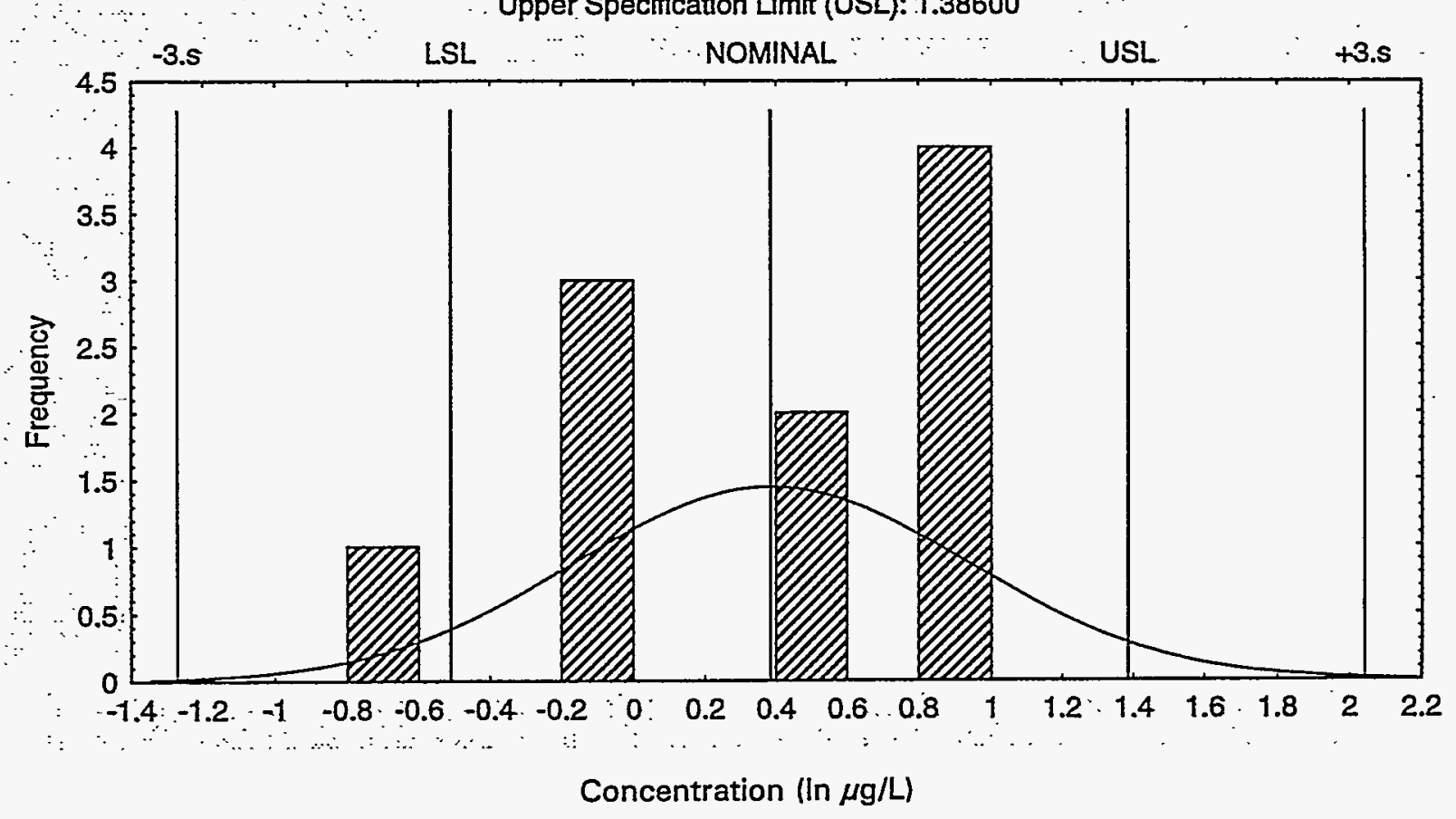

Figure H-4. Measured and log-normal distribution of beryllium in effluent steam TRA-764. 


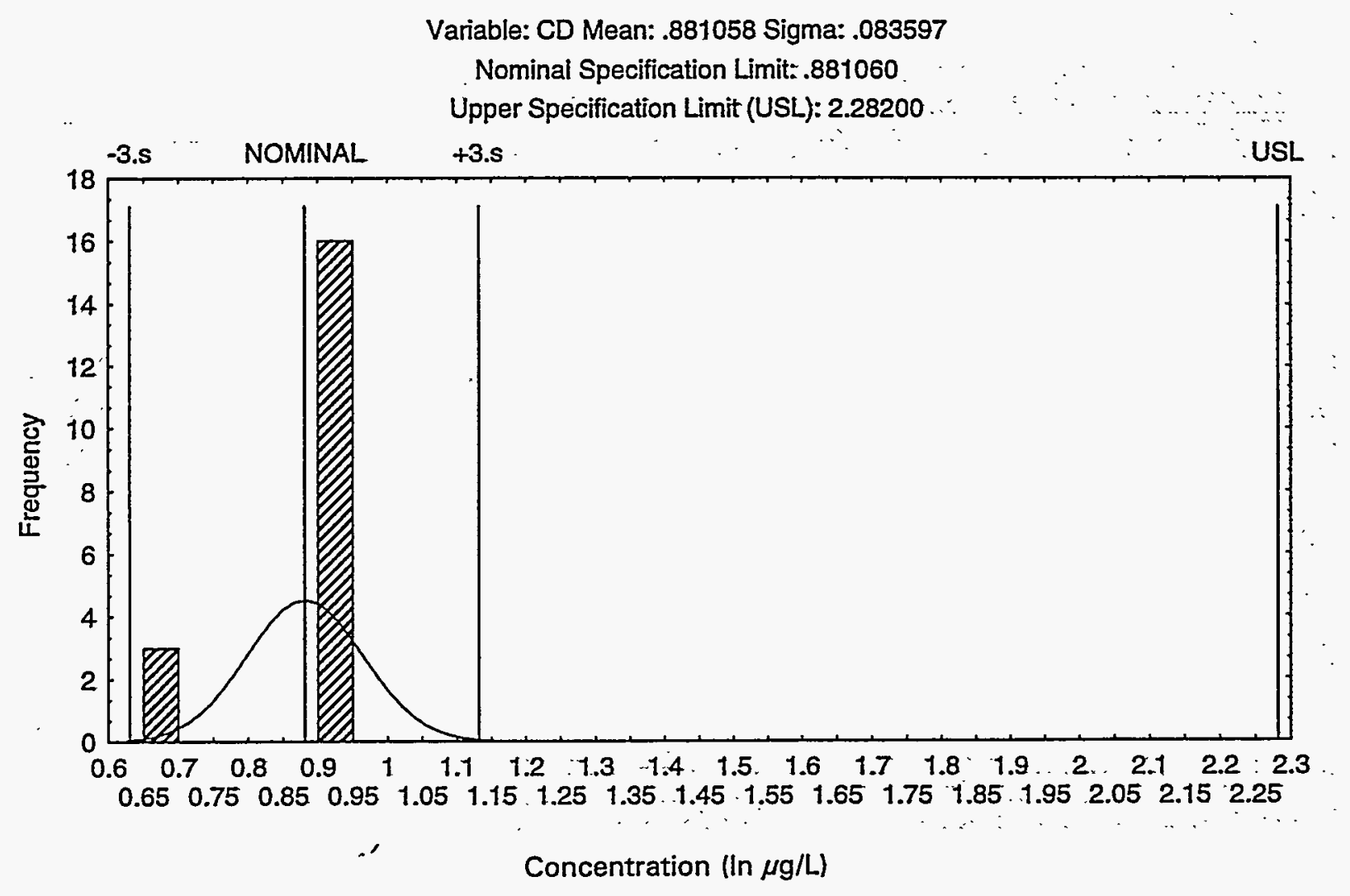

Figure H-5. Measured and log-normal distribution of cadmium in effluent steam TRA-764. 


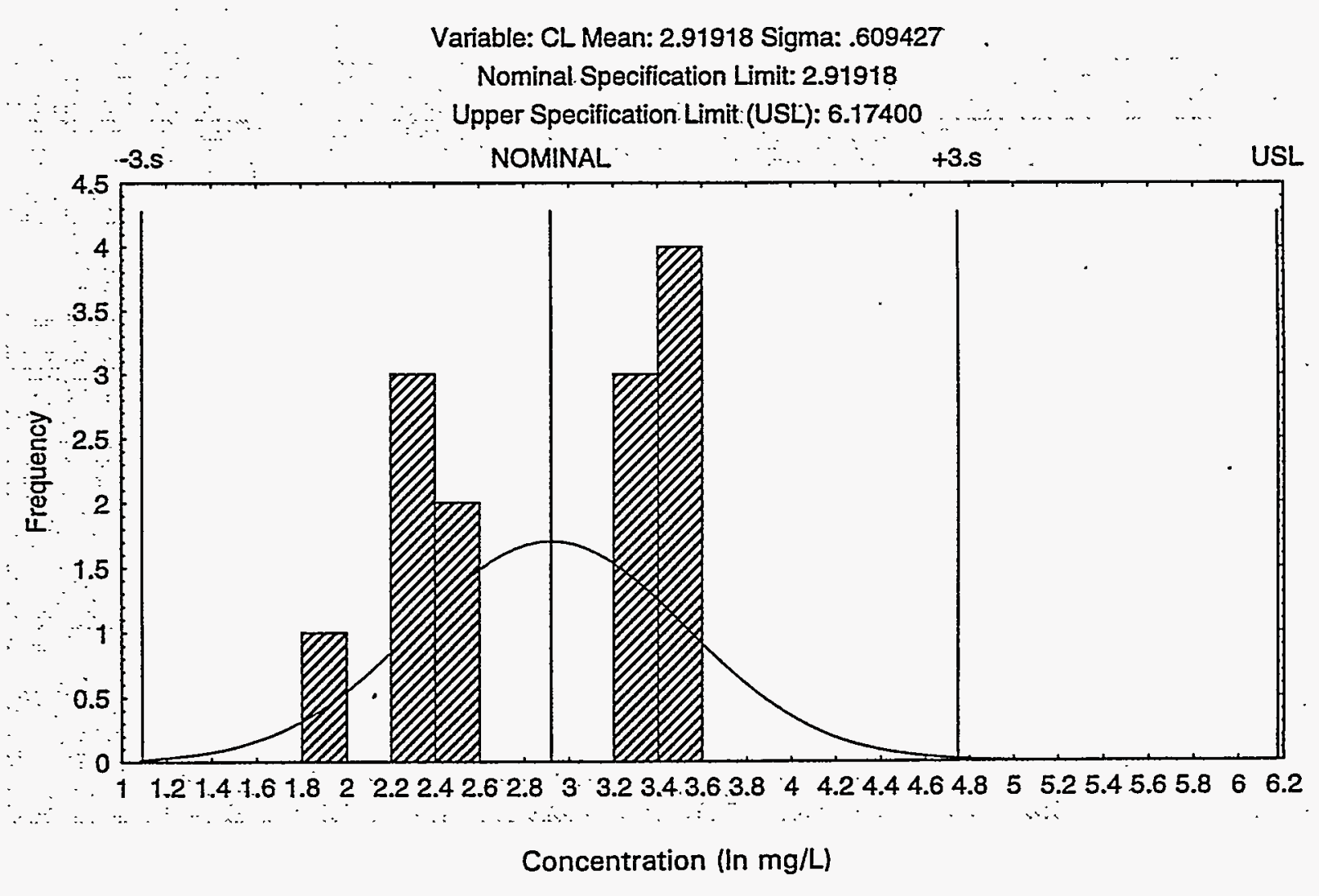

Figure H-6. Measured and log-normal distribution of chloride in effluent steam TRA-764. 


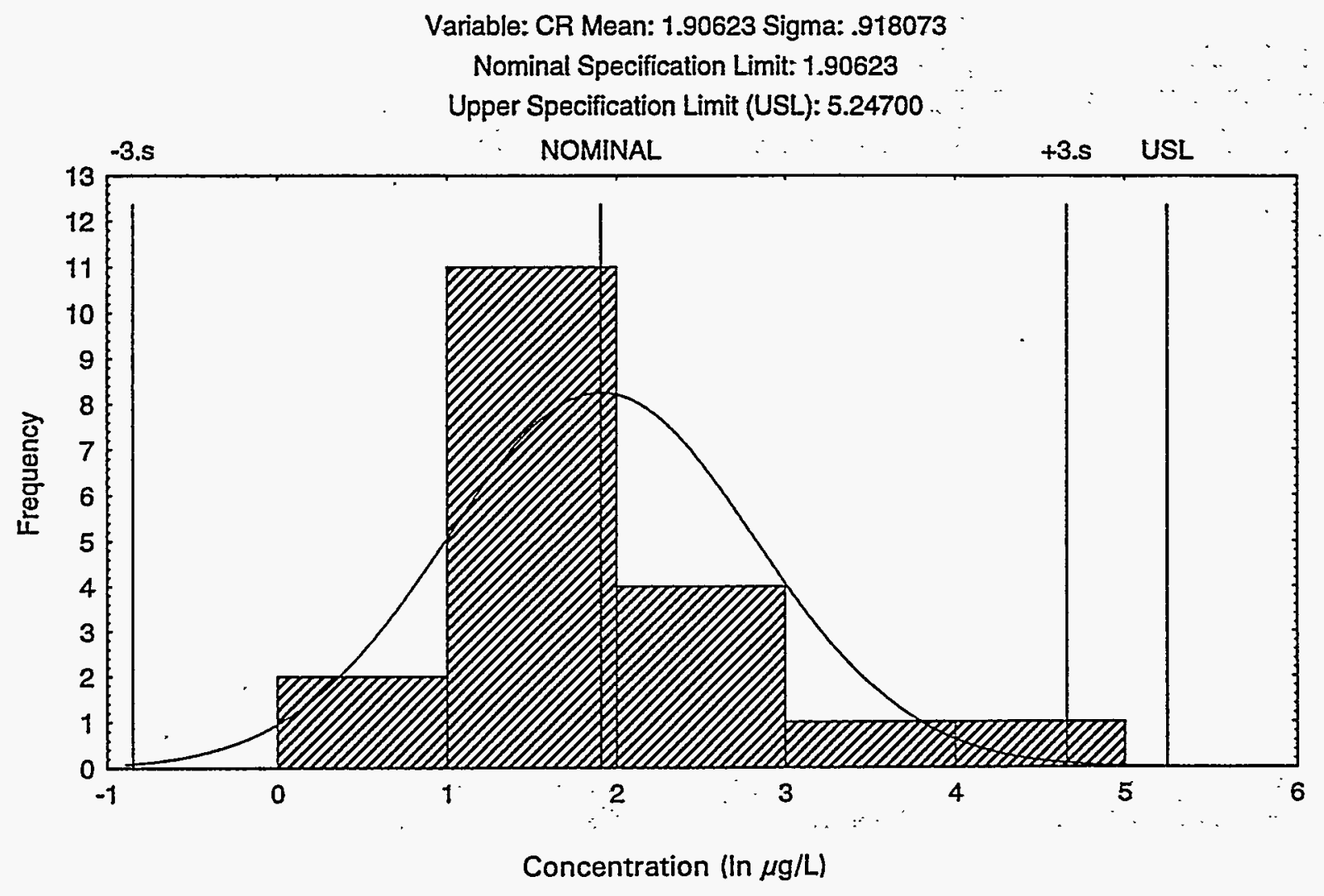

Figure H-7. Measured and log-normal distribution of chromium in effluent steam TRA-764. 


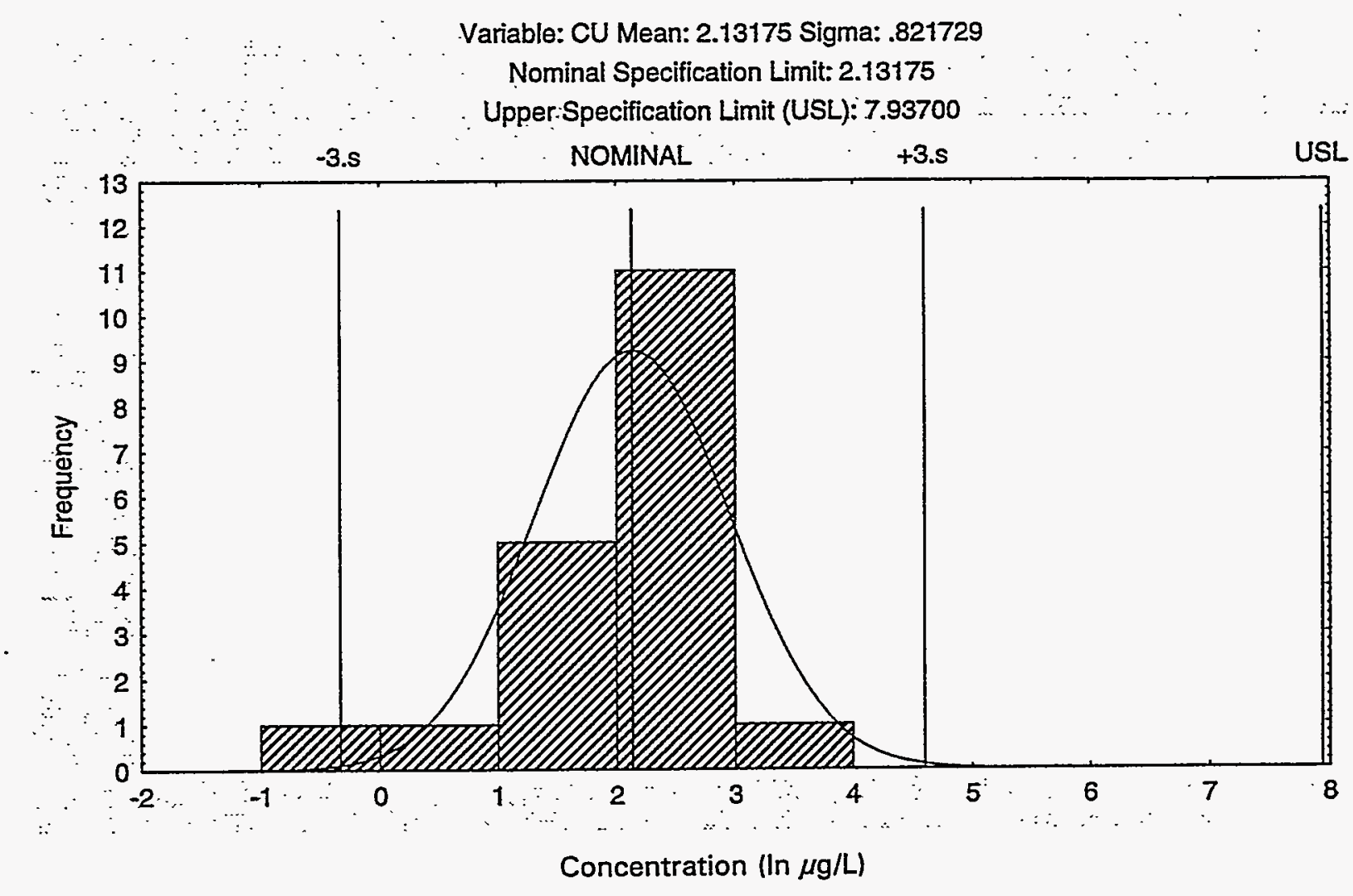

Figure H-8. Measured and log-normal distribution of copper in effluent steam TRA-764. 


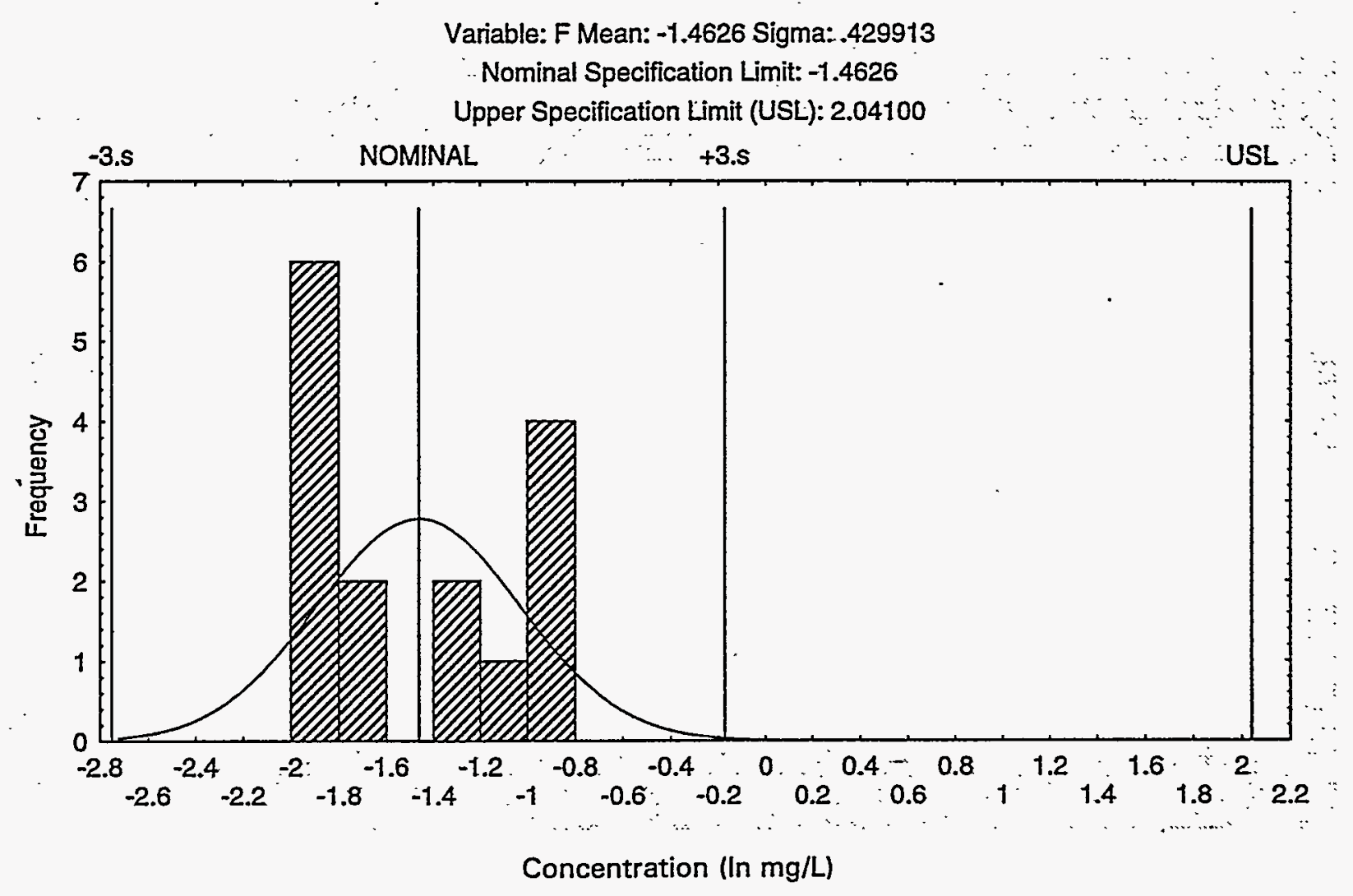

Figure H-9. Measured and log-normal distribution of fluoride in effluent steam TRA-764. 


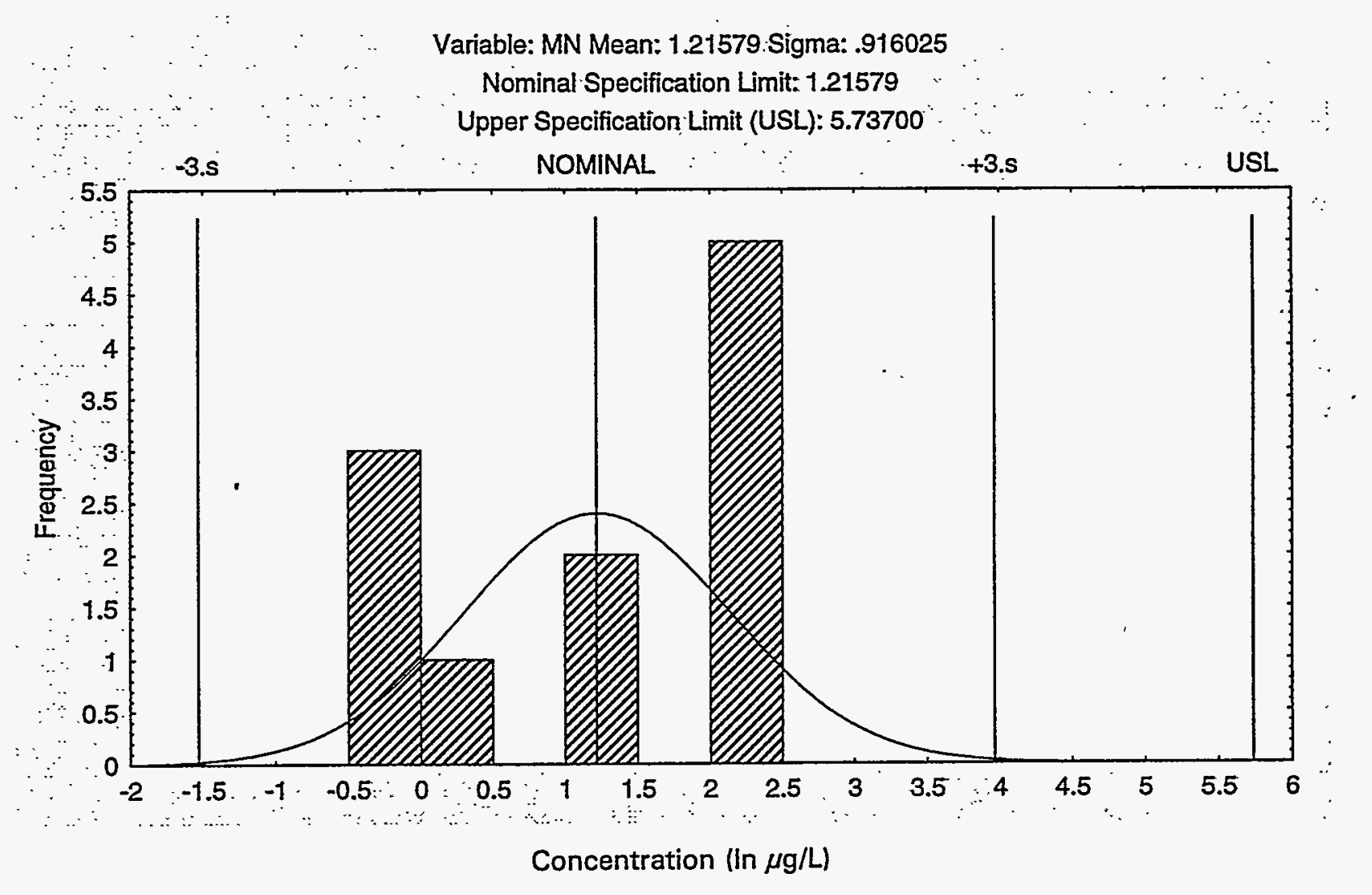

Figure H-10. Measured and log-normal distribution of manganese in effluent steam TRA-764. 


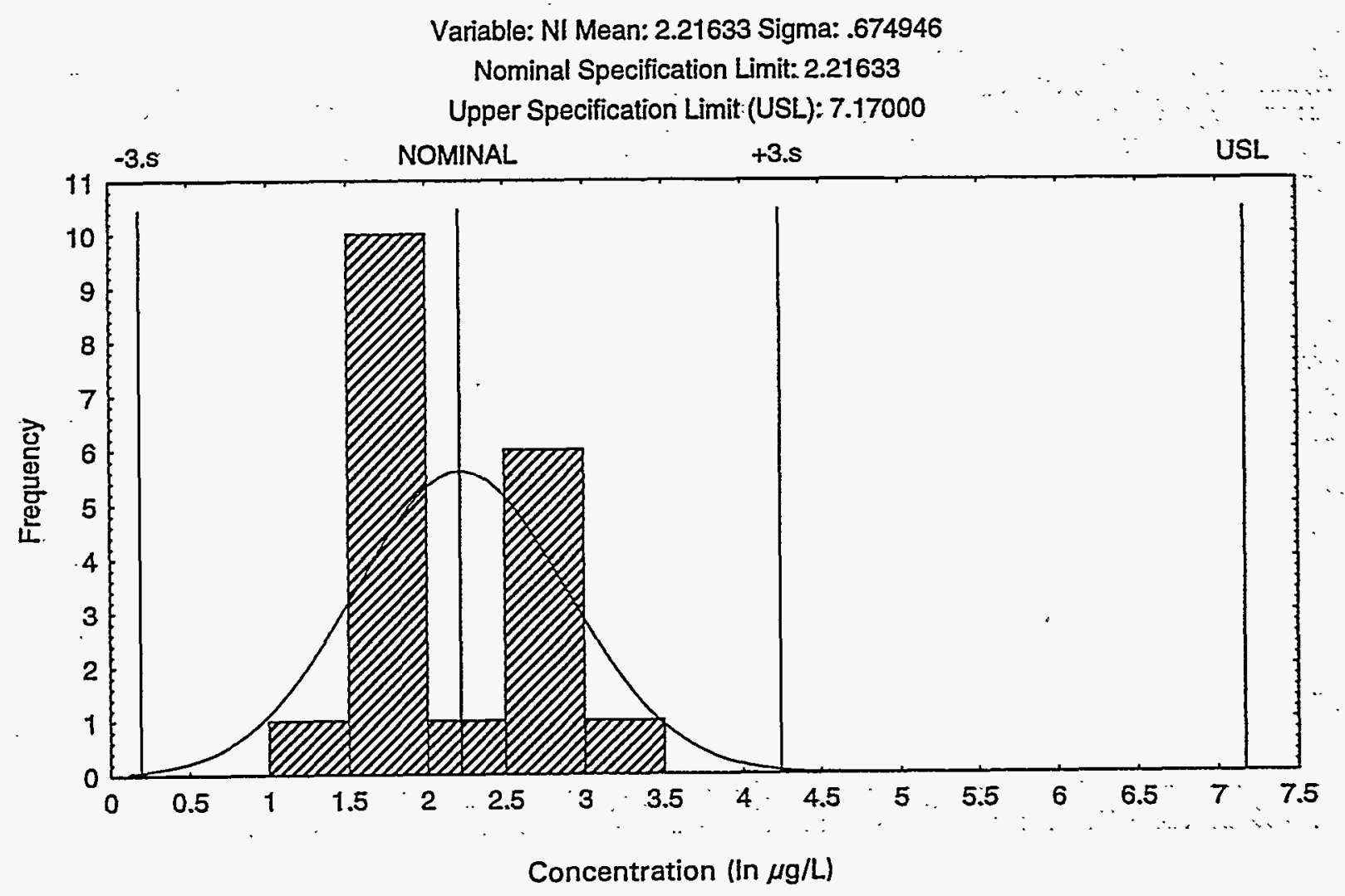

Figure H-11. Measured and log-normal distribution of nickel in effluent steam TRA-764. 


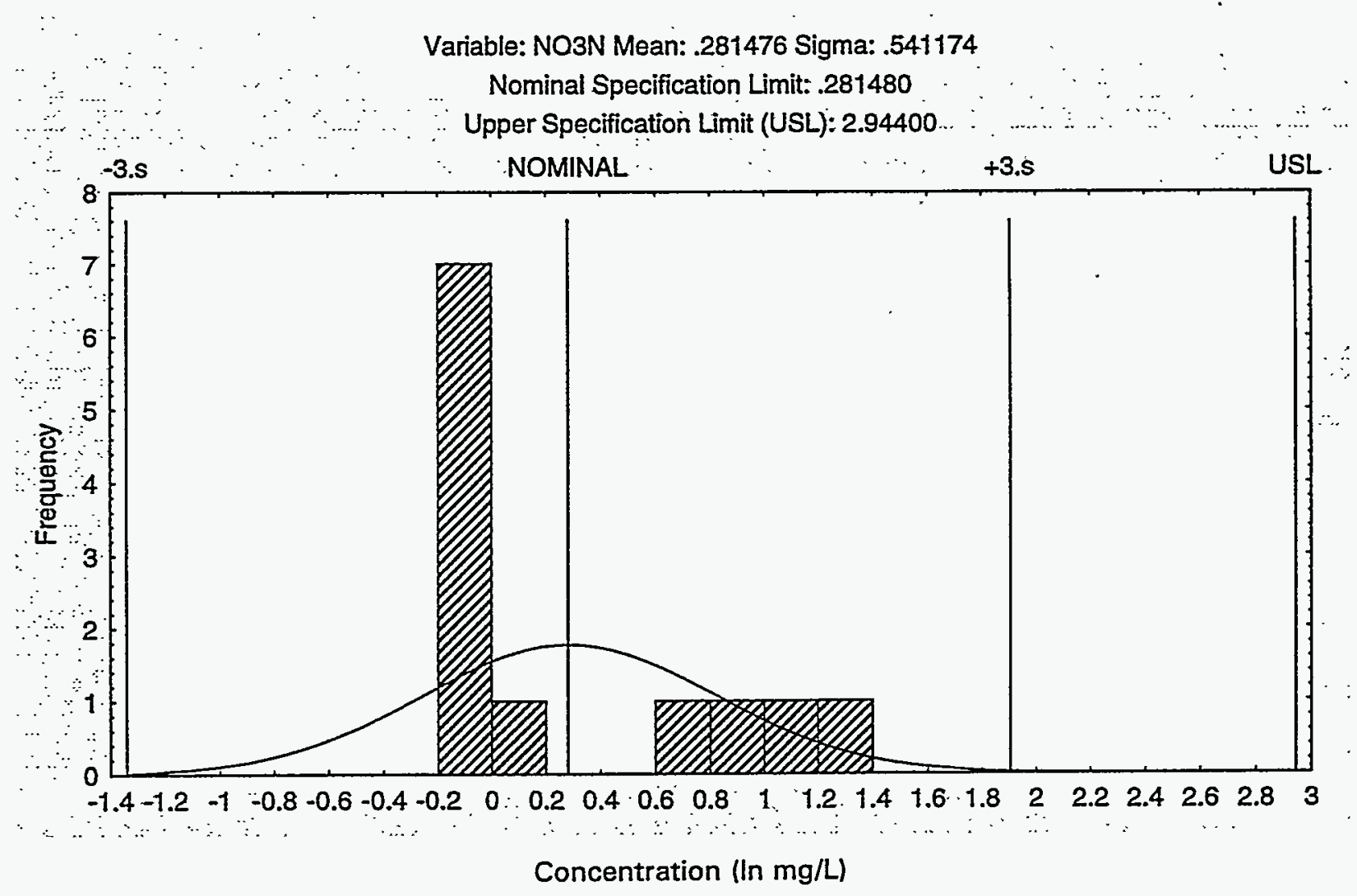

Figure H-12. Measured and log-normal distribution of nitrate nitrogen in effluent steam TRA-764. 


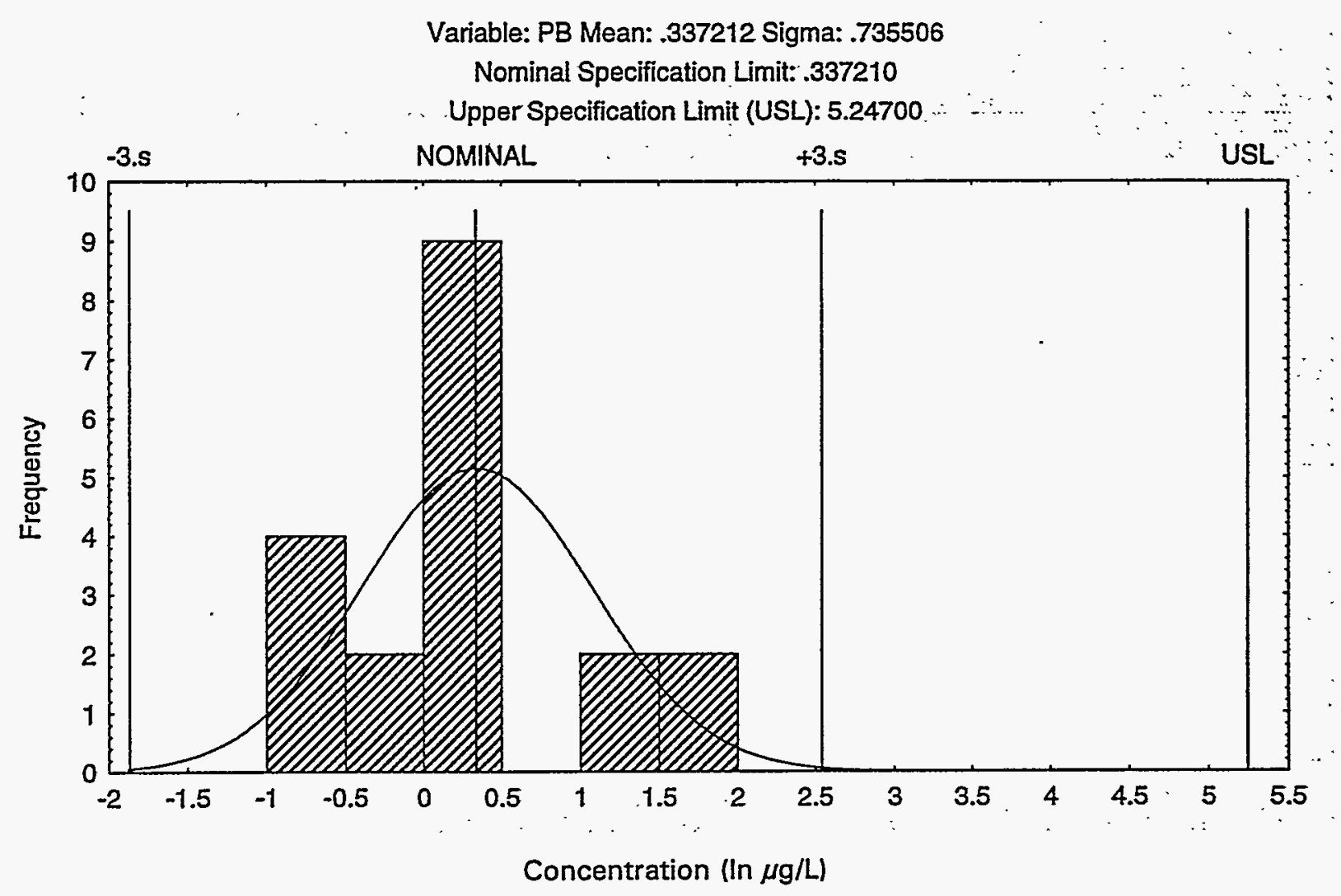

Figure H-13. Measured and log-normal distribution of lead in effluent steam TRA-764. 
Variable: PH Mean: 7.64222 Sigma:..480852

Specifications: Lower Specification Limit (LSL): 6.50000

Nominal Specification Limit: 7.64222

Upper Specification Limit (USL): 8.50000

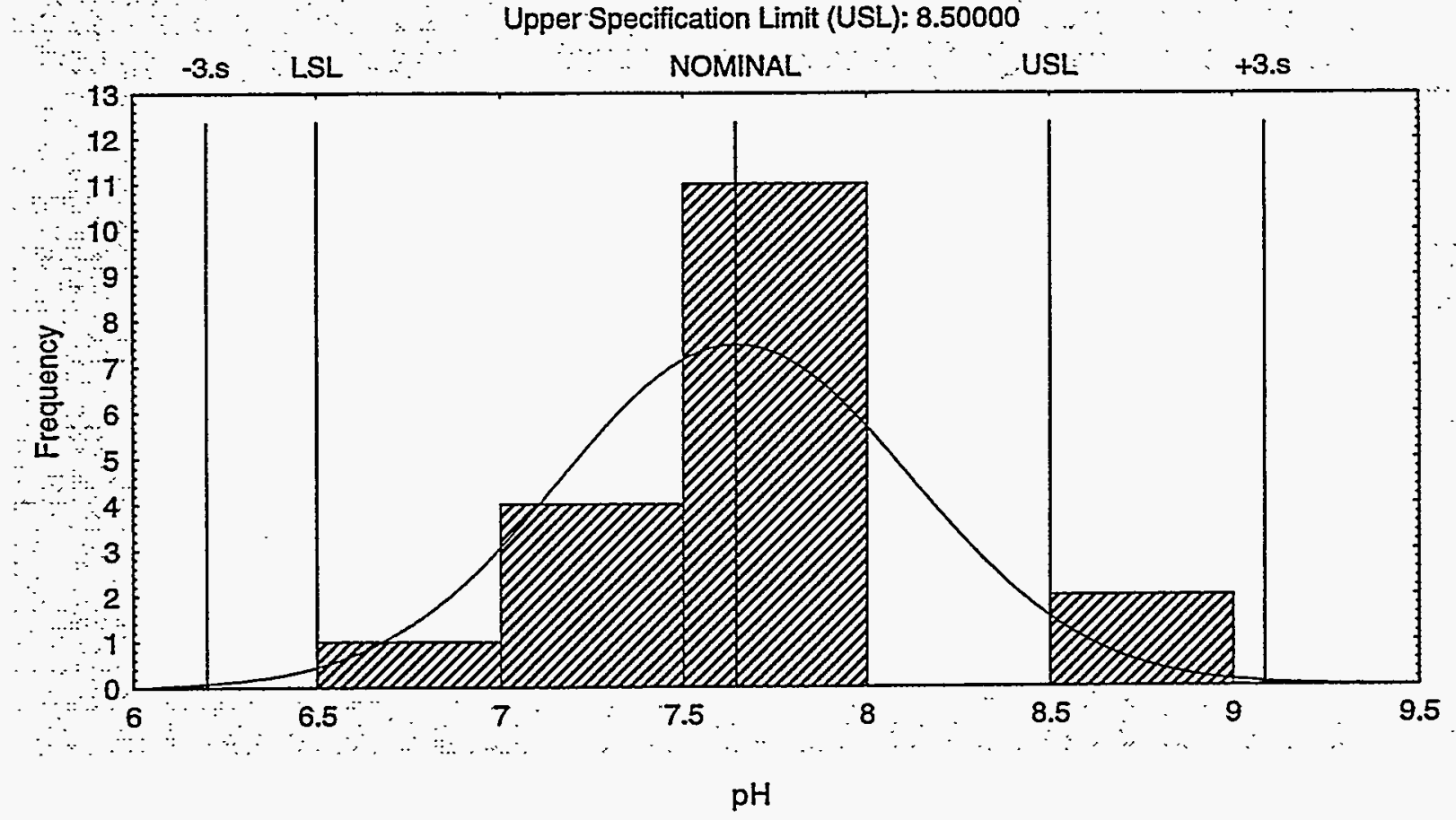

Figure H-14. Measured and normal distribution of $\mathrm{pH}$ in effluent steam TRA-764. 


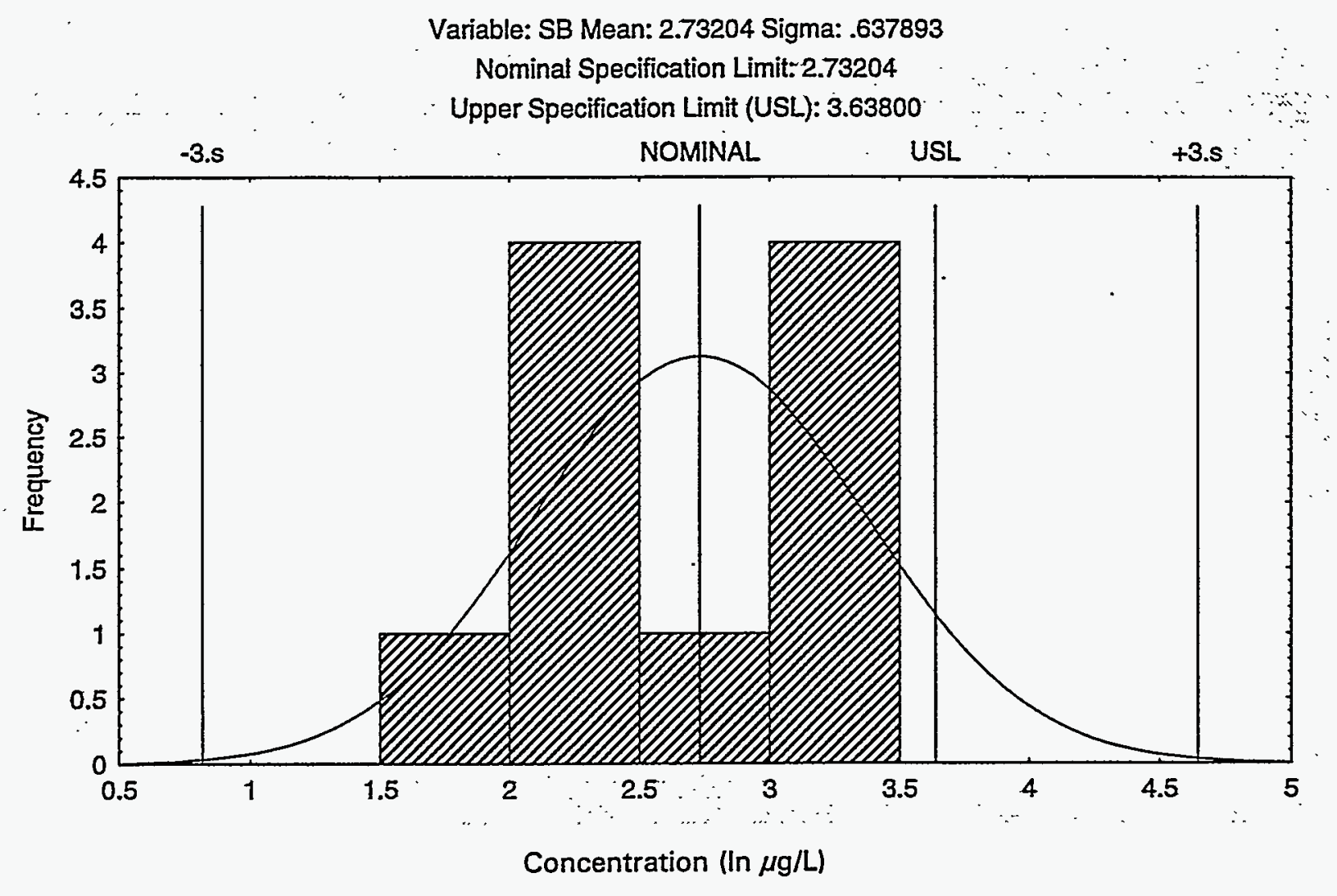

Figure H-15. Measured and log-normal distribution of antimony in effluent steam TRA-764. 


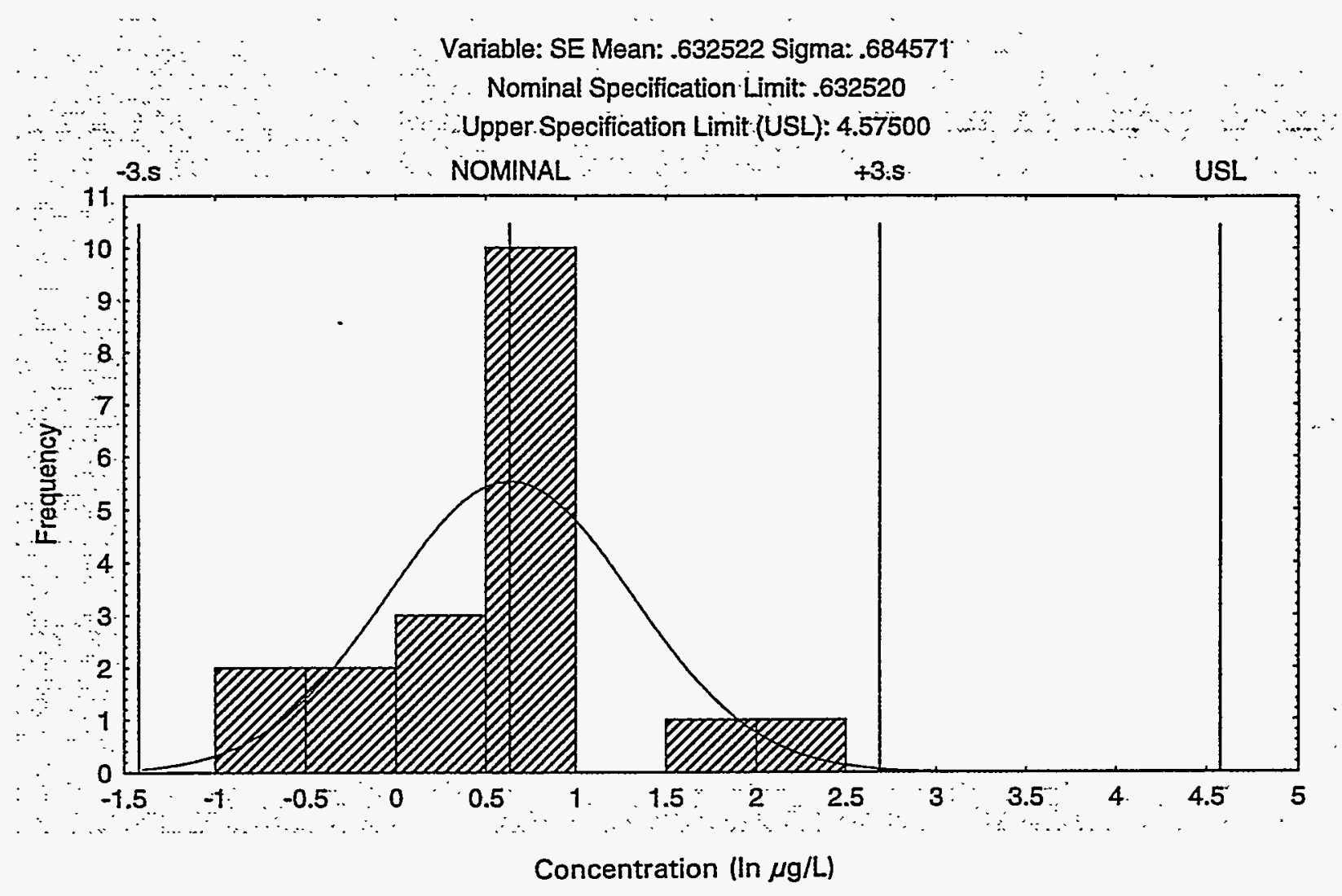

Figure H-16. Measured and log-normal distribution of selenium in effluent steam TRA-764. 


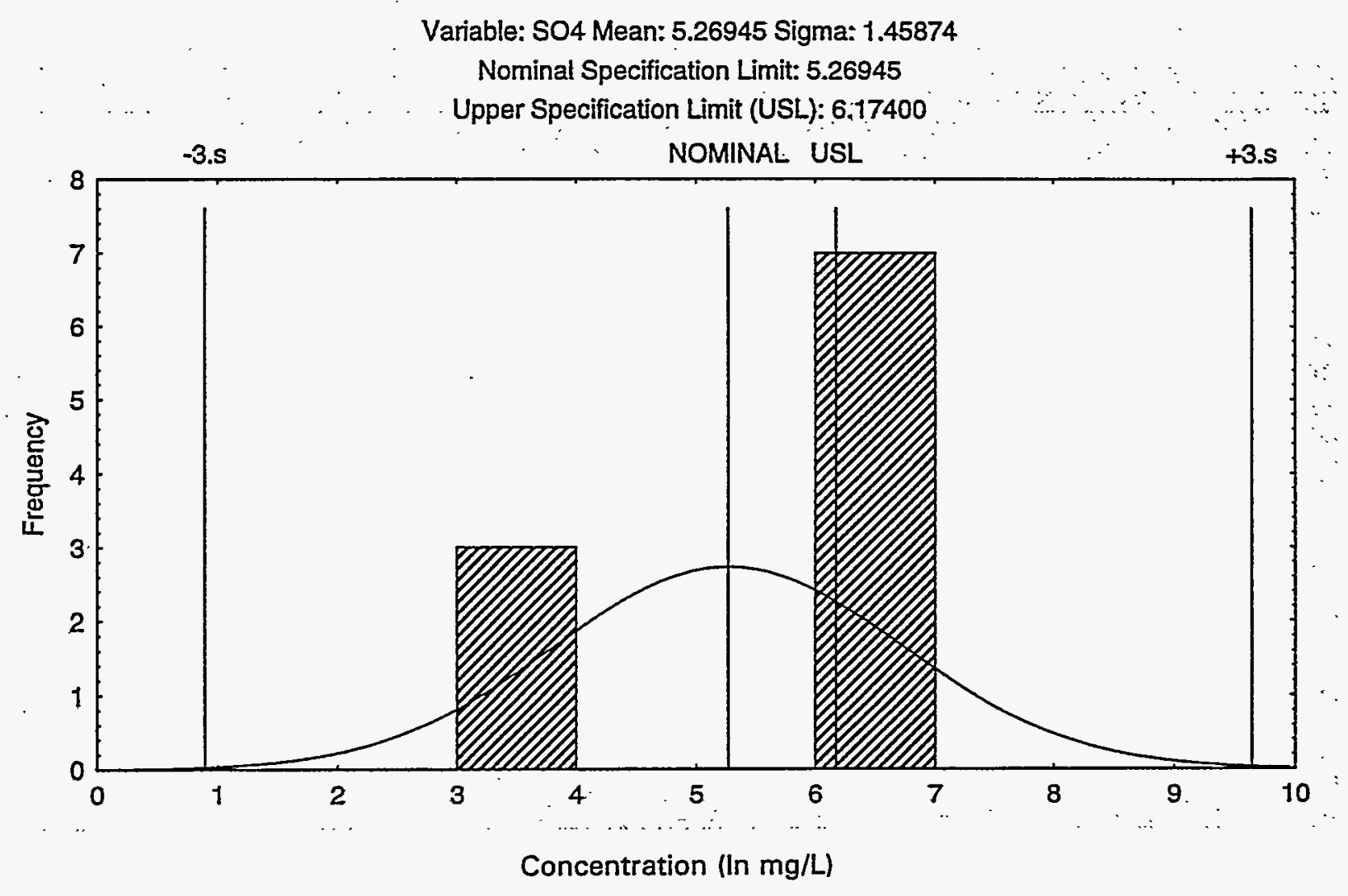

Figure H-17. Measured and log-normal distribution of sulfate in effluent steam TRA-764. 


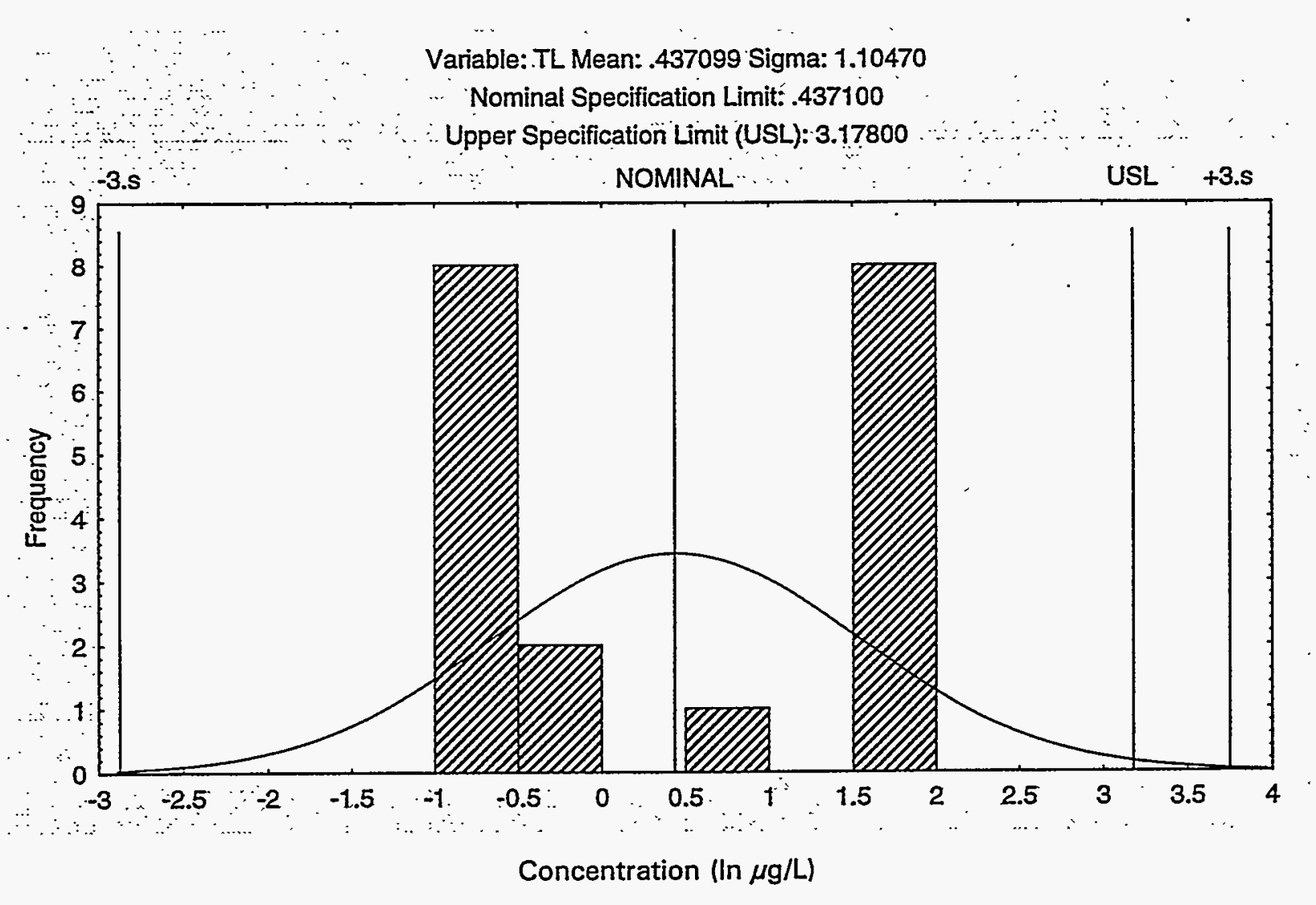

Figure H-18. Measured and log-normal distribution of thallium in effluent steam TRA-764. 


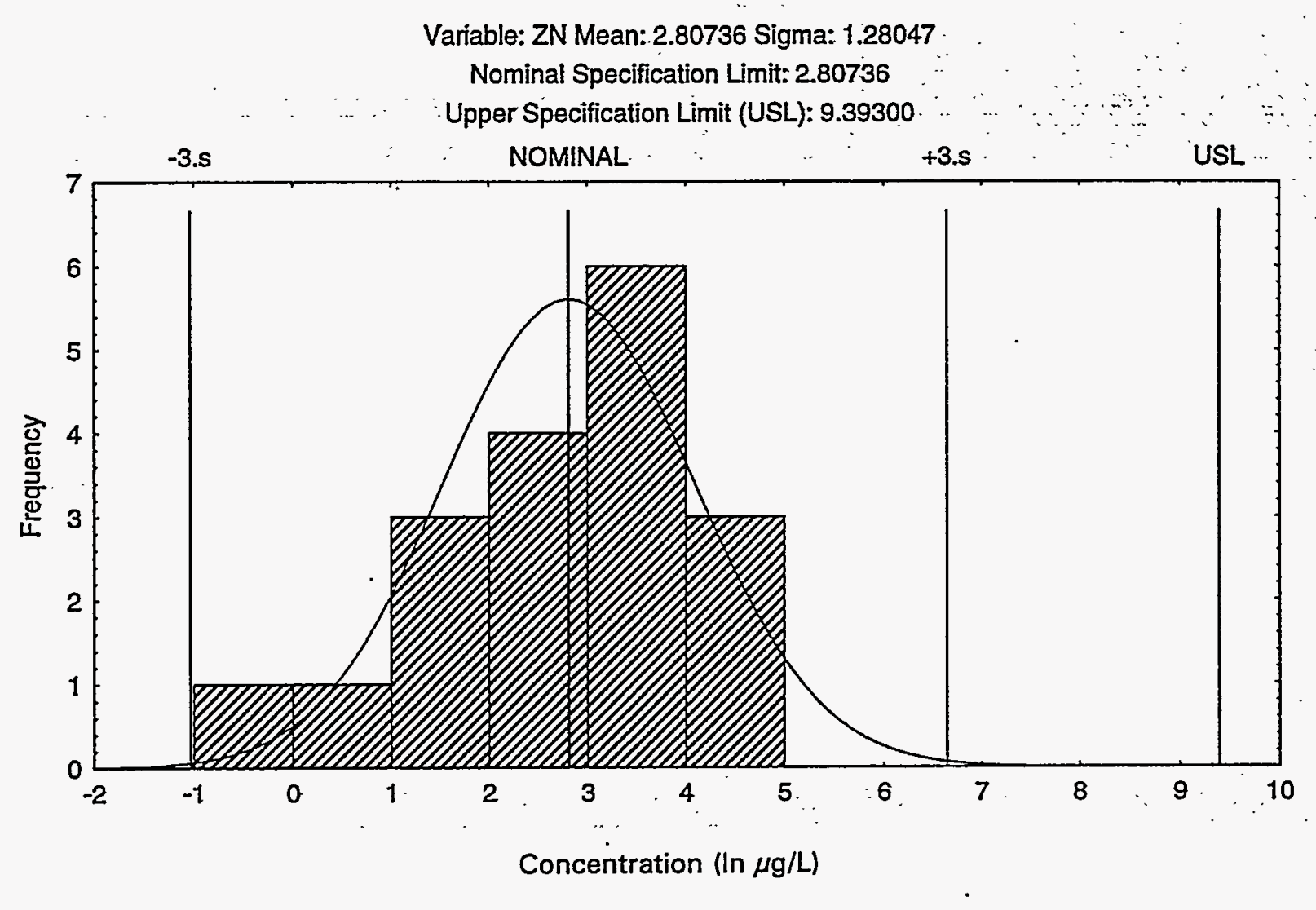

Figure H-19. Measured and log-normal distribution of zinc in effluent steam TRA-764. 

Appendix I. Frequency Histograms for Monitoring Parameters IF-603A, INEL Research Center 


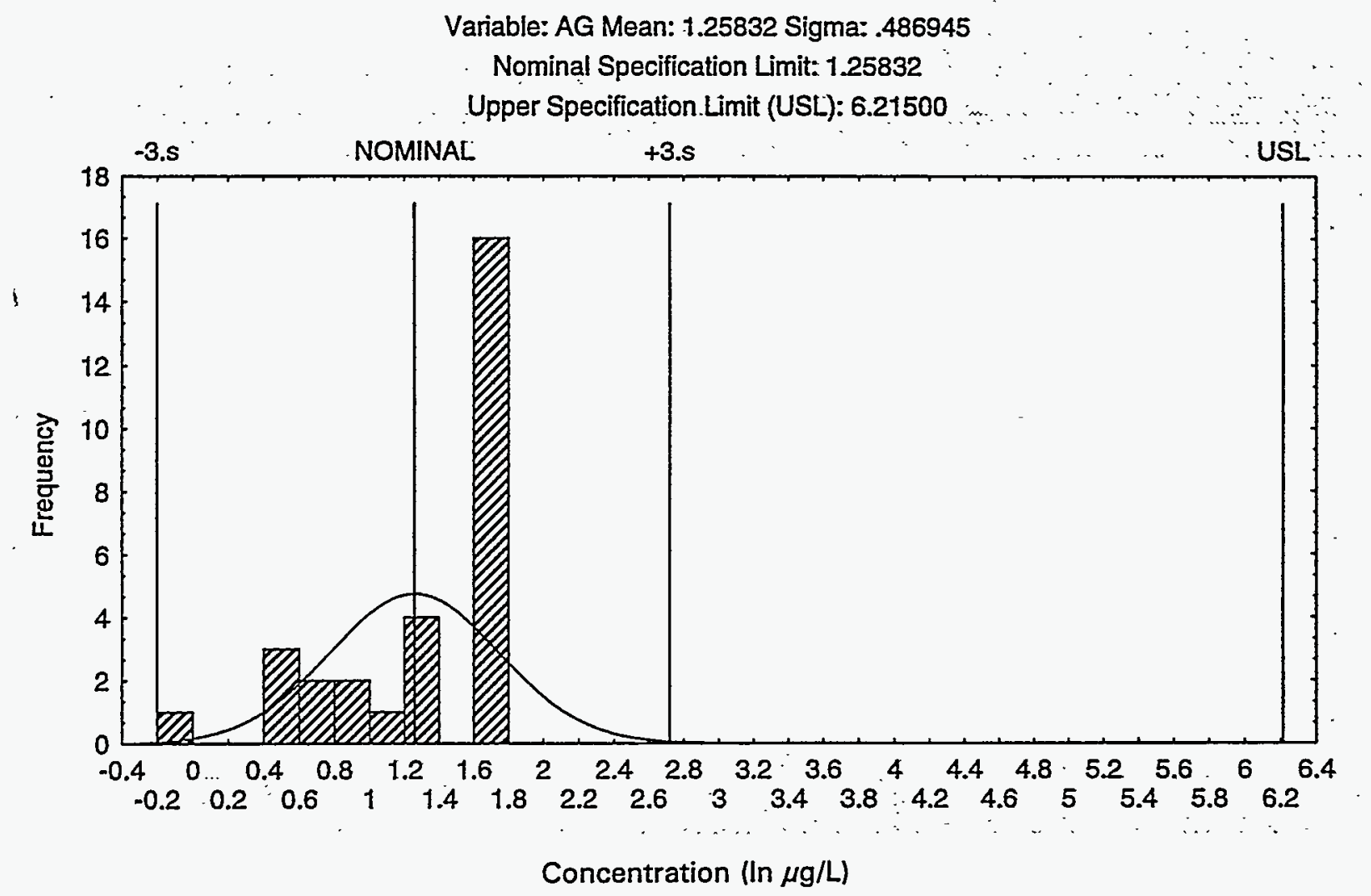

Figure 1-1. Measured and log-normal distribution of silver in effluent steam IF-603A. 


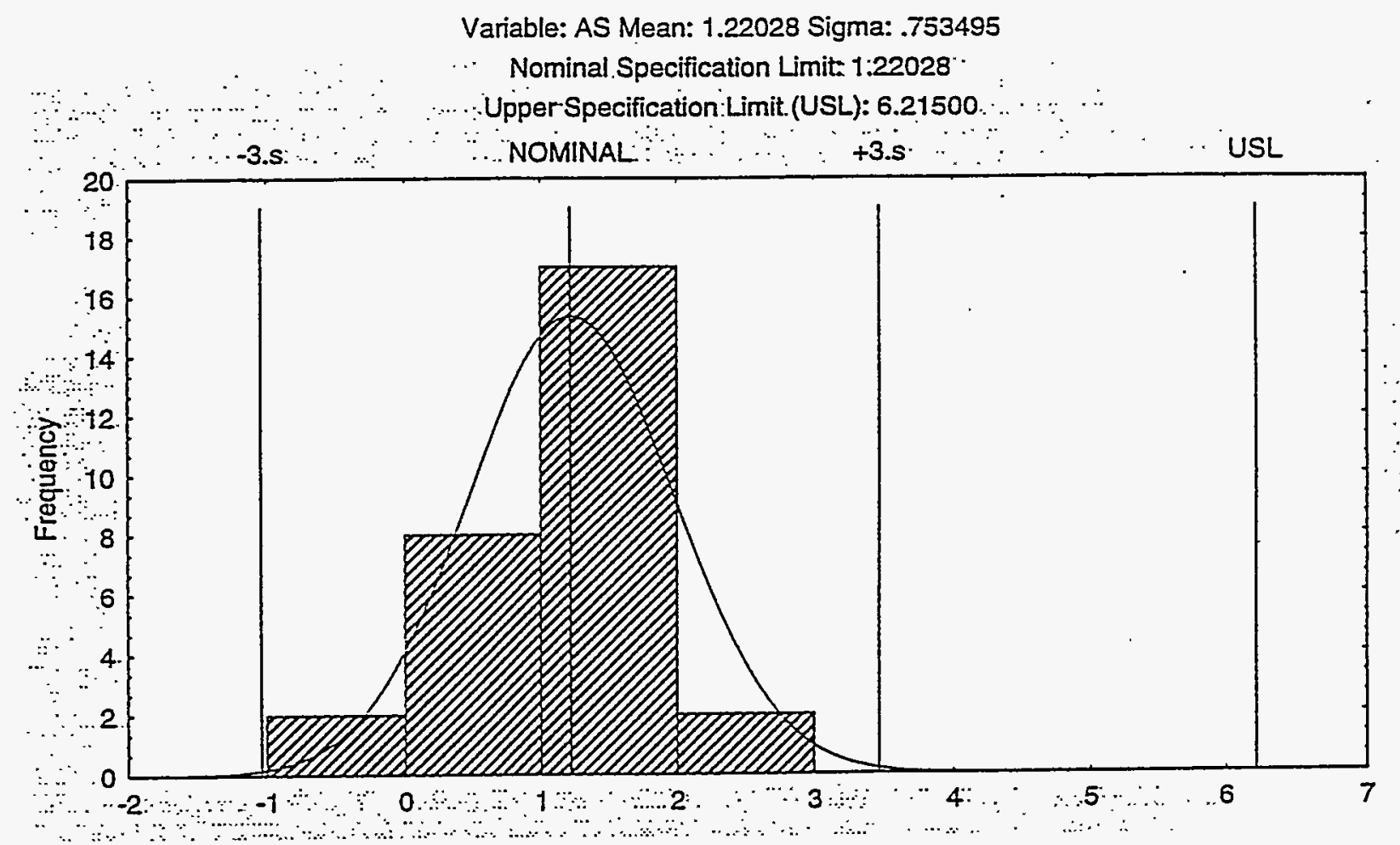

\section{Concentration (In $\mu \mathrm{g} / \mathrm{L}$ )}

Figure 1-2. Measured and log-normal distribution of arsenic in effluent steam IF-603A. 


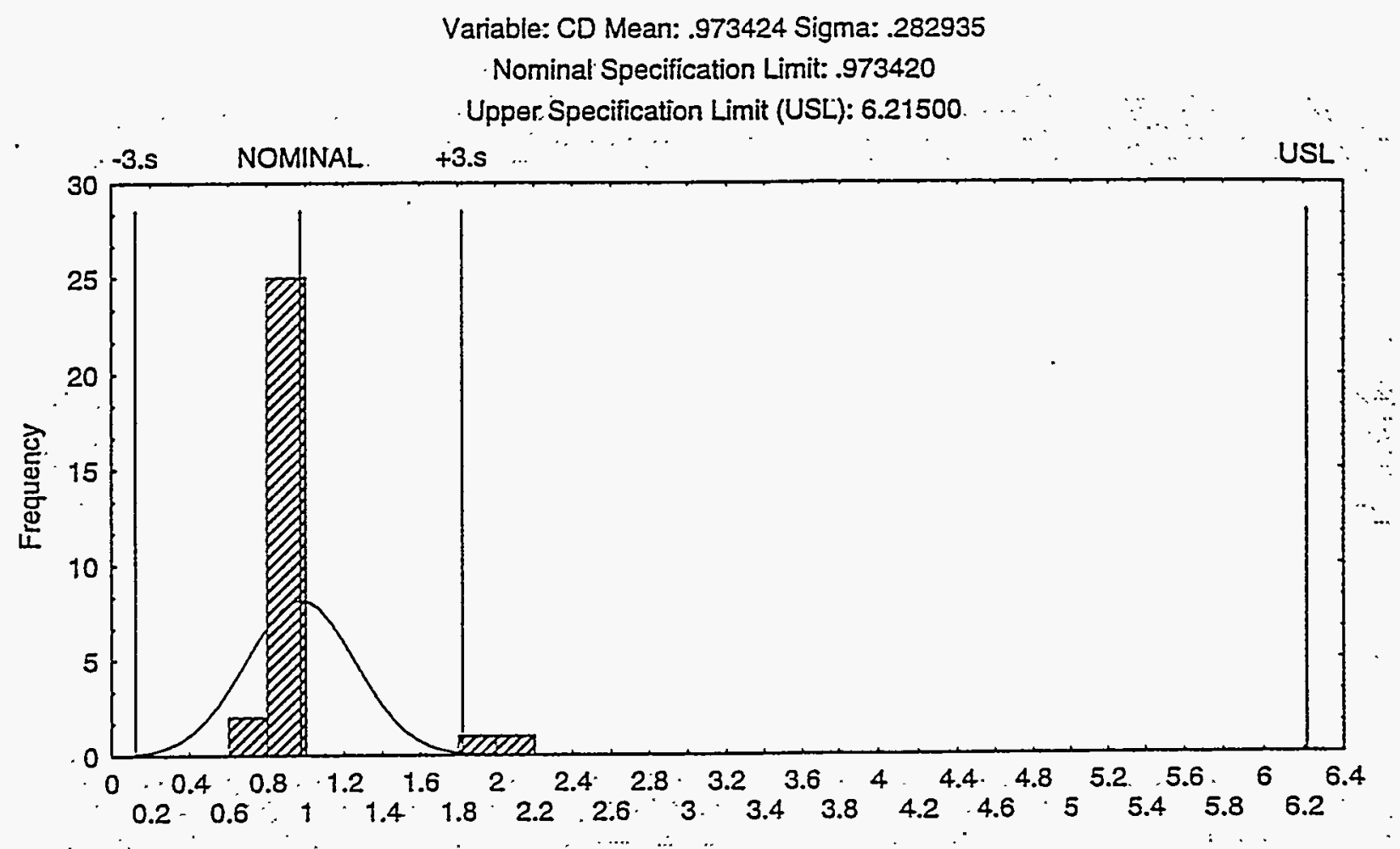

Concentration (ln $\mu \mathrm{g} / \mathrm{L})$

Figure 1-3. Measured and log-normal distribution of cadmium in effluent steam IF-603A. 


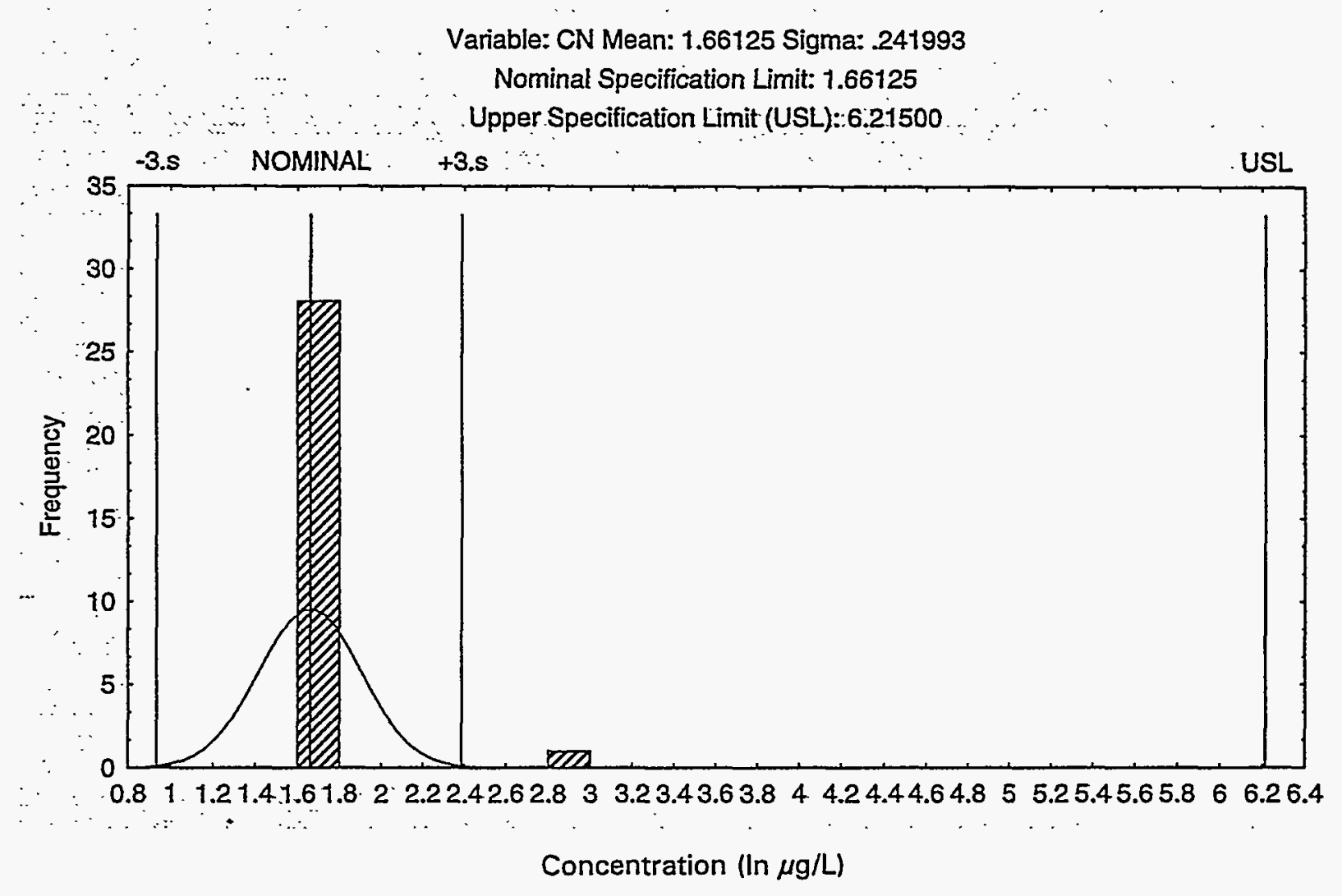

Figure 1-4. Measured and log-normal distribution of cyanide in effluent steam IF-603A. 


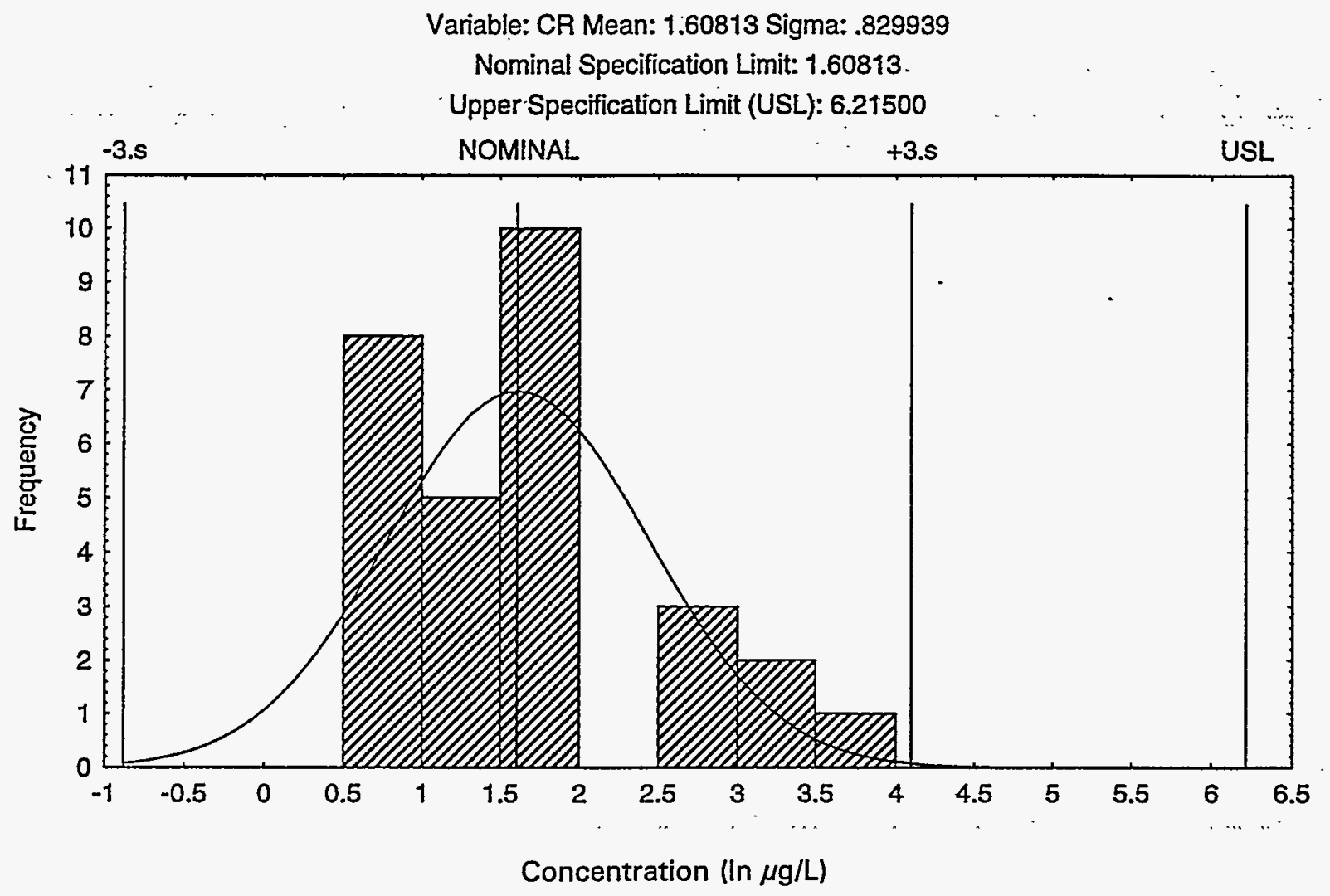

Figure 1-5. Measured and log-normal distribution of chromium in effluent steam IF-603A. 


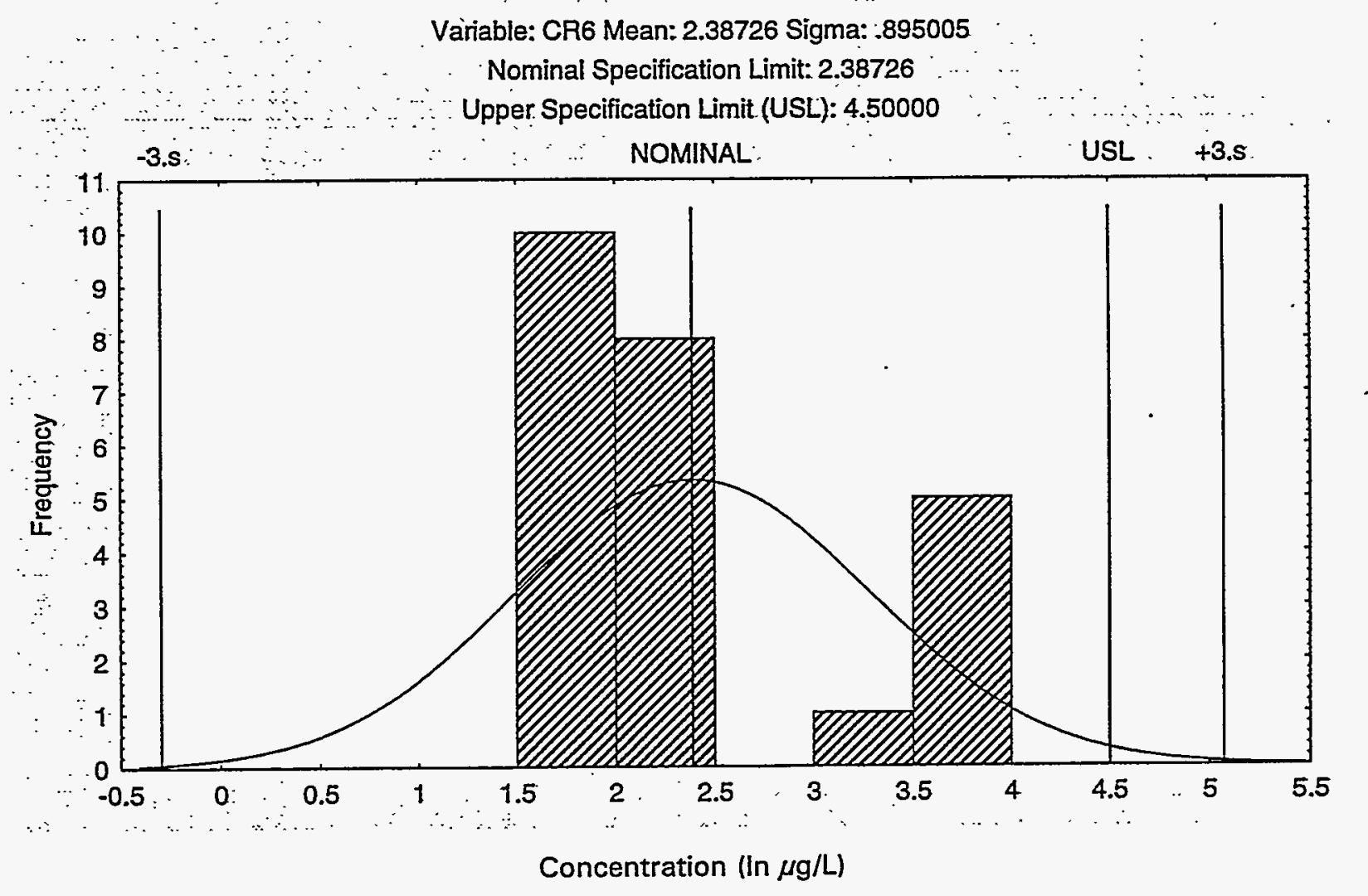

Figure 1-6. Measured and log-normal distribution of hexavalent chromium in effluent steam IF-603A. 


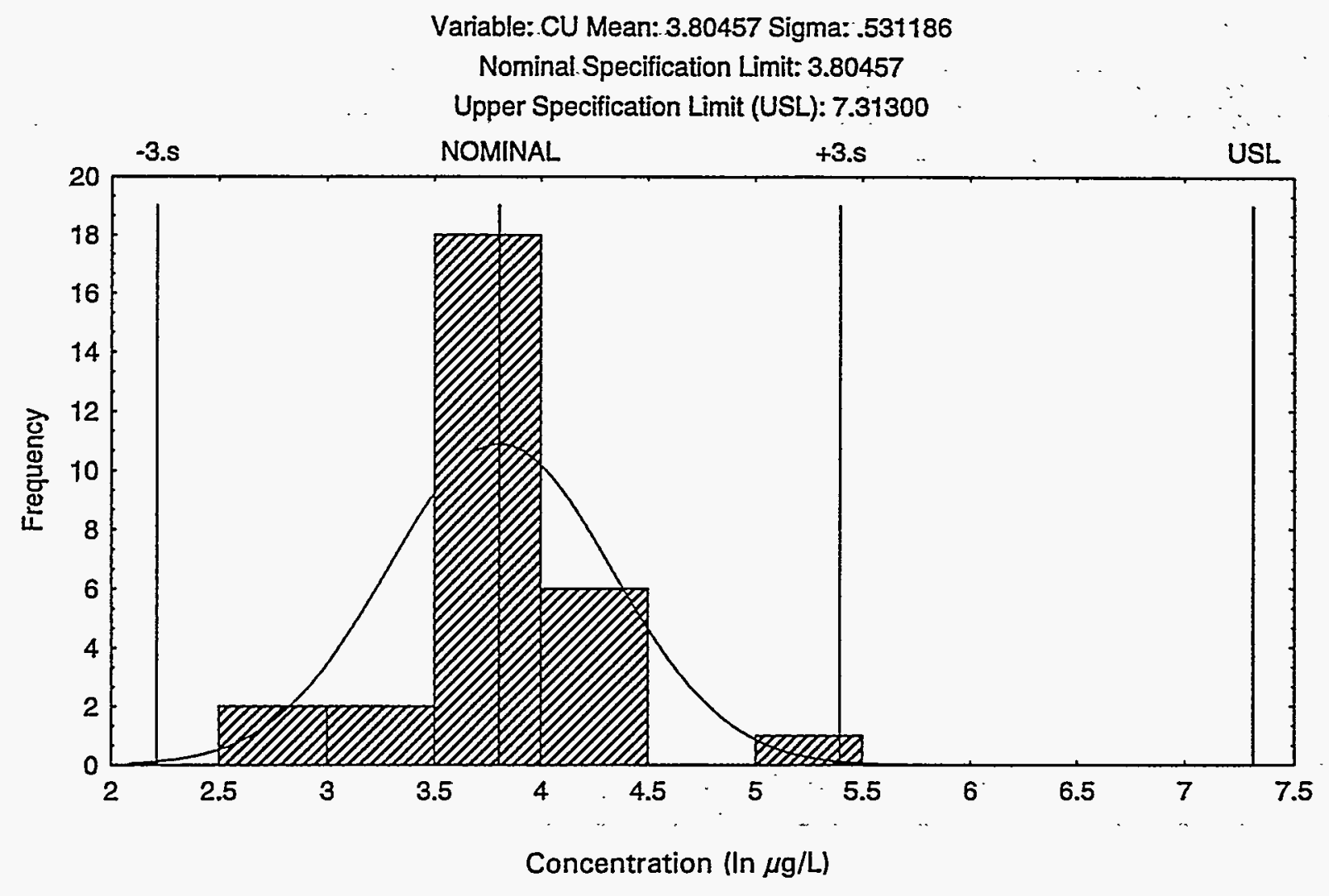

Figure 1-7. Measured and log-normal distribution of copper in effluent steam IF-603A. 


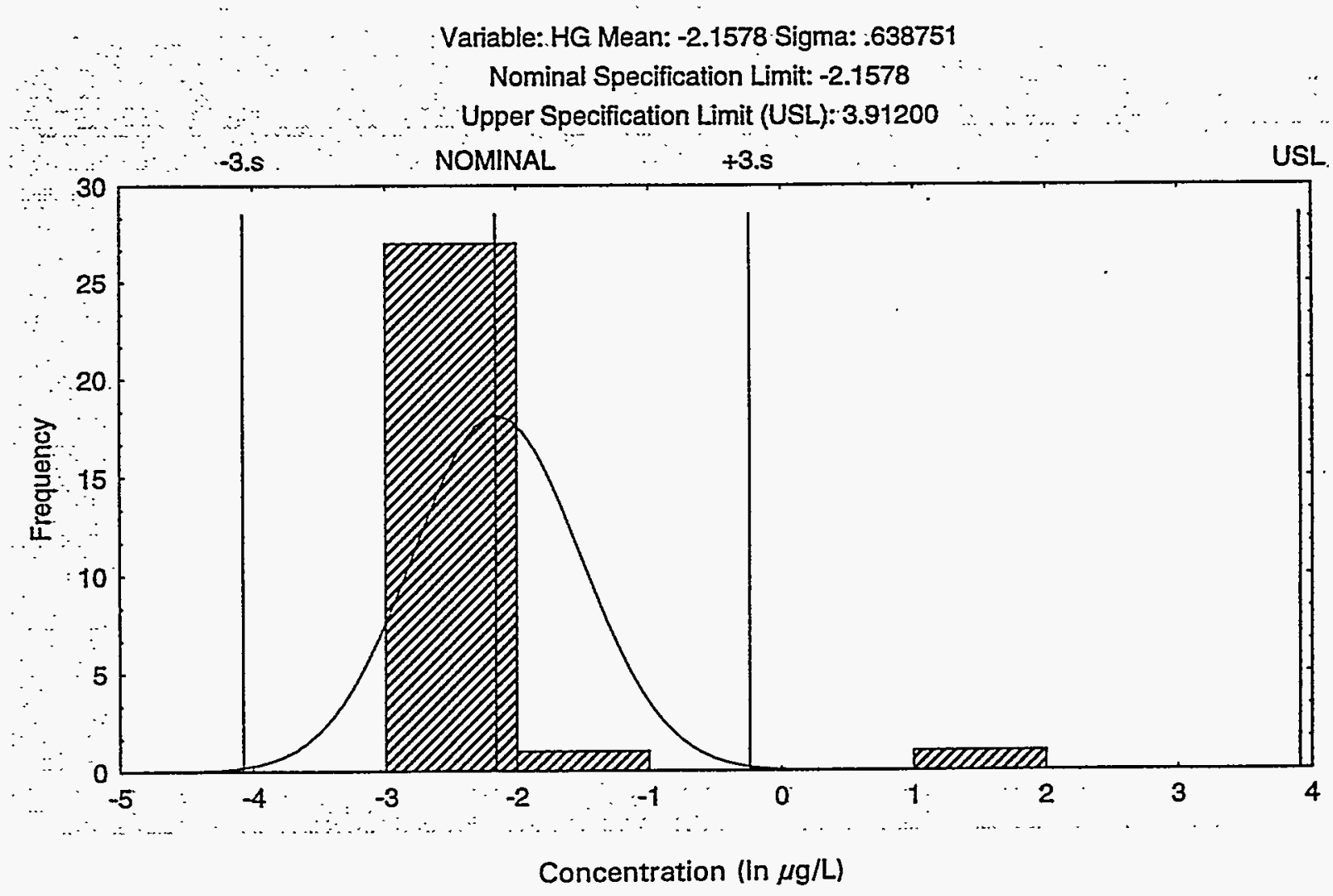

Figure 1-8. Measured and log-normal distribution of mercury in effluent steam IF-603A. 


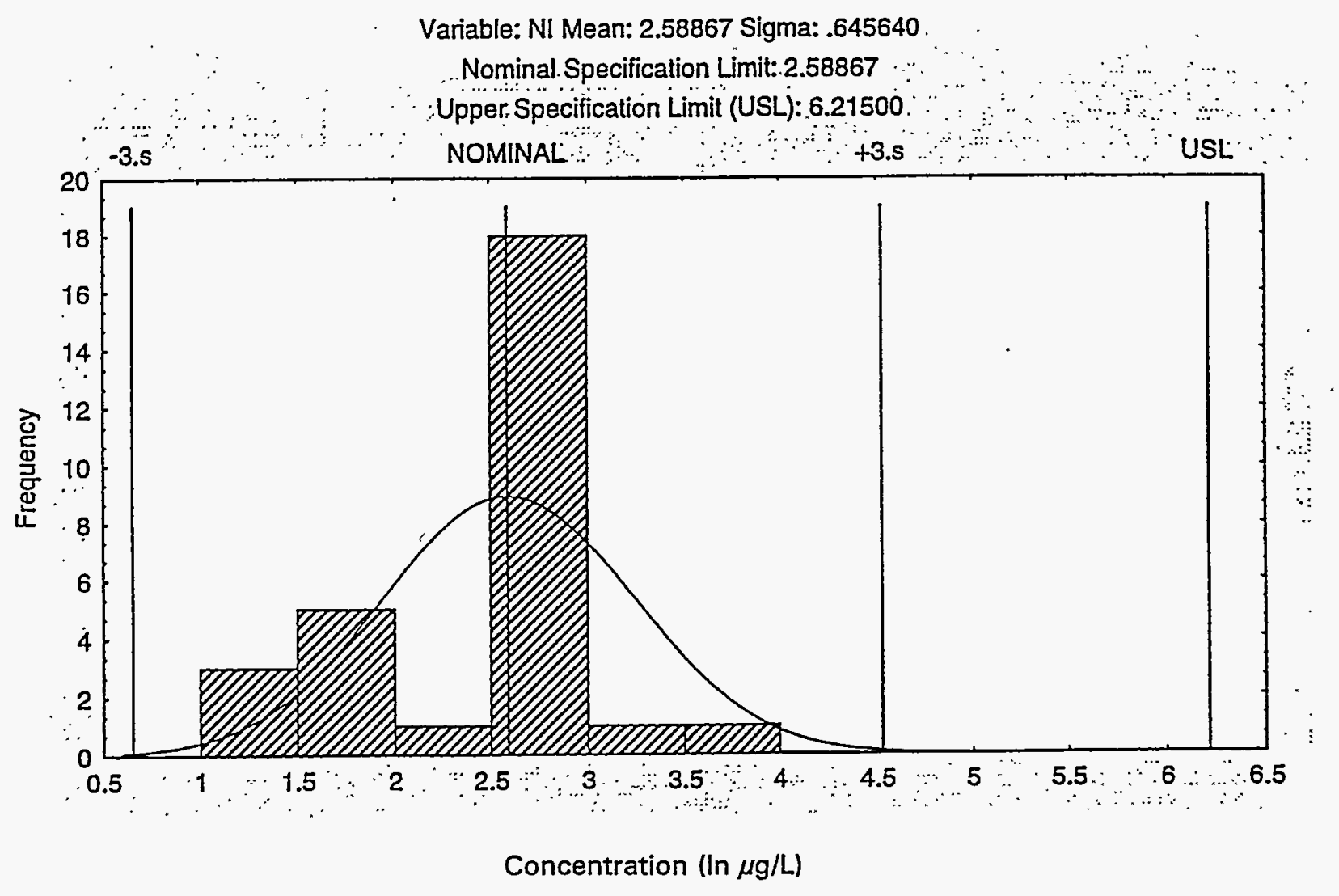

Figure I-9. Measured and log-normal distribution of nickel in effluent steam IF-603A. 


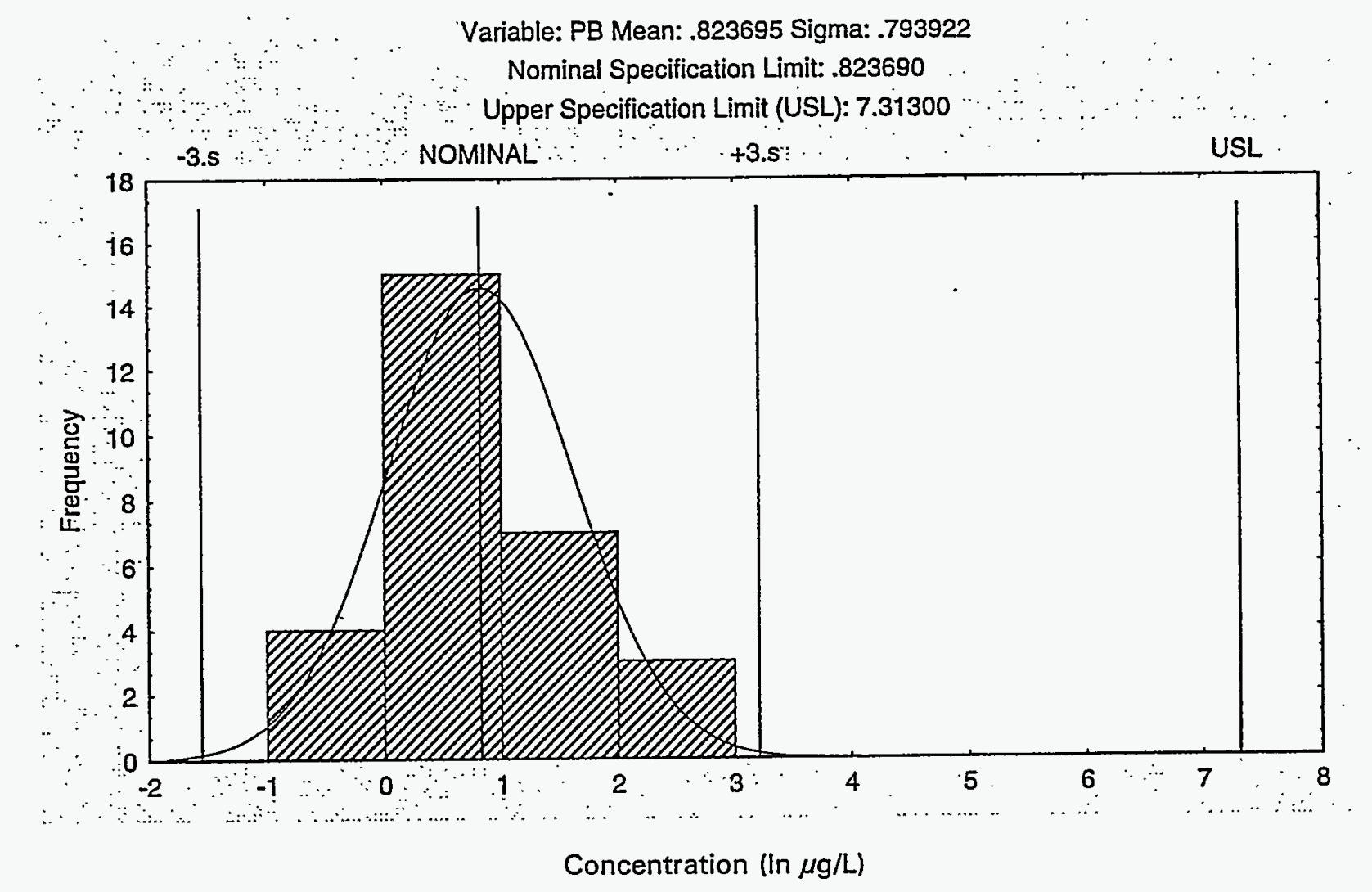

Figure 1-10. Measured and log-normal distribution of lead in effluent steam IF-603A. 
Variable: PH Mean: 7.45414 Sigma: .493418

Specifications: Lower Specification Limit (LSL): 5.50000

Nominal Specification Limit: 7.45414

Upper Specification Limit (USL): 9.00000

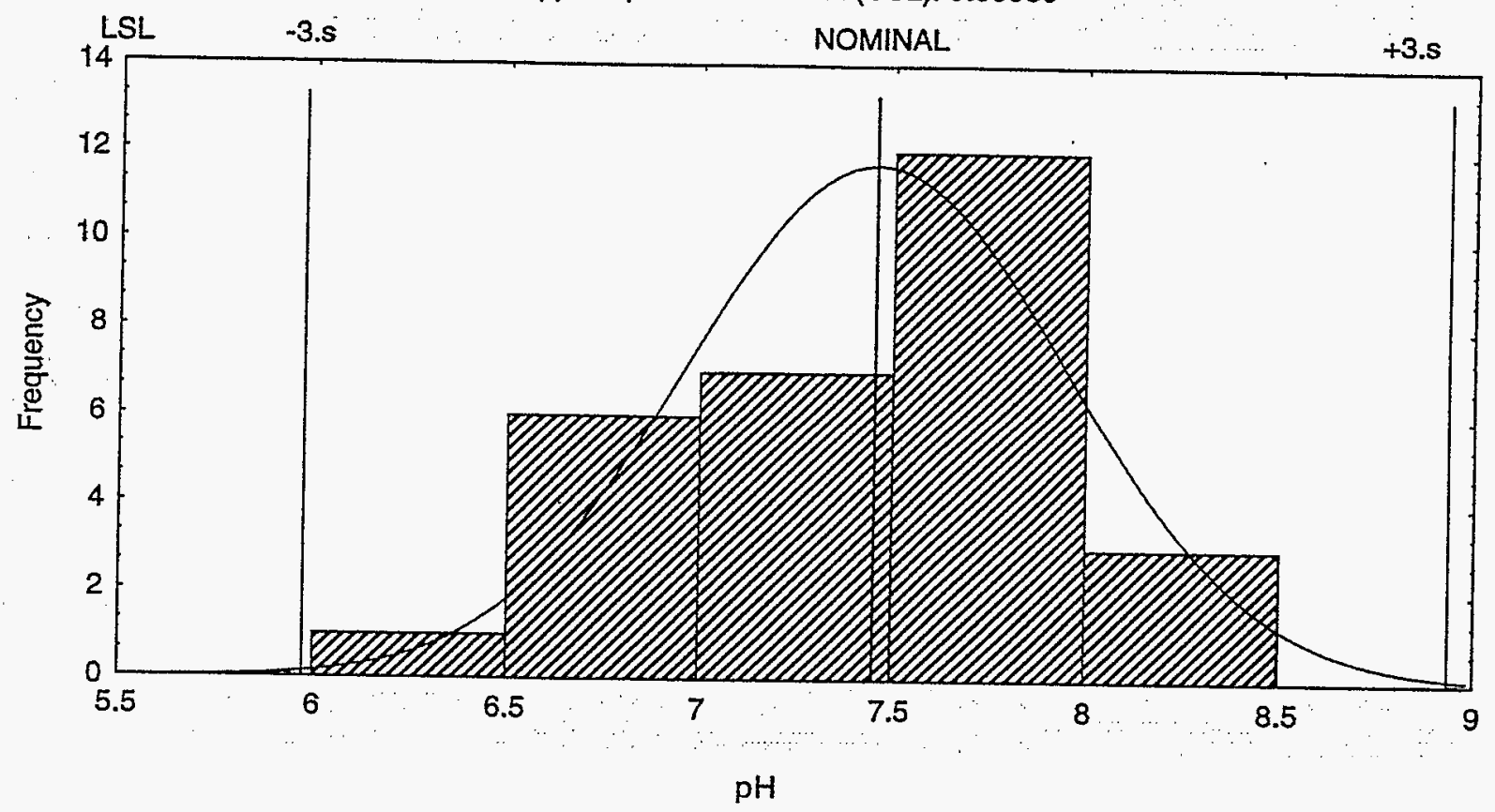

Figure 1-11. Measured and normal distribution of $\mathrm{pH}$ in effluent steam IF-603A. 
Variable: ZN Mean: 3.700 to Sigma: .383851

Nominal Specification Limit: 3.70010

Upper Specification Limit (USL): 7.31300

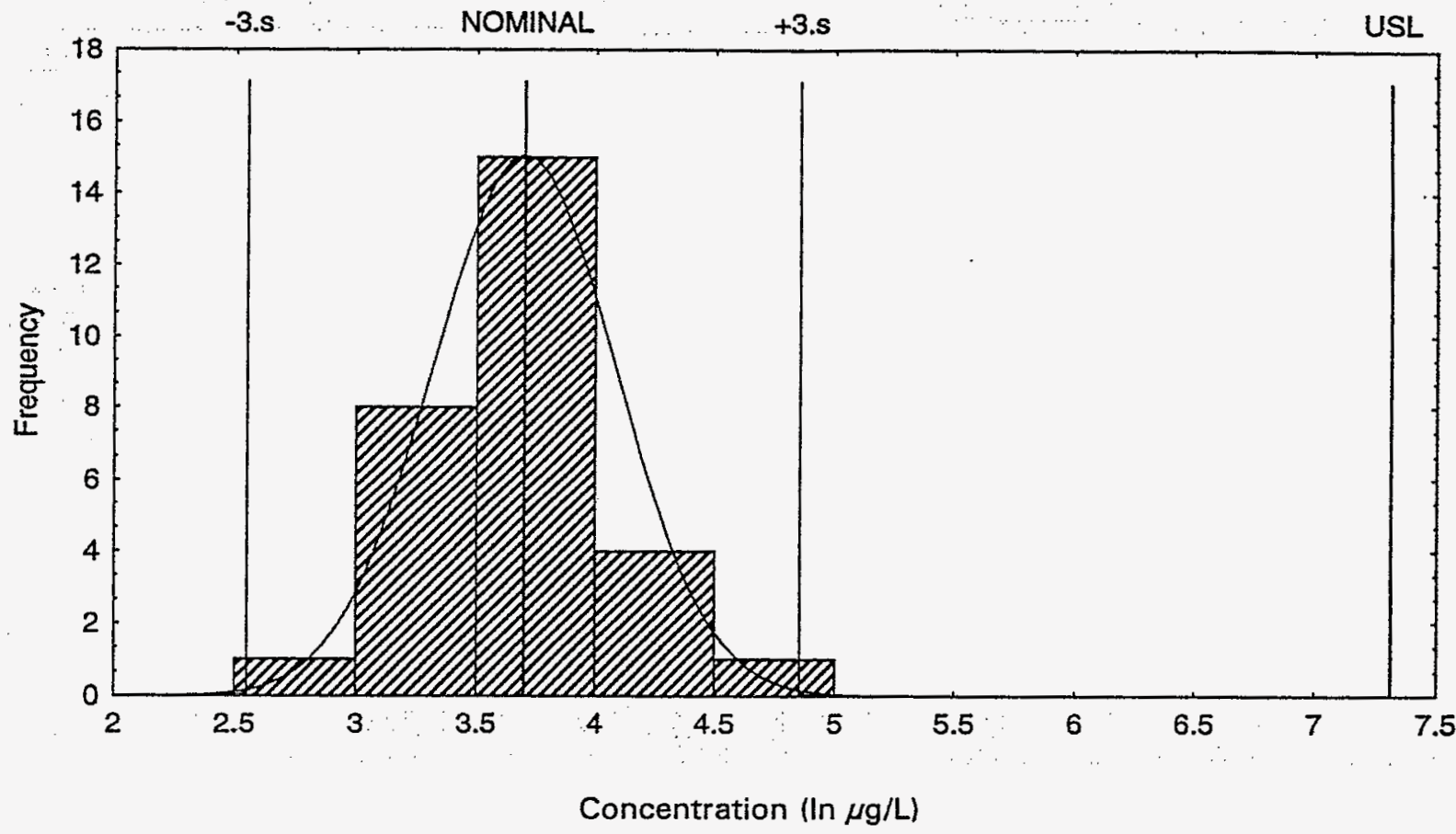

Figure I-12. Measured and log-normal distribution of zinc in effluent steam IF-603A. 